\title{
Riparian Ecological Community Assessment with an Emphasis on Wood Turtles (Glyptemys insculpta) in the Cacapon River Watershed, West Virginia
}

\author{
Kathryn R. P. McCoard \\ West Virginia University
}

Follow this and additional works at: https://researchrepository.wvu.edu/etd

\section{Recommended Citation}

McCoard, Kathryn R. P., "Riparian Ecological Community Assessment with an Emphasis on Wood Turtles (Glyptemys insculpta) in the Cacapon River Watershed, West Virginia" (2012). Graduate Theses, Dissertations, and Problem Reports. 3600.

https://researchrepository.wvu.edu/etd/3600

This Dissertation is protected by copyright and/or related rights. It has been brought to you by the The Research Repository @ WVU with permission from the rights-holder(s). You are free to use this Dissertation in any way that is permitted by the copyright and related rights legislation that applies to your use. For other uses you must obtain permission from the rights-holder(s) directly, unless additional rights are indicated by a Creative Commons license in the record and/ or on the work itself. This Dissertation has been accepted for inclusion in WVU Graduate Theses, Dissertations, and Problem Reports collection by an authorized administrator of The Research Repository @ WVU.

For more information, please contact researchrepository@mail.wvu.edu. 
Riparian Ecological Community Assessment with an Emphasis on Wood Turtles (Glyptemys insculpta) in the Cacapon River Watershed, West Virginia

\author{
Kathryn R. P. McCoard
}

Dissertation submitted to the Davis College of Agriculture, Natural Resources and Design at West Virginia University in partial fulfillment of the requirements for the degree of

Doctor of Philosophy in Forest Resources Science

James T. Anderson, Ph.D., Chair Anthony A. Billings, M.S. Edwin D. Michael, Ph.D. Thomas K. Pauley, Ph.D. Petra B. Wood, Ph.D.

Division of Forestry and Natural Resources

\author{
Morgantown, West Virginia \\ 2012
}

Keywords: wildlife; riparian zone; restoration; Glyptemys insculpta; ecology; range limitations Copyright 2012 Kathryn R. P. McCoard 


\section{ABSTRACT \\ Riparian Ecological Community Assessment with an Emphasis on Wood Turtles (Glyptemys insculpta) in the Cacapon River Watershed, West Virginia}

\section{Kathryn R. P. McCoard}

Riparian zones serve to maintain high water quality, low water temperatures, and structural complexity in aquatic and terrestrial environments, among other beneficial services. Riparian buffers provide habitat and corridors linking forest patches for terrestrial wildlife. High riparian vegetative structure and complexity attract a high diversity of wildlife, including birds, herpetofauna, and small mammals. Devegetated riparian zones, often a result of developmental and agricultural practices, lose their beneficial functions and require restorative actions to regain them. The Cacapon River watershed in West Virginia is agriculturally-dominated with many areas of riparian zone degradation. A section of the Cacapon River was selected for natural stream channel design restoration during 2009 to 2011. Our objectives were to: (1) monitor birds, small mammals, anurans, and vegetation along the restoration reach, 2 control (impaired) sites, and 2 reference (unimpaired) sites following a before-after control-impact design along the Cacapon River; (2) survey natural history characteristics of wood turtles (Glyptemys insculpta) using the riparian zone along the Cacapon River; and (3) assess factors limiting wood turtles along the southern extent of their geographic range along the Lost and North rivers, tributaries of the Cacapon River. We expected (1) the diversity of the riparian wildlife to remain stable or increase post-restoration, (2) wood turtles to undergo all natural history aspects within the riparian zone, and (3) geographical and environmental features to limit wood turtles along the southern border of their range in the Cacapon River watershed.

Monitoring of riparian wildlife along the Cacapon River occurred pre- (April 2009 to April 2010) and post-restoration (May 2010 to August 2011). Overall, 6 small mammal species, 79 bird species, 8 anuran species, and 96 plant species were recorded. Small mammal abundance declined initially in the restoration reach post-impact, but began to recover. Overall bird abundance, richness, and diversity increased along the restoration reach post-impact. The anurans were unaffected by the restoration activities, but showed species-specific timing of reproductive activities across the sites. Shrub and tree diversity, richness, and evenness increased over time, possibly indicating that the restoration reach began improving in vegetative complexity post-impact. The restoration was considered a success because the diversity of the riparian wildlife remained stable or increased post-restoration.

Monitoring of wood turtles along the Cacapon River occurred during spring 2009 to summer 2011. The turtles were observed primarily using the riparian zone $(80.7 \%)$ instead of the surrounding agricultural land (19.3\%). Adult males and females were larger than juveniles. Reproductively active males were longer, thicker, and heavier than reproductively active females. Home ranges were $0.62-36.97$ ha. Low bare ground and rock cover and high vertical density differentiated the turtles' habitat from random vegetation plots. The turtles were typically terrestrial during spring and summer and aquatic in autumn and winter. Mating occurred in autumn (64.3\%) after $1300 \mathrm{hrs}$ (75\%), sometimes terrestrially (35.7\%). Nesting attempts were made on sandy substrate in the early mornings and early evenings of spring. Basking occurred at $45^{\circ}$, angled to the sun, on a variety of surfaces. Dietary preference was for slugs (67\%), although other invertebrates, plant matter, and animal matter were consumed. The riparian zone provided the wood turtles with all of their natural history needs. 
Monitoring of wood turtles along the Lost and North rivers in the Cacapon River watershed was conducted during summer 2010. Habitat characteristics, potential dispersal barriers, and the approximate southern geographic boundary of the species in the watershed were assessed. Sixty-four of 100 randomly-selected sites contained wood turtles. Increasing stream depth, canopy cover, soil temperature, and proximity to the Cacapon River, and low elevation and slope positively influenced presence of the turtles. Field layer (woody and herbaceous plants $<1 \mathrm{~m}$ tall) species richness and diversity were greater in sites with wood turtles than without the turtles. Witch-hazel (Hamamelis virginianus) and ironwood (Ostrya virginiana) weakly separated sites without turtles from sites with them. The factors limiting wood turtles at the southern limits of their range in West Virginia included (1) inability to disperse over high elevations, (2) agricultural influences decreasing habitat availability and turtle survivorship, and (3) an intolerance to high temperatures. In agricultural areas bordering waterways, riparian buffers should be restored if they are degraded, managed to promote structurally complex vegetation, and monitored to determine whether the buffers are providing essential habitat for a diverse array of terrestrial wildlife that should promote adult survivorship and population stability. 


\section{ACKNOWLEDGMENTS}

I thank Dr. James T. Anderson for giving me the opportunity to pursue my doctoral degree in his lab at West Virginia University and for his guidance as I worked on a variety of projects. I thank Dr. Petra Bohall Wood and Dr. Edwin D. Michael for serving on my committee and for being available for me. I thank Anthony A. Billings for his invaluable statistical help, friendship, and support during this process. I also thank Dr. Thomas K. Pauley for his herpetological guidance and invaluable friendship as I struggled through the tougher times to make this research possible. Without them, this project would not have succeeded.

I am grateful for the help that I received during the course of my field work. I thank Steve Selego, Crissa Cooey, Cristiana Pawlik, Mark and Jo Allen Jones, Camille Concepcion, Logan Moon, Aaron Neidermeyer, and Ryan Harris for assistance with the wood turtle ecology research and small mammal trapping. I am thankful for continual access to my research sites provided by the Cacapon landowners, especially Jack and Mike Rudolph, Sandy and Michelle White, and Josh Frye who quickly became friends during my repeated visits, and to the landowners along the Lost and North rivers who granted me access as I pursued wood turtles.

I thank many agencies for providing funding, logistical support, and expertise to make this research possible. These include the National Fish and Wildlife Foundation (NFWF), Chesapeake Bay Trust, National Oceanic and Atmospheric Administration (NOAA), Farm Service Agency (FSA), Natural Resource Conservation Service (NRCS), the West Virginia Department of Environmental Protection (WVDEP), West Virginia Conservation Agency (WVCA), Canaan Valley Institute (CVI), Cacapon and Lost Rivers Land Trust (CLRLT), the West Virginia University Environmental Research Center, and the employees of Reymann Memorial Farm in Wardensville, WV.

I thank Mark and Jo Allen Jones for providing me with a home and friendship during my field work. I am more grateful than I can express for the support of my parents and siblings as I worked towards earning my doctorate. They were always there for me when I needed a shoulder to lean on and had unfailing belief in my ability to succeed. I especially thank my husband, Noah S. McCoard, whose emotional support kept me strong. He selflessly gave his weekends and days off to assist me for countless hours in the field. Without his unfailing help, I would not have accomplished as much as I did. Most importantly, I thank the Lord God who brought me to and through this experience, enabling me with everything that I needed to succeed. 


\section{Table of Contents}

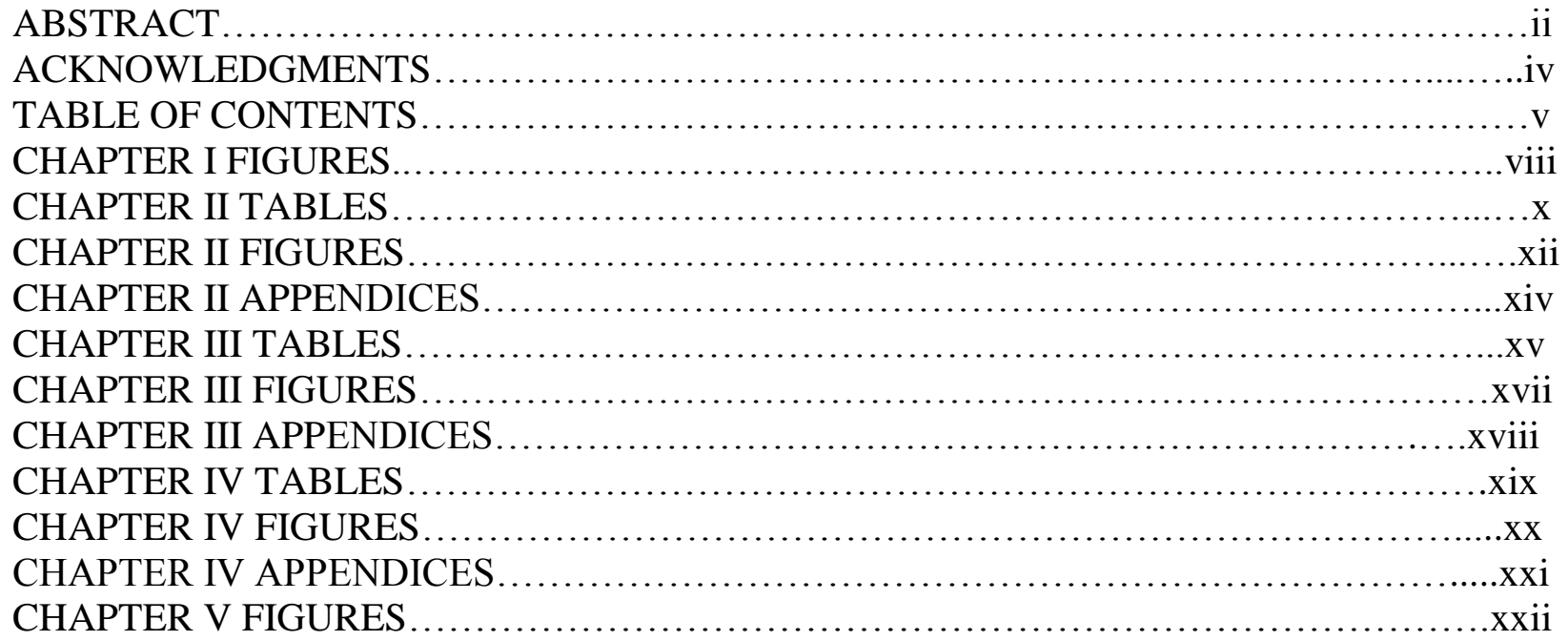

CHAPTER I..............................................................................

PROJECT OVERVIEW: OBJECTIVES AND LITERATURE REVIEW FOR STREAM RESTORATION AND WOOD TURTLE ECOLOGY, CACAPON RIVER WATERSHED,

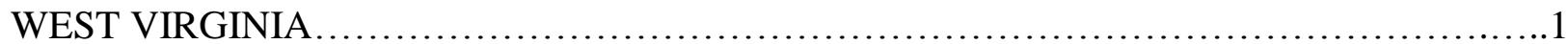

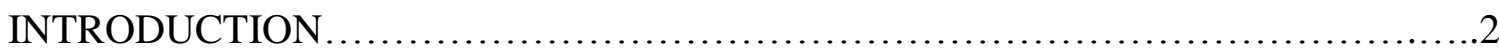

Role of the riparian zone.................................................

Stream restoration and natural stream design................................. 3

North American wood turtle................................................4

JUSTIFICATION ........................................................... 5

Importance of the riparian zone and stream restoration monitoring..............5

Status of the Cacapon River watershed riparium and its effects on wildlife........6

Decline of wood turtles..................................................... 8

OBJECTIVES ..................................................................

LITERATURE REVIEW ..................................................... 11

Riparian zone restoration, conservation, and wildlife use....................11

Metapopulations and riparian zone corridors............................. 16

Ecology of wood turtles............................................... 19

Factors influencing wood turtle declines and suggestions for their conservation........................................................22

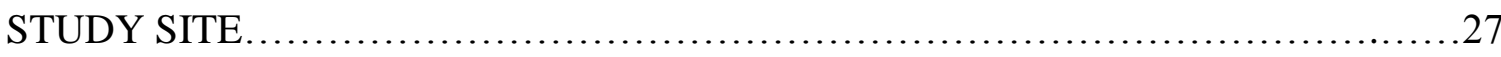

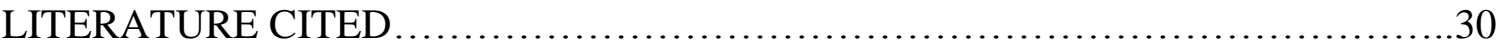

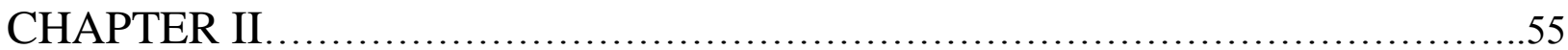

RIPARIAN ECOLOGICAL COMMUNITY ASSESSMENT OF A RESTORED REACH OF

THE CACAPON RIVER, WEST VIRGINIA ......................................55

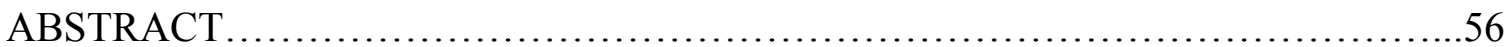

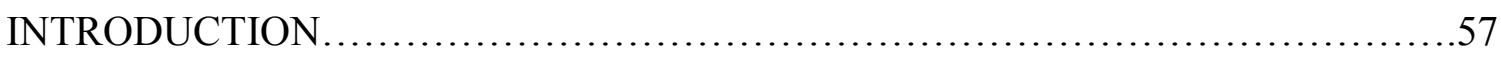

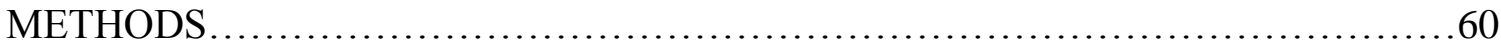

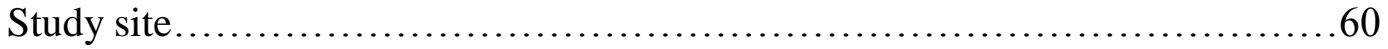




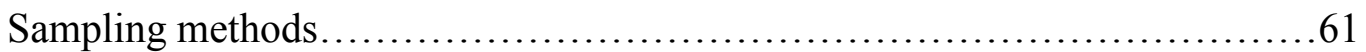

Statistical analyses...................................................... 64

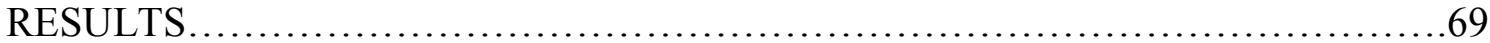

Small mammals......................................................69

Birds............................................................ 70

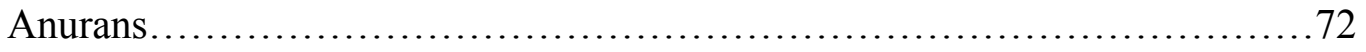

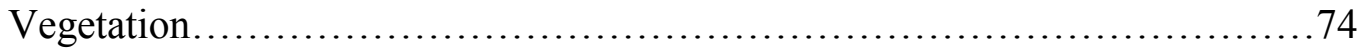

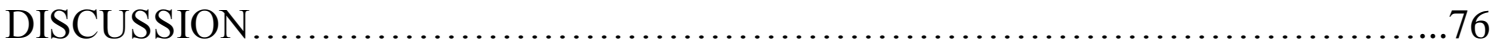

Small mammals................................................... 77

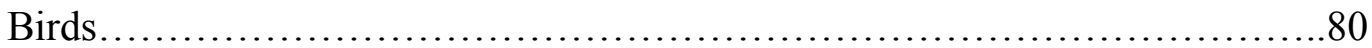

Herpetofauna..................................................... 82

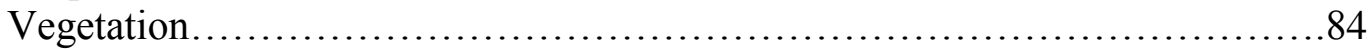

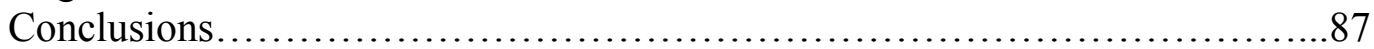

ACKNOWLEDGMENTS.................................................... 89

LITERATURE CITED................................................... 89

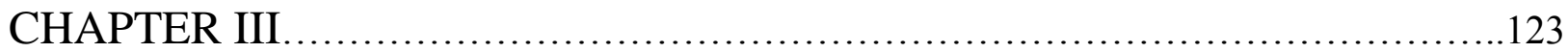

ECOLOGICAL ASPECTS OF WOOD TURTLES IN AN AGRI-FOREST ENVIRONMENT

IN THE CENTRAL APPALACHIANS ............................................. 123

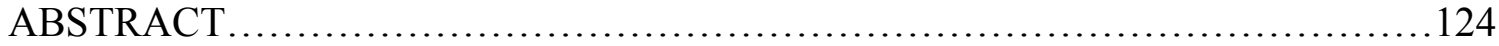

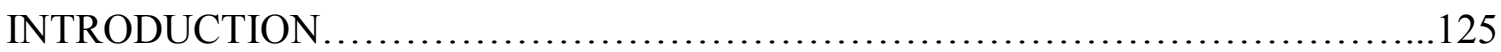

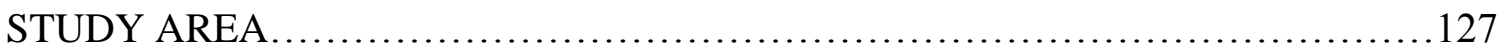

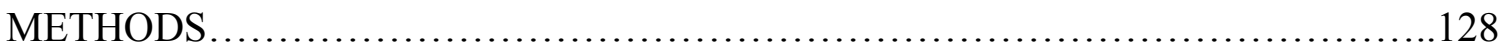

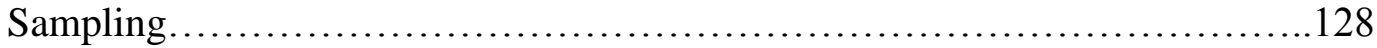

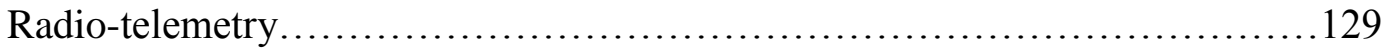

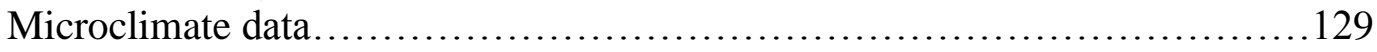

Vegetation surveys................................................. 130

Statistical analyses......................................................

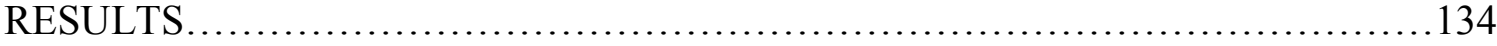

Morphometrics and sex-ratio............................................ 134

Home ranges and vegetation......................................... 135

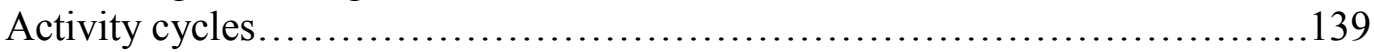

DISCUSSION ............................................................ 146

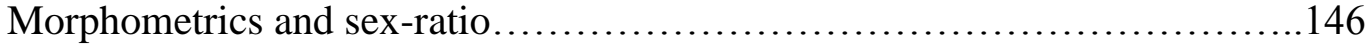

Home ranges and vegetation........................................... 148

Seasonal activity cycles............................................. 150

MANAGEMENT IMPLICATIONS ........................................... 157

ACKNOWLEDGMENTS.................................................. 158

LITERATURE CITED ..................................................... 158

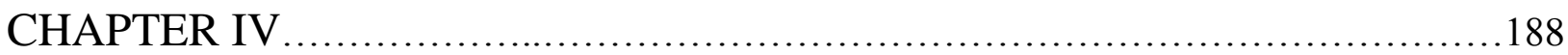

FACTORS AFFECTING WOOD TURTLES AT THE SOUTHERN LIMITS OF THEIR RANGE IN THE CENTRAL APPALACHIANS ......................................... 188

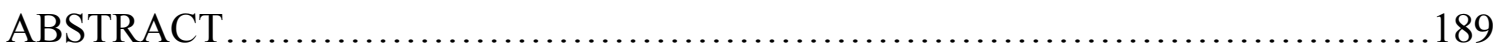

INTRODUCTION .......................................................... 190

STUDY AREA ......................................................... 193 


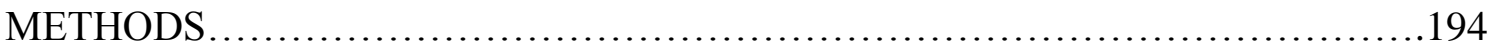

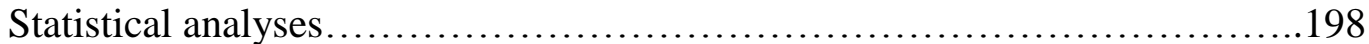

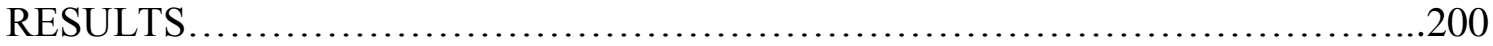

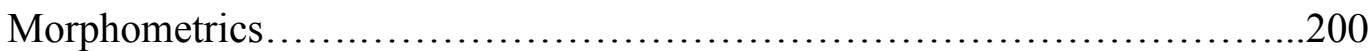

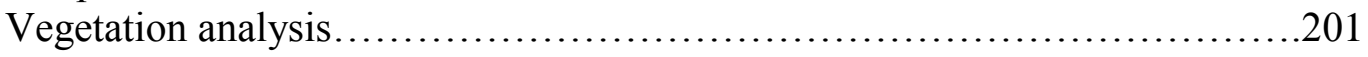

Environmental variable model...........................................203

Site occupancy probability...............................................204

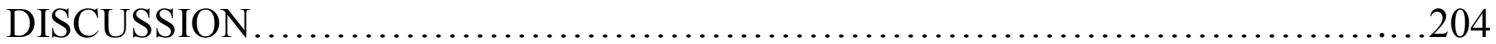

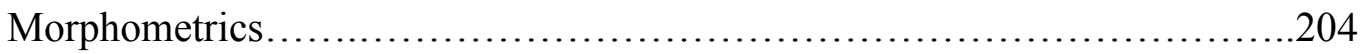

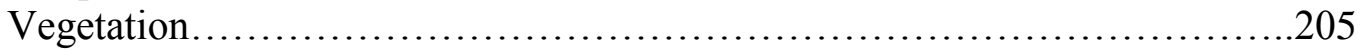

Environmental influences acting as southern range limitations................206

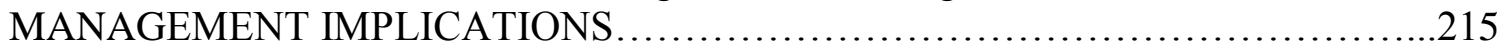

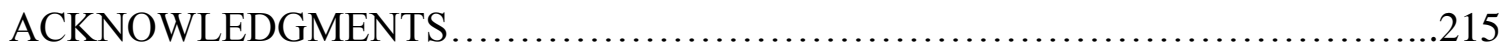

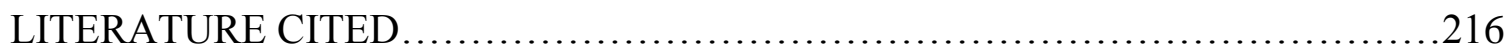

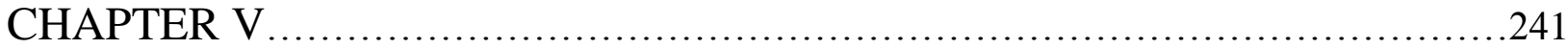

CONCLUSIONS, MANAGERIAL SUMMARY, AND FUTURE RESEARCH

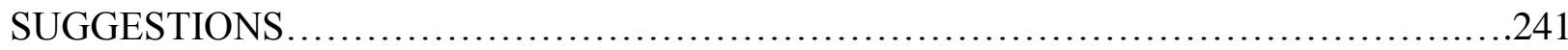

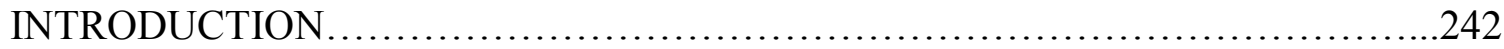

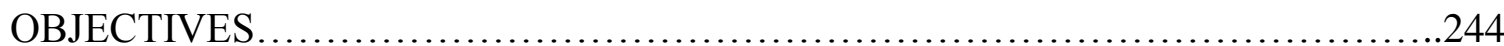

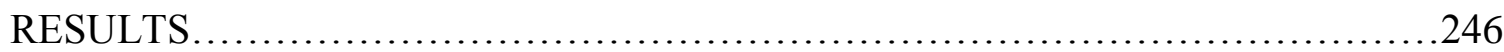

Responses of riparian fauna to stream restoration.............................246

Natural history aspects of wood turtles..................................249

Southern range limitations of wood turtles..................................250

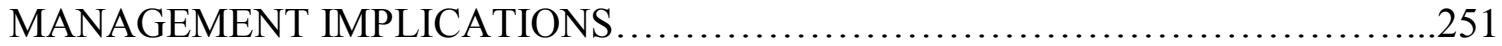

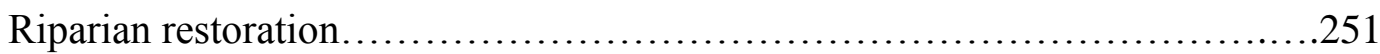

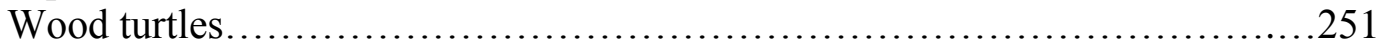

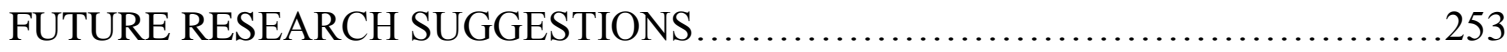

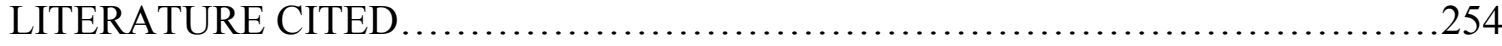




\section{Ch I: List of figures}

Figure 1. The Cacapon River watershed occurs in the eastern panhandle of West Virginia, USA. It is composed of the Cacapon, North, and Lost rivers. The watershed drains into the Potomac River which flows into the Chesapeake Bay watershed................................42

Figure 2. The right side of the restoration reach before restoration occurred, taken February 2009. The high, eroded banks with collapsing vegetation are clearly seen. The fence bordering the active pasture on the flooplain is at the edge of the streambank.

Figure 3. The eroded banks along the restoration reach were terraced to provide a gentler slope and small floodplain to decrease erosion and increase aggregation of sediment, taken May 2010 .

Figure 4. Geotextiles were laid down over the newly sculpted banks along the restoration reach

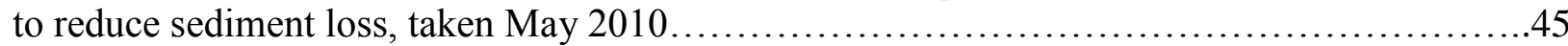

Figure 5. Log vanes were put into place along the restoration reach to deflect the main current from shore and decrease the erosion impact. The logs were anchored into the bank and held in place by large boulders. The inside angle was filled with streambed material. Coconut bio-logs were placed along the bottom of the contoured banks to catch sediment. The left side of the

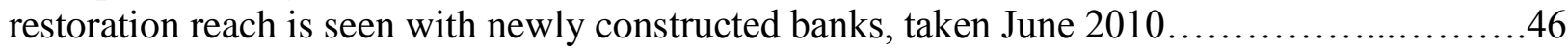

Figure 6. Trees and shrubs were planted on both sides of the restoration reach to re-establish the riparian zone and aid in bank stabilization. Tree tubes were placed around every sapling to

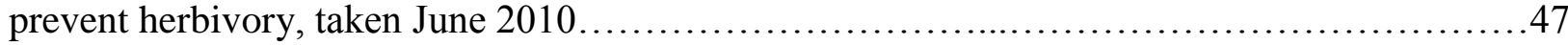

Figure 7. Construction of the barbed wire fence along the right side of the restoration reach. Thick posts are laying on the ground in the approximate locations that they will be placed, taken

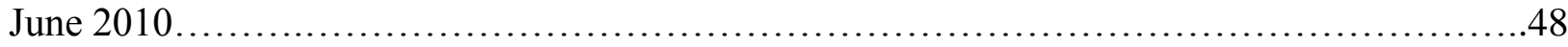

Figure 8. The site design for the restoration study along the Cacapon River, West Virginia, USA. The restoration reach was bordered on both ends by a reference site and a control site.

Figure 9. The upstream control site that was compared to the restoration reach to determine the success of the restoration. The banks at this site were not restored; vegetation and an old barbedwire fence are falling down the eroded banks, taken February 2009.

Figure 10. The downstream reference site that was compared to the restoration reach to determine the success of the restoration. The banks at this site were gently sloped and wellvegetated, taken February 2009.

Figure 11. The study design centered around the restoration reach (RR), with 8 sampling units. The restoration reach was bordered on either end by an upstream (RS 1) and downstream (RS 2) 
reference site and an upstream (CS 1) and downstream (CS 2) control site, with collective totals

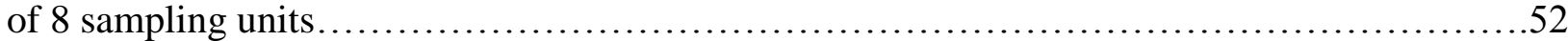

Figure 12. Each sampling unit was composed of a variety of wildlife surveys, including a bird transect, small mammal trapping grid, a point for frog call surveys, and a vegetation plot......53

Figure 13. Wood turtle sampling points along the Lost and North rivers, tributaries of the Cacapon River, within the Cacapon River watershed, West Virginia, USA. Surveys were

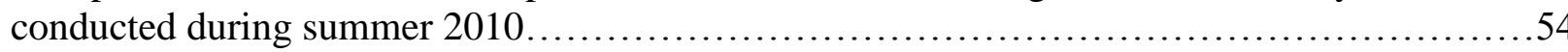




\section{Ch II: List of tables}

Table 1. Mean counts and standard errors (SE) of bird species that were observed along a 13.7$\mathrm{km}$ reach of the Cacapon River, West Virginia, USA, during spring 2009 to summer 2011. The sites where the species were observed were associated with a streambank restoration project: RR, $1,100 \mathrm{~m}$ restoration reach (RR 1, pre-restoration; RR 2, post-restoration); RS 1, upstream reference site; RS 2, downstream reference site; CS 1, upstream control site; and CS 2, downstream control site.................................................................. 98

Table 2. Number of captures per 100 trap-nights, with means and standard errors (SE) for small mammal species trapped along a 13.7-km reach of the Cacapon River, West Virginia, USA during summer 2009, 2010, and 2011. The sites were associated with a river restoration project: RR, 1,100 m restoration reach; RS 1, upstream reference site; RS 2, downstream reference site; CS 1, upstream control site; and CS 2, downstream control site.............................99

Table 3. Maximum calling index per 5 minute surveys recorded for frog and toad species heard calling along a 13.7-km reach of the Cacapon River, West Virginia, USA during April, June, and August of 2009, 2010, and 2011. The sites were associated with a river restoration project: RR, $1,100 \mathrm{~m}$ restoration reach; RS 1, upstream reference site; RS 2, downstream reference site; CS 1, upstream control site; and CS 2, downstream control site. The calling index values were: 0 , no calling heard; 1 , distinct non-overlapping calls; 2 , overlap of calls, but distinct individuals heard; and 3 , indistinct chorus, species instead of individuals heard. 102

Table 4. Odds ratio estimates and confidence intervals for significant contrasts of anuran species whose odds of being heard calling per 5 minute surveys were influenced by a time effect during surveys conducted along a 13.7-km reach of the Cacapon River, West Virginia, USA during April, June, and August of 2009 to 2011. The surveys were associated with a river restoration project. The months with higher odds are listed first in each contrast........................103

Table 5. Significant multiple comparison contrasts related to vegetation (overall [natives and exotics] and natives-only) surveys conducted along a 13.7-km reach of the Cacapon River, West Virginia, USA during June 2009, 2010, and 2011. The sites were associated with a river restoration project: RR, 1,100 m restoration reach; RS, reference site; and CS, control site. The vegetative layers were field: \% cover of woody and herbaceous plants $<1 \mathrm{~m}$ tall; shrub: abundance of woody plants $>1 \mathrm{~m}$ tall, $<5 \mathrm{~cm}$ in diameter at breast height (dbh); and tree: abundance of woody plants $>5 \mathrm{~cm}$ dbh per 100 -m radius survey circle

Table 6. Diversity index values, means, and standard errors (SE) for overall (natives and exotics) vegetative layers (i.e., field: \% cover of woody and herbaceous plants $<1 \mathrm{~m}$ tall; shrub: abundance of woody plants $>1 \mathrm{~m}$ tall, $<5 \mathrm{~cm}$ in diameter at breast height (dbh); and tree: abundance of woody plants $>5 \mathrm{~cm}$ dbh per 100-m radius survey circle) sampled along a $13.7-\mathrm{km}$ reach of the Cacapon River, West Virginia, USA, during June 2009, 2010, and 2011. The sites were associated with a river restoration project: $\mathrm{RR}, 1,100 \mathrm{~m}$ restoration reach; RS, reference site; and CS, control site. The means and SEs of sampling units (SU, $n=24)$ nested within sites were not calculated 
Table 7. Diversity index values, means, and standard errors (SE) for native vegetative layers (i.e., field: \% cover of woody and herbaceous plants < $1 \mathrm{~m}$ tall; shrub: abundance of woody plants $>1 \mathrm{~m}$ tall, $<5 \mathrm{~cm}$ in diameter at breast height (dbh); and tree: abundance of woody plants $>5 \mathrm{~cm}$ dbh per 100-m radius survey circle) sampled along a 13.7-km reach of the Cacapon River, West Virginia, USA, during June 2009, 2010, and 2011. The sites were associated with a river restoration project: RR, 1,100 m restoration reach; RS, reference site; and CS, control site. The means and SEs of sampling units (SU, $n=24)$ nested within sites were not

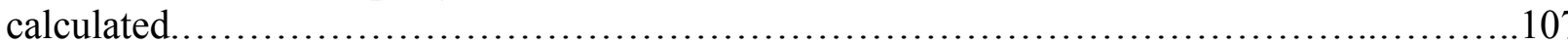




\section{Ch II: List of figures}

Figure 1. The natural stream channel restoration study design centered around the restoration reach (RR), with eight sampling units. The restoration reach was bordered on either side by an upstream (RS 1) and downstream (RS 2) reference site and an upstream (CS 1) and downstream (CS 2) control site, with collective totals of eight sampling units. Each sampling unit was separated by a minimum of $250 \mathrm{~m}$. Within each sampling unit, bird, small mammal, anuran, and

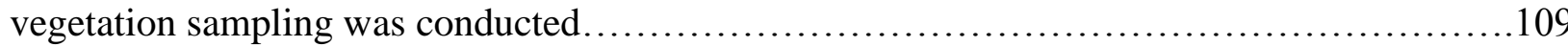

Figure 2. Before-after control-impact plots for overall small mammal abundances (number of small mammals/18 traps) observed within a restoration reach (RR), control sites (CS), and reference sites (RS) along a 13.7-km reach of the Cacapon River, West Virginia USA during summer 2009 (i.e., July to August, months 0 and 1), 2010 (i.e., June to August, months 11 to 13), and 2011 (i.e., May to August, months 22 to 25). The vertical line in the plot corresponds to the

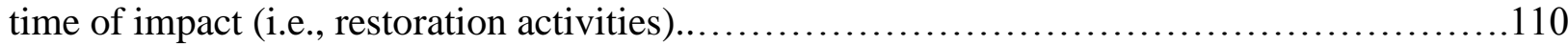

Figure 3. Before-after control-impact plots for the Peromyscus maniculatus and P. leucopus complex abundance (number of Peromyscus spp./18 traps) observed within a restoration reach (RR), control sites (CS), and reference sites (RS) along a 13.7-km reach of the Cacapon River, West Virginia USA summer 2009 (i.e., July to August, months 0 and 1), 2010 (i.e., June to August, months 11 to 13), and 2011 (i.e., May to August, months 22 to 25). The vertical line in the plot corresponds to the time of impact (i.e., restoration activities) .....................111

Figure 4. Before-after control-impact plots for overall small mammal diversity, richness, and evenness (average diversity metric/18 traps) observed within a restoration reach (RR), control sites (CS), and reference sites (RS) along a 13.7-km reach of the Cacapon River, West Virginia USA during summer 2009 (i.e., July to August, months 0 and 1), 2010 (i.e., June to August, months 11 to 13), and 2011 (i.e., May to August, months 22 to 25). The vertical line in the plot corresponds to the time of impact (i.e., restoration activities) ............................112

Figure 5. Before-after control-impact plots for the 5 most abundant bird species (number of birds/50-m transect) observed within a restoration reach (RR), control sites (CS), and reference sites (RS) along a 13.7-km reach of the Cacapon River, West Virginia USA during May 2009 (month 0) to August 2011 (month 27). The vertical line in the plots corresponds to the time of

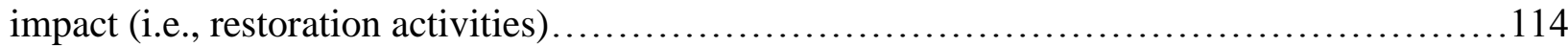

Figure 6. Before-after control-impact plots for (A) passerine and (B) overall bird (passerine and non-passerine) abundance (number of birds/50-m transect) observed within a restoration reach (RR), control sites (CS), and reference sites (RS) along a 13.7-km reach of the Cacapon River, West Virginia USA during May 2009 (month 0) to August 2011 (month 27). The vertical line in the plot corresponds to the time of impact (i.e., restoration activities)......................116

Figure 7. Before-after control-impact plots for passerine diversity, richness, and evenness (average diversity metric/50-m transect) observed within a restoration reach (RR), control sites (CS), and reference sites (RS) along a 13.7-km reach of the Cacapon River, West Virginia USA 
during May 2009 (month 0) to August 2011 (month 27). The vertical line in the plot corresponds to the time of impact (i.e., restoration activities) .............................................118

Figure 8. Before-after control-impact plots for overall bird diversity, richness, and evenness (average diversity metric/50-m transect) observed within a restoration reach (RR), control sites (CS), and reference sites (RS) along a 13.7-km reach of the Cacapon River, West Virginia USA during May 2009 (month 0) to August 2011 (month 27). The vertical line in the plot corresponds to the time of impact (i.e., restoration activities) ...........................................120

Figure 9. Before-after control-impact plot for frog and toad richness (number of species/5 minutes) observed within a restoration reach (RR), control sites (CS), and reference sites (RS) along a 13.7-km reach of the Cacapon River, West Virginia, USA during April (months 0, 12, and 24), June (months 2, 14, and 26), and August (months 4, 16, and 28) of 2009, 2010, and 2011. The vertical line in the plot corresponds to the time of impact (i.e., restoration activities) 


\section{Ch II: Appendices}

Appendix Ia. List of vegetation (means and standard errors, SE) recorded within sites associated with a streambank restoration project along a reach of the Cacapon River, West Virginia, USA during June 2009, 2010, and 2011. The vegetation was documented in three layers: field: \% cover of woody and herbaceous plants <1 m tall; shrub: abundance of woody plants $>1 \mathrm{~m}$ tall, $<5$ $\mathrm{cm}$ in diameter at breast height (dbh); and tree: abundance of woody plants $>5 \mathrm{~cm}$ dbh per $100-\mathrm{m}$ radius survey circle.

Appendix IIa. Diversity index means and standard errors (SE) for the site $\times$ time interactions related to overall (natives and exotics) vegetative layers (field: \% cover of woody and herbaceous plants $<1 \mathrm{~m}$ tall; shrub: abundance of woody plants $>1 \mathrm{~m}$ tall, $<5 \mathrm{~cm}$ in diameter at breast height (dbh); and tree: abundance of woody plants $>5 \mathrm{~cm} \mathrm{dbh}$ ) per $100-\mathrm{m}$ radius survey circle sampled along a 13.7-km reach of the Cacapon River, West Virginia, USA, during June 2009, 2010, and 2011. Sites were associated with a river restoration project: RR, 1,100 m restoration reach; $\mathrm{RS}$, reference site; and $\mathrm{CS}$, control site............................270

Appendix IIIa. Diversity index means and standard errors (SE) for the site $\times$ time interactions related to native vegetative layers (field: \% cover of woody and herbaceous plants $<1 \mathrm{~m}$ tall; shrub: abundance of woody plants $>1 \mathrm{~m}$ tall, $<5 \mathrm{~cm}$ in diameter at breast height (dbh); and tree: abundance of woody plants $>5 \mathrm{~cm}$ dbh) per 100-m radius survey circle sampled along a 13.7-km reach of the Cacapon River, West Virginia, USA, during June 2009, 2010, and 2011. Sites were associated with a river restoration project: RR, 1,100 m restoration reach; RS, reference site; and CS, control site. 


\section{Ch III: List of tables}

Table 1. Averages, standard errors (SE), minimum, and maximum of each morphometric variable recorded for all unique wood turtles ( $n=284$; males, $n=137$; females, $n=88$; juveniles, $n=59$ ) captured and all wood turtles observed mating (males, $n=25$; females, $n=18$ ) along a 13.7-km reach of the Cacapon River, West Virginia, USA during spring 2009 to summer 2011. All measurements are in mm, except mass (g). Within a row, means with the same letter are not different.

Table 2. Radio-telemetry data for wood turtles $(n=31)$ tracked along a $13.7-\mathrm{km}$ reach of the Cacapon River, West Virginia, USA during spring 2009 to summer 2011. Minimum Convex Polygon (MCP) home range sizes (calculated in package Adehabitat, statistical software program $\mathrm{R})$ are in hectares (ha). Home ranges were not generated for turtles tracked $\leq 10$ times.... .168

Table 3. Structural vegetative characteristics measured at random plots $(n=110)$ and wood turtle plots $(n=110)$ along a $13.7-\mathrm{km}$ reach of the Cacapon River, West Virginia, USA during spring 2009 to summer 2011. The variables recorded within $1-\mathrm{m}^{2}$ plots at the corners of a 10x $10-\mathrm{m}$ plot within a 100-m radius survey circle were: \% canopy cover (CC), \% bare ground and rock cover (BGR), \% leaf litter cover (LL), \% woody debris cover (WD), and vertical density $(\mathrm{VD}, \mathrm{cm})$. Measurements were averaged for the whole plot. Means followed by the same letter are not significantly different (Bonferroni correction: $\alpha=0.05 / 5$ tests $=0.01$ ).... 170

Table 4. Diversity and richness means and standard errors (SE) for vegetative layers (i.e., field: all plants $<1 \mathrm{~m}$ tall, shrub: woody plants $>1 \mathrm{~m}$ tall and $<5 \mathrm{~cm}$ diameter at breast height (dbh), and tree: woody plants $>5 \mathrm{~cm}$ dbh) associated with wood turtle plots $(n=110)$ and random plots $(n=$ 110) sampled along a 13.7-km reach of the Cacapon River, West Virginia, USA during spring 2009 to summer 2011

Table 5. Multiple comparison contrasts (significant and interaction simple effects [within years]) related to vegetation (overall [native and exotic] and natives-only) surveys associated with wood turtle plots (T; $n=110)$ and random plots $(\mathrm{R} ; n=110)$ sampled along a $13.7-\mathrm{km}$ reach of the Cacapon River, West Virginia, USA during spring 2009 to summer 2011. The vegetative layers were field: \% cover of woody and herbaceous plants <1 $\mathrm{m}$ tall; shrub: abundance of woody plants $>1 \mathrm{~m}$ tall, $<5 \mathrm{~cm}$ in diameter at breast height (dbh); and tree: abundance of woody plants $>5 \mathrm{~cm}$ dbh per $100-\mathrm{m}$ radius survey circle........................................... 173

Table 6. Diversity and richness means and standard errors (SE) for native vegetative layers (i.e., field: all plants $<1 \mathrm{~m}$ tall, shrub: woody plants $>1 \mathrm{~m}$ tall and $<5 \mathrm{~cm}$ diameter at breast height (dbh), and tree: woody plants $>5 \mathrm{~cm}$ dbh) associated with wood turtle plots $(n=110)$ and random plots $(n=110)$ sampled along a $13.7-\mathrm{km}$ reach of the Cacapon River, West Virginia, USA during spring 2009 to summer 2011. Means followed by the same letter are not significantly different (Bonferroni correction: $\alpha=0.05 / 6$ tests $=0.008$ ). Differences in main effect means were not interpreted when significant interactions occurred.................175

Table 7. Seasonal proportions of the overall wood turtle ( $n=1,443$ captures) population and of males $(n=751)$, females $(n=524)$, and juveniles $(n=168)$ based on terrestrial (T) or aquatic (A) 
occurrence along a 13.7-km reach of the Cacapon River, West Virginia, USA during spring 2009 to summer 2011 .

Table 8. Environmental variables (mean, standard error, and min - max) related to wood turtles ( $n=1,419$ captures) being aquatic (A) or terrestrial (T) depending on season along a 13.7-km reach of the Cacapon River, West Virginia, USA during spring 2009 to summer 2011. Headings are as follows: soil temperature (ST), air temperature (AT), water temperature (WT), soil moisture $(\mathrm{SM} ; 1=$ dry, $10=$ saturated $)$, and relative humidity $(\mathrm{RH})$ 178

Table 9. Locations of mating wood turtle pairs $(n=28)$ along a $13.7-\mathrm{km}$ reach of the Cacapon River, West Virginia, USA during late March to early June (Spring) and late August to early November (Autumn), 2009 to 2011 180 


\section{Ch III: List of figures}

Figure 1. Examples of home ranges for a male, female, and juvenile wood turtle in West Virginia, USA during spring 2009 to summer 2011. The Cacapon River flows through the center of each picture. Non-forested patches are agricultural land: hay fields, cornfields, and cattle pasture. The forested area to the right of each picture is mountainous

Figure 2. Non-metric multidimensional scaling (NMDS) plot of indicator species vegetation that differentiated the overall (natives and exotics) field (all plants $<1 \mathrm{~m}$ tall) community (A) between plots with wood turtles (T; blue: bedstraw) and random plots (R; red: reed canary grass) and (B) in spring (Sp;red: reed canary grass and ground ivy) and summer ( $\mathrm{Su}$; blue: Japanese stilt grass and bedstraw) along the Cacapon River, West Virginia, USA

Figure 3. Non-metric multidimensional scaling (NMDS) plot of indicator species vegetation that differentiated the native field (all plants $<1 \mathrm{~m}$ tall) community (A) in spring ( $\mathrm{Sp}$; red: reed canary grass) and summer (Su; blue: bedstraw) and (B) in 2009 (9; blue: Carex spp.) and 2011 (11; red: Japanese stilt grass and bedstraw) along the Cacapon River, West Virginia, USA. No indicators were present for 2010 . 184

Figure 4. Non-metric multidimensional scaling (NMDS) plot of the indicator species that differentiated the native shrub (woody plants $>1 \mathrm{~m}$ tall and $<5 \mathrm{~cm}$ in diameter at breast height) community in spring and summer (Su; red: Spicebush) along the Cacapon River, West Virginia, USA during 2009 to 2011 . No indicators were present for spring.

Figure 5. Non-metric multidimensional scaling (NMDS) plot of indicator species vegetation that differentiated the native tree ( $>5 \mathrm{~cm}$ diameter at breast height) community (A) between plots with wood turtles (T; red: tulip poplar) and random plots $(\mathrm{R}),(\mathrm{B})$ in spring $(\mathrm{Sp})$ and summer $(\mathrm{Su}$; red: sugar maple and tulip poplar), and (C) in 2009 (9), 2010 (10; red: tulip poplar), and 2011 (11; blue: eastern cottonwood) along the Cacapon River, West Virginia, USA. No indicators were present for random plots, spring, or 2009 


\section{Ch III: Appendices}

Appendix Ib. Means and standard errors (SE) of vegetation recorded within 110 random plots and 110 plots associated with wood turtle captures along the Cacapon River, West Virginia, USA during spring 2009 to summer 2011. The vegetation was documented in 3 layers: field (\% cover of woody and herbaceous plants $<1 \mathrm{~m}$ tall), shrubs (abundance of woody plants $>1 \mathrm{~m}$ tall, $<5 \mathrm{~cm}$ diameter at breast height $(\mathrm{dbh})$ ), and trees (abundance of woody plants $>5 \mathrm{~cm} \mathrm{dbh}$ )..........274

Appendix IIb. Interaction diversity and richness means and standard errors (SE) for overall (natives and exotics) vegetative layers (i.e., field: all plants $<1 \mathrm{~m}$ tall, shrub: woody plants $>1 \mathrm{~m}$ tall and $<5 \mathrm{~cm}$ diameter at breast height (dbh), and tree: woody plants $>5 \mathrm{~cm} \mathrm{dbh}$ ) associated with wood turtle plots $(n=110)$ and random plots $(n=110)$ sampled along a 13.7-km reach of the Cacapon River, West Virginia, USA during spring 2009 to summer $2011 \ldots \ldots \ldots \ldots \ldots . . .278$

Appendix IIIb. Interaction diversity and richness means and standard errors (SE) for native vegetative layers (i.e., field: all plants $<1 \mathrm{~m}$ tall, shrub: woody plants $>1 \mathrm{~m}$ tall and $<5 \mathrm{~cm}$ diameter at breast height ( $\mathrm{dbh}$ ), and tree: woody plants $>5 \mathrm{~cm} \mathrm{dbh}$ ) associated with wood turtle plots $(n=110)$ and random plots $(n=110)$ sampled along a $13.7-\mathrm{km}$ reach of the Cacapon River,

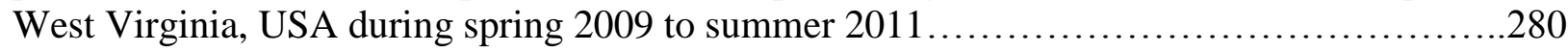




\section{Ch IV: List of tables}

Table 1. Morphological characteristics of a wood turtle population (males, $n=27$; females, $n=$ 22; juveniles, $n=11$ ) at the southern limits of their range along the North and Lost rivers of West Virginia, USA, during summer 2010. Means (followed by the same letter are not different $(P>$ $0.006[\alpha=0.05 / 8]$ ) across genders), standard errors (SE), and ranges (min and max) are given for each characteristic. All measurements are in $\mathrm{mm}$, except mass $(\mathrm{g}) \ldots \ldots \ldots \ldots \ldots \ldots \ldots \ldots \ldots \ldots . . .228$

Table 2. Diversity and richness means and standard errors (SE) for overall (natives and exotics) vegetative layers (field: woody and herbaceous plants < $1 \mathrm{~m}$ tall; shrub: woody plants $>1 \mathrm{~m}$ tall, $<5 \mathrm{~cm}$ in diameter at breast height ( $\mathrm{dbh}$ ); and tree: woody plants $>5 \mathrm{~cm} \mathrm{dbh}$ ) associated with sites related to the presence $(\mathrm{P})$ or absence $(\mathrm{A})$ of wood turtles sampled along the Lost (L) and North (N) rivers, Cacapon River Watershed, West Virginia, USA, during summer 2010. Means followed by the same letter are not different $(\alpha=0.05 / 6$ tests $=0.008)$; main effects were not interpreted when belonging to a significant interaction................................230

Table 3. Tukey tests (significant or, when relevant, interaction simple effects [site differences within rivers]) with $95 \%$ confidence intervals (CI) related to vegetative (field layer: woody and herbaceous plants, $<1 \mathrm{~m}$ tall; shrub: woody plants $>1 \mathrm{~m}$ tall, $<5 \mathrm{~cm}$ in diameter at breast height (dbh); and tree: woody plants $>5 \mathrm{~cm}$ dbh) diversity and richness within sites with the presence (P) or absence (A) of wood turtles along the Lost and North rivers, Cacapon River Watershed,

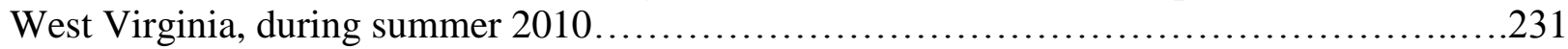

Table 4. Diversity and richness means and standard errors (SE) for native vegetative layers (field: woody and herbaceous plants $<1 \mathrm{~m}$ tall; shrub: woody plants $>1 \mathrm{~m}$ tall, $<5 \mathrm{~cm}$ in diameter at breast height (dbh); and tree: woody plants $>5 \mathrm{~cm} \mathrm{dbh}$ ) associated with sites related to the presence $(\mathrm{P})$ or absence $(\mathrm{A})$ of wood turtles sampled along the Lost $(\mathrm{L})$ and North $(\mathrm{N})$ rivers, Cacapon River Watershed, West Virginia, USA, during summer 2010. Means followed by the same letter are not different $(\alpha=0.05 / 6$ tests $=0.008)$. No site $\times$ river interactions were

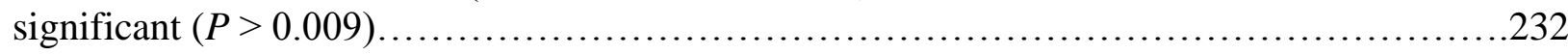

Table 5. Penalized likelihood ratio tests on the log-odds ratios and $95 \%$ profile penalized likelihood confidence intervals (CI; original data scale) computed for a model containing microhabitat variables related to the presence of wood turtles along the Lost and North rivers, Cacapon River Watershed, West Virginia, USA, during summer 2010. Distance refers to the distance $(\mathrm{km})$ of the Lost and North rivers to the Cacapon River. 


\section{Ch IV: List of figures}

Figure 1. Non-metric multidimensional scaling (NMDS) plot (vegan package, $R$ ) of native field layer (woody and herbaceous plants $<1 \mathrm{~m}$ tall) indicator species along the Lost (L) River, Cacapon River Watershed, West Virginia, USA, during summer 2010 surveys for wood turtles. The species were wingstem (VEAL) and reed canary grass (PHAR). No indicator species occurred along the North $(\mathrm{N})$ River, or with regards to the presence or absence of wood turtles.

Figure 2. Non-metric multidimensional scaling (NMDS) plot (vegan package, R) of (A) overall (natives and exotics) and (B) native shrub ( $>1 \mathrm{~m}$ tall, $<5 \mathrm{~cm}$ in diameter at breast height) indicator species observed along the North (N) River, Cacapon River Watershed, West Virginia, USA, during summer 2010 surveys for wood turtles. The only indicator species was spicebush (LIBE). No indicator species occurred along the Lost (L) River, or with regards to the presence or absence of wood turtles. .235

Figure 3. Non-metric multidimensional scaling (NMDS) plot (vegan package, R) of (A) overall (natives and exotics) and (B) native tree $(>5 \mathrm{~cm}$ in diameter at breast height) indicator species observed in sites with the absence (A) of wood turtles along the Lost and North rivers, Cacapon River Watershed, West Virginia, USA, during summer 2010 surveys for wood turtles. The species were witch-hazel (HAVI) and ironwood (OSVI). No indicator species occurred in sites with wood turtles $(\mathrm{P})$, or with regards to river.

Figure 4. Log-odds model-based plot of the predicted probability of wood turtle site occupancy along the North and Lost rivers as a function of standardized distance (centered and scaled) from the Cacapon River, Cacapon River Watershed, West Virginia, USA. On the original data scale and using the lower prediction limit, the $50 \%$ and $0 \%$ predicted probabilities of site occupancy occurs about 39 and $77 \mathrm{~km}$, respectively, from the North and Lost rivers' confluence with the Cacapon River.

Figure 5. The Cacapon River Watershed is composed of the Cacapon River and its 2 major tributaries, the North and Lost rivers, in the eastern panhandle of West Virginia, USA. A 95\% utilization distribution (UD; adaptive local convex hull, Adehabitat package, R) for wood turtles was generated from Lost and North river sampling efforts during summer 2010. Model-driven cutpoints (tick marks) for $50 \%$ and $0 \%$ predicted probabilities of site occupancy along the North

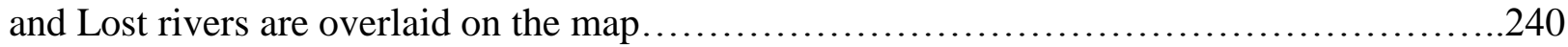




\section{Ch IV: Appendices}

Appendix Ic. Random sampling plots were surveyed along the North River $(n=61)$ and Lost River $(n=39)$, Cacapon River Watershed, West Virginia, USA during June to August 2010 for

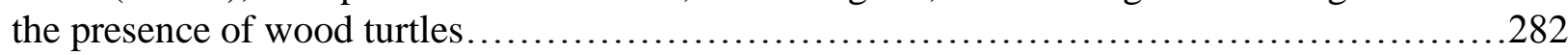

Appendix IIc. Means and standard errors (SE) of vegetation (field: \% cover of woody and herbaceous plants $<1 \mathrm{~m}$ tall; shrubs: abundance of woody plants $>1 \mathrm{~m}$ tall, $<5 \mathrm{~cm}$ diameter at breast height (dbh); and trees: abundance of woody plants $>5 \mathrm{~cm} \mathrm{dbh}$ ) recorded within 100 random sites along the Lost and North rivers, Cacapon River Watershed, West Virginia, during summer 2010 .283

Appendix IIIc. Diversity and richness means and standard errors (SE) for vegetative layers (field: woody and herbaceous plants <1 $\mathrm{m}$ tall; shrub: woody plants $>1 \mathrm{~m}$ tall, $<5 \mathrm{~cm}$ in diameter at breast height (dbh); and tree: woody plants $>5 \mathrm{~cm} \mathrm{dbh}$ ) associated with the interaction of sites (presence $[\mathrm{P}]$ or absence $[\mathrm{A}]$ of wood turtles) and rivers (Lost $[\mathrm{L}]$ and North $[\mathrm{N}]$ rivers), Cacapon

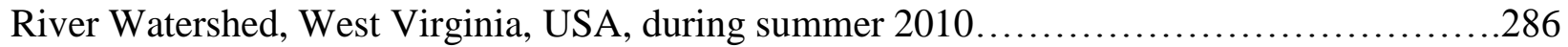




\section{Ch V: List of figures}

Figure 1. Photograph of Noah McCoard with a Peromyscus spp. individual to be processed, captured in a Sherman live-trap at the upstream control site, Cacapon River, West Virginia, USA, in August 2009.

Figure 2. Photograph of Kathryn McCoard processing 2 wood turtles and their habitat along the Cacapon River, West Virginia, USA, in October 2010.

Figure 3. Photograph of a bald eagle, one of the many bird species recorded along the 13.7-km study reach of the Cacapon River, West Virginia, USA; it was taken along the restoration reach, April 2009

Figure 4. Photograph of Noah McCoard holding an ear-tagged Peromyscus spp. individual during small mammal trapping, taken at the upstream control site, Cacapon River, West Virginia, USA in August 2009.

Figure 5. Photograph of a spring peeper, the most abundant anuran species along the 13.7-km study reach of the Cacapon River, West Virginia, USA; it was taken at the restoration reach, June 2010

Figure 6. Photograph of Kathryn McCoard preparing a wood turtle for radio-tracking by attaching a transmitter with epoxy to the rear corner of the carapace after the turtle was processed, along the Cacapon River, West Virginia, USA in July 2009.

Figure 7. Photograph of wood turtles mating terrestrially along the Cacapon River, West Virginia, USA during September 2010; the reproductive males (top) in this population were longer, heavier, and thicker (to support larger appendages) than the reproductive females (bottom)

Figure 8. Photograph of a juvenile wood turtle eating a slug, the primary prey of the turtles along the Cacapon River, West Virginia, USA in May 2010.

Figure 9. Photograph of a wood turtle (bottom) walking through an active pasture along the

Cacapon River, West Virginia, USA in May 2010.

Figure 10. Photograph of a wood turtle making a trail through the tall, thick herbaceous vegetation of typical wood turtle habitat along the Cacapon, Lost, and North rivers, in June 2010 


\title{
CHAPTER I
}

Project Overview: Objectives and Literature Review for Stream Restoration and Wood

Turtle Ecology, Cacapon River Watershed, West Virginia

\author{
Kathryn R. P. McCoard \\ roamingwild@gmail.com \\ West Virginia University \\ Division of Forestry and Natural Resources \\ PO Box 6125 \\ Morgantown, WV 26506
}




\section{Role of the Riparian Zone}

Riparian ecosystems compose about $1.5 \%$ of United States' land (United States Fish and Wildlife Service 1981). Riparian zones are the streamside vegetation corridors bordering streams and have a high water table because of their adjacency to streams (Mitsch and Gosselink 2007). They function through (1) filtering pollutants before they enter a stream, (2) decreasing stream bank erosion, (3) absorbing flood impacts, and (4) providing shade to keep microclimatic conditions cool (Constantz et al. 1995, Ndubisi et al. 1995). They are also a source of organic debris, including entire trees, for streams (Mitsch and Gosselink 2007) which aid in increasing in-stream habitat complexity. Riparian zones are environmentally sensitive areas, or landscape elements that are essential to the long-term sustainability of biodiversity, soil, water, or other natural resources both locally and regionally (Ndubisi et al. 1995). In impacted areas, riparian zones should be managed for them to continue providing beneficial services (Purcell et al. 2002, Suren et al. 2005). Management requires identifying and reducing or stopping sources of stream degradation, primarily silt and pollutants (Bodie 2001), that originate from agricultural and developmental practices. Degraded streams that receive restorative effects (e.g., riparian vegetative plantings and in-stream step-pools) can improve in biological and habitat integrity similar to that of reference sites (Purcell et al. 2002).

Multiple animal species can be found in riparian zones (Chapter 2), including amphibians (Rudolph and Dickson 1990, Crawford and Semlitsch 2007), reptiles (Bodie 2001), small mammals (Hannon et al. 2002), and birds (Thurmond et al. 1995, Machtans et al. 1996). Riparian zones are used by wildlife for a variety of life-history aspects that include nesting (Kus 1998, Saumure et al. 2007), foraging (Golet et al. 2008), and movement (i.e., dispersal and migration) corridors (Ndubisi et al. 1995, Machtans et al. 1996, Hilty and Merenlender 2004). 
Some animals are dependent upon riparian zones for every aspect of life, such as streamside salamanders that may travel less than $40 \mathrm{~m}$ from a stream edge (Crawford and Semlitsch 2007).

One species, wood turtles (Glyptemys insculpta), recently listed as a species of high conservation priority in the United States (Endangered Species Coalition 2008), rarely travels farther than 300 m from the stream edge (McCoard 2012, chapter 3; Brewster and Brewster 1991; Quinn and Tate 1991; Kaufmann 1992; Arvisais et al. 2002) and, due to a high rate of evaporative body-water loss, is possibly dependent upon riparian zones (Ernst 1968) for survival. The dependence of wildlife on riparian zones demonstrates the great need for conservation and restoration of this essential habitat if the ecological value of the ecosystem is to be maintained.

\section{Stream Restoration and Natural Stream Design}

The main purposes of many stream restoration projects are to (1) stabilize banks, (2) improve instream habitat, (3) reconfigure the channel, (4) increase water quality, and (5) manage the riparian zone (Bernhardt et al. 2005, Palmer et al. 2005). An effective restoration plan should include (1) clear objectives; (2) background data; (3) recognition of biotic refugia functions; (4) comparison with reference reaches; (5) commitment to extended planning, implementation, and monitoring; (6) criteria to determine success or failure; and (7) ability to learn from and adapt to all outcomes (Cairns and Heckman 1996, Wissmar and Beschta 1998, Morrison 2002, Bernhardt et al. 2005). Stream restoration designs, focused on small streams (first - third order), with the purpose of decreasing nutrient uptake, for example, need to consider the source of the nutrient, the discharge rate, and the annual nutrient load to provide necessary hydraulic resistance for high nutrient flows (Craig et al. 2008). Restoration in pursuit of improving water quality can also lead to improving habitat conditions and mitigating floods (Mitsch and Gosselink 2007). 
A stable stream system balances the flow of water and sediment through a watershed in such a way that the particles neither aggrade or degrade, maintaining the stream's form (Rosgen 1996). An unstable stream erodes and becomes incised through a variety of ways, including channelization, loss of riparian vegetation, large floods, development, and changes in sediment. The banks of incised streams are high and extremely erodible (Rosgen 1997), indicating a need for restorative activities. Using a process called natural stream channel design, restoration should begin with understanding the causes of a stream's instability, knowing the morphology of the stable form, or reference reaches, and restoring the flow of the incised reach in order to be successful (Cairns and Heckman 1996, Rosgen 1997); typically, the desire is to link the stream back to its abandoned floodplain (Rosgen 1997). Materials such as concrete, boulders, and bioengineering methods are used to stabilize the eroding banks (Rosgen 1997). In-stream manipulation methods are used to promote and restore fish habitat, decrease sediment load, reconstruct streambed substrate, and restore sinuosity and distribution of energy (Cairns and Heckman 1996). The morphology and function of the restored reaches are compared to the reference reaches to evaluate the success of the project (Rosgen 1997). We conducted a study to monitor the responses of birds, small mammals, and anurans during the course of a river restoration project that included revegetation of the riparian zone in order to evaluate the success of the restoration.

\section{North American Wood Turtle}

Wood turtles dispersed north to their current range from an Alabama or Georgia refugium as the glaciers melted post-Pleistocene (Amato et al. 2008). The main dispersal route was probably east of the Appalachian Mountains, but the populations that occur as far west as Iowa and Minnesota may have dispersed westward across the Appalachians or from a southern refugium 
that existed west of the Appalachians (Amato et al. 2008). Wood turtles currently occur in 17 states along the Great Lakes and northeastern United States, and in 4 eastern Canadian provinces (Conant and Collins 1998). Within the United States, they are listed as a Species of Special Concern in Connecticut, Massachusetts, Maine, Michigan, New Hampshire, and Vermont; threatened in New Jersey, Virginia, and Wisconsin; endangered in Iowa; and imperiled in West Virginia. Within Canada, they are listed as sensitive in New Brunswick, vulnerable in Nova Scotia and Quebec; and endangered in Ontario.

Wood turtles are declining from a variety of causes including over-collection, habitat fragmentation, predation, and nest depredation (Saumure and Bider 1998, Moll 2000, Turtle Conservation Fund 2002, Saumure et al. 2007, Walde et al. 2007, Endangered Species Coalition 2008). Aspects of their habitat use and population dynamics need to be understood for effective conservation (Quinn and Tate 1991, Kaufmann 1992, Bodie 2001). Little research has been conducted on the life history strategies and range limitations of wood turtles along the southern border of their geographic range, particularly in West Virginia. We conducted 2 wood turtle studies: (1) to determine the ecology of the species living in an agri-forest environment and (2) to determine what environmental and habitat features may be limiting the species from reoccupying their southern range.

\section{JUSTIFICATION}

\section{Importance of the Riparian Zone and Stream Restoration Monitoring}

It is estimated that of approximately 49.8 million ha of national riparian lands, only 9.3 million ha remain in a somewhat natural state (Constantz et al. 1995). Riparian corridors, wetlands, large forests, and reservoir watersheds are environmentally sensitive areas that are in need of immediate protection (Ndubisi et al. 1995). Identifying, halting, or managing (e.g., creating 
vegetation buffers) sources of stream degradation (e.g., silt and pollutants) is essential to streamside restoration plans (Bodie 2001). However, only about $10 \%$ of stream restoration projects nationwide have included monitoring of the project (Bernhardt et al. 2005). In the Chesapeake Bay watershed, which includes the Cacapon River watershed, only $6 \%$ of stream restoration project records indicated that monitoring occurred (Bernhardt et al. 2005), so information on stream quality improvements from restoration is critically lacking.

Monitoring of terrestrial wildlife responses to stream restoration efforts is especially lacking. For species that depend on the riparian zone for a variety of life history aspects, elimination or alteration of that habitat can affect nest production and thus juvenile recruitment (Kus 1998, Bodie 2001). Highly eroded streambanks can have drastic effects on wildlife populations that use the riparian zone by collapsing and burying individuals alive (Saumure et al. 2007). In-stream wildlife also depends upon riparian zone quality for clean water and contributions to habitat complexity (Jones et al. 1999, Schmetterling and Pierce 1999, Purcell et al. 2002). Restoration of degraded riparian zones along impacted streams is a necessary step towards sustaining wildlife populations that are dependent upon the riparian zones.

\section{Status of the Cacapon River Watershed Riparium and its Effects on Wildlife}

The upstream half of the Cacapon River Watershed is heavily farmed, with crops and pastureland pushed to the edge of the river (Constantz et al. 1995). Many pasture fields are not fenced and cattle are allowed free access to the river, lowering streambank soil retention and compacting floodplain soil. The riparian vegetation is thus diminished and degraded. The combined effects from the cattle are magnified during rain events when pollutants and loosened soil are carried in surface run-off to the stream, negatively affecting water quality and in-stream wildlife. The Cacapon Institute, an organization that works to protect the Cacapon River, urges 
the rebuilding of the riparian corridor as the first step to restoration along the river (Constantz et al. 1995).

The Cacapon River Watershed is $19 \%$ agriculture (NPS 1982), primarily along the upstream half of the watershed (Constantz et al. 1995), and, as a tributary of the Potomac River, could be contributing nutrients, such as nitrogen, to the Chesapeake Bay. Flow of excess nitrogen along rivers to coastal waterways is a concern due to its contributions to eutrophication (Howarth et al. 2002). A primary source of nitrogen is from agricultural runoff (Boyer et al. 2002, Craig et al. 2008). Methods used to reduce in-stream nitrogen include practices such as establishing riparian vegetation (Craig et al. 2008). Stream restoration is a valuable tool to reduce the flow of nutrients and sediment from small streams into larger water bodies that are used for a variety of human purposes.

The agricultural activities within the Cacapon River watershed have created fragmentation of forested habitat patches for wildlife. Metapopulations can thus be created. A metapopulation, defined as a "set of local populations within some larger area, where typically migration from one local population to at least some other patches is possible" (Hanski and Simberloff 1997), is driven by extinction and colonization of patches in a landscape (Gotelli 1991, Hanski and Ovaskainen 2000). In fragmented landscapes, such as the Cacapon River watershed, migration and dispersal occur along habitat corridors that link habitat patches (Bennett 1990), critical for the long-term persistence of wildlife populations existing within fragmented landscapes (Burke et al. 1995, Gibbons 2003). Riparian zones are such corridors and serve to facilitate movement between habitat patches (Ndubisi et al. 1995, Machtans et al. 1996, Hilty and Merenlender 2004) that connect metapopulations (Burke et al. 1995, Hilty and Merenlender 2004, Mandujano et al. 2005), but this service cannot be provided when the riparian 
zone is degraded by agricultural practices. The population of wood turtles, a species dependent upon healthy riparian zones, in the Cacapon River watershed may be developing into a metapopulation as a result of extensive agricultural activities at the southern limits of their range (Chapter 4).

\section{Decline of Wood Turtles}

Throughout their range, turtles are declining through road mortalities, overwintering nest mortalities, nest depredation, over-collecting, predation, and habitat fragmentation and destruction (Saumure and Bider 1998, Moll 2000, Turtle Conservation Fund 2002, Saumure et al. 2007, Walde et al. 2007, Endangered Species Coalition 2008). Characteristics of declining turtle populations over time include a decreasing proportion of females to males, as well as a decreasing proportion of juveniles (Stickel 1978). Habitat alteration and destruction of parts of a geographic area occupied by turtles can have unforeseen consequences on turtle abundances and have been the focus of few studies (Burke et al. 1995, Marchand et al. 2002, Steen and Gibbs 2004). According to the 2000 IUCN Red List of Threatened Species, about $45 \%$ of the freshwater turtles and tortoises worldwide are listed as threatened, and not all species have been evaluated for Red List status (Turtle Conservation Fund 2002).

In Quebec, Canada, wood turtles declined by $19.2 \%$ in 5 years (Saumure et al. 2007). Along the Sutton River of Quebec, a population of wood turtles declined by $50 \%$ in 7 years (Daigle and Jutras 2005). In Connecticut, 10 years after an area was opened for recreation, 2 wood turtle populations had declined 100\% (Garber and Burger 1995). In 1992, wood turtles were listed in CITES Appendix II as a species that may become threatened with extinction if trade in them is not regulated (CITES 2008). In 2007, the species was listed as threatened by the Committee on the Status of Endangered Wildlife in Canada, an updated status from the species' 
vulnerable listing in 1996 (COSEWIC 2009). In 2008, they were listed as one of the top 10 species recognized as threatened or endangered in the United States that is the most in need of protection by the Endangered Species Act (Endangered Species Coalition 2008). Few studies of wood turtles have occurred along the southern border of their range, and geographic gaps in the species' ecology should be filled to determine the status and needs of wood turtle populations in

West Virginia to plan effective conservation and management strategies.

\section{OBJECTIVES}

Study 1: The response of terrestrial wildlife to stream restoration was studied based on the following objective, with its corresponding hypotheses.

1. Compare the ecological communities of birds, small mammals, and anurans between the restoration site (RR), upstream (RS 1) and downstream (RS 2) reference sites, and upstream (CS 1) and downstream (CS 2) control sites before and after the restoration impact.

$\mathrm{H}_{\mathrm{ol}}$ : The abundance, richness, diversity, and evenness of birds, small mammals, and anurans will not differ between sites.

$\mathrm{H}_{\mathrm{a} 1}$ : The restoration reach will increase in bird, small mammal, and anuran abundance, richness, diversity, and evenness compared to control sites, but not yet equal to reference sites.

$\mathrm{H}_{\mathrm{o} 2}$ : Community compositions will not change within sites during the course of the study.

$\mathrm{H}_{\mathrm{a} 2}$ : Only the restoration reach community composition will undergo a change post-impact. 
Study 2: The ecology of wood turtles within the Cacapon River riparian zone, adjacent to agricultural lands, was studied based on the following objective. As this was an observational study, no formal hypotheses were formulated.

1. Identify natural history characteristics of wood turtles along the upper Cacapon River by determining:

a. Morphometrics of males, females, and juveniles;

b. Home range sizes of males, females, and juveniles;

c. Activity cycles, including mating, nesting, basking, diet, terrestriality, and hibernating activities.

Study 3: The factors affecting wood turtles along the Lost and North rivers, at the southern limits of their range in West Virginia, were studied based on the following objectives, with their corresponding hypotheses.

1. Determine aquatic and terrestrial habitat characteristics relevant to the presence or absence of wood turtles along the Lost and North rivers.

$\mathrm{H}_{\mathrm{o}}$ : Wood turtles are not limited by geographic or environmental features beyond their southern range boundary.

$\mathrm{H}_{\mathrm{a}}$ : Wood turtles are limited by geographic and environmental features that are unsuitable for their survival beyond their southern range boundary.

2. Determine the approximate southern geographic boundary of wood turtles within the Cacapon River Watershed.

$\mathrm{H}_{\mathrm{o}}$ : The geographic range of wood turtles does not reach a southern termination within the Cacapon River Watershed.

$\mathrm{H}_{\mathrm{a}}$ : The geographic range of wood turtles reaches a southern termination within 
the Cacapon River Watershed.

3. Identify potential dispersal barriers to the west or south of the current range.

$\mathrm{H}_{\mathrm{o}}$ : Wood turtles are not limited in their ability to disperse south or west of their current range extent.

$\mathrm{H}_{\mathrm{a}}$ : Wood turtles are limited in their ability to disperse by geographic features, such as river size and mountain elevation, preventing range expansion to the south or west.

\section{LITERATURE REVIEW}

\section{Riparian Zone Restoration, Conservation, and Wildlife Use}

Stream restoration success is often evaluated through aquatic wildlife responses (Jones et al. 1999, Schmetterling and Pierce 1999, Purcell et al. 2002, Selego et al. 2012), but rarely through monitoring terrestrial riparian wildlife (Bernhardt et al. 2005, Golet et al. 2008). Riparian wildlife respond positively to revegetation of degraded riparian zones (Kus 1998, Taylor and McDaniel 1998). Bird, amphibian, reptile, and small mammal biodiversity increase with revegetation and community compositions change from species of dry, open canopies to species of more mesic habitats (Taylor and McDaniel 1998). Young restored sites often contain species adapted for early successional riparian habitats, but older restored sites contain higher abundances and richness of various species (e.g., birds, bats, and beetles) that are similar to remnant riparian stands (Golet et al. 2008). Stream restoration can be considered successful in terms of wildlife responses if the restored riparian zone provides benefits for special-status species and largely restores the native faunal community (Golet et al. 2008).

An estimated 173 terrestrial vertebrate species rely on riparian zones in the eastern United States for various life history needs, including 70 amphibian species, 50 reptile species, 
27 bird species, and 26 mammal species, (unpublished data, cited in Crawford and Semlitsch 2007). The ability of riparian zones to function properly can affect aquatic life in streams, such as benthic macroinvertebrates (e.g., Purcell et al. 2002) and fishes (e.g., Jones et al. 1999, Schmetterling and Pierce 1999), as well. Laws specific for the conservation of riparian zones should be introduced or enforced to protect the vital link between terrestrial and aquatic habitats (Becker et al. 2007).

In the Nantahala National Forest of North Carolina, $95 \%$ of streamside salamanders were found to move up to $27 \mathrm{~m}$ from the stream edge during daily and nightly activities (Crawford and Semlitsch 2007). The investigators suggested buffer widths of $50 \mathrm{~m}$ would aid in minimizing edge effects and include the core riparian habitat necessary for the persistence of streamside salamander populations. This buffer width falls within a wide $(30-95 \mathrm{~m})$ riparian zone treatment that was found to contain a greater abundance of reptiles and amphibians than a narrow $(0-25 \mathrm{~m})$ zone treatment in a Texas study (Rudolph and Dickson 1990). This may have been due to higher canopy closure and more abundant leaf litter in the wide treatment compared to the narrow treatment. As a result, the researchers recommended maintaining riparian zones of at least $30 \mathrm{~m}$ for riparian-dependant species when development is occurring near streams.

In Quebec, Canada, historical removal of vegetation along a river led to current extensive erosion along fields and pastures bordering the river (Saumure et al. 2007). The researchers believed that survival of juvenile wood turtles at their site was negatively affected by river dredging and collapsing of eroded banks, leading to the burying of the juveniles hiding within the riparian zone. Wood turtles nest within natural erosion zones (Saumure et al. 2007), so nests can potentially become buried by restoration effects. Walde et al. (2007) urged additional studies to be conducted on how anthropogenic disturbances affect the nesting ecology of wood 
turtles. One possible disturbance could come from the restoration of riparian zones. However, restoration may ultimately be beneficial, as wood turtles exhibit strong associations with riparian zones (Quinn and Tate 1991, Arvisais et al. 2004). Restoring riparian zones may increase the dispersal ability of wood turtles and aid in a greater survival potential for their populations by providing more suitable habitat for them to undergo their natural history strategies (Chapter 3).

Birds will use riparian buffer strips connecting forest patches. In response to the formation of buffer strips after adjacent forest was harvested, the number of resident adults within the newly formed buffer strips decreased (Machtans et al. 1996). However, the number of juveniles within the buffers increased as they used buffers as dispersal corridors. The width of the riparian corridor can have an effect on the abundance and densities of birds, as well. Bird densities were highest in narrow $(15.2 \mathrm{~m})$ corridor zones for both resident breeding birds and winter residents, but abundances were highest in wide $(50 \mathrm{~m})$ zones for breeding birds and equivalent in all 3 treatments (narrow, medium [30.5 m], and wide) for winter residents (Thurmond et al. 1995). This result was for edge species, however. Forest interior-edge species abundances were high in the medium and wide zones with highest densities in the narrow zones. Forest interior species had low abundances in the 3 riparian zone widths. Riparian buffers up to $53.3 \mathrm{~m}$ in width may, therefore, be beneficial for the persistence of edge-dependent species, but do not appear to affect forest interior species.

While riparian width can affect birds, in some forest types, width may not affect small mammals and anurans. In northeastern Alberta, Canada, in mature upland boreal mixedwood forests, riparian buffers of $20 \mathrm{~m}, 100 \mathrm{~m}$, and $200 \mathrm{~m}$ were established as treatments around lakes while an $800 \mathrm{~m}$ buffer was used as a control (Hannon et al. 2002). The surrounding area was logged for the first time, leading to the formation of the varying buffer sizes and isolated habitat 
patches. After harvesting, small mammal compositions of red-backed voles (Clethrionomys gapperi), deer mice (Peromyscus maniculatus), and meadow voles (Microtus pennsylvanicus) did not change in relation to buffer widths and no species were lost in the treatments. Similarly, the composition of the 3 anuran species (wood frog [Rana sylvatica], Canadian toad [Bufo hemiophrys], and western toad [Bufo boreas]) were not affected by buffer width after harvesting. Bird species were affected in abundance by crowding in the 20 -m buffer but exhibited little response past that. Bird composition also was changed in the 20-m strip as forest interior birds left and edge species came. The investigators concluded that buffer strips may not be a useful conservation tool for maintaining the wholeness of old-growth forest vertebrate communities. They believed that riparian buffers should not be fixed-width but flexible and dependent upon the size of an area's functional riparian zones, the geographic locations of water bodies within an area, and local aquatic conditions.

Along the Sacramento River, California, small mammals were a pest concern for farmers (Golet et al. 2011); river restoration can increase the habitat of small mammals, so the California farmers were against river restoration because of its potential role as a source of small mammal pests (Golet et al. 2011). Small mammal abundance, diversity, richness, and evenness were compared in agricultural sites, young and old riparian restoration sites, and remnant riparian sites. No differences were found in abundance among the site types, exonerating restored riparian zones as sources of small mammal pests in agricultural lands adjacent to rivers. The primary regulating force was natural flooding events, depressing small mammal population growth. In addition to providing habitat for the small mammals, the riparian zone buffered adjacent farmland from the flooding impacts. 
Riparian zones may be essential for movements of large mammals. In northern California, mammalian predators were studied to determine whether they preferred to travel through riparian corridors or the surrounding developed landscape (vineyards) (Hilty and Merenlender 2004). A disproportionate number of mammals were observed in the corridors compared to the vineyards, especially wide riparian corridors compared to narrow or bare corridors. Protection of the riparian corridors may thus assist in the persistence of native mammalian predator populations.

Benthic macroinvertebrates that are sensitive to pollution are dependent upon the functioning ability of riparian zones. In California, a 70-m stretch of stream was restored through the planting of riparian vegetation and the establishment of in-stream step-pools (Purcell et al. 2002). The site was evaluated for benthic macroinvertebrates 3 years later. The results of the restored site were compared to an un-restored site and a reference site. The restored site fell between the other sites in family biotic index (pollution-tolerant species assessment), pollutionsensitive orders (Ephemeroptera, Plecoptera, and Trichoptera [EPT]) richness, and percent EPT individuals. Recolonization of many macroinvertebrate species was observed within the restored site. These results indicated that the restored site increased in biotic integrity post-restoration, approaching the habitat quality of an undisturbed reference site, due in part to establishing a riparian buffer along the degraded stream reach.

Fishes also are affected by the quality of the riparian zone. In Georgia, 12 streams were surveyed for fish in relation to stretches of deforested riparian zones (Jones et al. 1999). Overall fish density and habitat diversity decreased as the length of upstream deforested stretches increased. Downstream silt deposition increased with increasing length of upstream deforested patches. This led to a change in fish communities from non-guarding fishes (e.g., darters, dace, 
and suckers) to guarding fishes (e.g., sculpins and sunfishes), demonstrating how modification of riparian zones can affect the biological and physical nature of the streams they border.

In Montana, riparian zone logging and removal of in-stream woody debris decreased fish habitat complexity (Schmetterling and Pierce 1999). During natural stream channel design restoration, structures made of wood and rock (e.g., log dams, rock dams, and debris collectors) were constructed within the channel and pools were created. After a large flood, $85 \%$ of the structures were intact, with more being lost in the channel bordered by an extensive floodplain compared to a more confined channel reach bordered by valley walls. Project managers of stream restoration projects were encouraged to consider channel types and stream flow when designing the in-stream structures they would use for the restoration as not all methods will work for all streams; the structures were considered to be useful in re-establishing habitat complexity for fish.

\section{Metapopulations and Riparian Zone Corridors}

Population dynamics are best understood when the spatial and mobility requirements of an organism are considered (Camus and Lima 2002). The metapopulation concept is important for conservation because it indicates that many interconnected populations support the long-term existence of a species in a geographic area (Burke et al. 1995). The Cacapon River watershed is a heterogeneous mixture of forests, pastures, crops, roadways, mountains, residences, and streams. The patchiness of the environment creates habitat fragmentation that can affect survival, juvenile recruitment, and life history strategies of wood turtles who have extensive home ranges that include a variety of cover types. The riparian zone, upon which wood turtles are dependent, along the upstream half of the Cacapon River is highly degraded. Wood turtles within the watershed may be developing into a metapopulation as agricultural fields fragment 
and isolate their habitat patches, but if the riparian zones are repaired and maintained, the turtle populations should be able to maintain connectivity (Chapter 4). Beier and Noss (1998) define a corridor as "a linear habitat, embedded in a dissimilar matrix, that connects 2 or more larger blocks of habitat and that is proposed for conservation on the grounds that it will enhance or maintain the viability of specific wildlife populations in the habitat blocks." Riparian zones are such corridors.

Corridor movement between habitat patches for turtle species can be uncommon. Painted turtles (Chrysemys picta) were observed to move only once per year between occupied ponds (Bowne et al. 2006). This limited amount of movement by turtles, however, does not indicate that corridors should not be conserved for turtle population persistence. Conservation value should be applied to corridors as long as they are used to provide connectivity (Beier and Noss 1998). For many semi-aquatic turtle species, terrestrial corridors linking aquatic habitats are important for metapopulation persistence (Burke et al. 1995). In Virginia, $46 \%$ of recaptured painted turtles were found to move between occupied ponds; $6 \%$ of the recaptured turtles were found outside of the study area while 2 marked individuals from outside the study area immigrated into the study area (Bowne et al. 2006). In Ellenton Bay, South Carolina, $3.9 \%$ of slider turtles (Trachemys scripta) were recaptured outside of the study area (Burke et al. 1995). A small number $(0.3 \%)$ of turtles marked outside of the study area were recaptured within the bay. The investigators were able to determine through mark-recapture data that a metapopulation, composed of 9 subpopulations, occurred within the Ellenton Bay study area in a variety of microhabitats including permanent streams, semi-permanent Carolina bays, and seasonal ponds. 
Populations can be considered to be subpopulations of a metapopulation if the subpopulations are isolated and independent while still providing a limited degree of migration between the groups (Pannell and Obbard 2003). Dispersal within metapopulations is partly driven by conspecific attraction (Smith and Peacock 1990), demonstrated in grey speckled anole (Anolis aeneus) juveniles (Stamps 1987), barn swallows (Hirundo rustica) (Shields and Crook 1987, Shields et al. 1988), pied flycatchers (Ficedula hypoleuca) (Alatalo et al. 1982), and rock hyraxes (Procavia johnstoni) and bush hyraxes (Heterohyrax brucei) (Hoeck 1982, 1989). Occupied habitats of painted turtles, however, were bypassed during migrations for more distant occupied patches if the latter were of better quality (Bowne et al. 2006).

In Victoria, Australia, 8 species of small mammals were studied in 2 roadside corridors to determine population dynamics, corridor residents, and movement patterns between forest patches connected by the corridor (Bennett 1990). The mammals were found to use the corridor in 2 ways, dispersal (single pass through or temporary residency by dispersing males and subadult females) and gene flow (forest patch residents mating with corridor residents). Dispersal was influenced by corridor length, with individuals making fewer single-pass movements as the corridor length increased, but this was counteracted by the presence of corridor residents that could maintain gene flow between divided patch populations.

Howler monkey (genus Alouatta) populations in Mexico are quickly diminishing due to destruction and loss of habitat (Mandujano et al. 2005). Forest fragments, composed primarily of riparian zone patches, were occupied by the monkeys, resulting in a metapopulation. The monkeys moved between the patches by using "stepping stones", or patches of habitat that are greatly smaller than their home ranges. Connectivity of the habitat patches through development of larger stepping stones and riparian zones was suggested and encouraged as essential 
conservation measures to restore howler monkey population persistence and decrease the expected metatpopulation extinction probability. Riparian zones are environmentally sensitive areas that serve as habitat and movement corridors for a variety of wildlife (Ndubisi et al. 1995), including wood turtles, and should be protected.

\section{Ecology of Wood Turtles}

The geographic range of wood turtles extends from eastern West Virginia and northern Virginia north along the Atlantic states to Nova Scotia, Canada and west along the Great Lakes to eastern Minnesota (Conant and Collins 1998, Endangered Species Coalition 2008). In West Virginia, this species occurs in Berkeley, Grant, Hampshire, Hardy, Jefferson, Mineral, Morgan, and Pendleton counties (Green and Pauley 1987, WVDNR 2008).

Wood turtles have a brown carapace with scutes that are "deeply marked with radiating and concentric striae" (Holbrook 1842), giving the shell a sculpted appearance. The plastron is yellow, with a square black marking at the outside bottom corner of each scute. Near the tail, the plastron is deeply forked. The skin is dark brown with reddish-brown to reddish-orange covering the inside of the appendages (Holbrook 1842, Conant and Collins 1998). To the outside of the appendages is red speckling. The scaling on the front legs is prominent (Holbrook 1842). The head is large and dark brown. The eyes have a black pupil, brown iris, and a surrounding ring of yellow. Adult males have a concave plastron and long, thick tail. Juveniles are without reddish pigments on the appendages (Oldfield et al. 1994). At hatching, the tail is approximately the same length as the carapace. The hatchling carapace is greenish-gray, nearly flat, and unkeeled (Oldfield et al. 1994, Conant and Collins 1998).

Wood Turtles are primarily diurnal (Ernst 1986, Farrell and Graham 1991). They are a semi-aquatic species, spending time on land and in the water depending on season and activity 
(Ernst 1986, Farrell and Graham 1991, Kaufmann 1992, Arvisais et al. 2002, Arvisais et al. 2004). Wood turtles have a strong preference for aquatic zones (Arvisais et al. 2004). Their activity occurs primarily within 300 m of the stream edge (Brewster and Brewster 1991, Quinn and Tate 1991, Kaufmann 1992, Arvisais et al. 2002, Compton et al. 2002), possibly due to their high rate of evaporative water loss (Ernst 1968) restricting the turtles to ranges near water. Their activity level increases with increasing relative humidity (Strang 1983), further depicting the species dependence upon mesic conditions.

Wood turtle home ranges follow stream edges (Strang 1983) and the turtles return to the same home ranges yearly (Strang 1983, Quinn and Tate 1991, Arvisais et al. 2002). Wood turtles require multiple cover types for various annual activities (Quinn and Tate 1991, Kaufmann 1992, Compton et al. 2002), with a preference for bottomland habitats (Strang 1983). When terrestrial, they can be found in open grassy areas; speckled alder (Alnus rugosa), black birch (Betula lenta), oak (Quercus spp.), and red maple (Acer rubrum) stands; and grass-sedgeforb associations (Strang 1983, Quinn and Tate 1991, Kaufmann 1992, Saumure and Bider 1998, Arvisais et al. 2002), although males and females may select different microhabitat types (Kaufmann 1992, Compton et al. 2002). They prefer young forests ( $\leq 16$ years) with sparse tree density (25\%), moderate shrub density (35\%), and low canopy cover (0 - 50\%) (Arvisais et al. 2004). Wood turtles will bask on streambanks, streambank depressions, and floodplains (Ernst 1986, Farrell and Graham 1991, Kaufmann 1992), often soon after emerging from overnight locations (Tuttle and Carroll 2005).

When aquatic, wood turtles occupy main streams, beaver (Castor canadensis) ponds, marshlands, swamps, wet meadows, lakes, and brooks (Arvisais et al. 2004). Wood turtles tend to walk along stream beds (Brewster and Brewster 1991), rather than swimming, and may cross 
through a stream as often as every 2 days when primarily terrestrial (Strang 1983). Water channels near wood turtle populations vary in width from 3 to $20 \mathrm{~m}$ and depth from 0.3 to $2.3 \mathrm{~m}$ (Ernst 1986, Brewster and Brewster 1991, Greaves and Litzgus 2007). The channels tend to be composed of sandy substrate with large scattered rocks and logs (Brewster and Brewster 1991, Greaves and Litzgus 2007).

Wood turtles emerge from hibernation mid-March to mid-April (McCoard 2012, chapter 3; Greaves and Litzgus 2007). Courtship follows soon after hibernation ends, from March to mid-June and again from late August through November, depending on geographic location (Farrell and Graham 1991, Quinn and Tate 1991, Kaufmann 1992). Following courtship, nesting occurs primarily in June (Farrell and Graham 1991, Kaufmann 1992, Arvisais et al. 2002). Wood turtles nest within natural erosion zones, anthropogenic openings (e.g., agricultural fields), community gravel pits, and sandy roadsides (Quinn and Tate 1991, Kaufmann 1992, Saumure et al. 2007, Walde et al. 2007), often with sparse vegetation (Tuttle and Carroll 2005). Hatchlings emerge from late July to early October (McCoard 2012, chapter 3; Farrell and Graham 1991; Tuttle and Carroll 2005).

Wood turtles are primarily terrestrial from June to September (Ernst 1968, Kaufmann 1992, Arvisais et al. 2002), during which they undergo a heavy feeding period (Arvisais et al. 2002). Their diet is composed of green leaves, strawberries (Fragaria spp.), blackberries (Rubus spp.), raspberries (Rubus spp.), mushrooms, fish carrion, flowers, worms, slugs, and other invertebrates (Strang 1983, Farrell and Graham 1991, Compton et al. 2002, Tuttle and Carroll 2005). Wood Turtles will often stomp the ground to bring earthworms to the surface for consumption (Kaufmann 1986). By October or November, the turtles begin returning to streams to prepare for hibernation (Kaufmann 1992, Arvisais et al. 2002). They hibernate under 
overhanging streambanks, exposed tree roots, in stream substrate, within the riverbank, or exposed on the streambed (Kaufmann 1992, Arvisais et al. 2004), sometimes under an ice layer (Quinn and Tate 1991), and often at a depth of $1 \mathrm{~m}$ and $1 \mathrm{~m}$ from the shore (Greaves and Litzgus 2007).

\section{Factors Influencing Wood Turtle Declines and Suggestions for their Conservation}

Wood turtle populations depend upon high adult survival because their juvenile recruitment rate is low (Arvisais et al. 2002). Low food availability, low habitat productivity, low over-wintering nest survival, short egg incubation periods, and low hibernation survival may be factors limiting turtle species at the northern extent of their geographic ranges (St. Clair and Gregory 1990, Costanzo et al. 1995, Hecnar 1999, Arvisais et al. 2002, Greaves and Litzgus 2007, Walde et al. 2007), contributing to slow population growth rates and greater susceptibility to decline. A population of wood turtles along the Sutton River, Quebec, Canada, was studied over a 7-year period, from 1995 to 2002; during that time, the adult population decreased by nearly 50\%, although this may have been caused by slight habitat changes leading to emigration (Daigle and Jutras 2005). However, the sex ratio for the population remained the same, suggesting that emigration was not the driving force of the population decline. The researchers recommended more studies to be conducted on the causes of wood turtle mortalities. Because primary studies on wood turtles have been conducted in the middle and northern portions of their range, research on wood turtle populations (e.g., causes of mortality, limiting factors, use of the riparian zone) in the southern portion of their range are essential for filling in geographic data gaps to better understand the conservation and management needs of the species throughout their range. Agricultural effects — Wood turtles declined by 19.2\% during a 5-year study in Quebec, Canada (Saumure et al. 2007). Of 30 turtles that were tracked over 2 years, 6 died from 
agricultural practices, 1 died under a collapsed riverbank, 1 died from being buried during riverbank stablilization, and 1 died from being buried during the plowing of a field. Multiple other wood turtles were found to have mutilation injuries from agricultural equipment, believed to be inflicted when the turtles were fleeing from the agricultural field to the nearby river.

The mutilation rates of wood turtles by predators and agricultural activities were compared between a forest and agricultural site in southern Quebec (Saumure and Bider 1998). In both sites, the mutilation attributed to predators was similar $(15-19 \%)$. However, in the agricultural site, the mutilation of turtles by human activities (24.2\%) was nearly 3 times higher than in the forested site (9.7\%). An additional 10 turtles (30.3\%) in the agricultural site had wounds of unknown origins. Furthermore, fewer juveniles (23\%) were found in the agricultural site than in the forested site. These data indicate that agricultural practices detrimentally impact wood turtle populations and may be a contributing factor to their decline.

Turtle nest predation-Turtle nest predation contributes also to turtle species declines. Some nest predation studies have used other egg types to determine the potential degree of depredation that turtle nests undergo (Marchand et al. 2002, Marchand and Litvaitis 2004). In New Hampshire, $22 \%$ of all artificial nests were either depredated ( $\geq 1$ eggs consumed) or disturbed (exposed eggs) within a week of placement (Marchand et al. 2002). Clumped nests were preyed upon to a greater degree than scattered nests. Raccoons (Procyon lotor) were the most common predators, although fishers (Martes pennant) and gray foxes (Urocyon cinereoargenteus) preyed upon nests as well.

Female turtles will alter nesting behavior in the presence of predators to increase their survival, but offspring fitness may then be compromised (Spencer 2002). In southeastern Australia, red foxes (Vulpes vulpes), Australian bell magpies (Gymnorhina tibicen), and water 
rats (Hydromys chrysogaster) were primary predators of Macquarie turtles (Emydura macquarii) and their nests. In 2 nesting sites, red foxes were removed but were left in 2 other sites. In the removal sites, gravid females nested farther from shore (>25 m) than in high-predation (fox) sites (14-18 m). Nests were less clumped and farther from trees in the removal sites than in the highpredation sites. This resulted in fewer nests being easily found by predators and fewer nests being depredated by birds watching from trees. Nesting females appeared to make a tradeoff concerning nesting location to minimize personal and offspring mortality in the presence or absence of predators (Spencer and Thompson 2003). Nest site selection was thus improved when the pressure of predation on the nesting female or the nests was alleviated.

Marchand and Litvaitis (2004) also observed the distance of turtle nests from water bodies and the degree of nest scatter to influence mammalian predation. Clumped nests $(2 \mathrm{~m}$ apart) were depredated more often than scattered nests ( $\geq 30 \mathrm{~m}$ apart). Nests far $(100-150 \mathrm{~m})$ from shore were depredated at lower rates than nests near $(\leq 50 \mathrm{~m})$ shore. Near, clumped nests had the highest rate of predation (68\%), but far, scattered nests had the lowest rate (26\%). The primary predators were raccoons.

Nests may survive until the hatching event, but hatchlings are still in danger of predation while leaving the nest site. In New Hampshire, emerging wood turtle hatchlings were tracked until the young entered a water body (Tuttle and Carroll 2005). The nest site was visited regularly by birds (e.g., great blue herons [Ardea herodias] and American kestrels [Falco sparverius]) and small mammals (e.g., eastern chipmunks [Tamias striatus]), awaiting hatchling emergence. Hatchlings would use auditory and visual clues as a means to avoid predators, in addition to a homing mechanism to orient to water for safe cover. Predation on nests may be a factor contributing to wood turtle decline. 
Turtle Road Mortality — Habitat fragmentation through the building of roads has a negative influence on turtle populations by dividing populations and habitat, including habitat corridors used by migrating turtles (Steen and Gibbs 2004, Aresco 2005, Conner et al. 2005). Movement through corridors can differ among gender and age-class (Bowne et al. 2006), making some turtles more susceptible to road mortality than others. Gravid females migrating to nesting habitat, often along roadways, and dispersing hatchlings tend to suffer high rates of mortality on roadways (Conner et al. 2005). Gibbs and Shriver (2002) developed a model that suggests that road mortality is a major contributor to the decline of land and large-bodied pond turtles. Of 14 turtles radio-tracked by Bowne et al. (2006), 2 were killed by cars. In that study, roads were considered to be the most limiting factor affecting connectivity between habitat patches.

Road mortalities can affect sex-ratios of turtle populations. In a literature review on turtle populations occurring along North American roadways, Steen et al. (2006) determined that a greater number of females than males were found on roads (dead or alive). Females of 7 aquatic species and 6 semi-aquatic species were found in higher proportions on roads than off. The females of 2 out of 3 terrestrial species were more commonly found off roads than on. A trend towards male-biased sex ratios was observed, likely resulting from repeated nesting migrations undertaken by females crossing roads or nesting along sandy roadways (Quinn and Tate 1991, Steen and Gibbs 2004, Aresco 2005, Steen et al. 2006). Future outcomes caused by current road systems may be more drastic on turtle populations than previously thought (Steen and Gibbs 2004) as time length since the establishment of roads along turtle populations increases and male-bias sex-ratios remain the resulting trend.

In populations located along roadways, wood turtle females have been found on roads $(68 \%)$ in larger proportions than not on roads (Steen et al. 2006). Females may cross roadways 
often during nesting migrations, potentially decreasing the number of reproductive females in populations. Young dispersing from nest sites then have to cross roads to enter the population, possibly limiting population recruitment. Wood turtle populations along roadways are thus at a greater peril of extirpation than those that occur more inland, possibly contributing to their decline.

Conservation Suggestions - Further studies on riparian zone use by turtles, especially species of federal or international conservation concern, should be conducted (Bodie 2001) to determine the degree of use and dependence that turtles have on the habitat and how its degradation affects turtle population persistence. Wood turtles are such a species threatened by riparian zone degradation (Compton et al. 2002). If private landowners and farmers are notified about the presence and needs of turtles on their properties, populations may be better protected on these lands (Kaufmann 1992). Protected buffer strips, containing native hardwoods and herbaceous vegetation (e.g., black walnut, Juglans nigra; sycamore, Platanus occidentalis; wingstem, Verbesina alternifolia; and violets, Viola spp.), should be established along streams occupied by wood turtles to increase their conservation (Arvisais et al. 2002). A buffer as wide as $150 \mathrm{~m}$ is recommended for many freshwater turtles who migrate up to that distance from streams (Bodie 2001), although that amount is unrealistic for most private landowners. A more manageable, and minimum, buffer width for wood turtle protection is $10 \mathrm{~m}$ (Saumure et al. 2007). The density of roads in proximity to turtle populations should be considered also when planning conservation strategies (Steen and Gibbs 2004). Ultimately, for conservation to be effective for wood turtles, extensive areas covering all habitat types used by the species at different seasons should be protected (Quinn and Tate 1991). In order for this protection to happen, habitat selection and chronological use of cover types by wood turtles is important as a 
research focus (Arvisais et al. 2004) to better understand the needs of the species to carry out their life history strategies.

\section{STUDY SITE}

The study site was located within the Cacapon River watershed, composed of the Cacapon, Lost, and North rivers, which drains $2,321 \mathrm{~km}^{2}$ into the Potomac River and belongs to the Chesapeake Bay watershed (Constantz et al. 1995, Figure 1). The watershed was $79 \%$ forested, $19 \%$ agriculture, and 2\% residential, barren, or water cover (NPS 1982). Agricultural fields bordered most of the study reaches along the rivers with multiple locations of free access to the river by cattle, or cornfields and hay fields planted to the streambank edges (Constantz et al. 1995, Niederberger and Seidel 1999, K. R. P. McCoard, pers. obs), contributing the largest amounts of nonpoint source pollution to the rivers (Constantz et al. 1995). The average temperature of the 3 rivers was $23.7^{\circ} \mathrm{C}\left(\mathrm{SD}=2.34,18.4-30.7^{\circ} \mathrm{C}\right)$ and the average $\mathrm{pH}$ was $8.1(\mathrm{SD}=0.43,7.2-9.3)$ (Constantz et al. 1995). The geology is composed of limestone, shale, and sandstone (Constantz et al. 1995). The watershed covers the eastern halves of Hampshire, Hardy, and Morgan counties in the eastern panhandle of West Virginia, within the Ridge and Valley Province, which had trellis drainage (Strausbaugh and Core 1977) and received about $76 \mathrm{~cm}$ of precipitation annually (Kozar and Mathes 2001). The highest and lowest elevations in West Virginia occurred at the western and eastern edges of the Ridge and Valley Province, Spruce Knob (1,482 m) in Pendleton County and Harper's Ferry (73 m) in Jefferson County (Green and Pauley 1987).

The forest of the Ridge and Valley Province is oak-hickory-pine (Strausbaugh and Core 1977). Within the watershed, the riparian overstory vegetation is dominated by coniferous and deciduous species including sycamore, red maple (Acer rubrum), tulip poplar (Liriodendron tulipifera), black walnut, white pine (Pinus strobus), chestnut oak (Q. prinus), sugar maple (A. 
saccharum), and hickories (Carya spp.) (McCoard 2012, chapter 3, 4; Constantz et al. 1995; Niederberger and Seidel 1999). The midstory layer is primarily composed of multiflora rose (Rosa multiflora), spicebush (Lindera benzoin), autumn olive (Elaeagnus umbellata), and Japanese barberry (Berberis thunbergii) (Chapter 3, 4; Niederberger and Seidel 1999). The herbaceous layer is dominated by ground ivy (Glechoma hederacea), bluebells (Mertensia virginica), reed canary grass (Phalaris arundinacea), Japanese stilt grass (Microstegium vimineum), wingstem, wood sorrel (Oxalis spp.), sedges (Carex spp.), and lady's thumb (Polygonum spp.) (McCoard 2012, chapter 3, 4; Niederberger and Seidel 1999).

A 1,100 m reach of the Cacapon River was selected by West Virginia University and Canaan Valley Institute (Davis, West Virginia) personnel for natural stream channel design restoration, beginning in May 2010 (Figure 2; a detailed description of the restoration is provided in Selego 2011, chapter 1). Eroding banks on both sides of the reach were excavated by Red Creek Enterprises (Dry Fork, West Virginia) to create a more moderate slope (approximately $36^{\circ}$ ) with terraces to minimize erosion (Figure 3). Geotextile matting was then placed on the newly exposed banks and stapled down to hold it in place so that overland flow would not be able to displace the exposed soil (Figure 4). Large trees were used as log-vanes and were put in place by burying the rooted end of the tree into the bank and placing large boulders on the other end to hold it in place (Figure 5). The bouldered end faced upstream at a low angle from the bank and the area between the log and bank was filled with streambed material. The purpose of the log-vane was to divert water that was flowing directly towards the bank away from it to minimize the erosive impact.

Saplings (primarily swamp white oak, Quercus bicolor; pin oak, Q. palustris; buttonbush, Cephalanthus occidentalis; and black willow, Salix nigra) were planted $1.8 \mathrm{~m}$ apart by Arnette 
Landscapes, Inc. in rows paralleling the bank, both on the excavated portions of the banks down to the water's edge as well as a row or two outwards from the edge of the excavation (Figure 6). All of the trees had tree-tubes placed around them to minimize herbivory. The trees were watered weekly to promote survival during the ensuing hot, dry summer. The trees were planted to provide beneficial effects such as bank stabilization, shade to keep water temperatures low, detritus, and wildlife habitat. To decrease competition for the newly planted trees, Roundup® herbicide (Monsanto Co., St. Louis, Missouri, United States) was applied to the cut stems of invasive species (e.g., autumn olive and multiflora rose) in October 2010. Native wildflower seeds were planted to promote increased pollination along the restoration reach.

An electric fence was built along the right side of the river and a barbed wire fence along the left, based on landowner preference, by Bland Fencing LLC (Petersburg, West Virginia) (Figure 7). Large posts were used to try to keep the fences from being damaged during flooding events. The fences were built to the outside of the restoration work to prevent cattle from trampling the trees or destabilizing the constructed banks. Gates were installed at various points along the fence to allow access for the landowners and researchers.

The restoration reach was bordered on both sides by an upstream control and reference site and a downstream reference and control site (Figure 8). The control sites had high, eroding banks, but restoration was not conducted (Figure 9). The reference sites had gently sloping banks that were well-vegetated (Figure 10). The sites were separated 300 to 1,000 m from each other. Research on water quality and wildlife responses was regularly conducted within sampling units along the restoration reach and compared to sampling units within the reference and control sites to monitor the degree of success of the restoration project (Figures 11, 12). 
Random survey points $(n=100)$ were positioned along the entirety of the $79 \mathrm{~km}$ North River $(n=61)$ and $54 \mathrm{~km}$ Lost River $(n=39)$ for wood turtle surveys that were conducted during summer 2010 (Figure 13; McCoard 2012, chapter 4). The survey points were located by programming them into a global positioning system and narrowing in on each individual point, with the aid of maps. For points that occurred on private property, the landowners were asked permission for access to the river along their properties. For points on properties that were inaccessible, the nearest accessible location downstream was surveyed.

\section{LITERATURE CITED}

Alatalo, R. V., A. Lundberg, and M. Bjorklund. 1982. Can the song of male birds attract other males? An experiment with the pied flycatcher Ficedula hypoleuca. Bird Behaviour 4:4245.

Amato, M. L., R. J. Brooks, and J. Fu. 2008. A phylogeographic analysis of populations of the wood turtle (Glyptemys insculpta) throughout its range. Molecular Ecology 17:570-581.

Aresco, M. J. 2005. The effect of sex-specific terrestrial movements and roads on the sex ratio of freshwater turtles. Biological Conservation 123:37-44.

Arvisais, M., J. -C.Bourgeois, E. Levesque, C. Daigle, D. Masse, and J. Jutrus. 2002. Home range and movements of a wood turtle (Clemmys insculpta) population at the northern limit of its range. Canadian Journal of Zoology 80:402-408.

Arvisais, M., E. Levesque, J. -C.Bourgeois, C. Daigle, D. Masse, and J. Jutrus. 2004. Habitat selection by the wood turtle (Clemmys insculpta) at the northern limit of its range. Canadian Journal of Zoology 82:391-398.

Becker, C. G., C. R. Fonseca, C. F. B. Haddad, R. F. Batista, and P. I. Prado. 2007. Habitat split and the global decline of amphibians. Science 318:1775-1777. 
Beier, P., and R. F. Noss. 1998. Do habitat corridors provide connectivity? Conservation Biology $12: 1241-1252$.

Bennett, A. F. 1990. Habitat corridors and the conservation of small mammals in a fragmented forest environment. Landscape Ecology 4:109-122.

Bernhardt, E. S., M. A. Palmer, J. D. Allan, G. Alexander, K. Barnas, S. Brooks, J. Carr, S. Clayton, C. Dahm, J. Follstad-Shah, D. Galat, S. Gloss, P. Goodwin, D. Hart, B. Hassett, R. Jenkinson, S. Katz, G. M. Kondolf, P. S. Lake, R. Lave, J. L. Meyer, T. K. O’Donnell, L. Pagano, B. Powell, and E. Sudduth. 2005. Restoration of United States rivers-a national synthesis. Science 308:636-637.

Bodie, J. R. 2001. Stream and riparian management for freshwater turtles. Journal of Environmental Management 62:443-455.

Bowne, D. R., M. A. Bowers, and J. E. Hines. 2006. Connectivity in an agricultural landscape as reflected by interpond movements of a freshwater turtle. Conservation Biology 20:780791.

Boyer, E. W., C. L. Goodale, N. A. Jaworski, and R. W. Howarth. 2002. Anthropogenic nitrogen sources and relationships to riverine nitrogen export in the northeastern USA. Biogeochemistry 57:137-169.

Brewster, K. N., and C. M. Brewster. 1991. Movement and microhabitat use by juvenile wood turtles introduced into a riparian habitat. Journal of Herpetology 25:379-382.

Burke, V. J., J. L. Greene, and J. W. Gibbons. 1995. The effect of sample size and study duration on metapopulation estimates for slider turtles (Trachemys scripta). Herpetologica 51:451456.

Cairns, J. Jr., and J. R. Heckman. 1996. Restoration ecology: the state of an emerging field. 
Annual Review of Energy Environment. 21:167-189.

Camus, P. A., and M. Lima. 2002. Populations, metapopulations, and the open-closed dilemma: the conflict between operational and natural population concepts. Oikos 97:433-438.

Committee on the Status of Endangered Wildlife in Canada [COSEWIC]. 2009. Canadian wildlife species at risk. Ottawa, Ontario, Canada. <www.cosewic.gc.ca/eng/sct0/rpt/rpt_csar_e.cfm >. Accessed 15 October 2009.

Compton, B. W., J. M. Rhymer, and M. McCollough. 2002. Habitat selection by wood turtles (Clemmys insculpta): an application of paired logistic regression. Ecology 83:833-843.

Conant, R., and J. T. Collins. 1998. A field guide to reptiles and amphibians of eastern and central North America. Third edition, expanded. Houghton Mifflin, New York, New York, USA.

Conner, C. A., B. A. Douthitt, and T. J. Ryan. 2005. Descriptive ecology of a turtle assemblage in an urban landscape. American Midland Naturalist 153:428-435.

Constantz, G, N. Ailes, and D. Malakoff. 1995. Portrait of a river: the ecological baseline of the Cacapon River. Pine Cabin Run Ecological Laboratory. High View, West Virginia, USA. Convention on International Trade in Endangered Species of Wild Fauna and Flora (CITES). 2008. Appendices I, II, and III. International Environment House, Geneva, Switzerland.

Costanzo, J. P., J. B. Iverson, M. F. Wright, and R. E. Lee, Jr. 1995. Cold hardiness and overwintering strategies of hatchlings in an assemblage of northern turtles. Ecology $76: 1772-1785$.

Craig, L. S., M. A. Palmer, D. C. Richardson, S. Filoso, E. S. Bernhardt, B. P. Bledsoe, M. W. 
Doyle, P. M. Groffman, B. A. Hassett, S. S. Kaushal, P. M. Mayer, S. M. Smith, and P. R. Wilcock. 2008. Stream restoration strategies for reducing river nitrogen loads. Frontiers in Ecology and the Envrionment 6:529-538.

Crawford, J.A. and R.D. Semlitsch. 2007. Estimation of core terrestrial habitat for streambreeding salamanders and delineation of riparian buffers for protection of biodiversity. Conservation Biology 21:152-158.

Daigle, C. and J. Jutras. 2005. Quantitative evidence of decline in a southern Quebec wood turtle (Glyptemys insculpta) population. Journal of Herpetology 39:130-132.

Endangered Species Coalition. 2008. Without a net: top ten wildlife, fish and plants in need of Endangered Species Act protection. <www.stopextinction.org/images/WithoutANet-high.pdf>. Accessed 13 April 2009.

Ernst, C. H. 1968. Evaporative water-loss relationships of turtles. Journal of Herpetology 2:159161.

Ernst, C. H. 1986. Environmental temperatures and activities in the wood turtle, Clemmys insculpta. Journal of Herpetology 20:222-229.

Farrell, R. F., and T. E. Graham. 1991. Ecological notes on the turtle Clemmys insculpta in northwestern New Jersey. Journal of Herpetology 25:1-9.

Garber, S. D., and J. Burger. 1995. A 20-yr. study documenting the relationship between turtle decline and human recreation. Ecological Applications 5:1151-1162.

Gibbons, J. W. 2003. Terrestrial habitat: a vital component for herpetofauna of isolated wetlands. Wetlands 23:630-635.

Gibbs, J. P., and W. G. Shriver. 2002. Estimating the effects of road mortality on turtle populations. Conservation Biology 16:1647-1652. 
Golet, G. H., T. Gardali, C. A. Howell, J. Hunt, R. A. Luster, W. Rainey, M. D. Roberts, J. Silveira, H. Swagerty, and N. Williams. 2008. Wildlife response to riparian restoration on the Sacramento River. San Francisco Estuary and Watershed Science 6:article 1.

Golet, G. H., J. W. Hunt, and D. Koenig. 2011. Decline and recovery of small mammals after flooding: implications for pest management and floodplain community dynamics. River Research and Applications. doi: 10.1002/rra.1588

Gotelli, N. J. 1991. Metapopulation models: the rescue effect, the propagule rain, and the coresatellite hypothesis. American Naturalist 138:768-776.

Greaves, W. F., and J. D. Litzgus. 2007. Overwintering ecology of wood turtles (Glyptemys insculpta) at the species' northern range limit. Journal of Herpetology 41:32-40.

Green, N. B., and T. K. Pauley. 1987. Amphibians and reptiles in West Virginia. University of Pittsburgh, Pennsylvania, USA.

Hannon, S. J., C. A. Paszkowski, S. Boutin, J. DeGroot, S. E. Macdonald, M. Wheatley, and B. R. Eaton. 2002. Abundance and species composition of amphibians, small mammals, and songbirds in riparian forest buffer strips of varying widths in the boreal mixedwood of Alberta. Canadian Journal of Forest Research 32:1784-1800.

Hanski, I., and D. Simberloff. 1997. The metapopulation approach, its history, conceptual domain, and application to conservation. Pages 5-26 in I. A. Hanski and M. E. Gilpin, editors. Metapopulation biology: ecology, genetics, and evolution. Academic, San Diego, California, USA.

Hanski, I. and O. Ovaskainen. 2000. The metapopulation capacity of a fragmented landscape. Nature 404:755-758. 
Hecnar, S. J. 1999. Patterns of turtle species' geographic range size and a test of Rapoport's rule. Ecography 22:436-446.

Hilty, J. A., and A. M. Merenlender. 2004. Use of riparian corridors and vineyards by mammalian predators in northern California. Conservation Biology 18:126-135.

Hoeck, H. N. 1982. Population dynamics, dispersal and genetic isolation in two species of hyrax (Heterohyrax brucei and Procavia johnstoni) on habitat islands in the Serengeti. Zeitschrift fur Tierpsychologie 59:177-210.

Hoeck, H. N. 1989. Demography and competition in hyrax. A 17 year study. Oecologia 89:353360.

Holbrook, J. E. 1842 (1976). North American herpetology, volumes I-V. Society for the Study of Amphibians and Reptiles, Oxford, Ohio, USA.

Howarth, R. W., A. Sharpley, and D. Walker. 2002. Sources of nutrient pollution to coastal waters in the United States: implications for achieving coastal water quality goals. Estuaries 25:656-676.

Jones, E. B. D., III, G. S. Helfman, J. O. Harper, and P. V. Bolstad. 1999. Effects of riparian forest removal on fish assemblages in southern Appalachian streams. Conservation Biology 13:1454-1465.

Kaufmann, J. H. 1986. Stomping for earthworms by wood turtles, Clemmys insculpta: a newly discovered foraging technique. Copeia 1986:1001-1004.

Kaufmann, J. H. 1992. Habitat use by wood turtles in central Pennsylvania. Journal of Herpetology 26:315-321.

Kozar, M. D., and M. V. Mathes. 2001. Aquifer-characteristics data for West Virginia. Water- 
Resources Investigations Report 01-4036. U.S. Geological Survey, U.S. Department of the Interior. Charleston, USA.

Kus, B. E. 1998. Use of restored riparian habitat by the endangered least Bell's vireo (Vireo bellii pusillus). Restoration Ecology 6:75-82.

Machtans, C. S., M. -A. Villard, and S. J. Hannon. 1996. Use of riparian buffer strips as movement corridors by forest birds. Conservation Biology 10:1366-1379.

Mandujano, S., L. A. Escobedo-Morales, R. Palacios-Silva, V. Arroyo-Rodríguez, and E. M. Rodríguez-Toledo. 2005. A metapopulation approach to conserving the howler monkey in a highly fragmented landscape in Los Tuxtlas, Mexico. Pages 513-538 in A. Estrada, P. A. Garber, M. S. M. Pavelka, and L. Luecke, editors. New perspectives in the study of Mesoamerican primates: distribution, ecology, behavior, and conservation. Springer, New York, New York, USA.

Marchand, M. N., J. A. Litvaitis, T. J. Maier, and R. M. DeGraaf. 2002. Use of artificial nests to investigate predation on freshwater turtle nests. Wildlife Society Bulletin 30:1-7.

Marchand, M. N., and J. A. Litvaitis. 2004. Effects of landscape composition, habitat features, and nest distribution on predation rates of simulated turtle nests. Biological Conservation $117: 243-251$

McCoard, K. R. P. 2012. Riparian ecological community assessment with an emphasis on wood turtles (Glyptemys insculpta) in the Cacapon River watershed, West Virginia.

Dissertation, West Virginia University, Morgantown, USA.

Mitsch, W. J.. and J. G. Gosselink. 2007. Wetlands. Fourth edition. John Wiley \& Sons, Hoboken, New Jersey, USA.

Moll, E. O. 2000. Turtles and tortoises. Pages $72-81$ in T. Halliday and K. Adler, editors. The 
encyclopedia of reptiles and amphibians. Facts on File. New York, New York, USA.

Morrison, M. L. 2002. Wildlife restoration: techniques for habitat analysis and animal monitoring. Island, Washington, D.C., USA.

National Park Service [NPS]. 1982. Draft wild and scenic river study: Cacapon River, West Virginia. Department of Interior, USA.

Ndubisi, F., T. DeMeo, and N. D. Ditto. 1995. Environmentally sensitive areas: a template for developing greenway corridors. Landscape and Urban Planning 33:159-177.

Niederberger, A. J., and M. E. Seidel. 1999. Ecology and status of a Wood Turtle (Clemmys insculpta) population in West Virginia. Chelonian Conservation and Biology 3:414-418.

Oldfield, B., J. J. Moriarty, and W. J. Breckenridge. 1994. Amphibians and reptiles native to Minnesota. University of Minnesota. Minneapolis, USA.

Palmer, M. A., E Bernhardt, J. D. Allan, and the National River Restoration Science Synthesis Working Group. 2005. Standards for ecologically successful river restoration. Journal of Applied Ecology 42:208-217.

Pannell, J. R., and D. J. Obbard. 2003. Probing the primacy of the patch: what makes a metapopulation? Journal of Ecology 91:485-488.

Purcell, A. H., C. Friedrich, and V. H. Resh. 2002. An assessment of a small urban stream restoration project in northern California. Restoration Ecology 10:685-694.

Quinn, N. W. S., and D. P. Tate. 1991. Seasonal movements and habitat of wood turtles (Clemmys insculpta) in Algonquin Park, Canada. Journal of Herpetology 25:217-220.

Rosgen, D. L. 1996. Applied river morphology. Wildland Hydrology Books. Pagosa Springs, Colorado, USA.

Rosgen, D. L. 1997. A geomorphological approach to restoration of incised rivers. Proceedings 
of the Conference on Management of Landscapes Disturbed by Channel Incision. S. S. Y. Wang, E. J. Langendoen, and F. D. Shields, editors. University of Mississippi. Oxford, USA.

Rudolph, D. C., and J. G. Dickson. 1990. Streamside zone width and amphibian and reptile abundance. Southwestern Naturalist 35:472-476.

Saumure, R. A., and J. R. Bider. 1998. Impact of agricultural development on a population of wood turtles (Clemmys insculpta) in southern Quebec, Canada. Chelonian Conservation and Biology 3:37-45.

Saumure, R. A., T. B. Herman, and R. D. Titman. 2007. Effects of haying and agricultural practices on a declining species: the North American wood turtle, Glyptemys insculpta. Biological Conservation 135:565-575.

Schmetterling, D. A., and R. W. Pierce. 1999. Success of instream habitat structures after a 50year flood in Gold Creek, Montana. Restoration Ecology 7:369-375.

Selego, S. 2011. Fish and aquatic macroinvertebrate communities in the Cacapon River, West Virginia. Thesis, West Virginia University, Morgantown, USA.

Selego, S. M., C. L. Rose, G. T. Merovich, Jr., S. A. Welsh, and J. T. Anderson. 2012. Community-level response of fishes and aquatic macroinvertebrates to stream restoration in a third-order tributary of the Potomac River, USA. International Journal of Ecology, article ID 753634.

Shields, W. M., and J. R. Crook. 1987. Barn swallow coloniality: a net cost for group breeding in the Adirondacks? Ecology 68:1373-1386.

Shields, W. M., J. R. Crook, M. L. Hebblewaite, and S. S. Wiles-Ehmann. 1988. Ideal free 
coloniality in the swallows. Pages 189-228 in C. N. Slobodchikoff, editor. Ecology of social behavior. Academic Press, New York, New York, USA.

Smith, A. T., and M. M. Peacock. 1990. Conspecific attraction and the determination of metapopulation colonization rates. Conservation Biology 4:320-323.

Spencer, R. -J. 2002. Experimentally testing nest site selection: fitness trade-offs and predation risk in turtles. Ecology 83:2136-2144.

Spencer, R. -J. and M. B. Thompson. 2003. The significance of predation in nest site selection of turtles: an experimental consideration of macro- and microhabitat preferences. Oikos 102:592-600.

St. Clair, R. C., and P. T. Gregory. 1990. Factors affecting the northern range limit of painted turtles (Chrysemys picta): winter acidosis or freezing? Copeia 1990:1083-1089.

Stamps, J. A. 1987. Conspecifics as cues to territory quality: a preference of juvenile lizards (Anolis aeneus) for previously used territories. American Naturalist 129:629-642.

Steen, D. A., and J. P. Gibbs. 2004. Effects of roads on the structure of freshwater turtle populations. Conservation Biology 18:1143-1148.

Steen, D. A., M. J. Aresco, S. G. Beilke, B. W. Compton, E. P. Condon, C. K. Dodd, Jr., H. Forrester, J. W. Gibbons, J. L. Greene, G. Johnson, T. A. Langen, M. J. Oldham, D. N. Oxier, R. A. Saumure, F. W. Schueler, J. M. Sleeman, L. L. Smith, J. K. Tucker, and J. P. Gibbs. 2006. Relative vulnerability of female turtles to road mortality. Animal Conservation 9:269-273.

Stickel, L. F. 1978. Changes in a box turtle population during three decades. Copeia 1978:221225.

Strang, C. A. 1983. Spatial and temporal activity patterns in two terrestrial turtles. Journal of 
Herpetology 17:43-47.

Strausbaugh, P. D., and E. L. Core. 1977. Flora of West Virginia. Second edition. Seneca Books, Morgantown, USA.

Suren, A. M., T. Riis, B. J. F. Biggs, S. McMurtrie, and R. Barker. 2005. Assessing the effectiveness of enhancement activities in urban streams: I. Habitat responses. River Research and Applications 21:381-401.

Taylor, J. P., and K. C. McDaniel. 1998. Restoration of saltcedar (Tamarix sp.)-infested floodplains on the Bosque del Apache National Wildlife Refuge. Weed Technology $12: 345-352$.

Thurmond, D. P., K. V. Miller, and T. G. Harris. 1995. Effect of streamside management zone width on avifauna communities. Southern Journal of Applied Forestry 19:166-169.

Turtle Conservation Fund. 2002. A Global Action Plan for Conservation of Tortoises and Freshwater Turtles. Strategy and Funding Prospectus 2002-2007. Conservation International and Chelonian Research Foundation, Washington, D.C., USA.

Tuttle, S. E., and D. M. Carroll. 2005. Movements and behavior of hatchling wood turtles (Glyptemys insculpta). Northeastern Naturalist 12:331-348.

United States Fish and Wildlife Service. 1981. Riparian ecosystems. United States Department of the Interior, Kearneysville, West Virginia, USA.

Walde, A. D., J. R. Bider, D. Masse, R. A. Saumure, and R. D. Titman. 2007. Nesting ecology and hatching success of the Wood Turtle, Glyptemys insculpta, in Quebec. Herpetological Conservation and Biology 2:49-60.

West Virginia Division of Natural Resources [WVDNR]. 2008. Wood Turtle data. Wildlife Diversity Database. 
Wissmar, R. C., and R. L. Beschta. 1998. Restoration and management of riparian ecosystems: a catchment perspective. Freshwater Biology 40:571-585. 


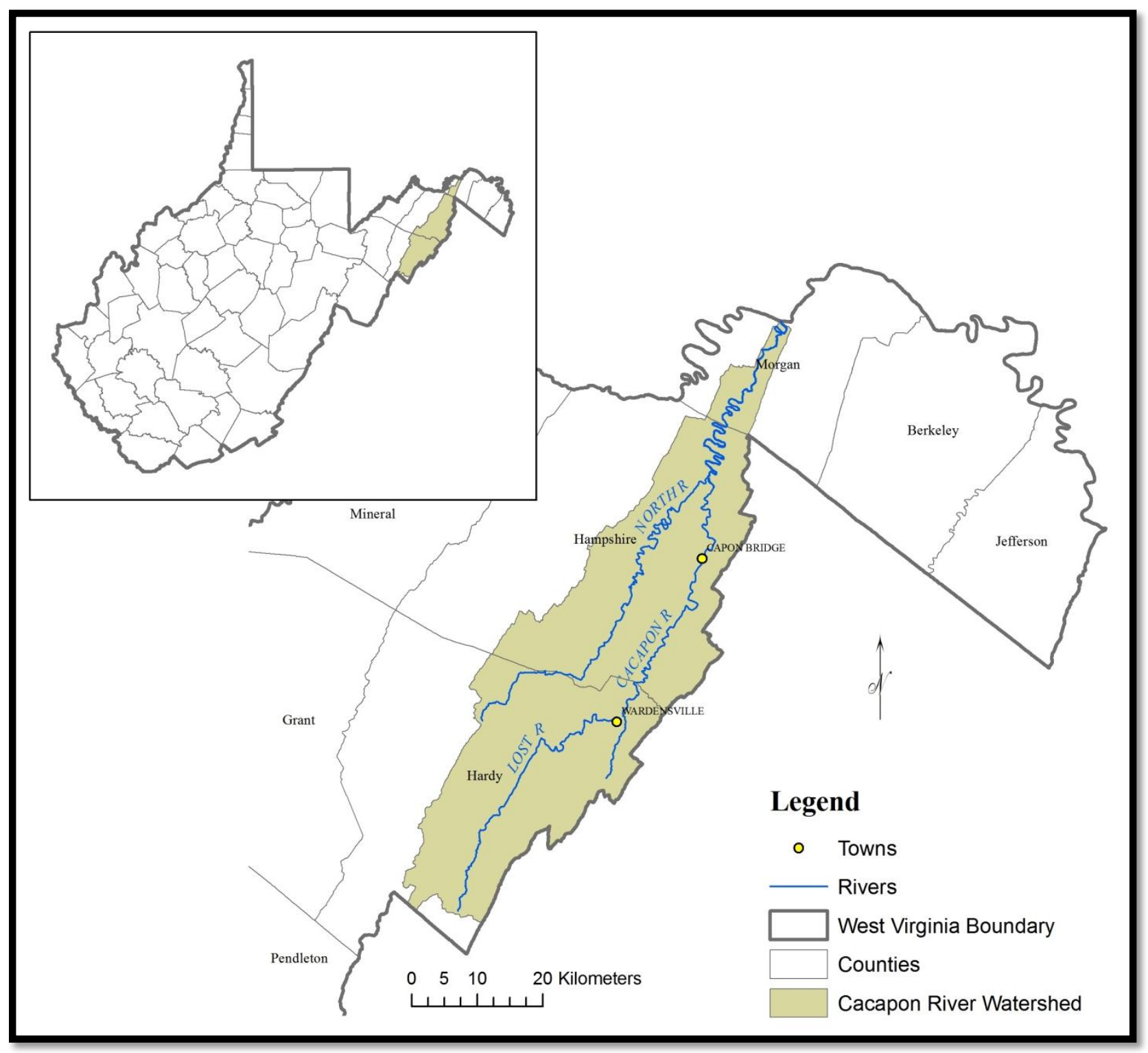

Figure 1. The Cacapon River watershed occurs in the eastern panhandle of West Virginia, USA. It is composed of the Cacapon, North, and Lost rivers. The watershed drains into the Potomac River which flows into the Chesapeake Bay watershed. 


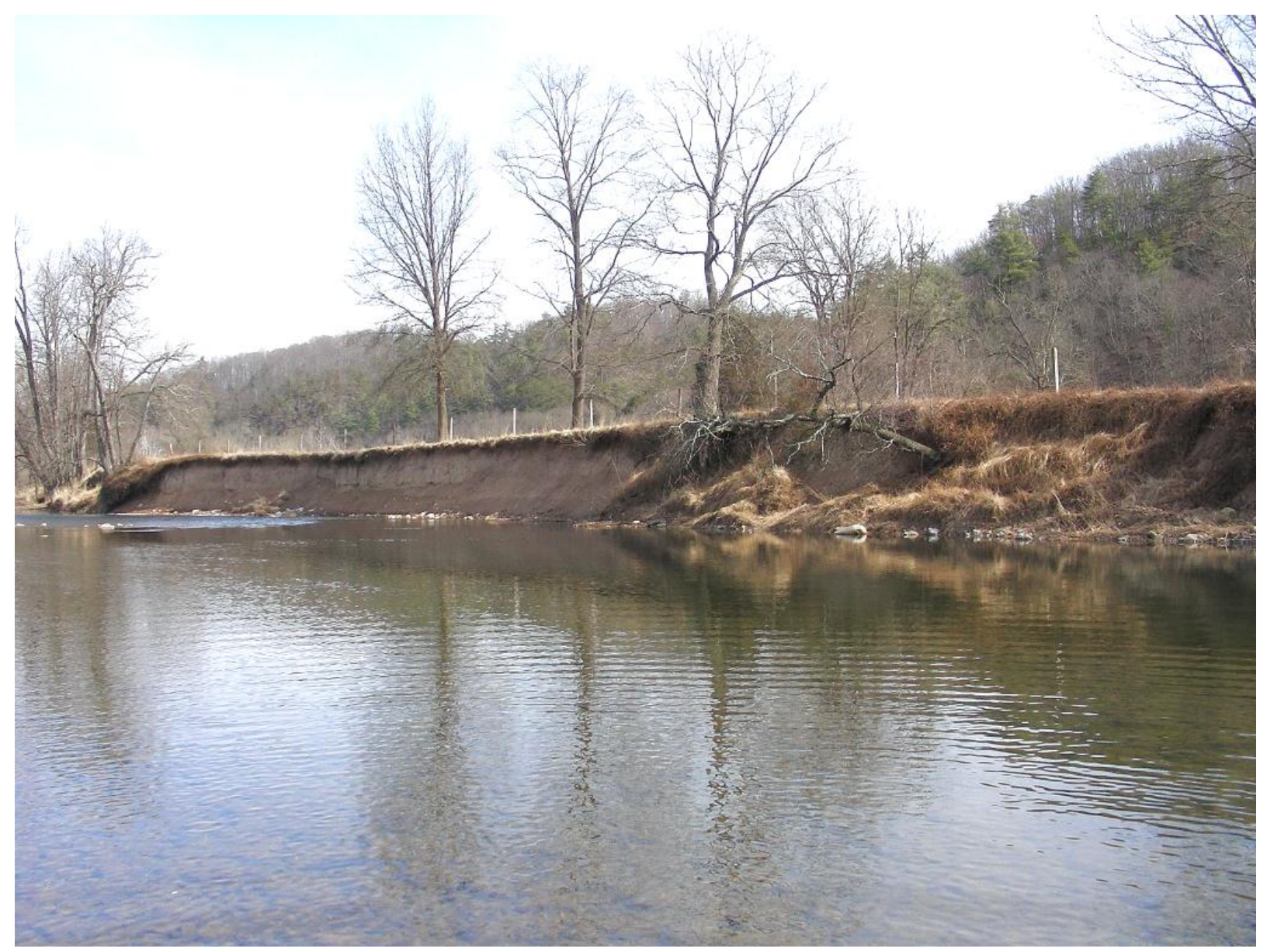

Figure 2. The right side of the restoration reach before restoration occurred, taken February 2009. The high, eroded banks with collapsing vegetation are clearly seen. The fence bordering the active pasture on the flooplain is at the edge of the streambank. 


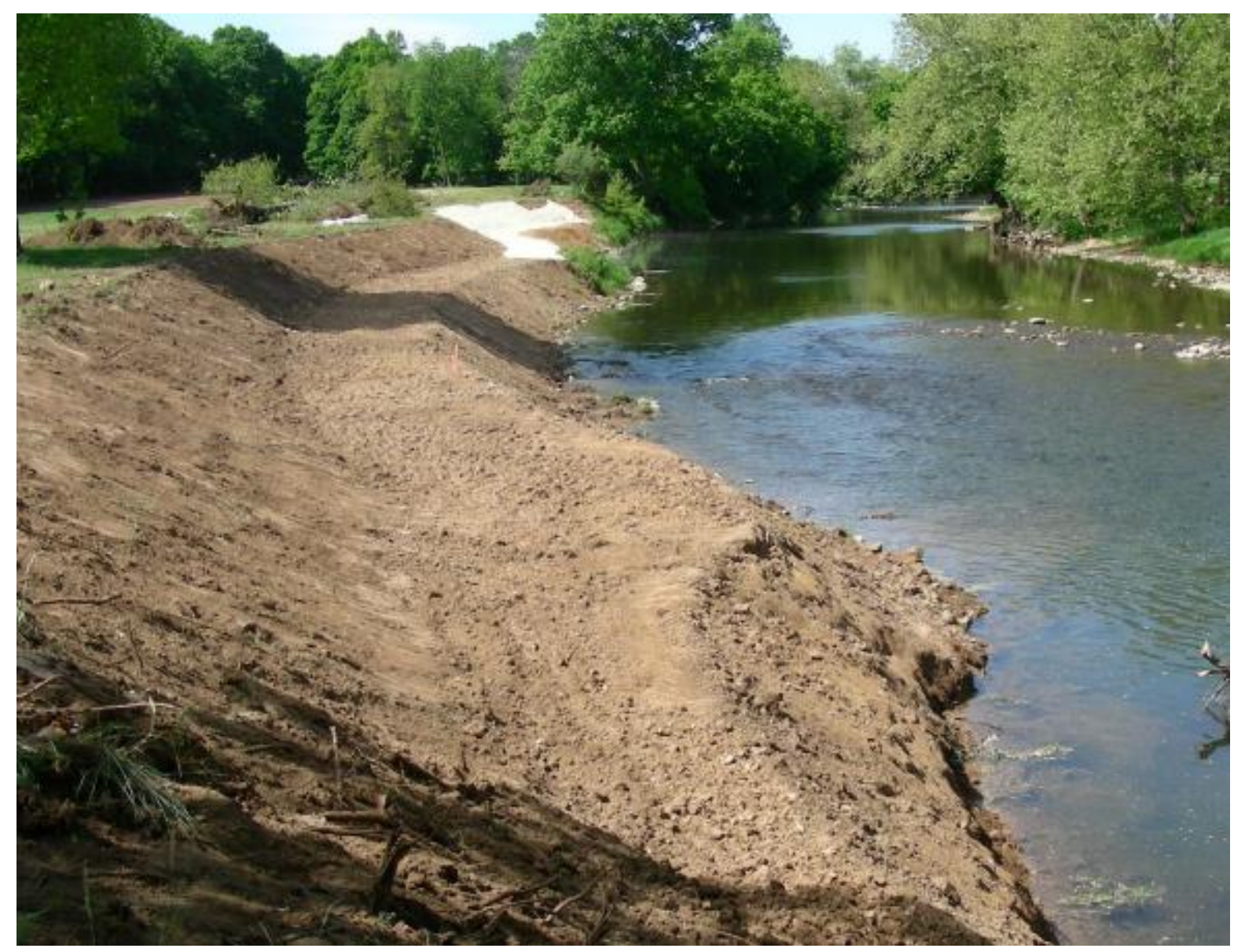

Figure 3. The eroded banks along the restoration reach were terraced to provide a gentler slope and small floodplain to decrease erosion and increase aggregation of sediment, taken May 2010. 


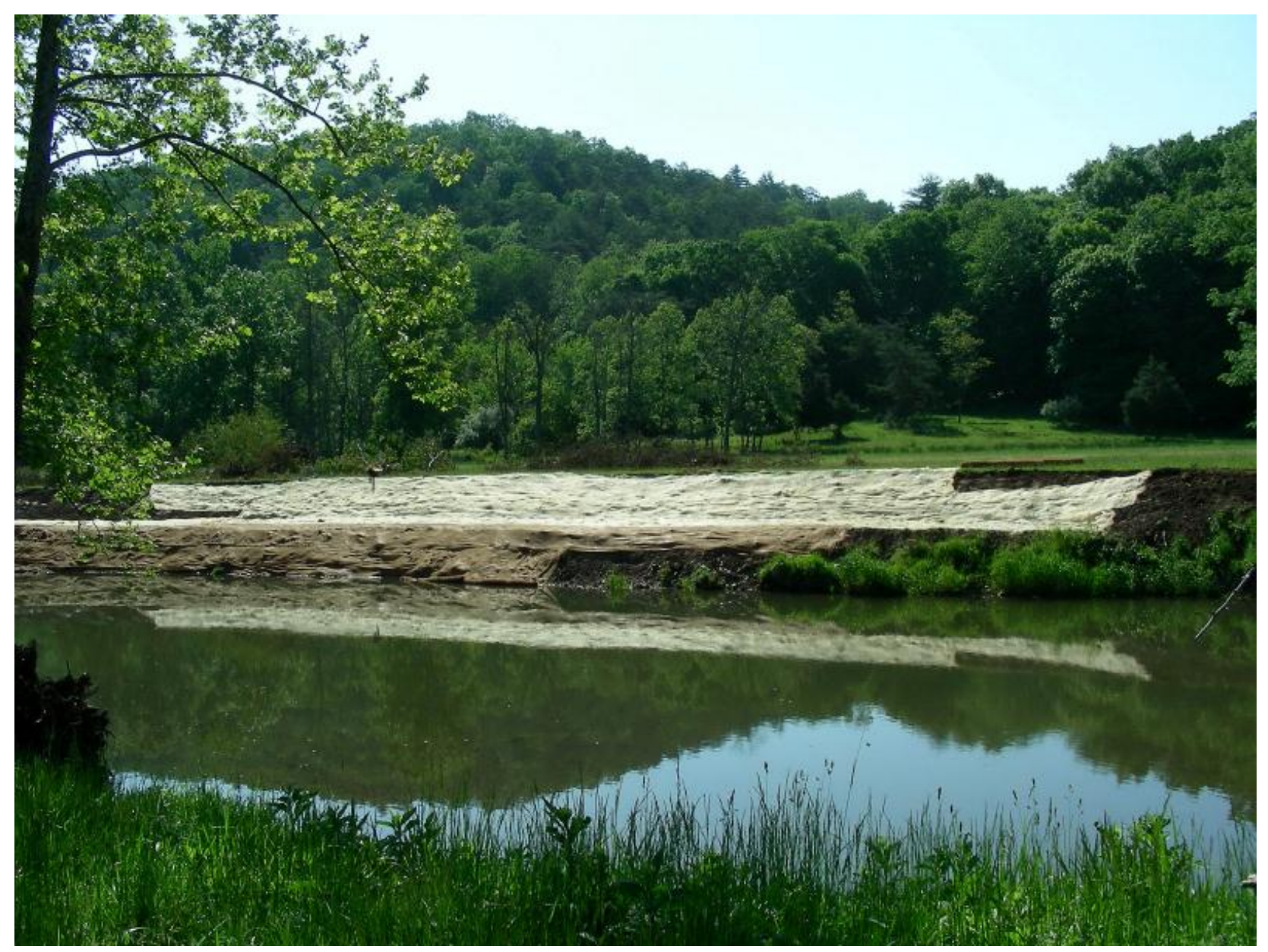

Figure 4. Geotextiles were laid down over the newly sculpted banks along the restoration reach

to reduce sediment loss, taken May 2010. 


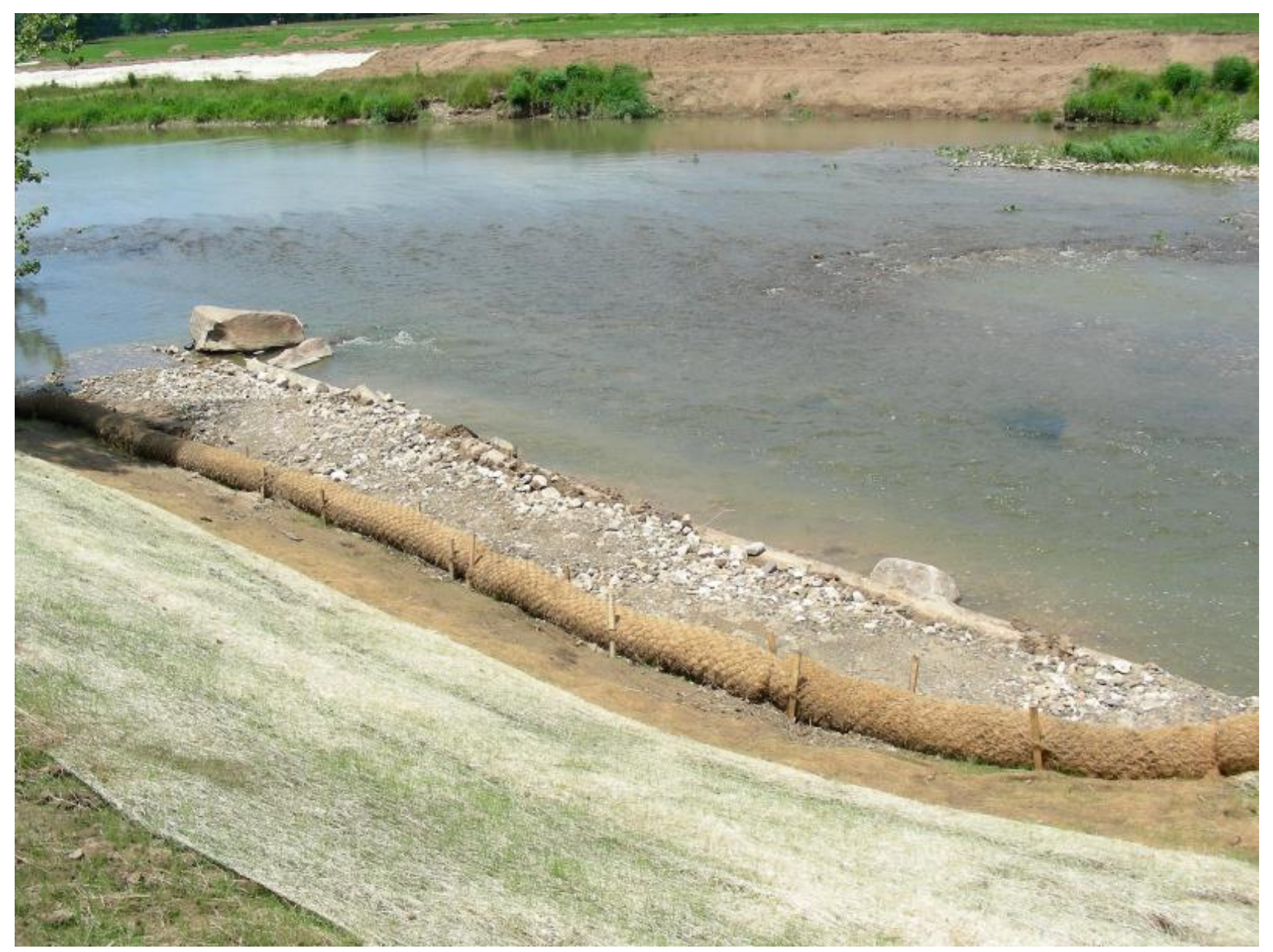

Figure 5. Log vanes were put into place along the restoration reach to deflect the main current from shore and decrease the erosion impact. The logs were anchored into the bank and held in place by large boulders. The inside angle was filled with streambed material. Coconut bio-logs were placed along the bottom of the contoured banks to catch sediment. The left side of the restoration reach is seen with newly constructed banks, taken June 2010. 


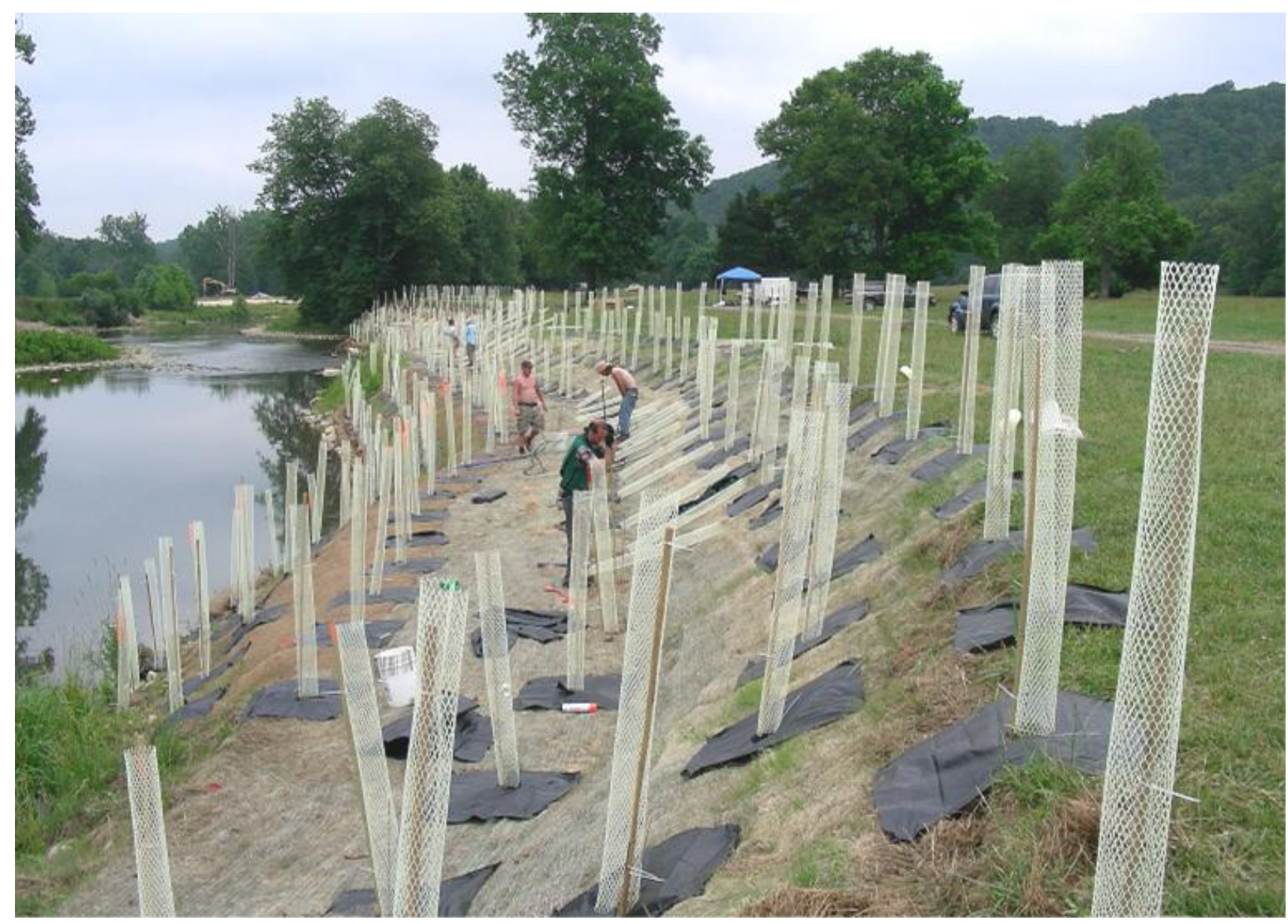

Figure 6. Trees and shrubs were planted on both sides of the restoration reach to re-establish the riparian zone and aid in bank stabilization. Tree tubes were placed around every sapling to prevent herbivory, taken June 2010. 


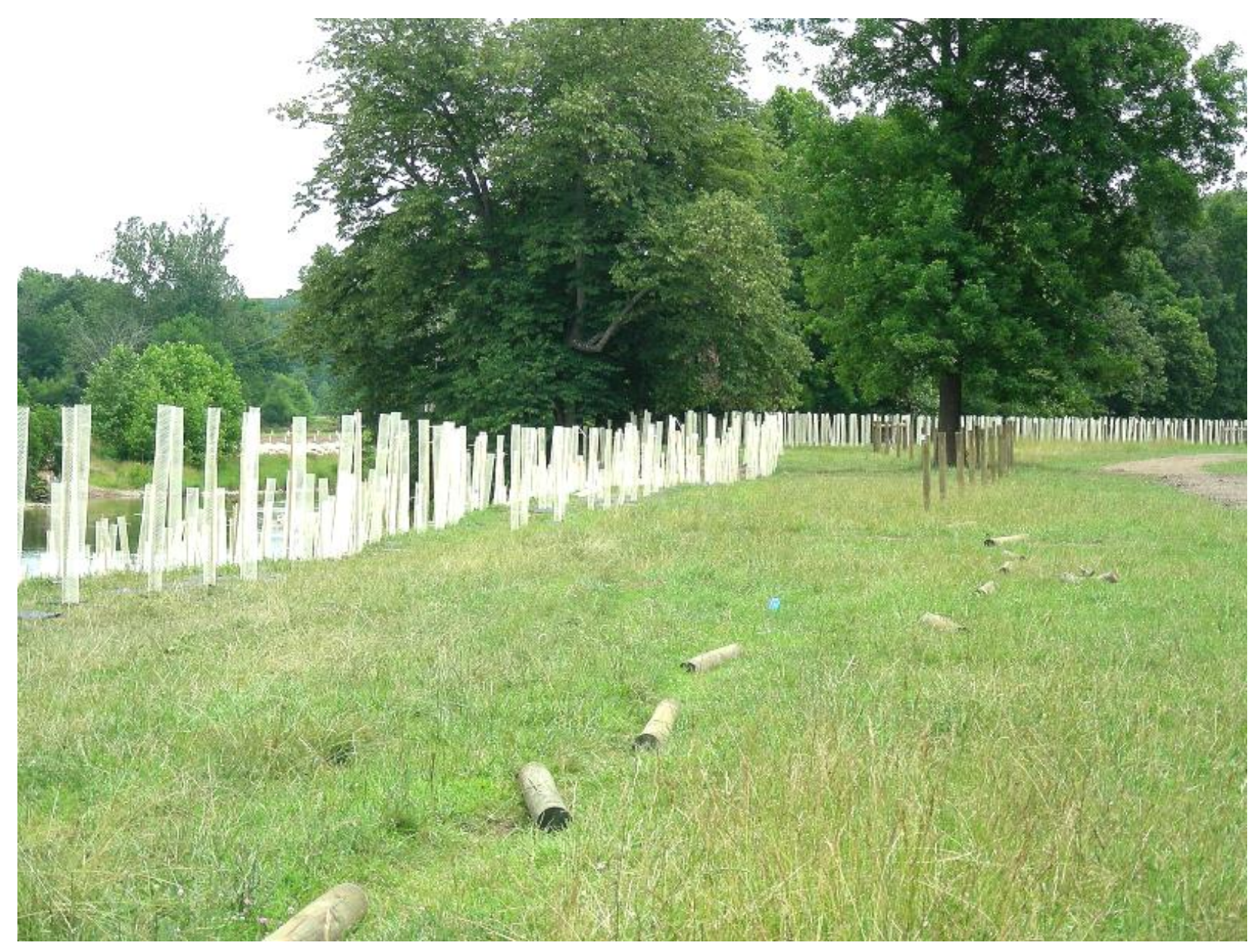

Figure 7. Construction of the barbed wire fence along the right side of the restoration reach.

Thick posts are laying on the ground in the approximate locations that they will be placed, taken June 2010. 


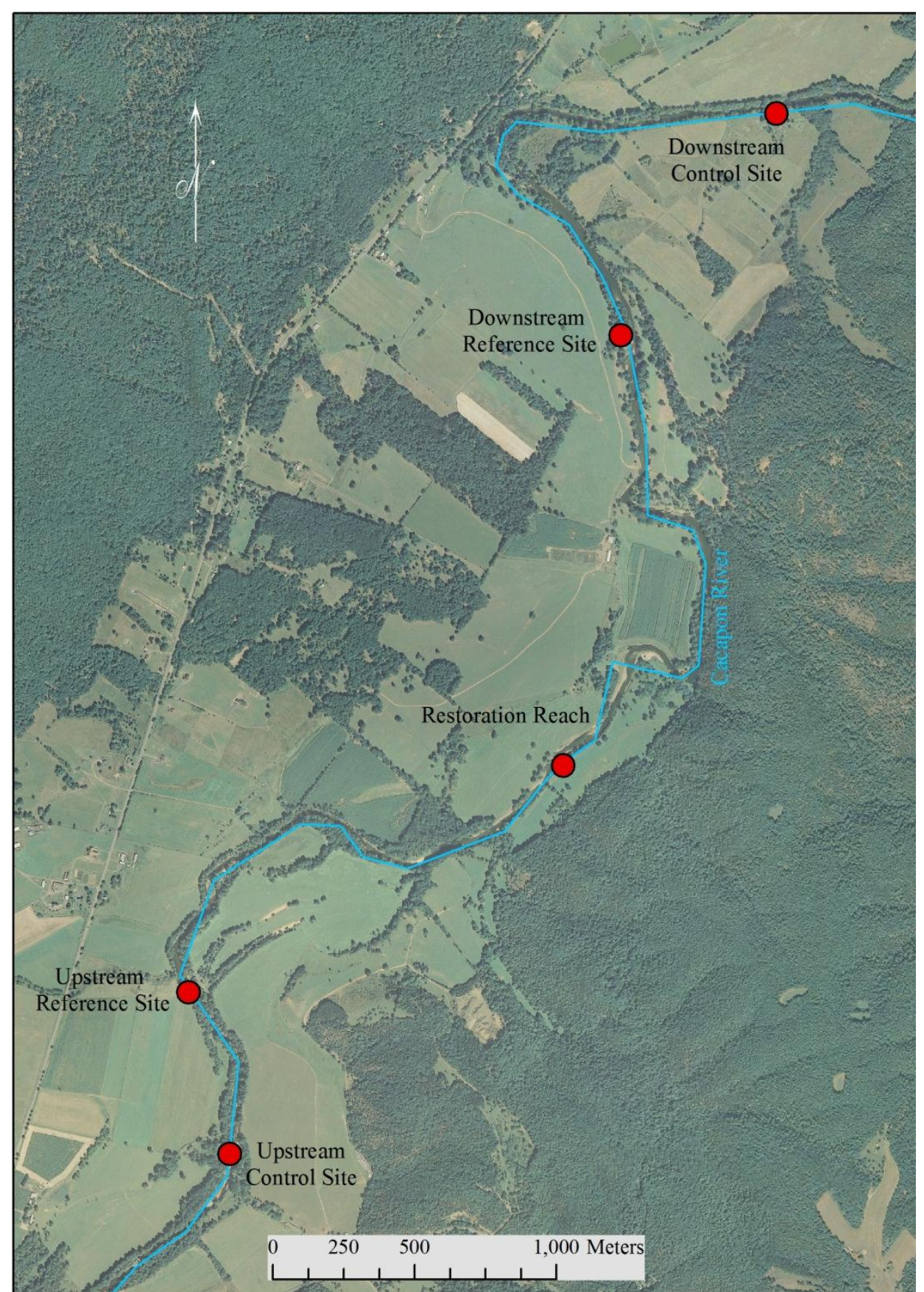

Figure 8. The site design for the restoration study along the Cacapon River, West Virginia,

USA. The restoration reach was bordered on both ends by a reference site and a control site. 


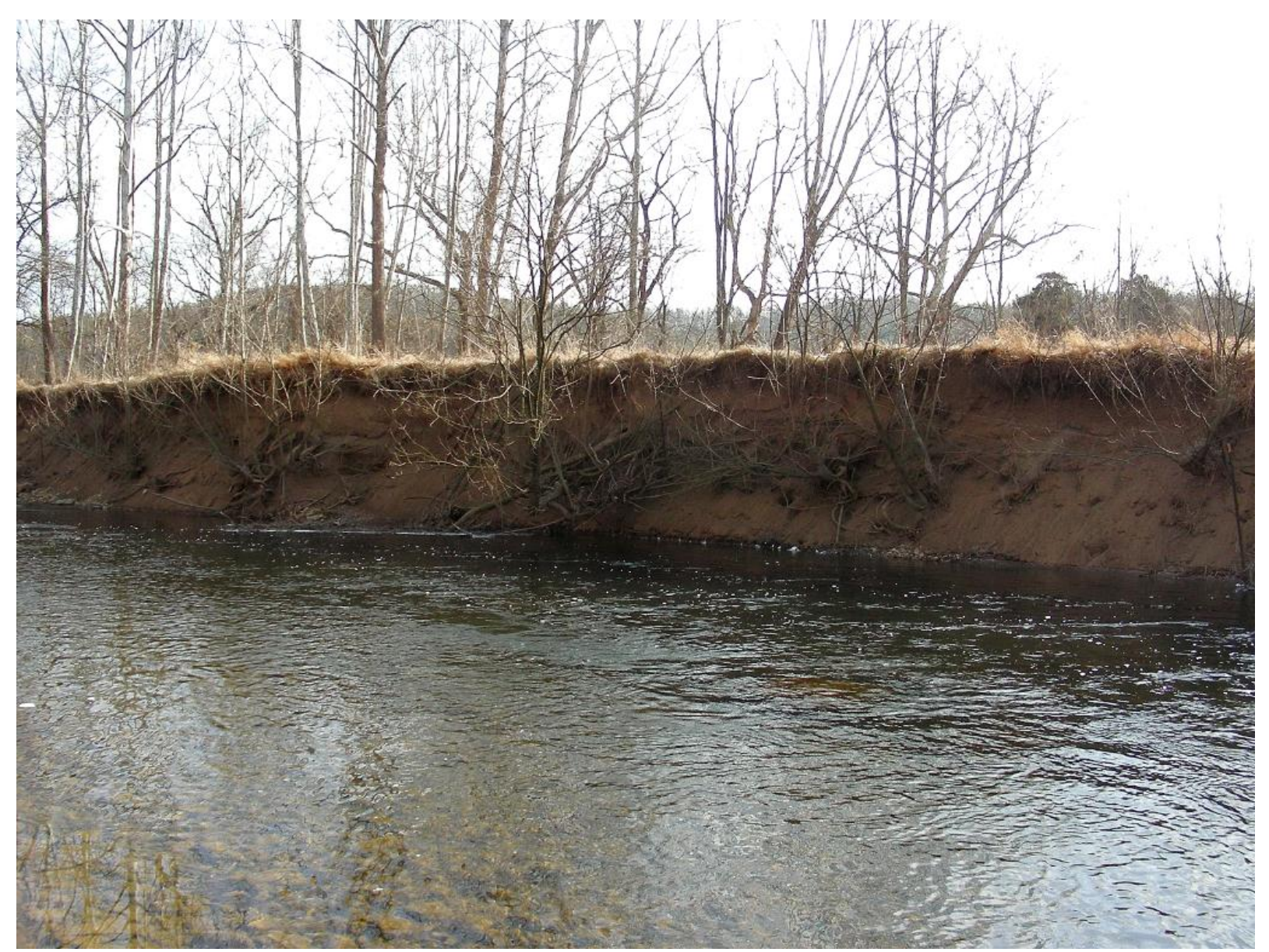

Figure 9. The upstream control site that was compared to the restoration reach to determine the

success of the restoration. The banks at this site were not restored; vegetation and an old barbedwire fence are falling down the eroded banks, taken February 2009. 


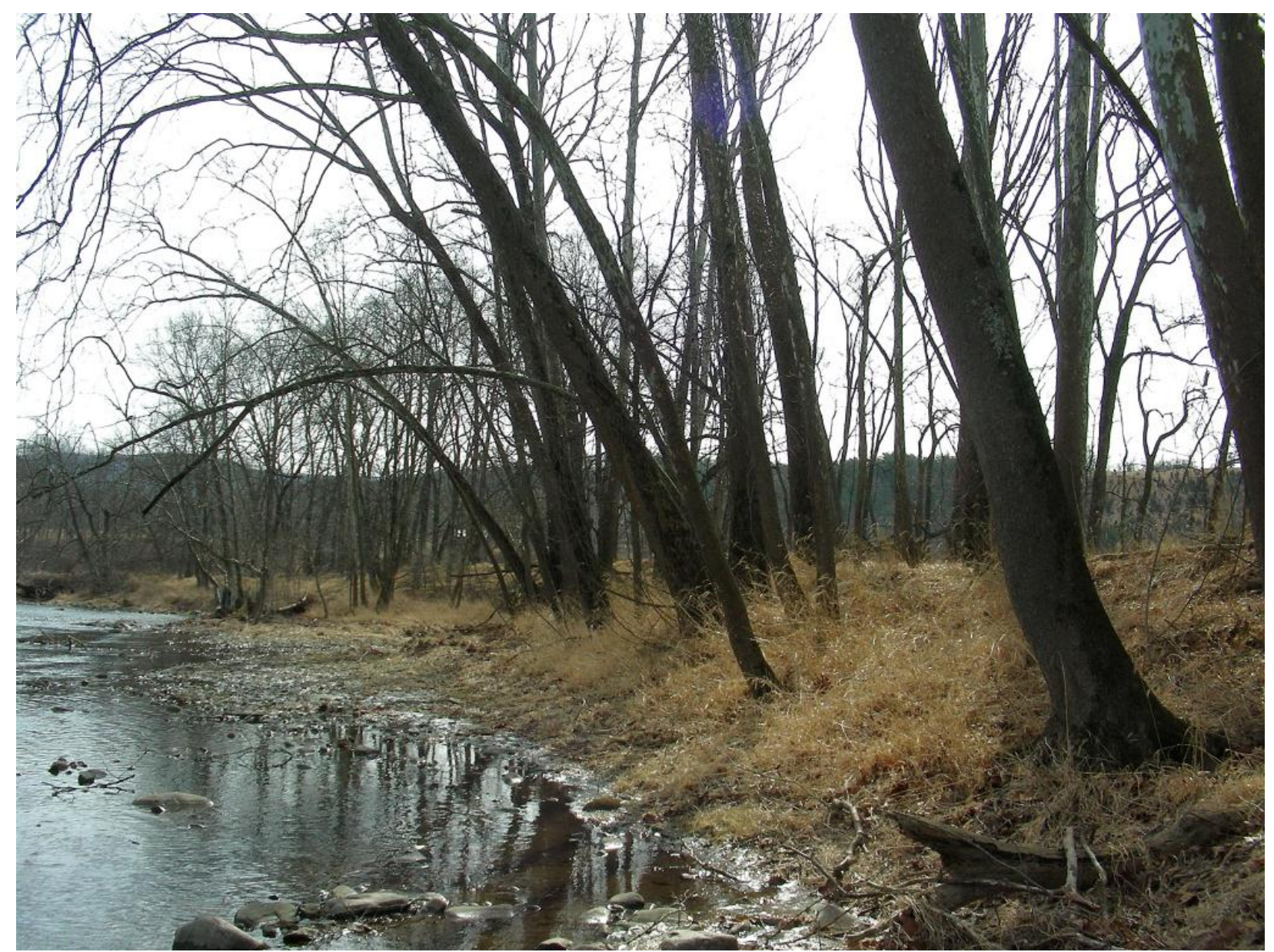

Figure 10. The downstream reference site that was compared to the restoration reach to

determine the success of the restoration. The banks at this site were gently sloped and wellvegetated, taken February 2009. 


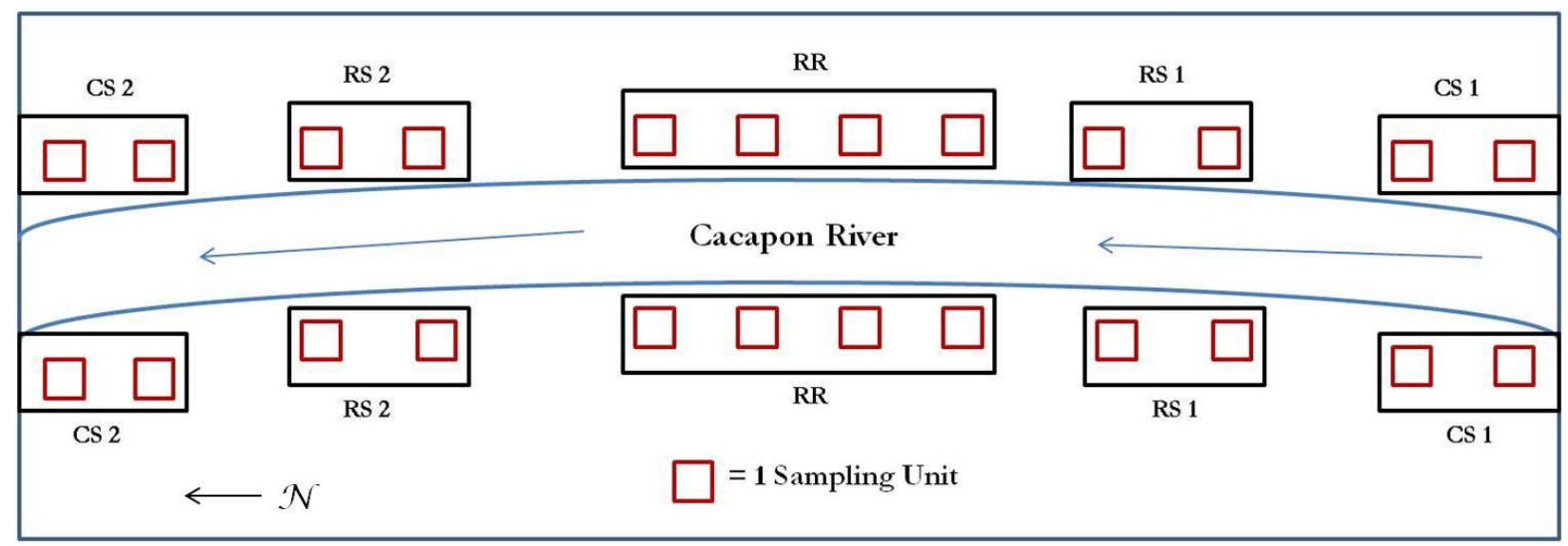

Figure 11. The study design centered around the restoration reach (RR), with 8 sampling units.

The restoration reach was bordered on either end by an upstream (RS 1) and downstream (RS 2) reference site and an upstream (CS 1) and downstream (CS 2) control site, with collective totals of 8 sampling units. 


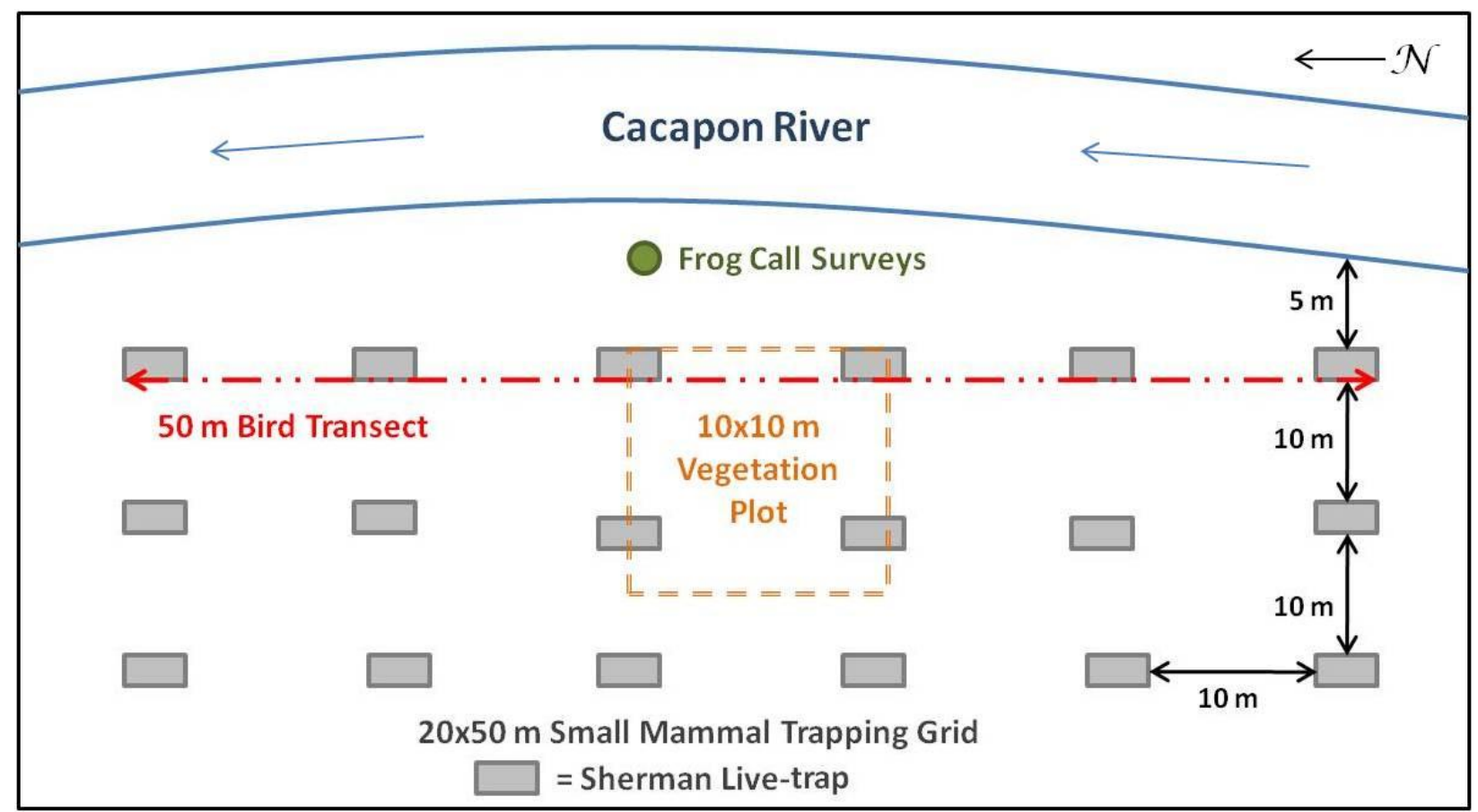

Figure 12. Each sampling unit was composed of a variety of wildlife surveys, including a bird transect, small mammal trapping grid, a point for frog call surveys, and a vegetation plot. 


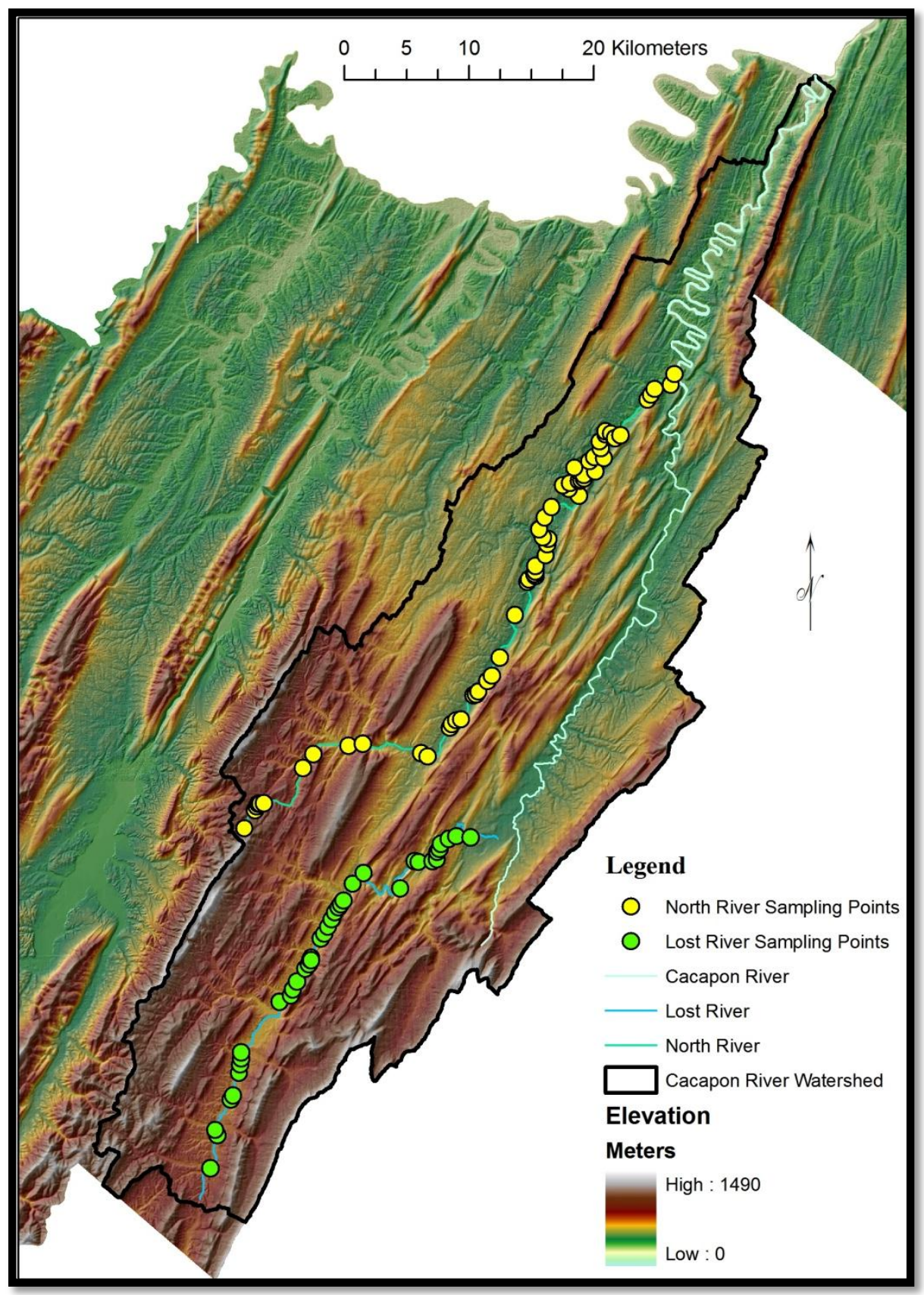

Figure 13. Wood turtle sampling points along the Lost and North rivers, tributaries of the Cacapon River, within the Cacapon River watershed, West Virginia, USA. Surveys were conducted during summer 2010. 
Chapter II

Riparian Ecological Community Assessment of a Restored Reach of the Cacapon River, West Virginia

Running Title: Riparian Wildlife Responses to Restoration

\author{
KATHryn R. P. MCCOARD" ${ }^{1}$, Anthony. A. BILlings ${ }^{2}$, And JAMES T. Anderson ${ }^{3}$ \\ ${ }^{1}$ West Virginia University, Division of Forestry and Natural Resources, P.O. Box 6125, \\ Morgantown, West Virginia 26506 USA [kpawlik@mix.wvu.edu] \\ ${ }^{2}$ West Virginia University, Department of Statistics, P.O. Box 6330, Morgantown, West Virginia \\ 26506 USA [abilling@stat.wvu.edu] \\ ${ }^{3}$ address correspondence to: West Virginia University, Division of Forestry and Natural \\ Resources and Environmental Research Center, P.O. Box 6125, Morgantown, West Virginia \\ 26506 USA [jim.anderson@mail.wvu.edu; 304-293-3825; fax: 304-293-2441]
}

Written in the style of:

The Journal of Applied Ecology 
Abstract.- Restoration of riparian zones, as part of stream restoration, can improve water quality and aquatic life by decreasing nutrient and sediment loads into streams and by minimizing erosion and flood effects. While in-stream monitoring is often a focus for evaluating restoration success, few studies have emphasized monitoring riparian wildlife as potential indicators of improving stream condition post-construction. Our objective was to monitor riparian wildlife responses during a natural stream channel design restoration project along a 1,100-m restoration reach (referred to as RR) of the Cacapon River, West Virginia. Reference (RS) and control (CS) sites were located upstream and downstream of the RR. Following a paired before-after controlimpact (BACIP) design, pre-impact surveys occurred April 2009 - April 2010 and post-impact surveys occurred May 2010 - August 2011. Within the sites, small mammal trapping, bird counts, frog call surveys, and vegetation surveys were conducted. Among the 5 sites, 6 species of small mammals, 79 species of birds, 8 species of anurans, and 96 species of plants were observed. Small mammal abundance had a minor time effect, and was higher in CS than RR post-impact. Small mammal richness, diversity, or evenness did not differ between sites, time periods, or in the site $\times$ time period interaction. Overall bird abundance, richness, and diversity were higher in the RR compared to CS post-impact. Passerine diversity, richness, and evenness did not differ in the site $\times$ time period interaction. Abundances of each of the five most common bird species was similar between sites, time periods, and their interaction. Anuran richness was similar among sites, time periods, and in the site $\times$ time period interaction. Diversity, richness, and evenness of the vegetation tended to be higher in the RS compared to the CS or RR, although the RR may be showing initial signs of improving complexity, and higher in June 2011 compared to June 2009 or 2010. Riparian restoration appeared successful for birds based on increases in their diversity indices compared to the control sites, although it may be too soon to 
tell for small mammals, anurans, and vegetation. We anticipate observing increasing riparian biodiversity as post-restoration time length increases and the riparian zone matures.

\section{Key Words: Amphibians, Avifauna, BACIP design, Natural stream channel design,}

\section{Riparian restoration, Small mammals}

Riparian zones are critical transition zones, connecting terrestrial and aquatic ecosystems, which provide ecosystem services including sediment accumulation, nutrient processing, flood control, erosion control, groundwater outlets, and microclimate cooling (Constantz, Ailes \& Malakoff 1995; Ewel et al. 2001; Semlitsch \& Bodie 2003). Riparian zones provide essential foraging and nesting habitat for a variety of wildlife species (Bodie 2001; Saumure, Herman \& Titman 2007), and serve as movement corridors in fragmented landscapes (Dickson \& Williamson 1988; Bennett 1990; Kondolf \& Micheli 1995; Machtans, Villard \& Hannon 1996; Rosenberg, Noon \& Meslow 1997). An estimated 173 terrestrial vertebrate species rely on riparian zones in the eastern United States for various life history needs, including 26 mammal, 27 bird, 50 reptile, and 70 amphibian species (unpublished data, cited in Crawford and Semlitsch 2007). In-stream wildlife also depends upon riparian zones to maintain water quality for their survival (Jones et al. 1999; Purcell, Friedrich \& Resh 2002). This interaction of wildlife and riparian zones demonstrates the great need for the conservation and restoration of this essential habitat if the ecological value of the ecosystem is to be maintained.

Riparian zones need to be effectively managed (e.g., establishing vegetation buffers on eroded banks, reducing sediment and nutrient loads from agriculture and development) to continue providing beneficial services (Bodie 2001; Purcell, Friedrich \& Resh 2002; Suren et al. 2005). It is estimated that of approximately 49.8 million ha of national riparian lands, only 9.3 million ha remain in a somewhat natural state (Constantz, Ailes \& Malakoff 1995). The 
alteration and loss of riparian zones, affecting the biological and physical nature of the streams they border, is an issue of great concern (Jones et al. 1999; Ewel et al. 2001), as water temperatures, erosion, floods, and sediment and nutrient transportation increase, dissolved oxygen decreases and wildlife habitat is lost with the removal of riparian vegetation (Belsky, Matzke \& Uselman 1999; Lake, Bond \& Reich 2007). Invasive vegetation and wildlife colonize the area, excluding native species and altering ecosystem communities (Bennett 1990; Morrison, Tennant \& Scott 1994). To counteract these changes, restoration of degraded streams, through practices such as planting native riparian vegetation and creating in-stream step-pools, can lead to biological and habitat integrity similar to that of reference sites (Purcell, Friedrich \& Resh 2002). Within the Chesapeake Bay watershed, a major component of reducing nutrient loads to the bay is through restoring riparian vegetation (Jorgensen, Canfield \& Kutz 2000).

In addition to revegetating degraded riparian zones and minimizing stressors (e.g., cattle exclusion fencing), a stream restoration plan includes restoring a stream's flow, a critical component of stream restoration (Cairns and Heckman 1996). This process is guided by the morphology of a stable reference site (Rosgen 1997) in a process called natural stream channel design (NSCD). NSCD requires understanding the cause of a stream's instability in order to be successful in linking the stream back to its abandoned floodplain (Rosgen 1997). In-stream manipulation methods are used to promote and restore fish and macroinvertebrate habitat, decrease sediment load, reconstruct streambed substrate, and restore sinuosity and distribution of energy (Cairns and Heckman 1996).

A stream restoration plan should include criteria used to determine success or failure so that the process can be monitored and subject to adaptive management (Kondolf \& Micheli 1995; Cairns and Heckman 1996); unfortunately, monitoring is often rare, fails to demonstrate 
ecological success, and limits learning from past mistakes (Kondolf \& Micheli 1995; Ewel et al. 2001; Alexander and Allan 2007). When monitoring does occur, the focus is often on aspects of implementation instead of ecological responses (Lake, Bond \& Reich 2007). Non-biotic variables typically monitored were stream flow measurements and nutrients (Alexander \& Allan 2007). Restoration studies that monitored wildlife focused on invertebrates (Purcell, Friedrich \& Resh 2002; Parkyn et al. 2003; Selego et al. 2012), fish (Jungwirth, Muhar \& Schmutz 1995; Moerke \& Lamberti 2003; Pretty et al. 2003), and plants (Rood et al. 2003; Suren et al. 2005); few studies focused on terrestrial wildlife responses to restoration (McCoy \& Mushinsky 2002; Alexander \& Allan 2007).

A successfully restored ecosystem is one that is composed of biotic and abiotic components that enable it to be self-sustaining without additional intervention, and that contains native species similar to those in reference sites (SER 2004). To effectively assess restoration success, multiple wildlife species should be monitored (Golet et al. 2011). To evaluate an aspect of NSCD restoration, riparian zone improvement, our goal was to monitor and compare the riparian ecological community of birds, small mammals, and anurans between restoration, reference, and control sites. We hypothesized that the restored riparian reach would increase bird, small mammal, and anuran abundances, richness, diversity, and evenness compared to control sites, but not yet equal to reference sites, and only the restoration reach community composition would undergo a change post-impact. We considered the restoration to be successful in the short-term (duration of the study) if the monitored wildlife did not decrease in abundance and diversity from pre-impact surveys to post-impact surveys. We considered the restoration to be successful in the long-term if wildlife responses increase above pre-restoration 
levels and draw in more riparian-dependent species as the riparian zone continues to recover and mature.

\section{Methods}

Study Site-The study was conducted along a 13.7-km reach of the Cacapon River from Wardensville, West Virginia to Capon Lake, West Virginia. The river is within the Cacapon River Watershed which occurs in the eastern halves of Hampshire, Hardy, and Morgan counties in the eastern panhandle of West Virginia, within the Ridge and Valley Province. West Virginia's Ridge and Valley region is composed of oak-hickory-pine forest (Strausbaugh \& Core 1977) and receives about $76 \mathrm{~cm}$ of precipitation annually (Kozar \& Mathes 2001). The highest elevation $(1,482 \mathrm{~m})$ in West Virginia is reached on Spruce Knob in Pendleton County, at the western border of the eastern panhandle, and the lowest elevation $(73 \mathrm{~m})$ is reached in Harper's Ferry in Jefferson County, at the eastern border of the panhandle (Green and Pauley 1987). The Cacapon River Watershed drains $2,321 \mathrm{~km}^{2}$ into the Potomac River and belongs to the Chesapeake Bay Watershed (Constantz, Ailes \& Malakoff 1995). The upstream half of the watershed is heavily used for crops and pasture (Constantz, Ailes \& Malakoff 1995), resulting in a loss of riparian vegetation and soil and an increase in erosion. Rebuilding the riparian corridor is the first step to restoration along the Cacapon River (Constantz, Ailes \& Malakoff 1995).

The restoration reach $(\mathrm{RR})$ was a continuous $1,100 \mathrm{~m}$ reach that was highly eroded due to cattle activities and stream flow effects. An agriculturally-degraded control site (CS; $n=2$ sites) and a stable reference site (RS; $n=2$ sites) were located both upstream and downstream of the RR ( $n=1$ site); the sites were separated by $300-1,000 \mathrm{~m}$. The CS's and RS's were $550 \mathrm{~m}$ long and selected based on rapid visual habitat assessment scores being equal in the CS's and RR and higher in the RS's (Selego et al. 2012). The restoration design was based on NSCD concepts. 
During May to June 2010, stream banks along the RR were terraced (Red Creek Enterprises, excavation company, Dry Fork, West Virginia, USA) to provide a gentler bank slope for flood control and overlain with geotextiles to retain soil. In-stream modifications, including nine logvanes, were established to deflect the stream's flow from the banks, decreasing erosive effects. Woody species (predominantly Quercus palustris Münchh., Q. bicolor Willd., Salix nigra Marsh., and Cephalanthus occidentalis L.) were planted to provide vegetation for sediment retention, pollutant filtration, and wildlife habitat. The saplings were surrounded by tree tubes to protect them from herbivory. The plantings and the riparian zone were protected additionally from cattle and Odocoileus virginianus Zimmermann by electric and barbed-wire fencing (Bland Fencing LLC, Petersburg, West Virginia, USA). In October 2010, invasive species (Berberis thunbergii DC., Elaeagnus umbellata Thunb., and Rosa multiflora Thunb.) were cut and sprayed with Roundup® herbicide (Monsanto Co., St. Louis, Missouri, USA) to decrease resource competition with the woody plantings.

Sampling Methods-Eight sampling units (SU) were established in the RR and 4 within each CS and RS, half occurring along each side of the river (Figure 1). The SU's were placed $250 \mathrm{~m}$ apart to allow for survey site independence (Ralph, Droege \& Sauer 1995). Within each SU, surveys were conducted for birds, small mammals, anurans, and vegetation. Following a paired before-after control-impact (BACIP) design (Stewart-Oaten, Murdoch \& Parker 1986; StewartOaten, Bence \& Osenberg 1992), pre-impact surveys were conducted from April 2009 to April 2010 and post-impact surveys were conducted from May 2010 to August 2011 to assess the effects of the restoration on riparian wildlife. Restoration activities occurred during May to June 2010. 
Small Mammal Trapping-A 20 x 50-m transect grid (18 traps) was established to capture small mammals at each SU. To sample within the riparian zone, the transect lines were placed $5 \mathrm{~m}, 15 \mathrm{~m}$, and $25 \mathrm{~m}$ from, and paralleling, the stream edge. Sherman live traps $(5.1 \times 6.4$ x $16.5 \mathrm{~cm}$, H.B. Sherman Traps, Tallahassee, Florida, USA) were placed $10 \mathrm{~m}$ apart along the transects and baited with an oatmeal and peanut butter mixture wrapped in wax paper (Edalgo \& Anderson 2007). Trapping occurred simultaneously in each SU for 2 consecutive nights once a month from July to August 2009, June to August 2010, and May to August 2011. Discrepancies in survey periods were due to logistical constraints (e.g. equipment availability, protocol approval). Traps were left open during the entire survey period and checked each day; all captured animals, excluding shrews, were equipped with \#1005-1 monel ear tags (National Band and Tag Company, Newport, Kentucky, USA) to determine recapture rates. Shrews were uniquely marked on their tails with nail polish (Bergström 2004). Date, time, site, SU, trap location, ear tag number, species, gender, and mass of each animal were recorded. Proper precautions were taken against hantavirus according to Mills et al. (1995). Trap-nights were calculated as the number of traps set times the number of nights set; a half trap-night was subtracted for each trap falsely snapped (Hannon et al. 2002).

Bird Transects - Bird counts were conducted once a month from May 2009 to August 2011 to obtain data for birds occurring in the riparian zone year-round. A SU was randomly selected as the beginning point of each survey period to avoid sampling bias. All SU's were surveyed within 4 hours after sunrise and surveys were not conducted during conditions of heavy rain, fog or wind. A 50-m transect was placed $5 \mathrm{~m}$ from the river's edge, parallel to the river, and in each SU on a single side of the river at each site, alternating sides each month. Transects were walked slowly for a minimum of 5 minutes (Ralph, Droege \& Sauer 1995). All birds heard 
or seen, and their distances from the transect, were recorded on both sides of the 20 to $30 \mathrm{~m}$ wide river. Birds flying overhead, except aerial feeders, were recorded but excluded from analysis (Martin et al. 2006), as well as birds recorded farther than $100 \mathrm{~m}$ from the river's edge. Air temperature $\left({ }^{\circ} \mathrm{C}\right)$, wind speed $(\mathrm{m} / \mathrm{s})$, stream noise (decibels), and start time were recorded at the beginning of transects; ending time was recorded at the end of each transect.

Anuran Surveys - Frog call surveys were conducted based on the North American Amphibian Monitoring Protocol (NAAMP). Surveys were conducted in April, June, and August 2009 - 2011 in each SU on a single side of the 20 - 30 m wide river; surveys were not alternated on both sides of the river as NAAMP protocol requires permanent survey locations. Frogs and toads could be heard calling clearly on both sides of the river as extraneous noises (e.g., traffic) were not an issue. Surveys, lasting 5 minutes each, occurred between half an hour after sunset and $0100 \mathrm{~h}$ when air temperatures were $>50^{\circ} \mathrm{C}$. Start and end time, air temperature $\left({ }^{\circ} \mathrm{C}\right)$, wind speed (Beaufort scale; $0=$ calm to $5=30.6-38.6 \mathrm{kph}$ breeze), sky code (cloud cover; $0=$ clear sky to 8 = showers), species, and calling index (0: no calling heard; 1 : distinct individuals calling; 2: overlap of calling, but distinct individuals; 3: indistinct chorus, species instead of individuals heard) were recorded.

Vegetation Surveys - In June each year, a vegetation analysis was conducted to provide additional habitat association data with the wildlife surveys. A $10 \times 10-\mathrm{m}$ plot was established within the center of each SU. Within the plot, all trees with diameter at breast height $(\mathrm{dbh})>5$ $\mathrm{cm}$ were identified and measured. All shrubs, including saplings, $>1 \mathrm{~m}$ tall and $<5 \mathrm{~cm}$ dbh were identified and stems counted. The field layer (woody and herbaceous plants < $1 \mathrm{~m}$ tall) was surveyed in $1 \mathrm{~m}^{2}$ sub-plots in each corner of the $10 \times 10-\mathrm{m}$ plot; identification and estimated percent cover of each species were recorded. At the center of each sub-plot, a Robel pole (Robel 
et al. 1970) was used to measure vertical density from visual obstruction readings taken $4 \mathrm{~m}$ from the pole (1-m height) in all 4 cardinal directions, and averaged for the plot. Canopy cover (\%; Robert E. Lemmon Forest Densiometer Model C, Bartlesville, OK) was recorded from the center of the $10 \times 10$-m plot.

Statistical Analyses - Analyses were conducted in SAS ${ }^{\circledR}$ [SAS Institute Inc., Cary, North Carolina, USA], R [R Development Core Team, Vienna, Austria], and SPSS ${ }^{\circledR} 17.0$ [SPSS Inc, Chicago, Illinois]. The responses, richness $(S)$, diversity $(H)$, and evenness $(E)$, comprised the response matrix in the bird and small mammal analyses. Evenness was defined as $\mathrm{e}^{H} / S$.

For small mammals, recaptures were not included in the analysis. There were 24 SU's measured for 2 to 4 months a year. There were eight SU's where data were missing at May 2011 (month 22) because of site inaccessibility due to extensive flooding. In these instances, the missing values were replaced with the respective median values from June to August 2011 (months 23, 24, and 25). For birds, there were 12 SU's measured monthly for 28 consecutive months. In cases where no species were recorded, $E$ was set equal to 0 to reflect a greater likelihood of a single species dominating rather than all species abundances being even. Passerines were the focus of analyses, although non-passerines were occasionally included. For anurans, there were 12 SU's measured for 3 months a year. Due to the nature of the calling index, diversity and evenness could not be calculated and their means obtained; therefore, only anuran richness was analyzed. For vegetation, there were 24 SUs measured in June of each year. As with the birds, $E$ was set equal to 0 where no species were recorded in the shrub and tree layers. Analyses were conducted with exotic species included and excluded from the dataset. Small mammals - To analyze the small mammal richness, diversity, and evenness data, repeated measures permutational multivariate analysis of variance (PERMANOVA) with factors 
site (containing levels CS, RR, and RS), time (containing ordered levels $0,1,11,12,13,22,23$, 24, and 25 [0 = July 2009, $25=$ August 2011]) and the interaction site $\times$ time, using 2,000 restricted permutations, was constructed in such a way as to acknowledge the temporal nature of the data collection within a sampling unit, and the Euclidean distance. The three $F$-tests produced were global, multivariate tests of means, with the following null $\left(\mathrm{H}_{0}\right)$ and alternative $\left(\mathrm{H}_{\mathrm{a}}\right)$ hypotheses:

$$
\begin{gathered}
\mathrm{H}_{0}: \mu_{\mathrm{CS}, S}=\mu_{\mathrm{RR}, S}=\mu_{\mathrm{RS}, S} \\
\text { and } \mu_{\mathrm{CS}, H}=\mu_{\mathrm{RR}, H}=\mu_{\mathrm{RS}, H} \\
\text { and } \mu_{\mathrm{CS}, E}=\mu_{\mathrm{RR}, E}=\mu_{\mathrm{RS}, E} \\
\mathrm{H}_{\mathrm{a}}: \operatorname{not} \mathrm{H}_{0}
\end{gathered}
$$

where the subscript notation denotes the factor level (i.e., CS: control site, RR: restoration reach, and RS: reference site) and response (i.e., $S$ : species richness, $H$ : species diversity, and $E$ : species evenness), respectively. PERMANOVA $F$-tests were done on individual response variables (at the same Bonferroni correction $(\alpha=0.05 / 3$ tests $=0.017)$-level as the multivariate PERMANOVA) only if the multivariate PERMANOVA test yielded any significant $F$-test. This was done to protect against inflation of the experimental error rate.

Before-after control-impact (BACI) contrasts under the same restricted permutation scheme were conducted, but at the multivariate (global) level, to assess the efficacy of the restoration impact. Contrasts were conducted at the univariate level if the multivariate contrasts were significant. The contrasts were as follows:

$$
\begin{aligned}
& \mu_{\mathrm{RR}, \text { pre }}-\mu_{\mathrm{CS} \text {, pre }}=\mu_{\mathrm{RR} \text {, post }}-\mu_{\mathrm{CS} \text {, post }} \\
& \mu_{\mathrm{RR} \text {, pre }}-\mu_{\mathrm{RS} \text {, pre }}=\mu_{\mathrm{RR} \text {, post }}-\mu_{\mathrm{RS} \text {, post }}
\end{aligned}
$$


where the subscript notation denotes the factor level (i.e., CS: control site, RR: restoration reach, and RS: reference site) and response (i.e., pre: before impact and post: after impact), respectively. If the restoration was successful, we expected the contrast between CS and RR to be equal $(=0)$ pre-impact and $>0$ post-impact as the degraded RR improves beyond the status of CS. If the restoration was successful, we expected the contrast between RS and RR to be $<0$ pre-impact and equal $(=0)$ post-impact as the degraded RR improves to the status of RS.

To analyze total small mammal abundance and Peromyscus spp. (P. maniculatus Wagner and P. leucopus Rafinesque complex) abundance (analyzed separately due to their high capture rate), linear mixed models with random sampling unit effects (i.e., variance was $>0$ ) and an error-covariance structure, chosen through Akaike Information criterion $\left(\mathrm{AIC}_{\mathrm{c}}\right)$, were used. The error-covariance matrix was used because of repeated measures and unequal time length intervals in the data. The power covariance structure was chosen because a dependence structure between time lengths existed. Multivariate $F$-tests and BACI contrasts were conducted to determine differences in fixed factor levels (site, time, and site $\times$ time) and between sites preversus post-impact.

Birds - Passerine richness, diversity, and evenness were analyzed using repeated measures analysis of variance (ANOVA) with Bonferroni correction $(0.05 / 3$ tests $=0.017)$ on the site (containing levels CS, RR, and RS) $\times$ time (containing ordered levels 0 to 27 [0 = May 2009, 27 = August 2011]) interaction and their main effects. The data violated assumptions of sphericity; therefore $F$-tests with the Greenhouse-Geisser correction for degrees of freedom was used. To determine whether the restoration had an impact on overall bird (passerine and nonpasserine) responses, multivariate BACI contrasts were conducted. Univariate contrasts were conducted if the multivariate contrasts were significant. 
To analyze passerine abundance, a generalized linear model was fit assuming a Poisson distribution with a log-link function. The abundance, or count, data were log-transformed (plus one) with one oulier removed to approximate normality. Univariate BACI contrasts were conducted with all species (passerine and non-passerine) included to assess the restoration impact.

To assess changes in individual species abundance, species that accounted for $>5 \%$ of all observations (passerine and non-passerine) were included in a response matrix of count data. These species were Melospiza melodia Wilson, Corvus brachyrhynchos Brehm, Cyanocitta cristata L., Picoides pubescens L., and Agelaius phoeniceus L. A repeated measures PERMANOVA analysis was conducted as described for the small mammal diversity indices. The hypotheses for the global, multivariate $F$-tests substituted the diversity index subscript notation with individual bird species. Multivariate BACI contrasts also were conducted.

Anurans - The frog and toad data were recorded as categorical calling indices; therefore, anuran diversity and evenness could not be analyzed because their means were meaningless. Anuran richness with air temperature as a covariate was analyzed using logistic regression with correlated errors via GEE in conjunction with a logit link and a two-dependent correlation structure on the errors. Temporal correlation was nonexistent.

Ordinal multinomial logistic regression with odds-ratios was conducted on each anuran species using SAS Proc Glimmix, using site (containing levels CS, RS, and RR), sampling units nested within sites (containing levels 1 to 24), and time (containing levels $0,2,4,12,14,16,24$, 26, and 28; $0=$ April 2009, $28=$ August 2011) as the main effects. Air temperature, wind code, and sky code were used as covariates. Various correlation matrixes were modeled to assess temporal correlations in the data, including heterogeneous autoregressive (correlated by temporal 
distance), heterogeneous compound symmetry (correlated temporally, regardless of distance), and variance components (temporal independence). Because similar $P$-values were obtained with each covariance structure, indicating data independence, the variance components correlation structure was selected. The Gauss-Hermite quadrature likelihood approximation method was used to estimate the effects due to convergence issues. If only a single main effect was significant for each species, interaction terms (to determine restoration status [site $\times$ time]) were considered to be unimportant and were not included in the analyses.

Vegetation-Multivariate analysis of variance (MANOVA) with Hotelling-Lawley (H-L) Trace $F$-statistic was used to analyze the response matrix of diversity, richness, and evenness of the overall vegetation (i.e., native and exotic species) by site (containing levels CS, RS, and RR), sampling units within sites (containing levels 1 to 24), time (containing levels 0,12 , and 24), and site $\times$ time interaction for the separate field, shrub, and tree layers. Vertical density was a covariate in the field layer model. Vertical density and canopy cover were covariates in the shrub model. Canopy cover was a covariate in the tree model. Univariate ANOVA tests with Bonferroni corrections $(\alpha=0.05 / 9$ tests $=0.006)$ on the individual diversity metrics for $(1)$ the overall vegetation and (2) native species only were then conducted. Least squares means contrasts (overall vegetation) and Tukey tests (native species) were used to determine where the significance occurred among factor levels within the significant main effects.

The vegetation community datasets (1. natives and 2. natives and exotics) were reduced by excluding species that accounted for $<5 \%$ of all observations. PERMANOVA (adonis function, vegan package; R Development Core Team, www.r-project.org) with Bonferroni correction $(0.05 / 3$ tests $=0.017)$ was used to compare community composition of the three vegetation layers between sites, time, and the site $\times$ time interaction. For significant main 
effects, indicator species analysis (ISA, indval function, labdsv package, R) was used to determine if any species were more characteristic within site type or time period, calculating the indicator values for each species by taking the product of its relative frequency and its relative average abundance within each category (Dufrêne and Legendre 1997). An indicator value threshold of 0.25 and $\alpha=0.05$ ( $p$-values generated through randomization procedures; Dufrêne and Legendre 1997) were used to determine which species characterized the site types and time periods.

\section{Results}

Small Mammals_-We captured 1,038 (489 recaptures) animals in 7,346 trap-nights

(Table 1). The Peromyscus spp. (P. maniculatus and P. leucopus complex; $n=513$ (93.4\%) original captures) were captured the most often, accounting for $96.4 \%$ of all captures. Blarina brevicauda Say, Zapus hudsonius Zimmermann, and Microtus pinetorum LeConte accounted for $0.02 \%, 0.009 \%$, and $0.004 \%$ of all captures, respectively. Scalopus aquaticus L., Microtus pennsylvanicus Ord, and two non-mammalian species, Anaxyrus americanus Holbrook and Glyptemys insculpta LeConte, accounted for $<0.002 \%$ of all captures.

Between sampling unit variation was present for overall small mammal abundances (estimate: 0.002, CI: $0.001-0.006, P=0.012$ ) and for Peromyscus spp. abundance (estimate: 0.001, CI: $0.000-0.002, P=0.015)$. Within sampling unit variance was present for overall small mammal abundances (estimate: 0.004, CI: $0.003-0.005, P<0.001$ ) and for Peromyscus spp. abundance (estimate: 0.002 , CI: $0.002-0.003, P<0.001$ ). A temporal auto correlation within sampling units was present for overall small mammal abundances (estimate: 0.430, CI: $0.256-0.604, P<0.001)$ and for Peromyscus spp. abundance (estimate: 0.244, CI: $0.043-$ $0.444, P=0.017)$, confirming a temporal nature in the data. 
Sites $\left(F_{2,21.4}=0.13, P=0.879\right)$ and the site $\times$ time period interaction $\left(F_{16,137}=1.36, P=\right.$ 0.170) did not differ for overall small mammal abundance, although there was a slight time effect $\left(F_{8,131}=1.95, P=0.058\right)$ which occurred between June and July $2010(-0.042$, CI: -0.070 --0.014 ) (Figure 2). When directly contrasting RS to RR, no differences in abundance were observed between the sites pre- and post-impact $\left(t_{53.8}=1.15, P=0.255\right)$. The CS's were slightly higher in overall abundance than $\mathrm{RR}\left(t_{53.8}=1.95, P=0.057\right)$ post-impact. When considering Peromyscus spp. abundance alone, no differences occurred between sites $\left(F_{2,21.2}=0.32, P=\right.$ $0.730)$ and the site $\times$ time period interaction $\left(F_{16,136}=1.39, P=0.156\right)$, although a time effect was present $\left(F_{8,130}=6.62, P<0.001\right)$ with high May abundances and low August abundances $(P$ $<0.001$, Tukey tests; Figure 3). No difference in Peromyscus spp. abundance occurred between RS and RR $\left(t_{57.2}=0.68, P=0.497\right)$, but CS had a higher abundance of Peromyscus spp. than RR post-impact $\left(t_{57.2}=2.40, P=0.020\right)$.

No differences in overall small mammal diversity, richness, or evenness occurred between sites $\left(F_{2,189}=2.51, P=0.330\right)$, time periods $\left(F_{8,189}=2.01, P=0.085\right)$, or the site $\times$ time period interaction $\left(F_{16,189}=1.50, P=0.068\right)$ (Figure 4). No differences in richness, diversity, or evenness were observed pre- versus post-impact between $\mathrm{RS}$ and $\mathrm{RR}\left(F_{1,214}=2.30, P=0.273\right)$ or between $\mathrm{CS}$ and $\mathrm{RR}\left(F_{1,214}=0.40, P=0.490\right)$.

Birds - We observed 79 (51 passerine) species (2,605 individuals; $80.7 \%$ passerine) of birds (Table 2) during May 2009 to August 2011. Agelaius phoeniceus ( $n=347,13.3 \%$ ) was the most abundant species, followed by M. melodia $(n=307,11.8 \%)$, C. brachyrhynchos $(n=142$, 5.5\%), C. cristata $(n=132,5.1 \%)$, and P. pubescens $(n=131,5.0 \%)$. All other species individually accounted for $<5 \%$ of the total observations. Abundances of these five common species (using averaged counts) was similar among sites $\left(F_{2,252}=1.93, P=0.346\right)$, time periods 
$\left(F_{27,252}=5.16, P=0.093\right)$, and in the site $\times$ time period interaction $\left(F_{54,252}=1.32, P=0.082 ;\right.$

Figure 5). The RS (reference sites) and RR (restoration reach) did not differ in the abundances of the five abundant species pre- versus post-impact $\left(F_{1,334}=1.77, P=0.258\right)$. Their abundances compared between CS (control sites) and RR also did not differ pre- versus post-impact $\left(F_{1,334}=\right.$ $3.81, P=0.089)$.

Passerine abundance was similar among sites $\left(\chi_{2}^{2}=0.51, P=0.773\right)$, time periods $\left(\chi_{27^{2}}=\right.$ $8.39, P=1.000)$, and in the site $\times$ time period interaction $\left(\chi_{53^{2}}=6.02, P=1.000\right)$ (Figure 6$)$. The RS and RR did not differ in bird total abundance pre- versus post-impact $\left(\chi^{2}=1.89, P=0.169\right)$, but RR was higher in abundance than CS post-impact $\left(\chi^{2}=4.65, P=0.031\right)$.

Passerine diversity $\left(F_{13.33,59.98}=1.63, P=0.099\right)$, richness $\left(F_{12.64,56.90}=1.97, P=0.043\right)$, and evenness $\left(F_{10.18,45.82}=2.10, P=0.043\right)$ did not differ in the site $\times$ time period interaction (Figure 7). When contrasting CS and RR, passerine diversity $\left(F_{4.76,28.58}=1.62, P=0.188\right)$, richness $\left(F_{4.23,25.35}=2.12, P=0.104\right)$, and evenness $\left(F_{3.71,22.26}=1.61, P=0.209\right)$ did not differ. Passerine diversity $\left(F_{5.24,31.43}=1.91, P=0.119\right)$, richness $\left(F_{4.79,28.73}=1.99, P=0.112\right)$, and evenness $\left(F_{4.43,26.56}=2.40, P=0.070\right)$ also were similar between RS and RR. Diversity $\left(F_{6.67,59.98}=14.35, P<0.001\right)$ and richness $\left(F_{6.32,56.90}=16.83, P<0.001\right)$ differed across time, but evenness $\left(F_{5.09,45.82}=2.04, P=0.090\right)$ did not. No differences in the overall (passerine and non-passerine) bird diversity indices occurred when contrasting RS to RR, pre- versus postimpact $\left(F_{1,334}=0.50, P=0.106\right.$; Figure 8$)$. When contrasting CS to RR, a pre- versus postimpact difference occurred in the diversity indices $\left(F_{1,334}=4.35, P=0.020\right)$. Evenness $\left(F_{1,334}<\right.$ $0.01, P=0.972)$ was similar pre- and post-impact between the sites, but richness $\left(F_{1,334}=4.12, P\right.$ $=0.022)$ and diversity $\left(F_{1,334}=5.46, P=0.015\right)$ were higher in RR compared to CS post-impact. 
Anurans —Eight species of frogs and toads were heard calling within the five sites (Table 3). Anaxyrus americanus Holbrook called primarily during April surveys, with less intensity during June and August surveys. Anaxyrus fowleri Hinckley, Lithobates clamitans Latreille, and L. catesbeianus Shaw called during June and August surveys. Lithobates palustris LeConte called during April surveys. Pseudacris crucifer Wied-Neuwied called primarily during April surveys, with occasional calling during June. Hyla versicolor LeConte called during all surveys (i.e., April, June, and August). Pseudacris feriarum Baird called on rare occasions during April surveys.

Anuran richness was similar among sites $\left(\chi_{2}^{2}=4.36, P=0.113\right)$, time periods $\left(\chi_{8}^{2}=\right.$ $11.88, P=0.157)$, and in the site $\times$ time period interaction $\left(\chi_{12}{ }^{2}=12.00, P=0.446\right)$ (Figure 9). The RS and RR did not differ in frog and toad richness pre- versus post-impact $\left(\chi^{2}=0.26, P=\right.$ 0.608). The RR also was similar to $\mathrm{CS}$ pre- versus post-impact $\left(\chi^{2}=0.20, P=0.657\right)$.

For all 8 species, restoration status ( site $\times$ time) was not considered to be important in influencing the odds of hearing the species call because only a single main effect, if any, were significant for each species. For Anaxyrus americanus, the non-significant covariates, sky code $\left(F_{1,83}=0.00, P=0.980\right)$, wind code $\left(F_{1,84}=0.91, P=0.344\right)$, and air temperature $\left(F_{1,85}=0.14, P\right.$ $=0.711$ ) did not differ in the odds of hearing the species call. The odds of hearing A. americanus in the reference or control sites compared to the restoration reach did not differ $\left(F_{2,86}=0.34, P=\right.$ $0.539)$ and were similar among the sampling units within each site type $\left(F_{9,86}=1.19, P=0.312\right)$. The odds of hearing the species was greater, however, in April and June compared to August $\left(F_{8,86}=2.70, P=0.011 ;\right.$ Table 4$)$.

Sky code $\left(F_{1,84}=0.94, P=0.335\right)$ and wind code $\left(F_{1,84}=3.41, P=0.068\right)$ did not influence the odds of Anaxyrus fowleri calling. The odds of hearing the species was similar 
among the sites $\left(F_{2,86}=0.31, P=0.829\right)$, the sampling units within the sites $\left(F_{9,86}=0.44, P=\right.$ $0.910)$, and time $\left(F_{8,86}=0.45, P=0.887\right)$. However, beginning at about $18^{\circ} \mathrm{C}$, the odds of hearing A. fowleri call increased 7 times with each $1^{\circ} \mathrm{C}$ increase in air temperature $\left(F_{1,86}=7.72\right.$, $P=0.007)$.

The covariates, sky code $\left(F_{1,84}=0.20, P=0.656\right)$, wind code $\left(F_{1,84}=0.26, P=0.614\right)$, and air temperature $\left(F_{1,84}=0.16, P=0.694\right)$ did not affect the odds of hearing Hyla versicolor call. The odds of hearing $H$. versicolor calling did not differ between sites $\left(F_{2,87}=0.76, P=\right.$ $0.360)$ or sampling units within sites $\left(F_{9,87}=0.77, P=0.641\right)$, but there was a greater chance of hearing the species during June and August compared to April $\left(F_{8,87}=4.29, P<0.001\right)$.

The odds of hearing Lithobates catesbeianus calling did not differ with sky code $\left(F_{1,85}=\right.$ 2.01, $P=0.160)$, wind code $\left(F_{1,85}=1.31, P=0.256\right)$, or air temperature $\left(F_{1,85}=1.21, P=0.275\right)$. The odds were similar among sites $\left(F_{2,88}=0.10, P=0.789\right)$, sampling units within sites $\left(F_{9,88}=\right.$ $0.70, P=0.709)$, and time $\left(F_{8,84}=0.55, P=0.817\right)$. Similarly, sky code $\left(F_{1,84}=1.02, P=0.315\right)$, wind code $\left(F_{1,84}=1.58, P=0.213\right)$, air temperature $\left(F_{1,84}=0.31, P=0.577\right)$, sites $\left(F_{2,87}=2.45, P\right.$ $=0.868)$, sampling units within sites $\left(F_{9,87}=0.31, P=0.970\right)$, and time $\left(F_{6,87}=0.35, P=0.908\right)$ did not differ in the odds of hearing L. clamitans calling. The odds of hearing the third Lithobates species, L. palustris, was similar also for sky code $\left(F_{1,85}=0.71, P=0.404\right)$, wind code $\left(F_{1,85}=0.16, P=0.694\right)$, air temperature $\left(F_{1,85}=0.13, P=0.722\right)$, sites $\left(F_{2,88}=0.00, P=\right.$ 0.988), sampling units within sites $\left(F_{9,88}=0.00, P=1.000\right)$, and time $\left(F_{8,88}=0.54, P=0.825\right)$.

Sky code $\left(F_{1,83}=0.87, P=0.355\right)$, wind code $\left(F_{1,83}=1.95, P=0.167\right)$, and air temperature $\left(F_{1,83}=0.01, P=0.935\right)$ did not influence the odds of hearing Pseudacris crucifer call. The odds did not differ among sites $\left(F_{2,86}=1.57, P=0.908\right)$ or sampling units within sites $\left(F_{9,86}=0.82, P=0.600\right)$. A time effect was present, however, as the odds of hearing the species 
was greater during April compared to June $\left(F_{8,86}=2.17, P=0.037\right)$. The species was not heard calling during August.

The covariates and main effects did not influence the odds of hearing Pseudacris feriarum calling. Sky code $\left(F_{1,85}=0.09, P=0.763\right)$, wind code $\left(F_{1,85}=0.01, P=0.941\right)$, and air temperature $\left(F_{1,85}=0.00, P=0.953\right)$ were non-significant. Differences in the odds did not occur among sites $\left(F_{2,88}=0.00, P=1.000\right)$, sampling units within sites $\left(F_{9,88}=0.08, P=0.999\right)$, or time periods $\left(F_{8,88}=0.01, P=1.000\right)$.

Vegetation-A total of 96 (73\% native) species was recorded in the field $(n=85)$, shrub $(n=11)$, and tree layers $(n=20)$; some species were observed in multiple layers (Appendix Ia). Mean field diversity, richness, and evenness of the overall (native and exotic species) vegetation were similar among sites before $\left(\mathrm{H}-\mathrm{L}\right.$ Trace $\left.=0.459, F_{6,23.6}=1.42, P=0.248\right)$ and after vertical density was removed $\left(\mathrm{H}-\mathrm{L}\right.$ Trace $\left.=0.471, F_{6,23.6}=1.46, P=0.236\right)$ and among time periods $(\mathrm{H}-\mathrm{L}$ Trace $\left.=0.230, F_{6,51.6}=1.52, P=0.192\right)$, but the site $\times$ time interaction differed $(\mathrm{H}-\mathrm{L}$ Trace $=$ $\left.0.831, F_{12,65.8}=2.72, P=0.005\right)$. Regarding the overall vegetation, a site $\times$ time effect was present for mean field evenness $\left(F_{4,42}=4.72, P=0.003\right.$; Table 5, Appendix IIa $)$. Mean field richness and diversity were similar among all variables (Table 6). When only native species were considered, mean field evenness had a site $\times$ time effect $\left(F_{4,42}=4.72, P=0.003\right.$; Appendix IIIa). Mean field diversity and richness of native species were similar among all variables (Table 7). The overall field community did not differ among sites (pseudo- $F_{2,63}=1.80, P=0.103$ ) or in the site $\times$ time interaction (pseudo- $F_{4,63}=1.36, P=0.176$ ). Time was important, as Microstegium vimineum Trin. (indicator value $=0.38, P=0.040$ ) characterized the 2010 overall field community and Phalaris arundinacea $\mathrm{L}$. (indicator value $=0.53, P=0.001$ ) characterized the 2011 community (pseudo- $F_{2,63}=4.85, P=0.002$ ). The native field community was similar 
among sites (pseudo- $F_{2,63}=2.00, P=0.109$ ) and the site $\times$ time interaction (pseudo- $F_{4,63}=1.50$, $P=0.153$ ). A time effect was present as Phalaris arundinacea (indicator value $=0.53, P=$ 0.001 ) characterized the native community in 2011 (pseudo- $F_{2,63}=5.92, P=0.003$ ).

Mean shrub diversity, richness, and evenness of the overall vegetation were similar among sites before $\left(\mathrm{H}-\mathrm{L}\right.$ Trace $\left.=0.169, F_{6,23.6}=0.52, P=0.785\right)$ and after canopy cover and vertical density were removed $\left(\mathrm{H}-\mathrm{L}\right.$ Trace $\left.=0.240, F_{6,23.6}=0.74, P=0.620\right)$ and among time periods $\left(\mathrm{H}-\mathrm{L}\right.$ Trace $\left.=0.299, F_{6,51.6}=1.97, P=0.087\right)$, but differed in the site $\times$ time interaction $\left(\mathrm{H}-\mathrm{L}\right.$ Trace $\left.=0.751, F_{12,65.8}=5.61, P=0.011\right)$. Within the univariate ANOVAs, mean overall shrub diversity and mean native shrub diversity, richness, and evenness were similar among all variables. The sampling units within sites differed in mean overall shrub richness $\left(F_{21,42}=3.47\right.$, $P<0.001)$ and minimally differed for evenness $\left(F_{21,42}=2.37, P=0.009\right)$, as did the site $\times$ time interactions for mean overall shrub richness $\left(F_{4,42}=4.46, P=0.004\right)$ and evenness $\left(F_{4,42}=4.79\right.$, $P=0.003$ ). The overall shrub community was similar among sites (pseudo- $F_{2,63}=1.18, P=$ 0.309 ), time periods (pseudo- $F_{2,63}=1.94, P=0.074$ ), and in the site $\times$ time interaction (pseudo$\left.F_{4,63}=0.59, P=0.865\right)$. The native shrub community also was similar among sites (pseudo- $F_{2,63}$ $=0.79, P=0.796$ ), time periods (pseudo- $F_{2,63}=0.79, P=0.747$ ), and in the site $\times$ time interaction (pseudo- $F_{4,63}=1.02, P=0.373$ ).

Mean overall tree richness, diversity, and evenness were similar among sites when canopy cover was included $\left(\mathrm{H}-\mathrm{L}\right.$ Trace $\left.=0.172, F_{6,23.6}=0.56, P=0.757\right)$ or removed $(\mathrm{H}-\mathrm{L}$ Trace $\left.=0.169, F_{6,23.6}=0.52, P=0.784\right)$, but differed between time periods $\left(\mathrm{H}-\mathrm{L}\right.$ Trace $=0.776, F_{6,51.6}=$ $5.11, P<0.001)$ and in the site $\times$ time interaction $\left(\mathrm{H}-\mathrm{L}\right.$ Trace $\left.=0.588, F_{12,65.8}=1.92, P=0.047\right)$. In the univariate ANOVAs, June 2011 was greater than June 2009 in mean overall tree diversity $\left(F_{2,42}=7.98, P=0.001\right)$, richness $\left(F_{2,42}=13.79, P<0.001\right)$, and evenness $\left(F_{2,42}=9.94, P<\right.$ 
0.001). Mean native tree diversity $\left(F_{2,42}=6.79, P=0.003\right)$, richness $\left(F_{2,42}=11.22, P<0.001\right)$, and evenness $\left(F_{2,42}=7.86, P=0.001\right)$ also were higher in June 2011 compared to June 2009 . Time influenced the tree community, as Platanus occidentalis L. (indicator value $=0.36, P=$ 0.003 ) characterized the overall (pseudo- $F_{2,63}=3.38, P=0.003$ ) and the native (pseudo- $F_{2,63}=$ $3.38, P=0.001) 2011$ community. Sites (pseudo- $F_{2,63}=2.04, P=0.046$ ) and the site $\times$ time interaction were non-significant (pseudo- $F_{4,63}=1.44, P=0.122$ ) for the overall tree community. The native tree community also was not influenced by sites (pseudo- $F_{2,63}=2.05, P=0.039$ ) or the site $\times$ time interaction (pseudo- $F_{4,63}=1.44, P=0.096$ ).

\section{Discussion}

Overall, the streambank restoration with regards to small mammals, birds, anurans, and vegetation was successful (i.e., no decline in wildlife abundances or diversity metrics) based on 2 years of post-impact monitoring. The abundance of small mammals, particularly the Peromyscus spp., declined in the restoration reach compared to the control sites after the impact. Yet, by the end of the study, the small mammal abundances were recovering and may continue to do so as the riparian vegetation further develops; additional monitoring is needed. The diversity, richness, and evenness of small mammals and passerines and the abundances of the five dominant bird species remained stable in the restoration reach throughout the study. Overall bird abundance, diversity, and richness increased in the restoration reach compared to the control sites after the impact. The anurans were unaffected by the restoration activities as habitat for them was fairly homogeneous among the study sites. Overall shrub richness was higher along the restoration reach in 2011 than in the reference sites in 2009, indicating increased vegetative complexity after the impact compared to before, although this was not yet relected with native vegetation. The planted vegetation along the restoration reach is young and should gradually 
increase in structural complexity over time. Riparian vegetation communities tend to be highly diverse structurally and compositionally (Gregory et al. 1991), attracting a diverse faunal community as well (Palone \& Todd 1997); long-term success from this study will be to achieve diverse floral and faunal communities within the riparian zone of the restoration reach.

Small mammals - In the short-term, the restoration efforts did not draw in a greater variety of small mammal species to the constructed riparian zone, but the small mammals within the RR appeared to remain despite the disturbance, indicating restoration success, as no sudden increases were documented in the CS and RS from dispersing individuals. Perhaps enough remnant patches existed within the RR for the small mammals to take refuge until after the construction ended. Movement between sampling units (SU), $250 \mathrm{~m}$ apart within a site, occasionally occurred, often between months and sometimes by the following trap-night. On a rare occasion, an individual would be trapped in a different site (e.g., move from CS to RS) the following month, moving distances of $300-1,500 \mathrm{~m}$ along the river. The distances travelled may demonstrate the use of riparian zones as movement corridors. Similar movements were observed by small mammals in Australia, moving up to $1.1 \mathrm{~km}$ through forested corridors linking two forested patches (Bennett 1990).

The Peromyscus spp. complex (P. maniculatus and P. leucopus) was captured in a variety of cover types dominated by grass, shrubs, or trees (K.R.P.M., pers. obs.). Zapus hudsonius and Blarina brevicauda were primarily captured in wooded areas with a grassy herbaceous layer. Microtus pinetorum and M. pennsylvanicus were found in grass-dominated cover. Scalopus aquaticus was captured at the edge of thick herbaceous vegetation along a hay field. All of the species except $S$. aquaticus live in a variety of cover types, from fields to forests, with herbaceous growth and leaf litter; S. aquaticus prefers well-drained soils in forests and fields 
(Merritt 1987). All of these cover types occurred within our study sites along the Cacapon River. In Saskatchewan, Canada, $P$. maniculatus abundance was highest along woodland edges surrounded by agriculture rather than in the forest interior (Bayne \& Hobson 1998). In Iowa and Pennsylvania, small mammal species (e.g., P. maniculatus, M. pennsylvanicus, and Z. hudsonius) intolerant to habitat alterations, such as grazing, were grassland species and tolerant species (e.g., B. brevicauda) occupied woodlands (Geier \& Best 1980; Giuliano \& Homyack 2004). Blarina brevicauda were observed only in mature riparian woodlands in Texas (Dickson \& Williamson 1988).

Overall small mammal abundance was higher in July 2010 than in June 2010, but because this did not happen solely in the RR, the response is not associated with the restoration. This time difference may instead reflect a cyclical peak in small mammal numbers, primarily of Peromyscus spp. which accounted for $96.4 \%$ of all observations. A smaller peak was repeated in July 2011, perhaps indicating a time-lag response to a decreased food supply $1-2$ years prior or possibly a density-dependent effect after the larger peak the year before. However, these peaks may not be related to cyclical timing in the small mammals' life-cycles, as females were found with newly born young in traps in July and August 2010, suggesting that the peak should have remained through August if reflective of additional young entering the community.

Peromyscus spp. abundance was almost consistently higher in May and lower in August compared to other months. Air temperature may have been influential, as average May temperature was $23^{\circ} \mathrm{C}$ and August was $29^{\circ} \mathrm{C}$. Abundance was lower in the RR compared to the structurally complex CS immediately after the restoration occurred, with less available cover for the mice; the RR was degraded due to bank reconstruction, followed by drought conditions, possibly resulting in the low numbers observed in 2010. In South Carolina, small mammal 
numbers also decreased during drought conditions (Constantine et al. 2004). However, P. maniculatus began to recover in 2011, following a population trend observed in the CS and RS, suggesting that riparian conditions began improving within 1 year of the restoration activities, providing greater cover and food for the species that was not available before.

Our small mammal responses may increase as the time length for restoration recovery increases. Other studies have documented a positive influence of riparian vegetative cover on small mammals. Small mammal densities, richness, and diversity were higher in riparian zones than upland forests, although community compositions differed, with riparian zones also serving as population sources (Doyle 1990; McComb, McGarigal \& Anthony 1993). In Canada, small mammal composition was not altered after formation of riparian buffers, from mature forest stands, varying in size from 20 to $800 \mathrm{~m}$ (Hannon et al. 2002), suggesting that buffers created from mature forest may better preserve small mammal populations than recreated buffers that take decades to mature. These mature forest corridors have increased habitat structure from the introduction of edge habitat but still contain forest of sufficient size to maintain populations (Constantine et al. 2004). The edge habitat provides thick, brushy vegetation that is often preferred small mammal cover (Dickson \& Williamson 1988). When thick riparian vegetation grew after being fenced off from agriculture, small mammal richness and abundance increased in Pennsylvania (Giuliano \& Homyack 2004). Species richness and diversity increased with distance into forest from agricultural edges in Brazil (Stevens \& Husband 1998). Species richness in remnant and restored riparian sites were similar in California; species assemblages in older restored riparian sites approximated those of remnant riparian stands, pointing towards success of riparian restoration (Golet et al. 2011). 
Birds—Five species dominated the riparian zones along the Cacapon River: Melospiza melodia, Corvus brachyrhynchos, Cyanocitta cristata, Agelaius phoeniceus, and Picoides pubescens. These species remained in the riparian zone or nearby throughout the year, despite the constructed riparian corridors being about $20 \mathrm{~m}$ wide, a size usually considered to be narrow for birds using riparian buffers. However, these species typically occupy brushy or wooded cover, often along cultivated or agricultural land (Peterson 2002), which lines the Cacapon River. Bird species abundance and richness tend to increase with increasing riparian corridor width (Stauffer \& Best 1980; Hodges \& Krementz 1996; Berges et al. 2010); the amount of resident adults tend to decrease, but juvenile dispersers increase when forest stands are reduced to corridor strips (Machtans, Villard \& Hannon 1996). Bird species composition is also influenced by corridor sizes, as ubiquitous species tend to be found in narrow $(20 \mathrm{~m})$ strips while forest species are found in riparian strips at least $60 \mathrm{~m}$ wide (Darveau et al. 1995); as narrow corridors are created, forest species leave and edge species move in (Hannon et al. 2002). Riparian corridors $\leq 53.3 \mathrm{~m}$ wide may best support edge-dependent breeding bird species and winter residents, but would not be sufficient for forest interior species (Thurmond, Miller \& Harris 1995).

Passerine abundances did not differ across sites and did not differ depending on time of year, most likely because the five most abundant species (all passerines excluding $P$. pubescens) were year-round residents along the Cacapon River. Passerine diversity and richness varied over time, as many of the other observed species migrated to summer breeding grounds or wintering grounds. The restoration of the riparian zone did affect overall (passerine and non-passerine) bird abundances, richness, and diversity compared to control sites. With the establishment of cattle exclusion fencing, newly planted saplings were able to flourish and herbaceous vegetation 
was able to grow tall and thick, providing structurally complex habitat that was not present before. In addition, the RR was already a heterogeneous landscape, with pastures and hayfields for grassland species, riparian zones for edge and riparian-dependent species, and mature forests for forest-interior and edge-interior species. This heterogeneity was not present, or was minimal, in the reference and control sites.

The complexity of riparian zones is highly influential on bird responses. Restoration of riparian woodlands dramatically affected bird responses in Nevada, with 21 original obligate riparian species recovering from one abundant species to 10 in 17 years of cottonwood reestablishment (Rood et al. 2003). In Iowa, restored riparian zones that had been planted with native vegetation had higher bird abundances, richness, and diversity than row crop and pasture sites; within the planted buffers, community composition differed with grassland species occurring in the 2 year old site, shrub and edge species in the 9 year old site, and forest species in the $>14$ year old site, reflective of the successional stages of the buffers (Berges et al. 2010). Bird assemblages changed as the riparian zone was altered in Australia, transitioning from a grazed forest containing insectivorous birds, to pasture containing nectarivore specialist species, to crops containing ground-foraging generalist species (Martin et al. 2006).

When vegetation was homogeneous between riparian and upland habitats in Virginia, bird species richness and abundance were similar in both, although certain species (Empidonax virescens and Seiurus motacilla) were dependent on riparian zones despite the homogeneous vegetation (Murray \& Stauffer 1995). In Iowa, bird richness was similar between riparian and upland woodlands, but the former supported greater bird densities (Stauffer \& Best 1980). Bird abundances, richness, and diversity were higher in riparian habitats compared to non-riparian habitats in Australia; this usage was disproportionately high compared to the area of riparian 
habitat available and $17 \%$ of the species observed were found exclusively in the riparian zone (Palmer \& Bennett 2006). Although a variety of bird species use riparian zones, the surrounding landscape is often essential to the species and used in a complementary manner to undergo all aspects of their life histories (Martin et al. 2006; Palmer \& Bennett 2006), suggesting the need for conservation of riparian zones to extend, to some degree, into adjacent habitats.

Herpetofauna - The odds of hearing the eight individual frog and toad species calling were not affected by site type, sampling units within sites, cloud cover (sky code), wind speed (wind code), or restoration status (site $\times$ time). Few macrodepressions for anuran breeding occurred directly within the riparian zone in any of the sites; most breeding locations were small, still coves tucked into the river banks or shallow wetlands in pastures nearby (K.R.P.M., personal observation). These limited breeding pools may have affected the distributions of the eight frog and toad species observed along the Cacapon River. All of the species may have been forced to share the few resources available within the sites, leading to similarities among sites and restoration status related to species richness and the odds of hearing any of the species call. During times of flooding, which occurred during the spring of each year, tadpoles in isolated pools may have been washed downstream, causing further homogenizing of the anuran community.

Although the breeding locations of the species were spatially similar, temporal differences occurred that likely aided in keeping the shared breeding pools from becoming too crowded. Anaxyrus americanus, Hyla versicolor, and Pseudacris crucifer had increased odds of calling depending on time of year. In our study, A. americanus called primarily during April, with less intensity during June as their breeding period came to an end, no longer calling in August. These results are consistent with other breeding reports of A. americanus, emerging 
from hibernation in March, calling soon after, metamorphing as early as May, and ending breeding by June or July depending on elevation and latitude (Green \& Pauley 1987; Conant \& Collins 1998; Elliott, Gerhardt \& Davidson 2009). Hyla versicolor called during all survey months (i.e., April, June, and August), with greater intensity during the latter 2 months. This is in line with reports of their breeding not beginning until late April in West Virginia (Green \& Pauley 1987), although they have been observed to breed from as early as March to July (Elliott, Gerhardt \& Davidson 2009). Pseudacris crucifer called primarily during April, with less intensity during June and silence during August. This species' breeding occurs shortly after hibernation emergence in mid-February to late March (Green \& Pauley 1987). The calling recorded during June may not have been linked to breeding, but may have been rain calls occasionally made by the species (Elliott, Gerhardt \& Davidson 2009). Anaxyrus fowleri was the only species whose calling was influenced by air temperature, with the chances of their calling increasing at about $18^{\circ} \mathrm{C}$. This species tends to emerge later in the spring than A. americanus (Green \& Pauley 1987; Conant \& Collins 1998; Elliott, Gerhardt \& Davidson 2009), when temperatures are warmer, possibly leading to the temperature effect observed.

Toadlets and anuran adults were regularly observed within the riparian zone during nonbreeding periods, suggesting that this habitat may be a complementary resource need that directly influences the abundance of locally breeding anurans (Pope, Fahrig \& Merriam 2000). Riparian zones are complementary habitat for a myriad of freshwater turtles that use them to complete aspects of their life-histories (Bodie 2001) and are essential habitat for many other reptile and amphibian species. In North Carolina, 95\% of streamside salamanders moved a maximum of $27 \mathrm{~m}$ from stream edges during daily activities (Crawford \& Semlitsch 2007). In Texas, higher numbers of reptile and amphibian species and individuals occurred within 
streamside zones compared to adjacent pine plantations (Rudolph \& Dickson 1990), demonstrating a strong dependence on riparian zones for these species' persistence.

Amphibian richness and diversity did not differ between streamside and upslope habitat in Oregon, although community composition differed (McComb, McGarigal \& Anthony 1993). In Canada, anuran composition did not change after the creation of vegetated riparian buffers varying in width from $20-800 \mathrm{~m}$ (Hannon et al. 2002). Similarly, in South Carolina, reptile and amphibian abundances and diversity were not affected by riparian zone width (Bowers et al. 2000). However, in Texas, amphibian and reptile abundances were higher in streamside zones that were at least $30 \mathrm{~m}$ wide compared to narrower zones (Rudolph \& Dickson 1990). In Pennsylvania, herpetofaunal richness, abundance, biomass, and community compositions did not differ between fenced and unfenced riparian buffers, possibly due to the vegetation structure only having $1-2$ years to develop since fencing from cattle, but anuran reproductive success was higher on fenced sites (Homyack \& Giuliano 2002). Core (essential) terrestrial habitat for a wide variety of amphibians and reptiles extends as far as $290 \mathrm{~m}$ from an aquatic habitat edge (Semlitsch \& Bodie 2003); protection of riparian buffers would protect these species which carry out many aspects of their life-histories within riparian zones.

Vegetation-Although the riparian zone was diverse in the number of species recorded (96 species), it was homogeneous in composition when comparing the sites and sampling periods to each other. Diversity, richness, evenness, and community composition tended not to differ among sites, sampling units within sites, time periods, or in the site $\times$ time interactions for the field, shrub, and tree layers. However, across all sites, the diversity metrics were often lower in June 2009 than in June 2010 or 2011, which may reveal initial indications of increasing vegetation complexity in the restoration reach, post-impact, as the vegetation along this site was 
able to establish and thrive after the riparian zone was fenced off from cattle, whereas the other sites had fairly consistent vegetative growth (K.R. P. M., pers. obs.). Mean tree diversity, richness, and evenness increased from June 2009 to June 2011, which may reflect the successful establishment and growth of the saplings planted during the restoration efforts, although this result could not be isolated to the restoration reach. The differences observed in mean shrub richness and evenness among sampling units within sites likely occurred between the upstream control site and reference site, which were dense with shrubs (primarily Lindera benzoin L. and Rosa multiflora Thunb.), and their corresponding downstream counterparts which contained very few shrubs (K. R. P. M. pers. obs.). Microstegium vimineum characterized the vegetation community in 2010 and Phalaris arundinacea and Platanus occidentalis characterized the vegetation community in 2011.

Vegetational characteristics can be used to delineate a riparian zone. In Ohio, although no differences occurred in species richness or diversity, community composition differed as riparian floodplains were dominated by Platanus occidentalis, Liriodendron tulipifera, and Fraxinus pennsylvanica and adjacent low slopes were dominant with Quercus velutina, $Q$. coccinea, and Nyssa sylvatica (Holmes, Goebel \& Hix 2007). The ground flora also differed between habitat types, with Polystichum accrostichoides, Lindera benzoin, and Arisaema triphyllum dominating the riparian floodplains and Vaccinium stamineum, Polygonatum biflorum, and Smilax glauca dominating the low slopes (Holmes, Goebel \& Hix 2007). In Oregon, streamside zones differed from adjacent upslope habitat by having a thinner litter layer, higher cover of $1.3-4 \mathrm{~m}$ tall shrubs, higher midstory cover, lower canopy cover, lower basal area of snags and conifers, and fewer stumps (McComb, McGarigal \& Anthony 1993). In Texas, narrow $(\leq 25 \mathrm{~m})$ streamside corridors had higher shrub and herbaceous cover, but wider $(30-90$ 
m) corridors had low shrub and herbaceous cover, thick leaf litter, and intact canopy and midstory cover (Rudolph \& Dickson 1990).

Riparian vegetation structure can be influential on wildlife. Tree and shrub richness and size were correlated with high bird abundances and total plant richness was associated with high bird densities in Iowa; if the woody structure in the riparian habitat was removed, $78 \%$ of the bird species would be lost (Stauffer \& Best 1980). Alternatively, in Iowa, small mammal diversity was highest in channelized habitats characterized by a lack of trees and a grassdominated herbaceous layer, and species abundances were associated with low plant species richness and high forb cover (Geier \& Best 1980). In South Carolina, however, abundances of reptiles and amphibians did not differ between planted and unplanted riparian zones (Bowers et al. 2000).

Grazing reduces vegetation structure and causes a resulting decrease in total wildlife species numbers, although some species (e.g., Tyrannus tyrannus, Peromyscus maniculatus, and Microtus pennsylvanicus) increase in grazed areas (Geier \& Best 1980; Scott, Skagen \& Merigliano 2003). Restoring a riparian buffer along a pasture may achieve greater results through attracting birds than a restored buffer along a crop field (Martin et al. 2006). With the removal of grazing activities in a riparian zone, sediment accumulated and vegetation structure increased, followed by an increase in bird richness and diversity and species composition changed from grassland species to shrub and forest species in Montana (Scott, Skagen \& Merigliano 2003). Grazed sites in Pennsylvania had higher herbaceous ground cover (albeit $<2$ cm tall), but less litter cover, than fenced sites (Giuliano \& Homyack 2004). Alteration of riparian agricultural land to wildlife habitat may take decades to achieve, but vegetation plantings may help advance the process (Homyack \& Giuliano 2002). 
Conclusions - The birds (passerine and non-passerine combined) along the restoration reach increased in abundance, diversity, and richness after the restoration activities, which corresponded with an increase in shrub richness and evenness and tree richness post-impact. Increasing complexity of riparian vegetation often leads to an increase in riparian faunal diversity, although this result was only observed with the birds. The five abundant bird species (4 of which were passerines) along the Cacapon River were habitat generalists that often occur along cultivated or agricultural areas, which is typical cover along the river. The riparian plantings created vegetative buffers that were only about $20 \mathrm{~m}$ wide and unsuitable for interior species, but as the vegetation matures, it may create cover that is suitable for supporting riparian dependent species.

The $20 \mathrm{~m}$ buffer appeared to be of suitable size for providing breeding habitat for anurans (i.e., small, fishless pools) and complementary terrestrial habitat during the remainder of the year. As the herbaceous vegetation is allowed to grow in the fenced-off riparian zones along the restoration reach, microclimate conditions (e.g., cool temperatures, high relative humidity) may become more favorable and lead to an increase in anuran diversity. The small mammal community also should benefit from the developing complexity of the riparian vegetation. Through the vegetative growth, a variety of niches will develop, allowing more species to occupy the riparian zone. Food and shelter will be available within the continuous riparian zone instead of the animals having to travel from the former riparian fragments across open agricultural fields to forest-edges to obtain what they need.

Riparian buffer widths of $50-100 \mathrm{~m}$ are recommended to provide terrestrial wildlife habitat (Palone \& Todd 1997). Riparian corridors $100 \mathrm{~m}$ wide may best preserve the continuity of common breeding bird populations (Hodges \& Krementz 1996) and those 150 m wide would 
best serve freshwater turtles (Bodie 2001), but large buffers, although often biologically essential (Semlitsch \& Bodie 2003), are difficult to obtain from landowners. Riparian corridors of at least $30-50 \mathrm{~m}$ are recommended to provide suitable conditions and core habitat for reptile and amphibian species when adjacent forest is lost (Rudolph and Dickson 1990; Crawford \& Semlitsch 2007); narrower buffers are insufficient for herpetofaunal protection (Semlitsch \& Bodie 2003).

Time scale and buffer length need to be considered when assessing riparian restoration success; giving a restored reach time to achieve shade covering by the developing canopy can decrease water temperature, an influential variable in the return of native forest fauna (Parkyn $e t$ al. 2003). A buffer length of at least $40 \mathrm{~m}$ next to a pasture is essential for microclimate conditions to become similar to those found in large native forest stands (Davies-Colley, Payne \& vanElswijk 2000). However, regardless of buffer length or condition, if the restored riparian buffer is isolated in a fragmented landscape, sources of local wildlife colonists may be depauperate and individuals may be limited in accessing the restored habitat (McCoy \& Mushinsky 2002; Lake, Bond \& Reich 2007).

Effective management of riparian zones requires knowledge of how the ecosystem is important, how adjacent land uses affect it, how to protect it, and how to communicate these matters to stakeholders (Ewel et al. 2001). Even in young restored buffers, excluding cattle from riparian buffers can lead to immediate improvements in bank stability and water clarity (Parkyn et al. 2003; Giuliano \& Homyack 2004). In New Zealand, restored riparian zones of differing ages $(2-24$ years $)$ had not yet increased in native forest fauna as found in remnant riparian stands (Parkyn et al. 2003). Long-term monitoring is thus essential to detect impacts (Hewitt, Thrush \& Cummings 2001), as wildlife initially may be forced into remnant cover in high 
densities and abundances, giving misleading results, until an altered site has begun to establish and individuals disperse into it (Darveau et al. 1995; Hannon et al. 2002).

\section{Acknowledgments}

We thank N.S. McCoard, S. Selego, A. Niedermeyer, R. Harris, and L. Moon for field assistance. Previous drafts of this manuscript were reviewed by N.S. McCoard, T.K. Pauley, P.BohallWood, and E.D. Michael. Statistical assistance was provided by P.J. Turk (repeated measures PerMANOVA) and S. Buerdsell (repeated measures ANOVA). Many landowners allowed us entrance on to their properties and we thank them for the access. Funding for this project was provided by the Chesapeake Bay Conservation Innovation Grant Program (USDA), the National Fish and Wildlife Foundation, the National Oceanic and Atmospheric Administration, and the West Virginia University Environmental Research Center. This is scientific article xxxx of the West Virginia University Agricultural and Forestry Experiment Station.

\section{Literature Cited}

Alexander, G.G. \& Allan, J.D. (2007) Ecological success in stream restoration: case studies from the midwestern United States. Environmental Management, 40, 245-255.

Bayne, E.M. \& Hobson, K.A. (1998) The effects of habitat fragmentation by forestry and agriculture on the abundance of small mammals in the southern boreal mixedwood forest. Canadian Journal of Zoology, 76, 62-69.

Belsky, A.J., Matzke, A. \& Uselman, S. (1999) Survey of livestock influences on stream and riparian ecosystems in the western United States. Journal of Soil and Water Conservation, 54, 419-431.

Bennett, A.F. (1990) Habitat corridors and the conservation of small mammals in a fragmented forest environment. Landscape Ecology, 4, 109-122. 
Berges, S.A., Schulte Moore, L.A., Isenhart, T.M. \& Schultz, R.C. (2010) Bird species diversity in riparian buffers, row crop fields, and grazed pastures within agriculturally dominated watersheds. Agroforestry Systems, 79, 97-110.

Bergström, A. 2004. Small mammal diversity in Kalahari- impact of land-use and pans in a semi-arid savanna, southwestern Botswana. Thesis, Uppsala University, Sweden.

Bodie, J.R. (2001) Stream and riparian management for freshwater turtles. Journal of Environmental Management, 62, 443-455.

Bowers, C.F., Hanlin, H.G., Guynn, D.C., Jr., McLendon, J.P. \& Davis, J.R. (2000) Herpetofaunal and vegetational characterization of a thermally-impacted stream at the beginning of restoration. Ecological Engineering, 15, S101-S114.

Cairns, J., Jr. \& Heckman, J.R. (1996) Restoration ecology: the state of an emerging field. Annual Review of Energy Environment 21, 167-189.

Conant, R. \& Collins, J.T. (1998) Reptiles and Amphibians: Eastern and Central North America, 3rd edn. Houghton Mifflin, New York.

Constantine, N.L., Campbell, T.A., Baughman, W.M., Harrington, T.B., Chapman, B.R. \& Miller, K.V. (2004) Effects of clearcutting with corridor retention on abundance, richness, and diversity of small mammals in the coastal plain of South Carolina, USA. Forest Ecology and Management, 202, 293-300.

Constantz, G, Ailes, N. \& Malakoff, D. (1995) Portrait of a river: the ecological baseline of the Cacapon River. Pine Cabin Run Ecological Laboratory. High View, West Virginia.

Crawford, J.A. \& Semlitsch, R.D. (2007) Estimation of core terrestrial habitat for streambreeding salamanders and delineation of riparian buffers for protection of biodiversity. Conservation Biology, 21, 152-158. 
Darveau, M., Beauchesne, P., Bélanger, L., Huot, J. \& Larue, P. (1995) Riparian forest strips as habitat for breeding birds in boreal forest. Journal of Wildlife Management, 59, 67-78.

Davies-Colley, R.J., Payne, G.W. \& vanElswijk, M. (2000) Microclimate gradients across a forest edge. New Zealand Journal of Ecology, 24, 111-121.

Dickson, J.G. \& Williamson, J.H. (1988) Small mammals in streamside management zones in pine plantations. Pages 375-378 In R.C. Szaro, K.E. Severson, \& D.R. Patton, tech. cords. Management of Amphibians, Reptiles, and Small Mammals in North America Symposium. USDA Forest Service General Technical Report RM-166.

Doyle, A.T. (1990) Use of riparian and upland habitats by small mammals. Journal of Wildlife Management, 71, 14-23.

Dufrêne, M. \& Legendre, P. (1997) Species assemblages and indicator species: the need for a flexible asymmetrical approach. Ecological Monographs, 67, 345-366.

Edalgo, J.A. \& Anderson, J.T. (2007) Effects of prebaiting on small mammal trapping success in a Morrow's Honeysuckle-dominated area. Journal of Wildlife Management, 71, 246-250.

Elliott, L., Gerhardt, C. \& Davidson, C. (2009) The Frogs and Toads of North America. Houghton Mifflin, New York.

Ewel, K.C., Cressa, C., Kneib, R.T., Lake, P.S., Levin, L.A., Palmer, M.A., Snelgrove, P. \& Wall, D.H. (2001) Managing critical transition zones. Ecosystems, 4, 452-460.

Geier, A.R. \& Best, L.B. (1980) Habitat selection by small mammals of riparian communities: evaluating effects of habitat alterations. Journal of Wildlife Management, 44, 16-24.

Giuliano, W.M. \& Homyack, J.D. (2004) Short-term grazing exclusion effects on riparian small mammal communities. Journal of Range Management, 57, 346-350.

Golet, G.H., Gardali, T., Hunt, J.W., Koenig, D.A. \& Williams, N.M. (2011) Temporal and 
taxonomic variability in response of fauna to riparian restoration. Restoration Ecology, 19, 126-135.

Gregory, S.V., Swanson, F.J., McKee, W.A. \& Cummins, K.W. (1991) An ecosystem perspective of riparian zones. BioScience, 41, 540-551.

Green, N.B. \& Pauley, T.K. (1987) Amphibians and Reptiles in West Virginia. University of Pittsburgh Press, Pittsburgh.

Hannon, S.J., Paszkowski, C.A., Boutin, S., DeGroot, J., Macdonald, S.E., Wheatley, M. \& Eaton, B.R. (2002) Abundance and species composition of amphibians, small mammals, and songbirds in riparian forest buffer strips of varying widths in the boreal mixedwood of Alberta. Canadian Journal of Forest Research, 32, 1784-1800.

Hewitt, J.E., Thrush, E. \& Cummings, V.J. (2001) Assessing environmental impacts: effects of spatial and temporal variability at likely impact scales. Ecological Applications, 11, 1502-1516.

Hodges, M.F., Jr. \& Krementz, D.G. (1996) Neotropical migratory breeding bird communities in riparian forests of different widths along the Altamaha River, Georgia. The Wilson Bulletin, 108, 496-506.

Holmes, K.L., Goebel, P.C. \& Hix, D.M. (2007) Influence of landform and soil characteristics on canopy and ground-flora composition and structure of first- and second-order headwater riparian forests in unglaciated Ohio. In: Proceedings of the 15th Central Hardwood Forest Conference. Vol. Gen. Tech. Rep. SRS-101.

Homyack, J.D. \& Giuliano, W.M. (2002) Effect of streambank fencing on herpetofauna in pasture stream zones. Wildlife Society Bulletin, 30, 361-369.

Jones, E.B.D., III, Helfman, G.S., Harper, J.O. \& Bolstad, P.V. (1999) Effects of riparian forest 
removal on fish assemblages in southern Appalachian streams. Conservation Biology, 13, 1454-1465.

Jorgensen, E.E., Canfield, T.J. \& Kutz, F.W. (2000) Restored riparian buffers as tools for ecosystem restoration in the MAIA; processes, endpoints, and measures of success for water, soil, flora, and fauna. Environmental Monitoring and Assessment, 63, 199-210.

Jungwirth, M., Muhar, S. \& Schmutz, S. (1995) The effects of recreated instream and ecotone structures on the fish fauna of an eppipotamal river. Hydrobiologia 303, 195-206.

Kondolf, G.M. \& Micheli, E.R. (1995) Evaluating stream restoration projects. Environmental Management, 19, 1-15.

Kozar, M.D. \& Mathes, M.V. (2001) Aquifer-characteristics data for West Virginia. WaterResources Investigations Report 01-4036. U.S. Geological Survey, U.S. Department of the Interior. Charleston.

Lake, P.S., Bond, N. \& Reich, P. (2007) Linking ecological theory with stream restoration. Freshwater Biology, 52, 597-615.

Machtans, C.S., Villard, M.-A. \& Hannon, S.J. (1996) Use of riparian buffer strips as movement corridors by forest birds. Conservation Biology, 10, 1366-1379.

Martin, T.G., McIntyre, S., Catterall, C.P. \& Possingham, H.P. (2006) Is landscape context important for riparian conservation? Birds in grassy woodland. Biological Conservation, 127, 201-214.

McComb, W.C., McGarigal, K. \& Anthony, R.G. (1993) Small mammal and amphibian abundance in streamside and upslope habitats of mature Douglas-fir stands, western Oregon. Northwest Science, 67, 7-15.

McCoy, E.D. \& Mushinsky, H.R. (2002) Measuring the success of wildlife community 
restoration. Ecological Applications, 12, 1861-1871.

Merritt, J.F. (1987) Guide to the mammals of Pennsylvania. University of Pittsburgh Press, Pittsburgh.

Mills, J.N., Yates, T.L., Childs, J.E., Parmenter, R.R., Ksiazek, T.G., Rollin, P.E. \& Peters, C.J. (1995) Guidelines for working with rodents potentially infected with hantavirus. Journal of Mammalogy, 76, 716-722.

Moerke, A.H. \& Lamberti, G.A. (2003) Responses in fish community structure to restoration of two Indiana streams. North American Journal of Fisheries Management 23, 748-759.

Morrison, M.L., Tennant, T. \& Scott, T.A. (1994) Laying the foundation for a comprehensive program of restoration for wildlife habitat in a riparian floodplain. Environmental Management, 18, 939-955.

Murray, N.L. \& Stauffer, D.F. (1995) Nongame bird use of habitat in central Appalachian riparian forests. Journal of Wildlife Management, 59, 78-88.

Palmer, G.C. \& Bennett, A.F. (2006) Riparian zones provide for distinct bird assemblages in forest mosaics of south-east Australia. Biological Conservation, 130, 447-457.

Palone, R.S. \& Todd, A.H. (editors) (1997) Chesapeake Bay riparian handbook: a guide for establishing and maintaining riparian forest buffers. USDA Forest Service. NA-TP-0297. Radnor, PA, USA.

Parkyn, S.M., Davies-Colley, R.J., Halliday, N.J., Costley, K.J. \& Croker, G.F. (2003) Planted riparian buffer zones in New Zealand: do they live up to expectations? Restoration Ecology, 11, 436-447.

Peterson, R.T. (2002) Birds of Eastern and Central North America, 5th edn. Houghton Mifflin, New York. 
Pope, S.E., Fahrig, L. \& Merriam, H.G. (2000) Landscape complementation and metapopulation effects on leopard frog populations. Ecology, 81, 2498-2508.

Pretty, J.L., Harrison, S.S.C., Shepherd, D.J., Smith, C., Hildrew, A.G. \& Hey, R.D. (2003) River rehabilitation and fish populations: assessing the benefit of instream structures. Journal of Applied Ecology 40, 251-265.

Purcell, A.H., Friedrich, C. \& Resh, V.H. (2002) An assessment of a small urban stream restoration project in northern California. Restoration Ecology, 10, 685-694.

Ralph, C.J., Droege, S. \& Sauer, J.R. (1995) Managing and monitoring birds using point counts: standards and applications. USDA Forest Service General Technical Report PSW-GTR149. pp. 161-168.

Robel, R.J., Briggs, J. N., Dayton, A. D., \& Hulbert, L. C. (1970) Relationships between visual obstruction measurements and weight of grassland vegetation. Journal of Range Management 23, 295-298.

Rood, S.B., Gourley, C.R., Ammon, E.M., Heki, L.G., Klotz, J.R., Morrison, M.L., Mosley, D., Scoppettone, G.G., Swanson, S. \& Wagner, P.L. (2003) Flows for floodplain forests: a successful riparian restoration. BioScience, 53, 647-656.

Rosenberg, D.K., Noon, B.R. \& Meslow, E.C. (1997) Biological corridors: form, function, and efficacy. BioScience, 47, 677-687.

Rosgen, D.L. (1997) A geomorphological approach to restoration of incised rivers. Proceedings of the Conference on Management of Landscapes Disturbed by Channel Incision.

Rudolph, D.C. \& Dickson, J.G. (1990) Streamside zone width and amphibian and reptile abundance. Southwestern Naturalist, 35, 472-476.

Saumure, R.A., Herman, T.B., \& Titman, R.D. (2007) Effects of haying and agricultural 
practices on a declining species: the North American wood turtle, Glyptemys insculpta. Biological Conservation, 135, 565-575.

Scott, M.L., Skagen, S.K. \& Merigliano, M.F. (2003) Relating geomorphic change and grazing to avian communities in riparian forests. Conservation Biology, 17, 284-296.

Selego, S.M., Rose, C.L., Merovich, G.T., Jr., Welsh, S.A. \& Anderson, J.T. (2012) Communitylevel response of fishes and aquatic macroinvertebrates to stream restoration in a thirdorder tributary of the Potomac River, USA. International Journal of Ecology, article ID 753634.

Semlitsch, R.D. \& Bodie, R. (2003) Biological criteria for buffer zones around wetlands and riparian habitats for amphibians and reptiles. Conservation Biology, 17, 1219-1228.

SER (Society for Ecological Restoration International Science \& Policy Working Group) (2004) The SER international primer on ecological restoration. $<$ www.ser.org/pdf/primer3.pdf> accessed 7 September 2012. Society for Ecological Restoration International, Tucson.

Stauffer, D.F. \& Best, L.B. (1980) Habitat selection by birds of riparian communities: evaluating effects of habitat alterations. Journal of Wildlife Management, 44, 1-15.

Stevens, S.M. \& Husband, T.P. (1998) The influence of edge on small mammals: evidence from Brazilian Atlantic forest fragments. Biological Conservation, 85, 1-8.

Stewart-Oaten, A., Murdoch, W.W. \& Parker, K.R. (1986) Environmental impact assessment: "pseudoreplication" in time? Ecology, 67, 929-940.

Stewart-Oaten, A., Bence, J.R. \& Osenberg, C.W. (1992) Assessing effects of unreplicated perturbations: no simple solutions. Ecology, 73, 1396-1404.

Strausbaugh, P. D. \& Core, E.L. (1977) Flora of West Virginia, 2nd edn. Seneca Books, Morgantown. 
Suren, A.M., Riis, T., Biggs, B.J.F., McMurtrie, S. \& Barker, R. (2005) Assessing the effectiveness of enhancement activities in urban streams: I. Habitat responses. River Research and Applications, 21, 381-401.

Thurmond, D.P., Miller, K.V. \& Harris, T.G. (1995) Effect of streamside management zone width on avifauna communities. Southern Journal of Applied Forestry, 19, 166-169. 
Table 1. Number of captures per 100 trap-nights, with means and standard errors (SE) for small mammal species trapped along a 13.7$\mathrm{km}$ reach of the Cacapon River, West Virginia, USA during summer 2009, 2010, and 2011. The sites were associated with a river restoration project: RR, 1,100 m restoration reach; RS 1, upstream reference site; RS 2, downstream reference site; CS 1, upstream control site; and CS 2, downstream control site.

\begin{tabular}{|c|c|c|c|c|c|c|c|c|c|c|c|c|c|}
\hline \multirow[b]{3}{*}{ Common Name } & \multirow[b]{3}{*}{ Scientific Name } & \multirow[b]{3}{*}{$\begin{array}{l}\text { Unique } \\
\text { Captures }\end{array}$} & \multirow[b]{3}{*}{$\begin{array}{c}\text { Total } \\
\text { Captures }\end{array}$} & \multicolumn{10}{|c|}{ Number of Captures/100 Trap-Nights } \\
\hline & & & & \multicolumn{2}{|c|}{ RS 1} & \multicolumn{2}{|c|}{ RS 2} & \multicolumn{2}{|c|}{ RR } & \multicolumn{2}{|c|}{ CS 1} & \multicolumn{2}{|c|}{ CS 2} \\
\hline & & & & $\bar{x}$ & SE & $\bar{x}$ & SE & $\bar{x}$ & SE & $\bar{x}$ & SE & $\bar{x}$ & SE \\
\hline $\begin{array}{l}\text { Deer mouse \& } \\
\text { White-footed mouse }\end{array}$ & $\begin{array}{l}\text { Peromyscus maniculatus \& } \\
\text { P. leucopus complex }\end{array}$ & 513 & 1,001 & 14.09 & 1.92 & 12.25 & 1.54 & 13.03 & 1.86 & 19.23 & 3.49 & 8.04 & 1.28 \\
\hline Short-tailed shrew & Blarina brevicauda & 22 & 22 & 0.16 & 0.16 & 0.75 & 0.38 & 0.16 & 0.11 & 0.39 & 0.17 & 0.39 & 0.39 \\
\hline Meadow jumping mouse & Zapus hudsonius & 9 & 9 & 0.00 & 0.00 & 0.31 & 0.31 & 0.22 & 0.14 & 0.00 & 0.00 & 0.00 & 0.00 \\
\hline Woodland vole & Microtus pinetorum & 4 & 4 & 0.00 & 0.00 & 0.00 & 0.00 & 0.06 & 0.06 & 0.12 & 0.12 & 0.24 & 0.24 \\
\hline Meadow vole & Microtus pennsylvanicus & 1 & 1 & 0.00 & 0.00 & 0.00 & 0.00 & 0.00 & 0.00 & 0.07 & 0.07 & 0.00 & 0.00 \\
\hline Eastern mole & Scalopus aquaticus & 1 & 1 & 0.00 & 0.00 & 0.00 & 0.00 & 0.03 & 0.03 & 0.00 & 0.00 & 0.00 & 0.00 \\
\hline Total & & 550 & 1,038 & & & & & & & & & & \\
\hline
\end{tabular}


Table 2. Mean counts and standard errors (SE) of bird species that were observed along a 13.7-km reach of the Cacapon River, West

Virginia, USA, during spring 2009 - summer 2011. The sites where the species were observed were associated with a streambank

restoration project: RR, 1,100 m restoration reach (RR 1, pre-restoration; RR 2, post-restoration); RS 1, upstream reference site; RS 2,

downstream reference site; CS 1, upstream control site; and CS 2, downstream control site.

\begin{tabular}{|c|c|c|c|c|c|c|c|c|c|c|c|c|c|c|}
\hline \multirow[b]{3}{*}{ Common Name } & \multirow[b]{3}{*}{ Scientific Name } & \multirow[b]{3}{*}{$\begin{array}{c}\text { Number of } \\
\text { Observations }\end{array}$} & \multicolumn{12}{|c|}{ Number of birds/50-m Transect } \\
\hline & & & \multicolumn{2}{|c|}{ RR 1} & \multicolumn{2}{|c|}{ RR 2} & \multicolumn{2}{|c|}{ RS 1} & \multicolumn{2}{|c|}{ RS 2} & \multicolumn{2}{|c|}{ CS 1} & \multicolumn{2}{|c|}{ CS 2} \\
\hline & & & $\bar{x}$ & $\mathrm{SE}$ & $\bar{x}$ & SE & $\bar{x}$ & SE & $\bar{x}$ & $\mathrm{SE}$ & $\bar{x}$ & SE & $\bar{x}$ & SE \\
\hline Acadian flycatcher* & Empidonax virescens & 1 & & & 0.02 & 0.00 & & & & & & & & \\
\hline American crow* & Corvus brachyrhynchos & 142 & 1.06 & 0.42 & 0.30 & 0.01 & 0.21 & 0.07 & 0.29 & 0.12 & 0.23 & 0.07 & 0.61 & 0.15 \\
\hline American goldfinch* & Spinus tristis & 48 & 0.29 & 0.15 & 0.16 & 0.01 & 0.09 & 0.04 & 0.09 & 0.06 & 0.09 & 0.04 & 0.16 & 0.06 \\
\hline American redstart* & Setophaga ruticilla & 1 & & & & & 0.02 & 0.02 & & & & & & \\
\hline American robin* & Turdus migratorius & 97 & 0.02 & 0.02 & 0.22 & 0.02 & 0.23 & 0.10 & 0.68 & 0.63 & 0.36 & 0.13 & 0.21 & 0.07 \\
\hline American woodcock & Scolopax minor & 3 & & & & & & & & & 0.02 & 0.02 & 0.04 & 0.03 \\
\hline Bald eagle & Haliaeetus leucocephalus & 7 & 0.04 & 0.03 & 0.05 & 0.00 & & & 0.02 & 0.02 & 0.02 & 0.02 & & \\
\hline Baltimore oriole* & Icterus galbula & 53 & 0.08 & 0.05 & 0.23 & 0.01 & 0.18 & 0.09 & 0.14 & 0.06 & 0.16 & 0.06 & 0.13 & 0.05 \\
\hline Barn swallow* & Hirundo rustica & 22 & 0.17 & 0.09 & 0.02 & 0.00 & & & 0.07 & 0.06 & 0.04 & 0.03 & 0.13 & 0.06 \\
\hline Belted kingfisher & Megaceryle alcyon & 38 & 0.25 & 0.06 & 0.06 & 0.00 & 0.13 & 0.05 & 0.13 & 0.05 & 0.07 & 0.03 & 0.07 & 0.04 \\
\hline Black-billed cuckoo & Coccyzus erythropthalmus & 4 & 0.02 & 0.02 & 0.02 & 0.00 & & & & & & & 0.04 & 0.03 \\
\hline $\begin{array}{l}\text { Black-capped } \\
\text { chickadee* }\end{array}$ & Poecile atricapillus & 20 & 0.06 & 0.06 & 0.09 & 0.01 & 0.07 & 0.04 & 0.07 & 0.06 & 0.05 & 0.03 & & \\
\hline $\begin{array}{l}\text { Black-crowned night- } \\
\text { heron }\end{array}$ & Nycticorax nycticorax & 1 & & & & & 0.02 & 0.02 & & & & & & \\
\hline Blue jay* & Cyanocitta cristata & 132 & 0.29 & 0.08 & 0.61 & 0.02 & 0.21 & 0.06 & 0.54 & 0.13 & 0.45 & 0.12 & 0.21 & 0.07 \\
\hline Blue-gray gnatcatcher* & Polioptila caerulea & 71 & 0.19 & 0.10 & 0.22 & 0.01 & 0.23 & 0.10 & 0.14 & 0.07 & 0.25 & 0.10 & 0.23 & 0.09 \\
\hline Brown creeper* & Certhia americana & 2 & & & 0.02 & 0.00 & 0.02 & 0.02 & & & & & & \\
\hline Brown thrasher* & Toxostoma rufum & 2 & 0.02 & 0.02 & & & 0.02 & 0.02 & & & & & & \\
\hline
\end{tabular}


Table 2 continued

\begin{tabular}{|c|c|c|c|c|c|c|c|c|c|c|c|c|c|c|}
\hline Brown-headed cowbird* & Molothrus ater & 1 & 0.02 & 0.02 & & & & & & & & & & \\
\hline Canada goose & Branta canadensis & 38 & 0.04 & 0.04 & 0.17 & 0.02 & 0.07 & 0.07 & 0.05 & 0.04 & 0.04 & 0.03 & 0.29 & 0.23 \\
\hline Carolina chickadee* & Poecile carolinensis & 39 & 0.04 & 0.03 & 0.09 & 0.01 & 0.13 & 0.05 & 0.13 & 0.05 & 0.14 & 0.05 & 0.16 & 0.08 \\
\hline Carolina wren* & Thryothorus ludovicianus & 91 & 0.31 & 0.11 & 0.27 & 0.01 & 0.20 & 0.08 & 0.13 & 0.06 & 0.55 & 0.09 & 0.18 & 0.07 \\
\hline Cedar waxwing* & Bombycilla cedrorum & 20 & 0.06 & 0.05 & & & & & 0.05 & 0.05 & 0.25 & 0.18 & & \\
\hline Chipping sparrow* & Spizella passerine & 3 & & & 0.03 & 0.00 & & & & & 0.02 & 0.02 & & \\
\hline Common grackle* & Quiscalus quiscula & 19 & 0.15 & 0.09 & 0.02 & 0.00 & 0.09 & 0.05 & 0.05 & 0.04 & 0.05 & 0.03 & & \\
\hline Common merganser & Mergus merganser & 26 & 0.13 & 0.13 & 0.05 & 0.00 & & & 0.04 & 0.04 & 0.27 & 0.19 & & \\
\hline Common raven* & Corvus corax & 1 & & & 0.02 & 0.00 & & & & & & & & \\
\hline Common yellowthroat* & Geothlypis trichas & 16 & 0.08 & 0.05 & 0.03 & 0.00 & & & & & 0.18 & 0.07 & & \\
\hline Dark-eyed junco* & Junco hyemalis & 28 & 0.04 & 0.03 & 0.31 & 0.04 & 0.07 & 0.07 & 0.02 & 0.02 & 0.02 & 0.02 & & \\
\hline Downy woodpecker & Picoides pubescens & 131 & 0.25 & 0.07 & 0.39 & 0.01 & 0.34 & 0.08 & 0.38 & 0.09 & 0.63 & 0.11 & 0.36 & 0.07 \\
\hline Eastern bluebird* & Sialia sialis & 49 & 0.04 & 0.03 & 0.22 & 0.01 & 0.14 & 0.05 & 0.20 & 0.09 & 0.16 & 0.07 & 0.13 & 0.05 \\
\hline Eastern kingbird* & Tyrannus tyrannus & 48 & 0.04 & 0.03 & 0.31 & 0.01 & 0.13 & 0.05 & 0.11 & 0.06 & 0.07 & 0.03 & 0.07 & 0.04 \\
\hline Eastern meadowlark* & Sturnella magna & 35 & 0.06 & 0.04 & 0.09 & 0.00 & 0.18 & 0.07 & 0.13 & 0.05 & & & 0.16 & 0.06 \\
\hline Eastern phoebe* & Sayornis phoebe & 16 & & & 0.02 & 0.00 & & & 0.09 & 0.06 & 0.11 & 0.06 & 0.07 & 0.04 \\
\hline Eastern towhee* & Pipilo erythrophthalmus & 14 & 0.06 & 0.04 & 0.05 & 0.00 & & & & & 0.09 & 0.04 & 0.02 & 0.02 \\
\hline Eastern wood-peewee* & Contopus virens & 47 & 0.19 & 0.06 & 0.06 & 0.00 & 0.18 & 0.06 & 0.04 & 0.03 & 0.20 & 0.06 & 0.20 & 0.07 \\
\hline European starling* & Sturnus vulgaris & 26 & & & 0.39 & 0.04 & & & 0.02 & 0.02 & & & & \\
\hline Field sparrow* & Spizella pusilla & 4 & & & 0.03 & 0.00 & & & & & & & 0.04 & 0.03 \\
\hline Gray catbird* & Dumetella carolinensis & 27 & 0.04 & 0.04 & 0.03 & 0.00 & 0.02 & 0.02 & 0.04 & 0.03 & 0.36 & 0.10 & & \\
\hline Great blue heron & Ardea herodias & 13 & & & 0.02 & 0.00 & 0.04 & 0.03 & 0.04 & 0.03 & 0.02 & 0.02 & 0.09 & 0.05 \\
\hline Green heron & Butorides virescens & 17 & 0.02 & 0.02 & 0.13 & 0.01 & & & 0.05 & 0.03 & 0.13 & 0.06 & & \\
\hline Hairy woodpecker & Picoides villosus & 10 & & & 0.02 & 0.00 & 0.04 & 0.03 & 0.05 & 0.03 & 0.04 & 0.03 & 0.05 & 0.03 \\
\hline Hooded merganser & Lophodytes cucullatus & 10 & & & & & 0.18 & 0.18 & & & & & & \\
\hline Indigo bunting* & Passerina cyanea & 83 & 0.15 & 0.05 & 0.28 & 0.01 & 0.18 & 0.06 & 0.23 & 0.07 & 0.34 & 0.09 & 0.29 & 0.09 \\
\hline Killdeer & Charadrius vociferous & 5 & & & & & 0.02 & 0.02 & 0.05 & 0.04 & 0.02 & 0.02 & & \\
\hline Lesser yellowlegs & Tringa flavipes & 1 & & & 0.02 & 0.00 & & & & & & & & \\
\hline Louisiana waterthrush* & Parkesia motacilla & 8 & 0.08 & 0.07 & & & & & 0.04 & 0.03 & & & 0.04 & 0.03 \\
\hline Mallard & Anas platyrhynchos & 6 & 0.04 & 0.04 & & & 0.04 & 0.04 & 0.04 & 0.04 & & & & \\
\hline Mourning dove & Zenaida macroura & 28 & 0.04 & 0.03 & 0.25 & 0.01 & 0.02 & 0.02 & 0.07 & 0.04 & 0.05 & 0.03 & 0.04 & 0.03 \\
\hline Northern cardinal* & Cardinalis cardinalis & 30 & 0.15 & 0.07 & 0.13 & 0.01 & 0.05 & 0.03 & 0.05 & 0.03 & 0.14 & 0.05 & 0.02 & 0.02 \\
\hline
\end{tabular}

*Passerine species 
Table 2 continued

\begin{tabular}{|c|c|c|c|c|c|c|c|c|c|c|c|c|c|c|}
\hline Northern flicker & Colaptes auratus & 47 & 0.19 & 0.06 & 0.11 & 0.01 & 0.02 & 0.02 & 0.14 & 0.05 & 0.16 & 0.05 & 0.23 & 0.06 \\
\hline Northern harrier & Circus cyaneus & 1 & & & 0.02 & 0.00 & & & & & & & & \\
\hline Northern mockingbird* & Mimus polyglottos & 1 & 0.02 & 0.02 & & & & & & & & & & \\
\hline Northern waterthrush* & Parkesia noveboracensis & 3 & & & & & & & & & 0.05 & 0.04 & & \\
\hline Osprey & Pandion haliaetus & 2 & & & 0.02 & 0.00 & & & 0.02 & 0.02 & & & & \\
\hline Pileated woodpecker & Dryocopus pileatus & 28 & 0.08 & 0.04 & 0.14 & 0.01 & 0.02 & 0.02 & 0.07 & 0.04 & 0.13 & 0.06 & 0.07 & 0.04 \\
\hline Pine warbler* & Setophaga pinus & 1 & & & & & 0.02 & 0.02 & & & & & & \\
\hline Red-bellied woodpecker & Melanerpes carolinus & 50 & 0.06 & 0.04 & 0.17 & 0.01 & 0.09 & 0.04 & 0.07 & 0.04 & 0.23 & 0.07 & 0.23 & 0.07 \\
\hline Red-breasted nuthatch* & Sitta canadensis & 5 & & & 0.05 & 0.00 & & & 0.02 & 0.02 & 0.04 & 0.04 & & \\
\hline Red-eyed vireo* & Vireo olivaceus & 45 & 0.08 & 0.04 & 0.16 & 0.01 & 0.11 & 0.05 & 0.13 & 0.05 & 0.11 & 0.04 & 0.18 & 0.06 \\
\hline Red-shouldered hawk & Buteo lineatus & 1 & & & & & 0.02 & 0.02 & & & & & & \\
\hline Red-tailed hawk & Buteo jamaicensis & 6 & 0.04 & 0.03 & 0.02 & 0.00 & & & 0.05 & 0.03 & & & & \\
\hline Red-winged blackbird* & Agelaius phoeniceus & 347 & 0.75 & 0.23 & 1.33 & 0.04 & 0.59 & 0.14 & 1.82 & 0.39 & 0.63 & 0.18 & 1.00 & 0.26 \\
\hline Rose-breasted grosbeak* & Pheucticus ludovicianus & 2 & & & & & & & & & 0.04 & 0.04 & & \\
\hline Ruby-throated hummingbird & Archilochus colubris & 7 & 0.02 & 0.02 & 0.02 & 0.00 & 0.04 & 0.03 & 0.02 & 0.02 & 0.04 & 0.03 & & \\
\hline Scarlet tanager* & Piranga olivacea & 16 & 0.04 & 0.03 & 0.08 & 0.00 & 0.04 & 0.03 & 0.04 & 0.03 & 0.07 & 0.04 & 0.02 & 0.02 \\
\hline Song sparrow* & Melospiza melodia & 307 & 0.90 & 0.16 & 0.98 & 0.02 & 0.80 & 0.13 & 1.02 & 0.15 & 0.91 & 0.13 & 0.84 & 0.13 \\
\hline Swamp sparrow* & Melospiza georgiana & 6 & & & & & & & 0.11 & 0.11 & & & & \\
\hline Tree swallow* & Tachycineta bicolor & 7 & & & 0.06 & 0.00 & & & 0.04 & 0.03 & & & & \\
\hline Tufted titmouse* & Baeolophus bicolor & 68 & 0.29 & 0.13 & 0.14 & 0.01 & 0.30 & 0.14 & 0.18 & 0.06 & 0.18 & 0.05 & 0.14 & 0.05 \\
\hline Turkey vulture & Cathartes aura & 2 & & & 0.02 & 0.00 & 0.02 & 0.02 & & & & & & \\
\hline White-breasted nuthatch* & Sitta carolinensis & 61 & 0.04 & 0.03 & 0.11 & 0.00 & 0.18 & 0.06 & 0.21 & 0.07 & 0.27 & 0.07 & 0.27 & 0.08 \\
\hline Wild turkey & Meleagris gallopavo & 3 & & & & & 0.05 & 0.05 & & & & & & \\
\hline Willow flycatcher* & Empidonax traillii & 1 & & & 0.02 & 0.00 & & & & & & & & \\
\hline Wood duck & Aix sponsa & 13 & & & & & & & 0.05 & 0.04 & & & 0.30 & 0.18 \\
\hline Yellow warbler* & Setophaga petechia & 20 & 0.02 & 0.02 & 0.19 & 0.01 & & & 0.04 & 0.03 & 0.02 & 0.02 & 0.05 & 0.03 \\
\hline Yellow-billed cuckoo & Coccyzus americanus & 4 & & & 0.03 & 0.00 & & & & & & & 0.04 & 0.03 \\
\hline Yellow-rumped warbler* & Setophaga coronate & 10 & & & & & 0.02 & 0.02 & 0.09 & 0.09 & 0.09 & 0.07 & & \\
\hline Yellow-throated vireo* & Vireo flavifrons & 2 & & & 0.03 & 0.00 & & & & & & & & \\
\hline Yellow-throated warbler* & Setophaga dominica & 5 & & & & & & & 0.05 & 0.04 & & & 0.04 & 0.03 \\
\hline Passerine Total & & 2,103 & & & & & & & & & & & & \\
\hline Overall Total & & 2,605 & & & & & & & & & & & & \\
\hline
\end{tabular}

*Passerine species 
Table 3. Maximum calling index per 5 minute surveys recorded for frog and toad species heard calling along a 13.7-km reach of the Cacapon River, West Virginia, USA during April, June, and August of 2009, 2010, and 2011. The sites were associated with a river restoration project: RR, 1,100 m restoration reach; RS 1, upstream reference site; RS 2, downstream reference site; CS 1, upstream control site; and CS 2, downstream control site. The calling index values were: 0 , no calling heard; 1, distinct non-overlapping calls; 2, overlap of calls, but distinct individuals heard; and 3, indistinct chorus, species instead of individuals heard.

\begin{tabular}{llccccc}
\hline Common Name & Scientific Name & RR & RS 1 & RS 2 & CS 1 & CS 2 \\
\hline American toad & Anaxyrus americanus & 2 & 2 & 2 & 3 & 2 \\
Fowler's toad & Anaxyrus fowleri & 2 & 1 & 2 & 1 & 2 \\
Gray treefrog & Hyla versicolor & 2 & 2 & 2 & 2 & 2 \\
Green frog & Lithobates clamitans & 2 & 1 & 2 & 2 & 2 \\
American bullfrog & Lithobates catesbeianus & 1 & 1 & 1 & 1 & 1 \\
Pickerel frog & Lithobates palustris & 1 & 1 & 1 & 1 & 1 \\
Spring Peeper & Pseudacris crucifer & 3 & 3 & 3 & 3 & 3 \\
Upland chorus frog & Pseudacris feriarum & 2 & 0 & 0 & 0 & 0 \\
\hline
\end{tabular}


Table 4. Odds ratio estimates and confidence intervals for significant contrasts of anuran species whose odds of being heard calling per 5 minute surveys were influenced by a time effect during surveys conducted along a 13.7-km reach of the Cacapon River, West Virginia, USA during April, June, and August of 2009 to 2011. The surveys were associated with a river restoration project. The months with higher odds are listed first in each contrast.

\begin{tabular}{|c|c|c|c|}
\hline Species & Contrast & Estimate & $95 \%$ Confidence Interval \\
\hline \multirow[t]{7}{*}{ Anaxyrus americanus } & April $2009-$ August 2010 & 75.65 & $6.11-937.35$ \\
\hline & April 2009 - August 2011 & 7.90 & $1.40-44.62$ \\
\hline & June 2009 - August 2010 & 39.56 & $3.38-462.46$ \\
\hline & April 2010 - August 2010 & 70.28 & $5.72-863.54$ \\
\hline & April 2010 - August 2011 & 7.34 & $1.31-41.02$ \\
\hline & April 2011 - August 2010 & 0.06 & $0.01-0.67$ \\
\hline & June 2011 - August 2010 & 0.05 & $0.01-0.62$ \\
\hline \multirow[t]{18}{*}{ Hyla versicolor } & June 2009 - April 2010 & 21.09 & $3.23-137.75$ \\
\hline & June 2009 - June 2010 & 4.98 & $1.02-24.18$ \\
\hline & June 2009 - April 2011 & 10.77 & $1.98-58.63$ \\
\hline & August 2009 - April 2010 & 36.95 & $5.28-258.42$ \\
\hline & August 2009 - June 2010 & 8.72 & $1.67-45.59$ \\
\hline & August 2009 - April 2011 & 18.87 & $3.22-110.47$ \\
\hline & August 2010 - April 2010 & 0.01 & $0.00-0.11$ \\
\hline & June 2011 - April 2010 & 0.01 & $0.00-0.08$ \\
\hline & August 2011 - April 2010 & 0.06 & $0.01-0.40$ \\
\hline & April 2009 - April 2010 & 0.13 & $0.02-0.80$ \\
\hline & August 2010 - June 2010 & 0.06 & $0.01-0.36$ \\
\hline & June 2011 - June 2010 & 0.04 & $0.01-0.27$ \\
\hline & August 2010 - April 2011 & 36.92 & $5.44-250.43$ \\
\hline & August 2010 - April 2009 & 9.36 & $1.60-54.73$ \\
\hline & June 2011 - April 2011 & 0.02 & $0.00-0.14$ \\
\hline & August 2011 - April 2011 & 0.12 & $0.02-0.65$ \\
\hline & June 2011 - August 2011 & 7.09 & $1.04-48.35$ \\
\hline & June 2011 - April 2009 & 14.68 & $2.14-100.89$ \\
\hline \multirow[t]{6}{*}{ Pseudacris crucifer } & April 2009 - June 2009 & 0.08 & $0.01-0.56$ \\
\hline & April 2010 - June 2009 & 0.12 & $0.02-0.77$ \\
\hline & April 2011 - June 2009 & 0.08 & $0.01-0.56$ \\
\hline & April 2009 - June 2010 & 0.01 & $0.00-0.14$ \\
\hline & April 2010 - June 2010 & 59.03 & $5.17-674.75$ \\
\hline & April 2011 - June 2010 & 0.01 & $0.00-0.14$ \\
\hline
\end{tabular}


Table 5. Significant multiple comparison contrasts related to vegetation (overall [native and exotic] and natives-only) surveys conducted along a 13.7-km reach of the Cacapon River, West Virginia, USA during June 2009, 2010, and 2011. The sites were associated with a river restoration project: RR, 1,100 m restoration reach; RS, reference site; and CS, control site. The vegetative layers were field: \% cover of woody and herbaceous plants < $1 \mathrm{~m}$ tall; shrub: abundance of woody plants $>1 \mathrm{~m}$ tall, $<5 \mathrm{~cm}$ in diameter at breast height (dbh); and tree: abundance of woody plants $>5 \mathrm{~cm}$ dbh per 100 -m radius survey circle.

\begin{tabular}{|c|c|c|c|}
\hline Stratus & Contrast & Difference & $P$ \\
\hline \multicolumn{4}{|l|}{ Overall Field Evenness } \\
\hline & CS 2010 - RS 2009 & 0.217 & 0.002 \\
\hline & RS 2010 - RS 2009 & 0.243 & $<0.001$ \\
\hline & RS $2011-$ RS 2009 & 0.211 & 0.002 \\
\hline & RR 2009 - RS 2009 & 0.207 & 0.002 \\
\hline \multicolumn{4}{|l|}{ Native Field Evenness } \\
\hline & CS 2009 - RS 2009 & 0.230 & 0.029 \\
\hline & CS 2010 - RS 2009 & 0.266 & 0.007 \\
\hline & RS 2010 - RS 2009 & 0.252 & 0.011 \\
\hline & RS 2011 - RS 2009 & 0.226 & 0.035 \\
\hline \multicolumn{4}{|l|}{ Overall Shrub Richness } \\
\hline & RS 2010 - RS 2009 & 1.500 & $<0.001$ \\
\hline & RR 2011 - RS 2009 & 1.250 & 0.001 \\
\hline \multicolumn{4}{|l|}{ Overall Shrub Evenness } \\
\hline & RS 2010 - RS 2009 & 0.737 & $<0.001$ \\
\hline & RR 2011 - RS 2009 & 0.726 & $<0.001$ \\
\hline & RR 2009 - RS 2009 & 0.603 & 0.002 \\
\hline \multicolumn{4}{|l|}{ Overall Tree Diversity } \\
\hline & $2011-2009$ & 0.430 & $<0.001$ \\
\hline \multicolumn{4}{|l|}{ Native Tree Diversity } \\
\hline & $2011-2009$ & 0.403 & 0.002 \\
\hline \multicolumn{4}{|l|}{ Overall Tree Richness } \\
\hline & $2011-2009$ & 1.417 & $<0.001$ \\
\hline \multicolumn{4}{|l|}{ Native Tree Richness } \\
\hline & $2011-2009$ & 1.292 & $<0.001$ \\
\hline \multicolumn{4}{|l|}{ Overall Tree Evenness } \\
\hline \multirow{2}{*}{ Native Tree Evenness } & $2011-2009$ & 0.518 & $<0.001$ \\
\hline & $2011-2009$ & 0.477 & 0.001 \\
\hline
\end{tabular}


Table 6. Diversity index means and standard errors (SE) for overall (natives and exotics) vegetative layers (field: \% cover of woody and herbaceous plants $<1 \mathrm{~m}$ tall; shrub: abundance of woody plants $>1 \mathrm{~m}$ tall, $<5 \mathrm{~cm}$ in diameter at breast height (dbh); and tree: abundance of woody plants $>5 \mathrm{~cm}$ dbh) per 100-m radius survey circle sampled along a 13.7-km reach of the Cacapon River, West Virginia, USA, during June 2009, 2010, and 2011. Sites were associated with a river restoration project: RR, 1,100 m restoration reach; RS, reference site; and CS, control site. Means and SEs of sampling units (SU, $n=24)$ nested within sites were not calculated.

\begin{tabular}{|c|c|c|c|c|c|c|c|c|c|c|c|}
\hline \multirow[b]{3}{*}{ Stratus } & \multirow[b]{3}{*}{ Index } & \multicolumn{8}{|c|}{ Site } & & \\
\hline & & \multicolumn{2}{|c|}{ CS } & \multicolumn{2}{|c|}{ RR } & \multicolumn{2}{|c|}{$\mathrm{RS}$} & \multirow[b]{2}{*}{$F$} & \multirow[b]{2}{*}{$P$} & \multicolumn{2}{|c|}{ SU (Sites) } \\
\hline & & $\bar{x}$ & SE & $\bar{x}$ & SE & $\overline{\bar{x}}$ & SE & & & $F$ & $P$ \\
\hline \multicolumn{12}{|l|}{ Field } \\
\hline & Diversity & 1.88 & 0.13 & 1.99 & 0.10 & 2.08 & 0.09 & 0.79 & 0.469 & 1.38 & 0.182 \\
\hline & Richness & 11.21 & 1.10 & 12.17 & 0.68 & 13.13 & 0.82 & 0.90 & 0.422 & 1.58 & 0.104 \\
\hline & Evenness & 0.67 & 0.03 & 0.65 & 0.03 & 0.66 & 0.03 & 0.14 & 0.873 & 1.34 & 0.203 \\
\hline \multicolumn{12}{|l|}{ Shrub } \\
\hline & Diversity & 0.18 & 0.07 & 0.17 & 0.07 & 0.17 & 0.06 & 0.00 & 0.995 & 1.72 & 0.067 \\
\hline & Richness & 0.83 & 0.21 & 1.08 & 0.19 & 0.92 & 0.20 & 0.22 & 0.801 & 3.47 & $<0.001$ \\
\hline & Evenness & 0.48 & 0.10 & 0.67 & 0.09 & 0.48 & 0.09 & 0.93 & 0.409 & 2.37 & 0.009 \\
\hline \multicolumn{12}{|l|}{ Tree } \\
\hline & Diversity & 0.24 & 0.08 & 0.23 & 0.09 & 0.39 & 0.10 & 1.19 & 0.324 & 1.30 & 0.228 \\
\hline & Richness & 1.13 & 0.21 & 1.13 & 0.23 & 1.50 & 0.26 & 1.15 & 0.337 & 1.12 & 0.364 \\
\hline & Evenness & 0.70 & 0.09 & 0.69 & 0.09 & 0.73 & 0.09 & 0.07 & 0.931 & 0.68 & 0.829 \\
\hline
\end{tabular}


Table 6 continued

\begin{tabular}{|c|c|c|c|c|c|c|c|}
\hline \multicolumn{8}{|c|}{ Time } \\
\hline \multicolumn{2}{|c|}{2009} & \multicolumn{2}{|c|}{2010} & \multicolumn{2}{|c|}{2011} & \multirow[b]{2}{*}{$F$} & \multirow[b]{2}{*}{$P$} \\
\hline$\overline{\boldsymbol{x}}$ & SE & $\bar{x}$ & SE & $\bar{x}$ & SE & & \\
\hline 1.84 & 0.11 & 2.20 & 0.07 & 1.92 & 0.12 & 3.87 & 0.029 \\
\hline 11.04 & 0.78 & 13.33 & 0.67 & 12.13 & 1.11 & 2.02 & 0.145 \\
\hline 0.63 & 0.03 & 0.71 & 0.02 & 0.64 & 0.04 & 2.56 & 0.089 \\
\hline 0.12 & 0.07 & 0.17 & 0.06 & 0.24 & 0.07 & 1.14 & 0.329 \\
\hline 0.67 & 0.21 & 0.13 & 0.19 & 1.04 & 0.19 & 2.87 & 0.068 \\
\hline 0.40 & 0.10 & 0.63 & 0.09 & 0.60 & 0.10 & 2.75 & 0.075 \\
\hline $0.06 \mathrm{~A}$ & 0.04 & 0.30 & 0.09 & $0.49 \mathrm{~B}$ & 0.11 & 7.98 & 0.001 \\
\hline $0.54 \mathrm{~A}$ & 0.13 & 1.25 & 0.23 & $1.96 \mathrm{~B}$ & 0.24 & 13.79 & $<0.001$ \\
\hline $0.46 \mathrm{~A}$ & 0.10 & 0.69 & 0.09 & $0.98 \mathrm{~B}$ & 0.01 & 9.94 & $<0.001$ \\
\hline
\end{tabular}

Bonferroni correction: $\alpha=0.05 / 9$ tests $=0.006$; means followed by different letters are significantly different 
Table 7. Diversity index means and standard errors (SE) for native vegetative layers (field: \% cover of woody and herbaceous plants $<1 \mathrm{~m}$ tall; shrub: abundance of woody plants $>1 \mathrm{~m}$ tall, $<5 \mathrm{~cm}$ in diameter at breast height (dbh); and tree: abundance of woody plants $>5 \mathrm{~cm} \mathrm{dbh}$ ) per 100-m radius survey circle sampled along a 13.7-km reach of the Cacapon River, West Virginia, USA, during June 2009, 2010, and 2011. Sites were associated with a river restoration project: RR, 1,100 m restoration reach; RS, reference site; and CS, control site. Means and SEs of sampling units $(\mathrm{SU}, n=24)$ nested within sites were not calculated.

\begin{tabular}{|c|c|c|c|c|c|c|c|c|c|c|c|}
\hline \multirow[b]{3}{*}{ Stratus } & \multirow[b]{3}{*}{ Index } & \multicolumn{8}{|c|}{ Site } & & \\
\hline & & \multicolumn{2}{|c|}{ CS } & \multicolumn{2}{|c|}{ RR } & \multicolumn{2}{|c|}{$\mathrm{RS}$} & \multirow[b]{2}{*}{$F$} & \multirow[b]{2}{*}{$P$} & \multicolumn{2}{|c|}{ SU (Sites) } \\
\hline & & $\overline{\bar{x}}$ & SE & $\bar{x}$ & $\mathrm{SE}$ & $\overline{\bar{x}}$ & SE & & & $F$ & $P$ \\
\hline \multicolumn{12}{|l|}{ Field } \\
\hline & Diversity & 1.48 & 0.12 & 1.62 & 0.08 & 1.67 & 0.10 & 1.29 & 0.286 & 1.61 & 0.095 \\
\hline & Richness & 7.13 & 0.79 & 8.08 & 0.42 & 8.67 & 0.59 & 2.00 & 0.147 & 1.67 & 0.078 \\
\hline & Evenness & 0.72 & 0.03 & 0.66 & 0.03 & 0.67 & 0.04 & 1.38 & 0.264 & 1.33 & 0.212 \\
\hline \multicolumn{12}{|l|}{ Shrub } \\
\hline & Diversity & 0.00 & 0.00 & 0.03 & 0.03 & 0.00 & 0.00 & 1.00 & 0.377 & 1.00 & 0.483 \\
\hline & Richness & 0.29 & 0.09 & 0.42 & 0.12 & 0.08 & 0.06 & 3.50 & 0.039 & 1.46 & 0.146 \\
\hline & Evenness & 0.29 & 0.09 & 0.38 & 0.10 & 0.08 & 0.06 & 3.41 & 0.042 & 1.53 & 0.121 \\
\hline \multicolumn{12}{|l|}{ Tree } \\
\hline & Diversity & 0.24 & 0.08 & 0.22 & 0.09 & 0.32 & 0.09 & 0.46 & 0.634 & 1.00 & 0.482 \\
\hline & Richness & 1.08 & 0.22 & 1.13 & 0.23 & 1.33 & 0.23 & 0.48 & 0.621 & 0.91 & 0.577 \\
\hline & Evenness & 0.66 & 0.10 & 0.69 & 0.09 & 0.73 & 0.09 & 0.17 & 0.848 & 0.73 & 0.777 \\
\hline
\end{tabular}


Table 7 continued

\begin{tabular}{|c|c|c|c|c|c|c|c|}
\hline \multicolumn{8}{|c|}{ Time } \\
\hline \multicolumn{2}{|c|}{2009} & \multicolumn{2}{|c|}{2010} & \multicolumn{2}{|c|}{2011} & \multirow[b]{2}{*}{$F$} & \multirow[b]{2}{*}{$P$} \\
\hline$\overline{\boldsymbol{x}}$ & SE & $\bar{x}$ & SE & $\bar{x}$ & SE & & \\
\hline 1.41 & 0.10 & 1.80 & 0.08 & 1.56 & 0.11 & 5.01 & 0.011 \\
\hline 6.96 & 0.54 & 8.67 & 0.50 & 8.25 & 0.76 & 2.63 & 0.084 \\
\hline 0.65 & 0.03 & 0.75 & 0.02 & 0.65 & 0.04 & 3.93 & 0.027 \\
\hline 0.03 & 0.03 & 0.00 & 0.00 & 0.00 & 0.00 & 1.00 & 0.377 \\
\hline 0.25 & 0.11 & 0.29 & 0.09 & 0.25 & 0.10 & 0.07 & 0.931 \\
\hline 0.21 & 0.08 & 0.29 & 0.09 & 0.25 & 0.09 & 0.26 & 0.770 \\
\hline $0.06 \mathrm{~A}$ & 0.04 & 0.26 & 0.08 & $0.46 \mathrm{~B}$ & 0.11 & 6.79 & 0.003 \\
\hline $0.54 \mathrm{~A}$ & 0.13 & 1.17 & 0.21 & $1.83 \mathrm{~B}$ & 0.23 & 11.22 & 0.052 \\
\hline $0.46 \mathrm{~A}$ & 0.10 & 0.69 & 0.09 & $0.93 \mathrm{~B}$ & 0.04 & 7.86 & 0.084 \\
\hline
\end{tabular}

Bonferroni correction: $\alpha=0.05 / 9$ tests $=0.006$; means followed by different letters are significantly different 


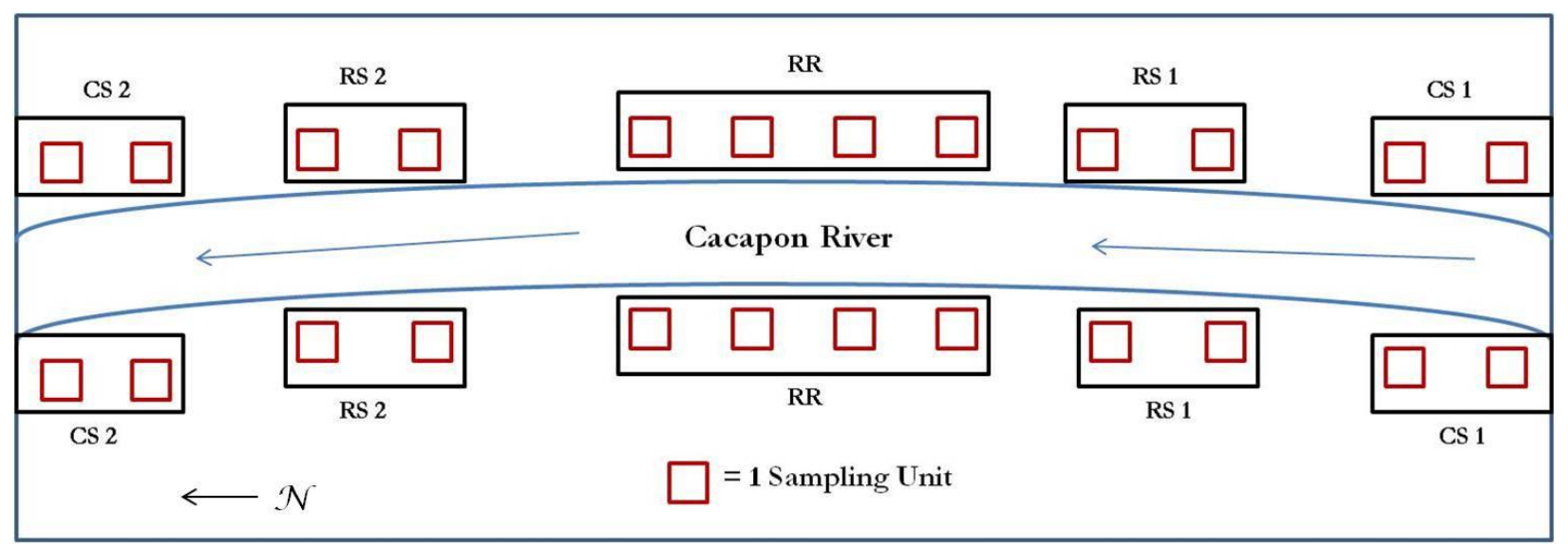

Figure 1. The natural stream channel restoration study design centered around the restoration reach (RR), with eight sampling units. The restoration reach was bordered on either side by an upstream (RS 1) and downstream (RS 2) reference site and an upstream (CS 1) and downstream (CS 2) control site, with collective totals of eight sampling units. Each sampling unit was separated by a minimum of $250 \mathrm{~m}$. Within each sampling unit, bird, small mammal, anuran, and vegetation sampling was conducted. 


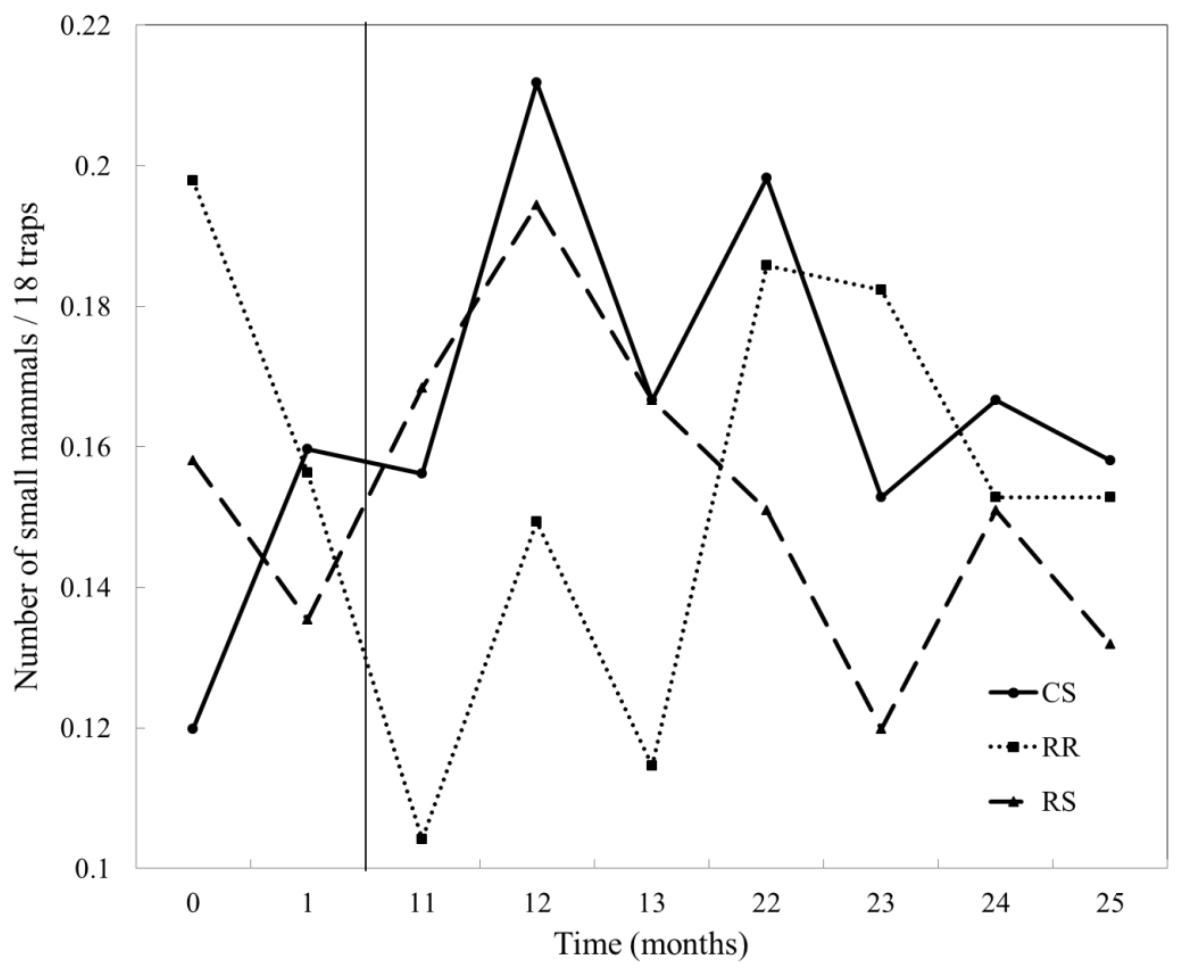

Figure 2. Before-after control-impact plots for overall small mammal abundance (number of small mammals/18 traps) observed within a restoration reach (RR), control sites (CS), and reference sites (RS) along a 13.7-km reach of the Cacapon River, West Virginia USA during summer 2009 (i.e., July to August, months 0 and 1), 2010 (i.e., June to August, months 11 to 13), and 2011 (i.e., May to August, months 22 to 25). The vertical line in the plot corresponds to the time of impact (i.e., restoration activities). 


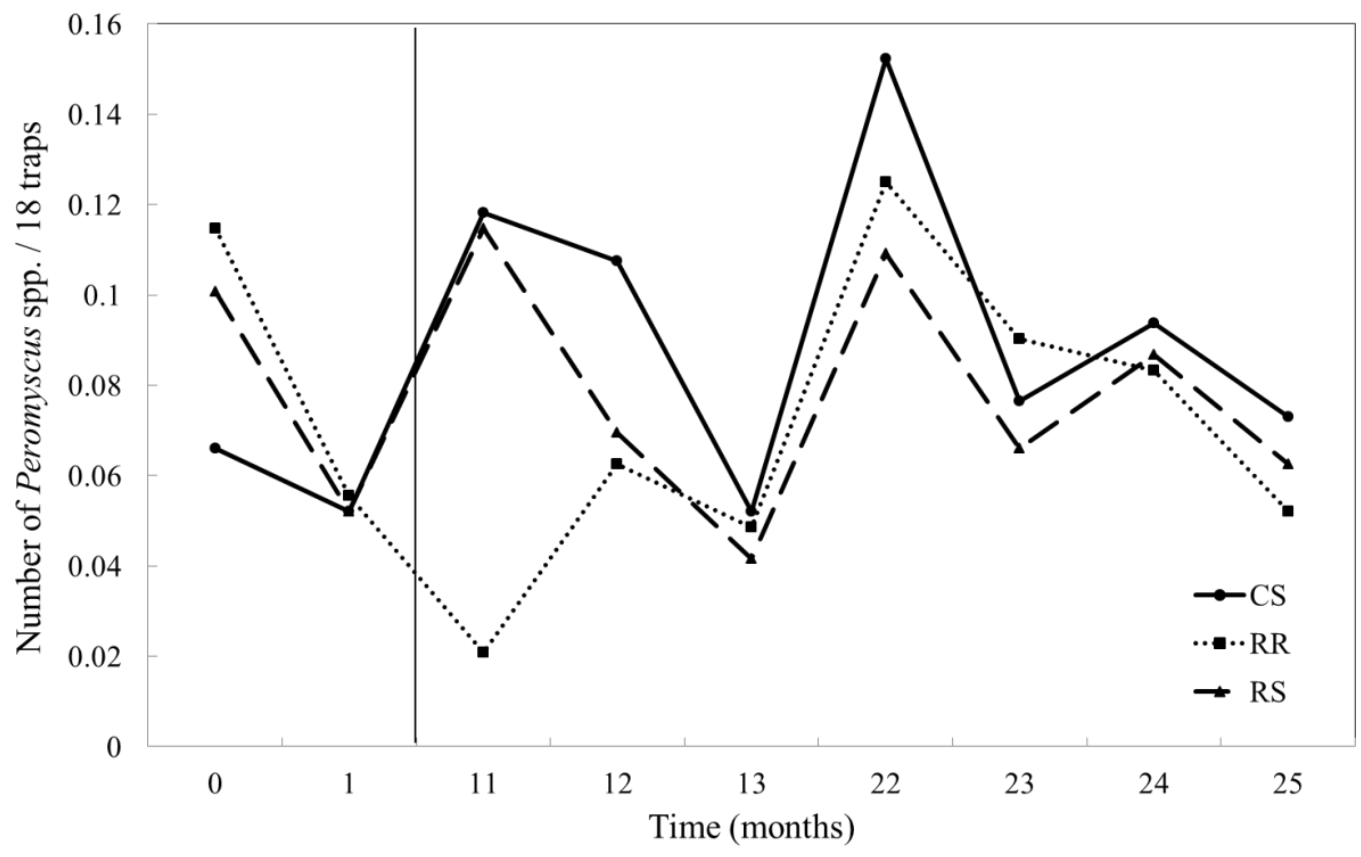

Figure 3. Before-after control-impact plots for the Peromyscus maniculatus and P. leucopus complex abundance (number of Peromyscus spp./18 traps) observed within a restoration reach (RR), control sites (CS), and reference sites (RS) along a 13.7-km reach of the Cacapon River, West Virginia USA summer 2009 (i.e., July to August, months 0 and 1), 2010 (i.e., June to August, months 11 to 13), and 2011 (i.e., May to August, months 22 to 25). The vertical line in the plot corresponds to the time of impact (i.e., restoration activities). 

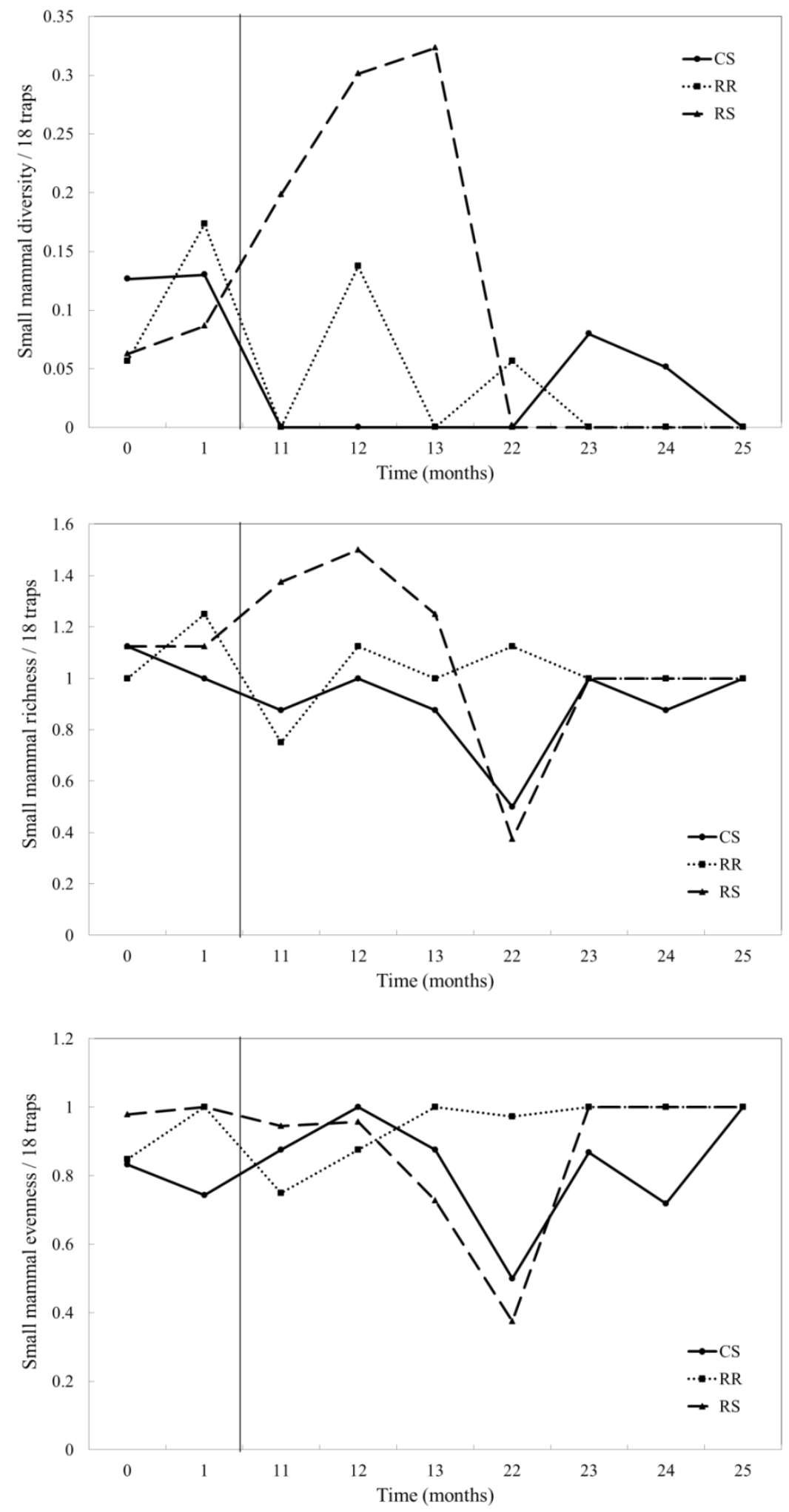

Figure 4. Before-after control-impact plots for overall small mammal diversity, richness, and evenness (average diversity metric/18 traps) observed within a restoration reach (RR), control 
sites (CS), and reference sites (RS) along a 13.7-km reach of the Cacapon River, West Virginia USA during summer 2009 (i.e., July to August, months 0 and 1), 2010 (i.e., June to August, months 11 to 13), and 2011 (i.e., May to August, months 22 to 25). The vertical line in the plot corresponds to the time of impact (i.e., restoration activities). 

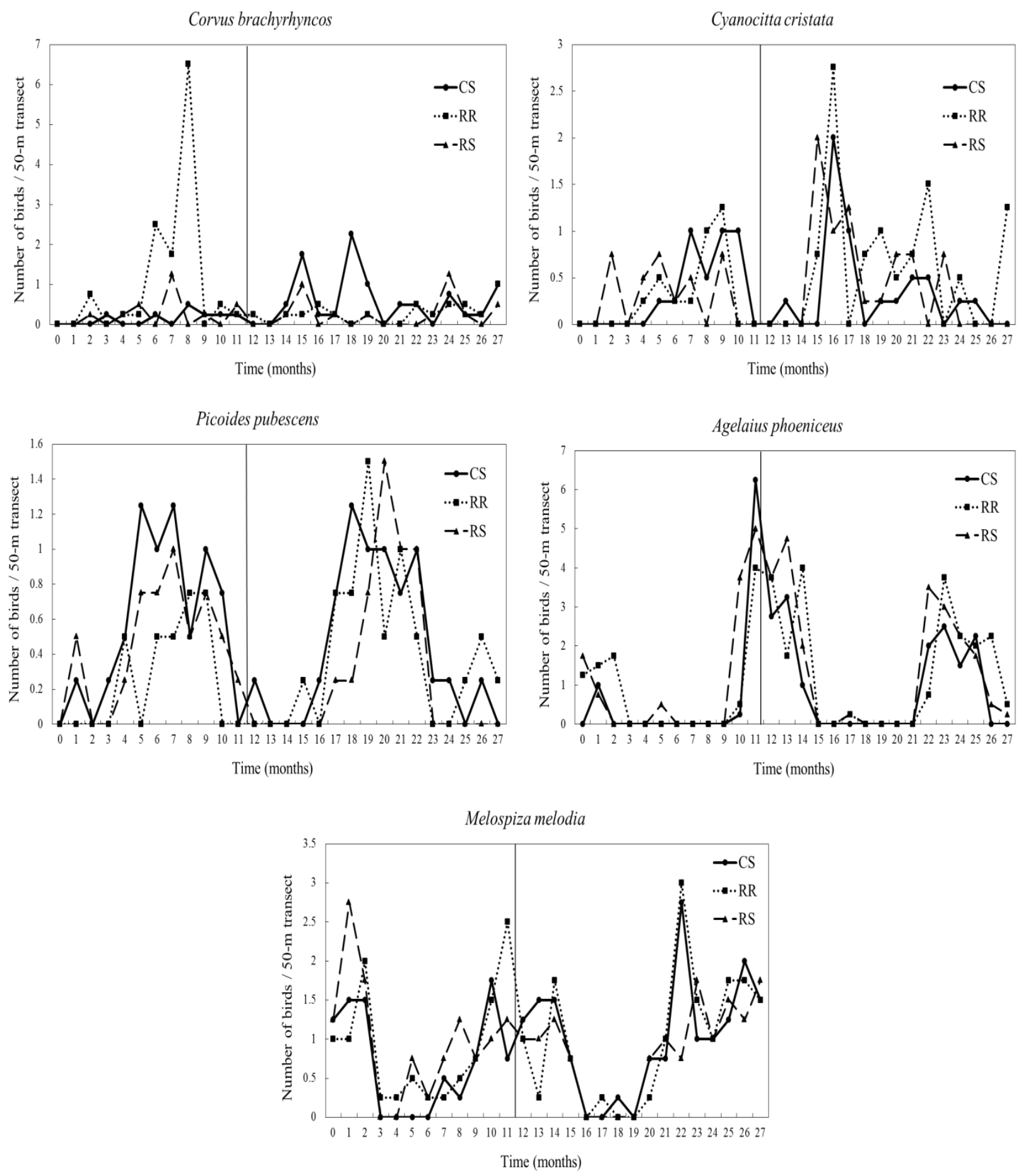

Figure 5. Before-after control-impact plots for the five most abundant bird species (number of birds/50-m transect) observed within a restoration reach (RR), control sites (CS), and reference sites (RS) along a 13.7-km reach of the Cacapon River, West Virginia USA during May 2009 
(month 0) to August 2011 (month 27). The vertical line in the plots corresponds to the time of impact (i.e., restoration activities). 

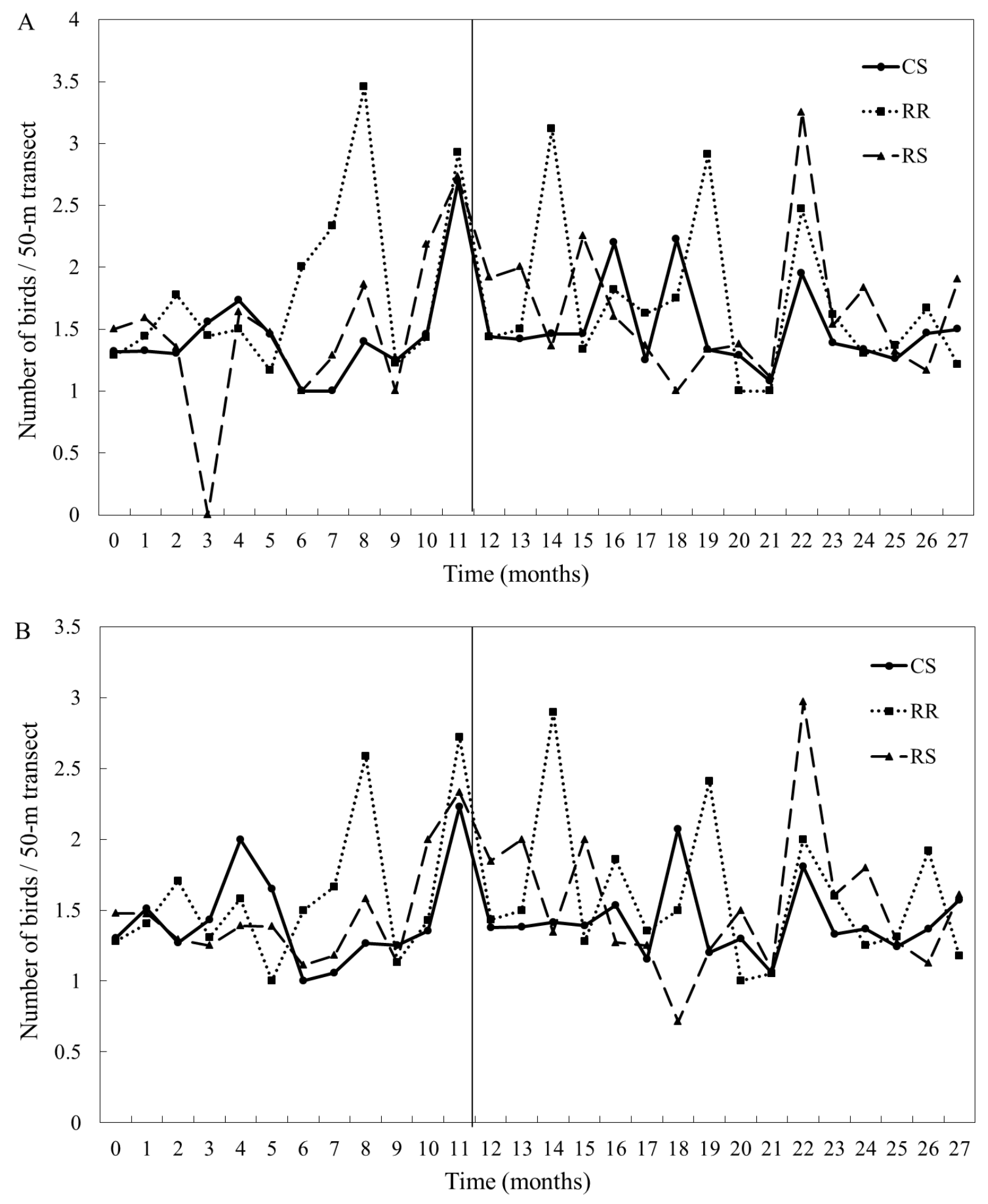

Figure 6. Before-after control-impact plots for (A) passerine and (B) overall bird (passerine and non-passerine) abundance (number of birds/50-m transect) observed within a restoration reach 
(RR), control sites (CS), and reference sites (RS) along a 13.7-km reach of the Cacapon River, West Virginia USA during May 2009 (month 0) to August 2011 (month 27). The vertical line in the plot corresponds to the time of impact (i.e., restoration activities). 

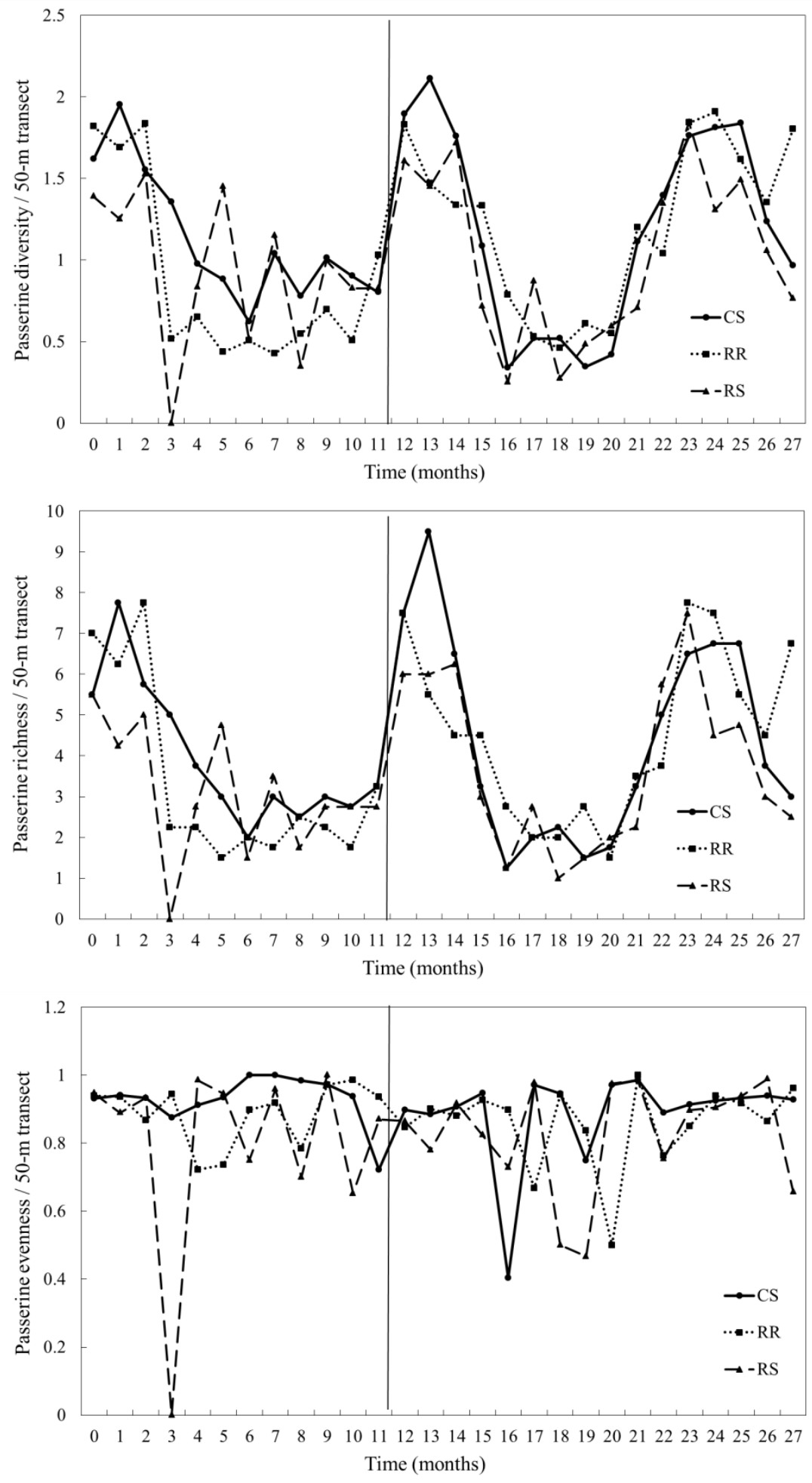

Figure 7. Before-after control-impact plots for passerine diversity, richness, and evenness (average diversity metric/50-m transect) observed within a restoration reach (RR), control sites 
(CS), and reference sites (RS) along a 13.7-km reach of the Cacapon River, West Virginia USA during May 2009 (month 0) to August 2011 (month 27). The vertical line in the plot corresponds to the time of impact (i.e., restoration activities). 

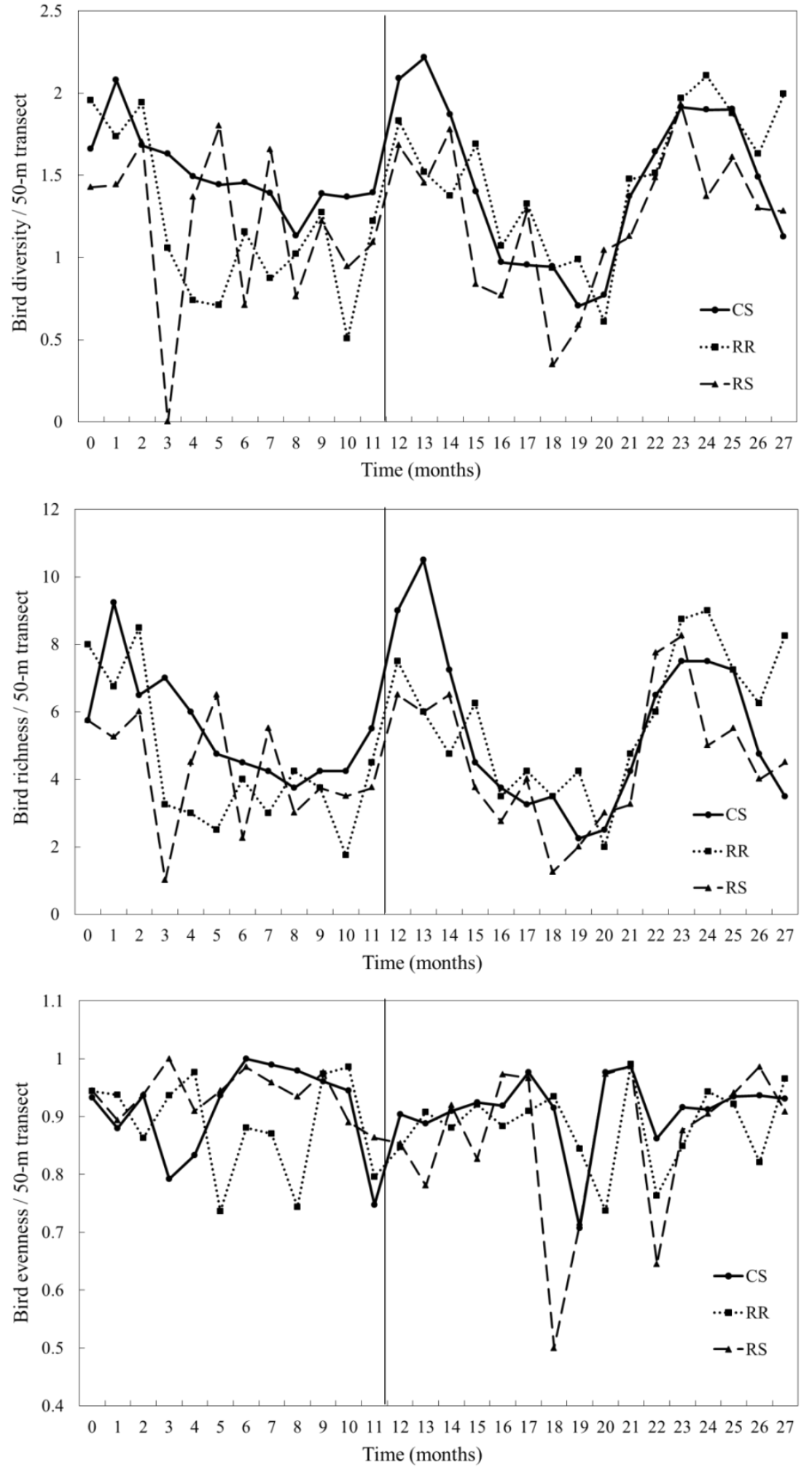

Figure 8. Before-after control-impact plots for overall bird diversity, richness, and evenness (average diversity metric/50-m transect) observed within a restoration reach (RR), control sites 
(CS), and reference sites (RS) along a 13.7-km reach of the Cacapon River, West Virginia USA during May 2009 (month 0) to August 2011 (month 27). The vertical line in the plot corresponds to the time of impact (i.e., restoration activities). 


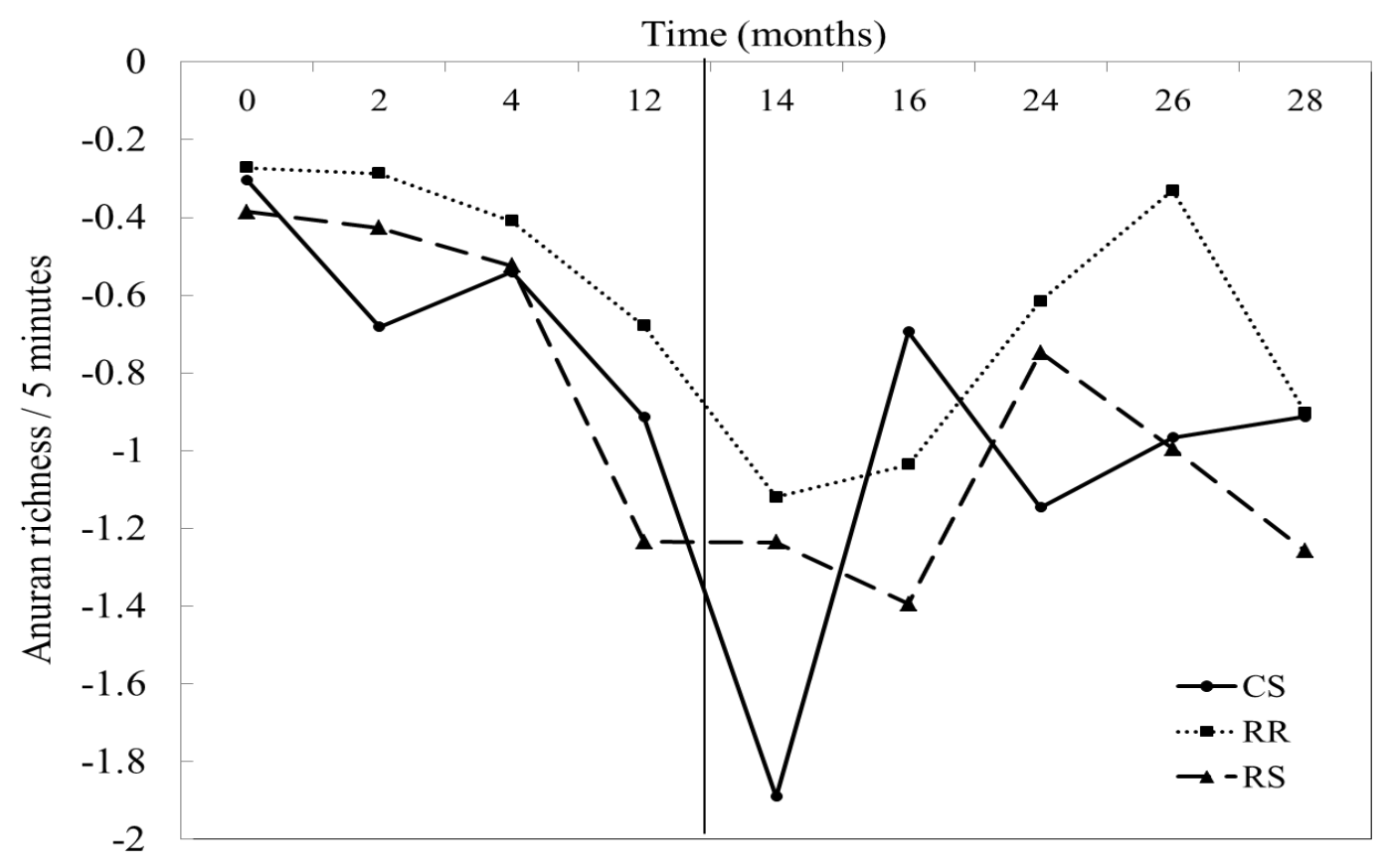

Figure 9. Before-after control-impact plot for frog and toad richness (number of species/5 minutes) observed within a restoration reach (RR), control sites (CS), and reference sites (RS) along a 13.7-km reach of the Cacapon River, West Virginia, USA during April (months 0, 12, and 24), June (months 2, 14, and 26), and August (months 4, 16, and 28) of 2009, 2010, and 2011. The vertical line in the plot corresponds to the time of impact (i.e., restoration activities). 


\section{CHAPTER III}

28 November 2012

Kathryn R. P. McCoard

West Virginia University

Division of Forestry and Natural Resources, P. O. Box 6125, Morgantown, WV 26506

Phone 740/464-1024

roamingwild@gmail.com

RH: McCoard and Anderson • Ecological Aspects of Wood Turtles

Ecological Aspects of Wood Turtles in an Agri-forest Environment in the Central

\section{Appalachians}

KATHRYN R. P. MCCOARD West Virginia University, Division of Forestry and Natural

Resources, P.O. Box 6125, Morgantown, West Virginia 26506 USA

JAMES T. ANDERSON West Virginia University, Division of Forestry and Natural Resources, P.O. Box 6125, Morgantown, West Virginia 26506 USA $^{1}$

1.jim.anderson@mail.wvu.edu

Written in the style of:

The Journal of Wildlife Management 
ABSTRACT The ecology of wood turtles (Glyptemys insculpta) is well known from the middle and northern portions of their geographic range, but detailed information from the southern extent is minimal. Our objectives were to determine natural history characteristics, including morphometrics, home range sizes, habitat, activity cycles, and diet of wood turtles along the Cacapon River, near the southern border of their geographic range in West Virginia, during spring 2009 to summer 2011. Along a $13.7 \mathrm{~km}$ reach of the Cacapon River, 137 adult males, 88 females, and 59 juveniles were captured. Morphometric difference occurred between adult males $(n=25)$ and females $(n=18)$ observed mating; males were longer, thicker, and heavier than females. Home ranges varied from 0.62 to 36.97 ha; male home ranges tended to be elongated along the Cacapon River, but female and juvenile home ranges encompassed a greater degree of terrestrial habitat. Low bare ground and rock cover and high vertical density were structural vegetative characteristics associated with the turtles' habitat compared to random vegetation plots. Wood turtles were more terrestrial during spring and summer but more aquatic in autumn and winter. Mating occurred in the spring from late March to early June after hibernation emergence and again from late August to early November. Of all mating observations, $64.3 \%$ occurred in autumn, $75 \%$ occurred after $1300 \mathrm{hrs}$, and $35.7 \%$ were terrestrial. Nesting attempts were made in late May to early June in the early morning and early evening on sandy substrate. Aquatic activity included walking along the riverbed and exploring log jams. Terrestrial activity included burrowing during high temperatures and walking along deer trails. Turtles commonly basked at $45^{\circ}$, angled to the sun, on streambanks, deer trails, clearings in vegetation, rocky beaches, and propped up against matted grasses and woody debris. Dietary preference was for slugs (67\%), although worms, June bugs, small mammal and bird remains, autumn olive (Elaeagnus umbellata) berries, wild black cherries (Prunus serotina), 
pokeweed (Phytolacca americana) berries, jewelweed (Impatiens spp.), green dragon (Arisaema dracontium), dandelion (Taraxacum officinale), and violets (Viola spp.) were also consumed. In October, turtles began entering the river and by mid-November, they were hibernating. This study aids in filling geographic information gaps and in planning management strategies for southern wood turtle populations by providing information about essential natural history requirements (e.g., diet, habitat) that will promote the survival and sustainability of the species along the southern border of their range. We recommend establishing and maintaining riparian zones along waterways bordering agricultural fields to provide essential wood turtle habitat for the species to undergo all aspects of their natural histories.

KEY WORDS diet, dominance, ecology, Glyptemys insculpta, home range, reproduction, West Virginia.

Wood turtles (Glyptemys insculpta) require multiple cover types for various life history needs (Quinn and Tate 1991, Kaufmann 1992a, Compton et al. 2002), with a preference for floodplains (Strang 1983), especially riparian zones (Arvisais et al. 2004), associated with streams with gradients $<1 \%$ (Jones and Sievert 2009). Wood turtles rarely cross hilly, xeric, or extensively exposed terrain, even when these areas occur between suitable habitat patches (Carroll and Ehrenfeld 1978), and may be considered dependent upon riparian zones due to their propensity to desiccate easily (Ernst 1968). They are a semi-aquatic species and will spend time on land and in the water depending on season and activity (Ernst 1986, Farrell and Graham 1991, Kaufmann 1992a, Arvisais et al. 2002). Individuals rarely travel farther than $300 \mathrm{~m}$ from stream edge (Brewster and Brewster 1991, Quinn and Tate 1991, Kaufmann 1992a, Arvisais et al. 2002) and often cross streams (Strang 1983). Their home ranges are elongated and follow stream edges 
(Strang 1983). They are active throughout the year except for the coldest months (Carroll and Ehrenfeld 1978) and are adapted to cool climates (Ernst 2001).

Wood turtles are a freshwater species that is declining due to anthropogenic causes, such as over-collecting and habitat fragmentation, and natural causes, including predation and nest depredation (Saumure and Bider 1998, Moll 2000, Turtle Conservation Fund 2002, Saumure et al. 2007, Walde et al. 2007, Endangered Species Coalition 2008). They occur in 17 states along the Great Lakes and northeast United States, and in 4 Canadian Provinces in the southeast (Conant and Collins 1998). During the Pleistocene, the range extended south as far as Georgia and Tennessee (Holman 1976, Parmalee and Klippel 1981). In West Virginia, the species is listed as an S2, or a species considered to be very rare and imperiled (WVNHP 2007), and is a priority 1 Species in Greatest Need of Conservation (SGNC) in the Wildlife Conservation Action Plan (WVDNR 2005). In 1992, wood turtles were listed in the Convention on International Trade in Endangered Species of Wild Fauna and Flora (CITES) Appendix II as a species that may become threatened with extinction if trade in them is not monitored (CITES 2008). In 2007, wood turtles were listed as threatened by the Committee on the Status of Endangered Wildlife in Canada, an updated status from the species' special concern listing in 1996 (COSEWIC 2009). In 2008, wood turtles were listed as one of the top 10 species recognized as threatened or endangered in the United States that is the most in need of protection by the Endangered Species Act (Endangered Species Coalition 2008).

Wood turtles are in need of conservation, but further aspects of their habitat use and population dynamics need to be better understood for conservation to be effective (Quinn and Tate 1991, Kaufmann 1992a, Bodie 2001). Season and geography influence the habitat preference of wood turtles, affecting when they are terrestrial or aquatic and the cover types they 
use within those environments (Harding and Bloomer 1979). Although many studies of wood turtle ecology have occurred in the middle and northern regions of their range (Farrell and Graham 1991, Kaufmann 1992a, Arvisais et al. 2004, Tuttle and Carroll 2005, Walde et al. 2007), few have been conducted in the southern extent. Wood turtle reproduction and growth (Akre 2002) and home ranges and hibernation (Sweeten 2008) have been studied in Virginia, but studies on natural history characteristics of wood turtles in West Virginia (Niederberger 1993, Breisch 2006) are minimal. Our objectives were to determine natural history characteristics of wood turtles in West Virginia, including morphometrics, home range sizes, habitat, activity cycles, and diet. Information on these subjects will aid in filling geographic information gaps and in planning management strategies for southern wood turtle populations.

\section{STUDY AREA}

Our study site was located along a 13.7-km reach of the Cacapon River within West Virginia, USA. Agricultural fields, primarily hay fields, cornfields, and cattle pastures, bordered most of the river along this reach. The Cacapon River is part of the Cacapon River Watershed, which includes the Lost and North rivers and occurs in the eastern halves of Hampshire, Hardy, and Morgan counties in the eastern panhandle of West Virginia, within the Ridge and Valley Province. West Virginia's Ridge and Valley region received about $76 \mathrm{~cm}$ of precipitation annually (Kozar and Mathes 2001). The highest elevation (1,482 m) in West Virginia is reached on Spruce Knob in Pendleton County, at the western entrance to the eastern panhandle, and the lowest elevation $(73 \mathrm{~m})$ is reached in Harper's Ferry in Jefferson County, at the eastern edge of

the eastern panhandle (Green and Pauley 1987). The Cacapon River Watershed drains 2,321 km² into the Potomac River (Constantz et al. 1995). The watershed was $79 \%$ forested, $19 \%$ agriculture, and $2 \%$ was composed of residential areas, water, and barren lands (Constantz et al. 
1995), although our study area within the watershed was primarily agriculture. A description of the Cacapon River can be found in Niederberger and Seidel (1999).

\section{METHODS}

\section{Sampling}

We surveyed 5 primary sites corresponding with sites used in a concurrent river restoration project (Selego et al. 2012). Our surveys along these sites varied from 600 to $1,100 \mathrm{~m}$ of river length and $150 \mathrm{~m}$ perpendicularly from the river's edge on both sides of the river; the sites were 300 to $1,000 \mathrm{~m}$ apart from their neighboring sites. These site lengths and distances matched survey constraints from the restoration project (e.g., $250 \mathrm{~m}$ separation of bird surveys) and the site widths encompassed 95\% of freshwater turtle migration distances (Bodie 2001). We conducted surveys from May 2009 to August 2011. We opportunistically captured turtles by hand or dipnet as the sites were intensively surveyed on foot or by canoe. We captured the turtles under permits from the West Virginia Division of Natural Resources and the West Virginia University Animal Care and Use Committee, protocol \# 09-0408. We uniquely marked adult turtles with a triangular file based on a system developed by Cagle (1939); juveniles <2 yrs. were similarly marked with white enamel to avoid early physical alteration of the young turtles by use of a marking file. Upon initial capture of each turtle, we measured to the nearest millimeter $(\mathrm{mm})$ carapace length and width, plastron length and width, bridge height and width, and depth with 200-mm $( \pm 0.2 \mathrm{~mm})$ Mitutoyo $^{\mathrm{TM}}$ Dial Calipers. We determined gender on individuals that were $\geq 160 \mathrm{~mm}$ in carapace length; males have longer, thicker tails, larger appendages, and a concave plastron compared to females (Harding and Bloomer 1979). We measured mass to the nearest gram using 1,000-g $( \pm 10 \mathrm{~g})$ or 2,500-g $( \pm 20 \mathrm{~g})$ Pesola ${ }^{\circledR}$ Spring Scales. To determine age, we counted annual carapace scute rings (Harding and Bloomer 1979), 
up to about 20 years, after which the rings begin to fade. For every capture, we recorded date, time, global positioning system (GPS) location, weather conditions, observed activity when captured, identification marks, and perpendicular distance from the river. We released all captured wood turtles at the point of capture after they were marked.

\section{Radio-Telemetry}

Advanced Telemetry Systems (ATS) (Isanti, MN) made the 3 Element Folding Yagi Antenna and R2000 Challenger Receiver that we used to track turtles. We applied the transmitters (ATS model R1860, mass = $15.3 \mathrm{~g}$ ) with epoxy to the back right edge of the turtles' carapaces. We observed all tagged turtles initially to make certain that they could move without hindrance and that the transmitters did not interfere with their regular activities. We tracked a sample of the turtles (15 adult males, 10 adult females, and 6 juveniles) by radio-telemetry to provide specific movement information. We tracked relatively equal proportions of turtles at each site (i.e., reference sites, $n=9$; control sites, $n=9$; and restoration reach, $n=13$ ). We conducted tracking 1 to 2 times a week between 0800 to 1930 hrs from March to October and once a month from November to February each year, with the position of each turtle determined by homing to its specific location (Bowne et al. 2006, Saumure et al. 2007).

\section{Microclimate Data}

We collected microclimatic data in our study to aid in determining conditions that were preferred by wood turtles for their various activities in West Virginia (Reagan 1974, Ernst 1986). We recorded the same habitat data for mark-recapture and tracked turtles because the results should not differ between them (Kaufmann 1992a). If the captured turtles were terrestrial, we took the data directly under them to gain close approximates of the environment being used and included a single reading of soil temperature ( $\pm 1 \%$ of scale; Forestry-Suppliers Soil Thermometer), soil 
pH $\left( \pm 0.01\right.$; Oakton ${ }^{\circledR}$ Double Junction Waterproof pH Tester 30$)$, and soil moisture $(1=$ dry, 10 = saturated; 23-cm Lincoln Soil Moisture Meter). If the turtles were aquatic, we measured water temperature $\left({ }^{\circ} \mathrm{C} ; 15-\mathrm{cm}\right.$ Enviro-Safe ${ }^{\circledR}$ Armor Case Pocket Thermometer) and water $\mathrm{pH}( \pm 0.01$; Oakton® Double Junction Waterproof pH Tester 30) next to them. We recorded air temperature $\left( \pm 1^{\circ} \mathrm{C}\right)$ and relative humidity $\left( \pm 5 \%\right.$; Oakton ${ }^{\circledR}$ Digital Max/Min Thermohygrometer) either next to terrestrial turtles or above the water's surface directly over aquatic turtles.

\section{Vegetation Surveys}

We conducted vegetation surveys within $10 \times 10$-m plots centered on a random sample $(n=110)$ of the overall turtle captures. During primary plant growth and production in spring and summer, 2009 to 2011, we randomly generated a number between 1 and 30 ( $n=31$ tracked turtles) each radio-telemetry day to determine which turtle capture of the day would have an associated vegetation survey, regardless of the turtle captured being marked, unmarked, or radiotagged. Only a single vegetation plot was conducted per day due to time and personnel constraints. We captured un-marked turtles and changed the beginning tracking site almost every telemetry day which reduced the probability of the same turtles being associated with the vegetation plots. Within the plots, we identified and measured all trees with diameters larger than $5 \mathrm{~cm}$ for their diameter at breast height (dbh). We identified all shrubs, including saplings, taller than $1 \mathrm{~m}$ and less than $5 \mathrm{~cm}$ in diameter and counted their number of stems. We surveyed the field layer (all plants, woody and herbaceous, $<1 \mathrm{~m}$ tall) in $1-\mathrm{m}^{2}$ sub-plots in each corner of the $10 \times 10$-m plot. We identified and estimated percent cover of each species in the field layer, as well as leaf litter, woody debris, and bare ground and rock. At the center of each sub-plot, we used a Robel pole (Robel et al. 1970) to determine vertical density from visual obstruction readings taken $4 \mathrm{~m}$ from the pole (1-m height) in all 4 cardinal directions, and averaged for the 
plot. From the center of the $10 \times 10 \mathrm{~m}$ plot, we documented canopy cover $(\%)$ and a description of the local cover type (e.g., pasture, crop field, wetland, forest). We paired random vegetation plots $(n=110)$ with each turtle plot, randomly located up to $300 \mathrm{~m}$ in a random cardinal direction from the turtle plots.

\section{Statistical Analyses}

We performed all statistical analyses in R 2.10 .1 with $\alpha=0.05$ (R Development Core Team). To estimate population size, we used the Peterson mark-recapture estimate (Robson and Regier 1964):

$$
N=(M C) / R
$$

where $M$ is the number of marked and released animals, $C$ is the total number of subsequent captures, $R$ is the number of marked individuals in subsequent captures, and $N$ is the estimated population size. We calculated the standard error for the mark-recapture population estimate (Brower and Zar 1984) as:

$$
\mathrm{SE}=\sqrt{\frac{M^{2}(n+1)(n-R)}{(R+1)^{2}(R+2)}}
$$

where the variables are the same except substituting $C$ for $n$. We used 1-way analysis of variance (ANOVA) to analyze population morphometric data, modeling each measurement by gender (male, female, and juvenile). The ANOVA model assumes that the probability distributions of each factor level are normal with constant variance, and that the responses are random and independent of other factor level responses (Lunney 1970, Kutner et al. 2005); all morphometric models met these assumptions, so we did not transform data. To determine differences among genders, we used Tukey honest significant difference (TukeyHSD) tests at 95\% confidence, using the studentized range distribution to compare all pairwise contrasts 
(Kutner et al. 2005). We used independent $t$-tests, comparing sample means, to determine if the adult male-to-female sex-ratio and juvenile-to-adult ratio differed significantly from $1: 1$. We analyzed mating morphometric data using independent $t$-tests. We used a Bonferroni correction to adjust the $\alpha$-level for multiple $t$-tests $(\alpha=0.05 / 8$ morphometric variable tests $=0.006)$. To determine if the number of terrestrial and aquatic mating observations differed significantly based on the autumn and spring mating seasons, we used a Pearson chi-square $\left(\chi^{2}\right)$ test, which assumes independent observations, replicated data, and sufficient sample sizes (Kutner et al. 2005).

We calculated home range sizes using $50 \%$ and $95 \%$ minimum convex polygons (MCP; Adehabitat package, R) for each turtle tracked $>10$ times. We used a 1-way ANOVA to determine if there was a difference between the home range sizes of males, females, and juveniles. After conducting residual diagnostics, we removed 1 outlier (female, 95\% home range: $36.97 \mathrm{ha}$ ) from the analysis; the data then met the test assumptions. Using ArcMap software (Environmental Systems Research Institute, Inc., Redlands, CA), we uploaded the radio-telemetry capture locations and measured the distances from the furthest terrestrial point of each tracked turtle to the river's edge. We used a 1-way ANOVA to determine if the maximum overland distance travelled from the river by males, females, and juveniles differed; transformation of the response was not needed to meet assumptions. We used Tukey tests at 95\% confidence to determine how the genders differed. To determine if the number of males, females, and juveniles differed in being terrestrial or aquatic based on season, we used a contingency table with a $\chi^{2}$ test. If a significant marginal (over all genders) association was found, we used a Fisher's exact test (stats package, R), which tests the independence of rows and 
columns of the contingency table, to determine if a significant conditional (within gender) association existed.

We used multivariate analysis of variance (MANOVA) with Pillai test statistic to determine if structural (i.e., canopy cover, bare ground and rock cover, leaf litter cover, woody debris cover, and vertical density) differences in vegetation between plot type (i.e., turtle and random), seasons (i.e., spring and summer), years (i.e. 2009, 2010, and 2011), and plot type $\times$ year or season interactions existed. MANOVA assumes joint multivariate normality, equal variances, and independent observations (Finch 2005). We square-root transformed bare ground and rock, leaf litter, and woody debris covers; log-transformed vertical density; and inverse logtransformed canopy cover to approximate normality. If the global MANOVA indicated significance, we used the structural variables in univariate ANOVAs (Bonferroni correction: $\alpha=$ $0.05 / 5$ structural variable tests $=0.01)$ with TukeyHSD tests to determine where the significance occurred.

We calculated (1) overall (native and exotic) and (2) natives-only vegetation species diversity $(H)$ and richness $(S)$ (diversity and specnumber functions, vegan package, $\mathrm{R}$ ) for the field, shrub, and tree layers. We used ANOVAs with Bonferroni correction $(\alpha=0.05 / 6$ tests $=$ 0.008), followed by Tukey tests, to analyze $H$ and $S$ of each layer by plot type, season, year, and plot type $\times$ season or year interactions. We checked all vegetation models for normality and equal variances. For the overall vegetation, we square-root (plus 1)-transformed shrub diversity and richness, square-root transformed tree diversity, and natural log (plus 1)-transformed tree richness. For the native vegetation, we square-root (plus 1)-transformed shrub and tree diversity and richness. To compare if overall and native community composition differed between plot types, seasons, years, and their interactions, we used permutational multivariate analysis of 
variance (PerMANOVA, 1,000 permutations; adonis function, vegan package, $\mathrm{R}$ ) with Bonferroni correction $(0.05 / 3$ tests $=0.017)$ on the field, shrub, and tree layers separately. PerMANOVA is robust to departures from parametric distribution assumptions and suitable for community composition analysis (Walters and Coen 2006, Lorion and Kennedy 2009). For significant main effects (i.e., plot type, season, or year), we used indicator species analysis (ISA, indval function, labdsv package, R) to determine which species were more likely to occur, calculating the indicator values for each species by taking the product of its relative frequency and its relative average abundance within the plot types (Dufrêne and Legendre 1997). An indicator value threshold of 0.25 and $\alpha=0.05$ ( $p$-values generated through randomization procedures; Dufrêne and Legendre 1997) were used to determine which species characterized the plot types, seasons, and years. We plotted significant main effects and species with non-metric multidimensional scaling (NMDS) ordination (metaMDS and envfit functions, vegan package, $\mathrm{R})$.

\section{RESULTS}

\section{Morphometrics and Sex-Ratio}

We captured 284 unique wood turtles $($ males $=137$, females $=88$, and juveniles $=59)$. Total captures numbered 1,443 (1,159 recaptures, $80.3 \%)$. We estimated the population size to be 354 $(\mathrm{SE}=4.60)$ individuals. All characteristics measured were similar for males and females, although they were larger than juveniles (Table 1). Males $>20$ years old accounted for $76.6 \%$ ( $n$ $=105)$ of all male captures. Females $>20$ years old accounted for $58 \%(n=51)$ of all female captures. Due to wearing of the annual rings in wood turtles $>20$ years of age, an average age could not be determined for the adult turtles. The youngest male with secondary sexual characteristics (i.e., concave plastron) was 7 years. The youngest female was 9 years old 
(carapace length: $167.6 \mathrm{~mm}$ ). Juveniles ranged in age from 0 (hatchling) -8 years, the average being 4 years $(\mathrm{SE}=0.29)$. When only mating wood turtles were analyzed, males $(n=25)$ were larger than females $(n=18)$ in mean carapace length, mean bridge height, and mean mass $(P \leq$ 0.005). The youngest males found mating were 15 years old and the youngest females were 16 years old. Of the mating males and females, respectively, $80 \%$ and $72.2 \%$ were $>20$ years old. The adult male-to-female sex-ratio was 1.6:1 and did not differ from 1:1 $\left(t_{5.95}=0.91, P=0.399\right)$. The juvenile-to-adult ratio (1:3.8) varied from 1:1 $\left(t_{13.46}=2.76, P=0.016\right)$.

\section{Home Ranges and Vegetation}

We tracked 31 turtles (15 males, 10 females, and 6 juveniles) to determine home range sizes (Table 2). The turtles that we tracked $\leq 10$ times $(n=7)$ were not included in the analysis; the rest of the turtles (i.e., 13 males, 9 females, and 2 juveniles; $n=24$ ) were tracked 23 to 75 times $(\bar{x}=45.2, \mathrm{SE}=2.57)$ during June 2009 to August 2011. The limited tracking was either due to early failure of the transmitters, the turtles walking out of range, or burial and death during early spring floods. The $50 \%$ home ranges varied in size from 0.09 to 4.63 ha $(\bar{x}=0.90, \mathrm{SE}=0.19)$; males $(\bar{x}=0.87, \mathrm{SE}=0.33)$, females $(\bar{x}=1.05, \mathrm{SE}=0.19)$, and juveniles $(\bar{x}=0.47, \mathrm{SE}=0.10)$ had similar $50 \%$ home range sizes $\left(F_{2,21}=0.31, P=0.737\right)$. The $95 \%$ home ranges varied in size from 0.62 to 36.97 ha $(\bar{x}=5.75, \mathrm{SE}=1.46)$.

Mean home range sizes $(95 \%)$ of males $(\bar{x}=4.29, \mathrm{SE}=0.78)$, females $(\bar{x}=11.03, \mathrm{SE}=$ 3.68), and juveniles $(\bar{x}=4.04, \mathrm{SE}=2.39)$ were similar when the outlier (female, $95 \%$ home range: $36.97 \mathrm{ha})$ was included $\left(F_{2,21}=0.86, P=0.437\right)$ and when it was removed $\left(F_{2,20}=0.06, P\right.$ $=0.946$ ). Male home ranges tended to be elongated along the river and female and juvenile home ranges encompassed a greater degree of terrestrial habitat (Figure 1). Agricultural land, including cornfields, active pastures, and hay fields were traversed on a regular basis by marked 
and tracked turtles $(19.3 \%)$, although most captures occurred within the forested riparian zone $(52 \%)$ or were aquatic $(28.7 \%)$. All individuals returned to their home ranges yearly after most individuals hibernated outside of their home ranges.

In ArcMap, a 300-m buffer around the Cacapon River encompassed all 1,443 capture locations except 2. Considering only tracked turtles, the mean maximum distances (m) travelled overland from the river differed between genders $\left(F_{2,28}=7.26, P=0.003\right)$. Mean male distances travelled $(\bar{x}=85.67, \mathrm{SE}=19.67)$ did not differ from mean juvenile distances $(\bar{x}=30.5, \mathrm{SE}=$ 12.48) $(P=0.244$, Tukey HSD test $)$. However, mean distances that females travelled $(\bar{x}=139.8$, $\mathrm{SE}=25.79)$ were greater than either mean male distances $(P=0.032$, Tukey HSD test $)$ or mean juvenile distances travelled $(P=0.003$, Tukey HSD test $)$.

We recorded $142(72.5 \%$ native) plant species in the field $(n=128)$, shrub $(n=32)$, and tree layers $(n=33)$; some species were recorded in multiple layers (Appendix Ib). Structural vegetative characteristics differed between turtle plots $(n=110)$ and random plots $(n=110)$ $\left(\right.$ Pillai $\left.=0.11, F_{5,208}=4.98, P<0.001\right)$ and years $\left(\right.$ Pillai $\left.=0.20, F_{10,418}=4.66, P<0.001\right)$, but not between seasons (Pillai $\left.=0.05, F_{5,208}=1.97, P=0.084\right)$, the plot type $\times$ season interaction (Pillai $\left.=0.01, F_{5,208}=0.53, P=0.752\right)$, or the plot type $\times$ year interaction $\left(\right.$ Pillai $=0.04, F_{10,418}=0.77$, $P=0.656)$. Leaf litter $\left(F_{1 \text { or } 2,212} \geq 0.14, P \geq 0.233\right)$ and woody debris $\left(F_{1 \text { or } 2,212} \geq 0.42, P \geq\right.$ 0.033) cover were similar among all variables (Table 3). Canopy cover differed by year, decreasing from 2009 to $2011\left(F_{2,212}=11.49, P<0.001\right)$. Turtle plots had less bare ground and $\operatorname{rock} \operatorname{cover}\left(F_{1,212}=18.47, P<0.001\right)$ and higher vertical density $\left(F_{1,212}=8.09, P=0.005\right)$ than random plots. Vertical density was lower in 2011 than 2009 or $2010\left(F_{2,212}=5.73, P=0.004\right)$. Mean field diversity $\left(F_{2,212}=5.24, P=0.006\right.$; Table 4$)$ and mean field richness $\left(F_{2,212}=\right.$ 9.32, $P<0.001$ ) of the overall (natives and exotics) vegetation only differed in the plot $\times$ year 
interaction (Appendix IIb), with turtle plots in 2009 and 2010 having higher diversity and richness than in 2011, although differences among plots within years did not occur (Table 5). Mean field diversity of the native vegetation was higher in 2010 than $2011\left(F_{2,212}=7.02, P=\right.$ 0.001; Table 6). Mean native field richness differed in the plot $\times$ year interaction $\left(F_{2,212}=8.65\right.$, $P<0.001$; Appendix IIIb) similar to the mean overall field richness. Overall field layer composition was similar between years (pseudo- $F_{2,212}=0.86, P=0.554$ ) and the plot $\times$ year interaction (pseudo- $F_{2,212}=1.61, P=0.109$ ), but differed in the plot $\times$ season interaction (pseudo- $F_{1,212}=4.58, P=0.001$ ). Native field layer composition was similar between plots (pseudo- $F_{1,212}=2.22, P=0.074$ ), plot $\times$ season (pseudo- $F_{1,212}=1.32, P=0.217$ ), and plot $\times$ year (pseudo- $F_{2,212}=2.19, P=0.045$ ) interactions, but differed by season (pseudo- $F_{1,212}=8.16, P=$ 0.001 ) and year (pseudo- $\left.F_{2,212}=10.13, P=0.001\right)$. Reed canary grass (Phalaris arundinacea; indicator value (IV): $0.38, P=0.011$ ) differentiated random plots and bedstraw (Galium spp.; IV: $0.28, P=0.002$ ) differentiated turtle plots (Figure 2). Reed canary grass (IV: $0.42, P=0.002$ ) and ground ivy (Glechoma hederacea; IV: $0.37, P=0.006$ ) characterized the overall field vegetation in spring and bedstraw (IV: $0.34, P=0.001$ ) and Japanese stilt grass (Microstegium vimineum; IV: $0.45, P=0.004)$ characterized the overall field vegetation in summer; reed canary grass and bedstraw also differentiated the native field vegetation (same seasons and values; Figure 3). Reed canary grass and bedstraw influenced the overall interaction between plots and seasons. By year, reed canary grass (IV: $0.55, P=0.001$ ) and wingstem (Verbesina alternifolia; IV: $0.39, P=0.022$ ) characterized the native field vegetation in 2011 and sedges (Carex spp.; IV: $0.37, P=0.002)$ characterized the community in 2009 .

Mean overall shrub diversity differed in the plot $\times$ year interaction, with turtle plots having greater diversity than random plots in $2010\left(F_{2,212}=7.25, P=0.001\right)$. Mean overall 
richness of the shrub layer was higher in 2010 compared to $2009\left(F_{2,212}=8.89, P<0.001\right)$. Mean native shrub diversity $\left(F_{1 \text { or } 2,212} \geq 0.09, P \geq 0.080\right)$ and richness $\left(F_{1 \text { or } 2,212} \geq 0.03, P \geq\right.$ 0.080) were similar among all variables. Overall shrub composition was similar among plots (pseudo- $\left.F_{1,212}=0.78, P=0.594\right)$, seasons (pseudo- $\left.F_{1,212}=1.66, P=0.141\right)$, years $\left(\right.$ pseudo- $F_{2,212}$ $=1.03, P=0.400)$, plot $\times$ season $\left(\right.$ pseudo $\left.-F_{1,212}=0.17, P=0.969\right)$, and plot $\times$ year $\left(\right.$ pseudo- $F_{2,212}$ $=2.04, P=0.069$ ) interactions. Native shrub composition was similar among plots (pseudo$\left.F_{1,212}=0.46, P=0.888\right)$, years $\left(\right.$ pseudo $\left.-F_{2,212}=0.19, P=0.961\right)$, plot $\times$ season $\left(\right.$ pseudo- $F_{1,212}=$ $1.22, P=0.260)$, and plot $\times$ year (pseudo- $\left.F_{2,212}=0.31, P=0.887\right)$ interactions, but differed among seasons (pseudo- $F_{1,212}=4.44, P=0.002$ ). Spicebush (Lindera benzoin; IV: $0.15, P=$ 0.001) differentiated summer vegetation plots from spring plots (Figure 4). However, the shrub indicator species had a value less than the 0.25 threshold and may not be ecologically important in distinguishing between the seasons.

Mean overall diversity $\left(F_{1 \text { or } 2,212} \geq 0.38, P \geq 0.018\right)$ and mean native diversity $\left(F_{1 \text { or } 2,212} \geq\right.$ $0.14, P \geq 0.024)$ of the tree layer were similar among all variables. Mean overall tree richness differed in the plot $\times$ season interaction, with turtle plots having greater richness than random plots in the spring $\left(F_{1,212}=13.68, P<0.001\right)$. Mean native tree richness differed in the plot $\times$ year interaction, with random plots having greater richness than turtle plots in $2011\left(F_{2,212}=\right.$ $6.90, P=0.001)$. Overall tree composition was similar among plots (pseudo- $F_{1,212}=1.78, P=$ 0.046), seasons (pseudo- $F_{1,212}=1.26, P=0.237$ ), years (pseudo- $\left.F_{2,212}=1.10, P=0.337\right)$, plot $\times$ season (pseudo- $\left.F_{1,212}=0.65, P=0.770\right)$, and plot $\times$ year $\left(\right.$ pseudo- $\left.F_{2,212}=0.44, P=0.996\right)$ interactions. A difference occurred in tree composition between seasons (pseudo- $F_{1,212}=2.61, P$ $=0.015)$ and plot $\times$ year interaction $\left(\right.$ pseudo- $\left.F_{2,212}=2.62, P=0.005\right)$, but not in the plot $\times$ season interaction (pseudo- $F_{1,212}=2.41, P=0.025$ ). Tulip poplars (Liriodendron tulipifera; IV: 0.17, $P$ 
$=0.004$ ) differentiated turtle plots from random plots (Figure 5). Tulip poplars (IV: 0.14, $P=$ 0.011) differentiated the tree community in 2010 and eastern cottonwoods (Populus deltoides; IV: $0.11, P=0.004)$ in 2011 . Tulip poplars influenced the plot $\times$ year interaction. Tulip poplars (IV: $0.15, P=0.004)$ and sugar maples (A. saccharum; IV: $0.11, P=0.040$ ) characterized summer plots. All of the tree indicator species had values less than the 0.25 threshold and may not be ecologically important in distinguishing between the plot types, seasons, or years.

\section{Activity Cycles}

Season influenced whether wood turtles (males, females, and juveniles, collectively) were terrestrial or aquatic $\left(\chi_{3}^{2}=245.54, P<0.001\right)$ (Table 7), and these locations differed during variable environmental conditions (Table 8). The overall trend supported high terrestrial activity in spring and summer, roughly equal terrestrial and aquatic activity in autumn with leanings toward the latter, and a highly aquatic stage in the winter. Males were primarily terrestrial in spring and summer and aquatic in autumn and winter $(P<0.001)$. Females were almost equally aquatic and terrestrial in spring and autumn, but predominantly terrestrial in summer and aquatic in winter $(P<0.001)$. Juveniles followed the same trend as males, with more equal proportions in autumn $(P<0.001)$.

In West Virginia, wood turtles became active mid-March, after hibernation. Mating occurred in the spring from late March to early June when mean temperatures were as follows: soil, $11.5^{\circ} \mathrm{C}\left(\mathrm{SE}=0.84\right.$; range $\left.=7-17^{\circ} \mathrm{C}\right) ;$ air, $13.2^{\circ} \mathrm{C}\left(\mathrm{SE}=1.36\right.$; range $\left.=7.1-27.3^{\circ} \mathrm{C}\right)$; and water, $11^{\circ} \mathrm{C}\left(\mathrm{SE}=0.57\right.$; range $\left.=8-16^{\circ} \mathrm{C}\right)$. Autumn mating occurred from late August to early November when mean temperatures were as follows: soil, $14.1^{\circ} \mathrm{C}\left(\mathrm{SE}=0.73\right.$; range $\left.=8-21^{\circ} \mathrm{C}\right)$; air, $18.8^{\circ} \mathrm{C}\left(\mathrm{SE}=0.87\right.$; range $\left.=8.8-27.9^{\circ} \mathrm{C}\right)$; and water, $15.1^{\circ} \mathrm{C}\left(\mathrm{SE}=0.85 ;\right.$ range $\left.=8-24^{\circ} \mathrm{C}\right)$; slightly warmer than the average spring temperatures. Twenty-eight mating pairs $(n=45$ 
individuals) were seen (Table 9); 8 (17.8\%; 5 females and 3 males) of the individuals were found mating more than once (with different partners except in 1 case) between autumn 2009 and spring 2011. Autumn mating accounted for $64.3 \%$ of all observations, and $75 \%$ of all observations occurred after $1300 \mathrm{hrs}(0920-1814 \mathrm{hrs})$. Of the mating pairs, $10(35.7 \%)$ were terrestrial at an average distance of $13.5 \mathrm{~m}(\mathrm{SE}=3.06$; range $=0-30 \mathrm{~m})$ from the river's edge; $90 \%$ of those mating attempts were in autumn. When mating was aquatic, $18(64.3 \%)$ turtle pairs were an average of $2.64 \mathrm{~m}(\mathrm{SE}=0.71$; range $=0-10 \mathrm{~m})$ from the shore and $0.5 \mathrm{~m}(\mathrm{SE}=$ 0.066 ; range $=0.25-1 \mathrm{~m}$ ) deep; $50 \%$ of those occurred in autumn. All aquatic pairs were seen in quiet pools or adjacent to the river's main current. The number of terrestrial and aquatic mating attempts was not different with respect to season (i.e., spring and autumn; $\chi_{1}^{2}=0.034, P$ $=0.853)$. When the turtles were observed attempting mating, the male would wrap his front and back claws under the female's carapace and hold on. When the female was unresponsive, the male would push up from the female and slam his plastron down on her carapace. The male would extend his neck and peer down at the female, biting her if she tried to extend her neck or flee. No actual copulation was observed and the majority of the males would release the female upon notice of us. Occasionally, the male would begin pursuing the female again soon after the disruption.

We made 3 nesting observations of females digging multiple nests and of them quickly abandoning the pursuit before the nests were fully dug. The attempts were made in late May to early June in the early morning and early evening. Throughout this period, many small holes were observed along the stream banks that appeared to be nest attempts; however, no turtles were observed creating all of the holes observed. All abandoned nests typically terminated in substrate that was too rocky. The nest sites were sandy, intermixed with pebbles, with little to no 
vegetation. They were typically 0.3 to $1 \mathrm{~m}$ above water level and $<15 \mathrm{~m}$ from the river's edge. The single female found fully nesting was in a trance-like state as she laid the eggs. She used one back foot to brace herself and the other to catch the eggs and maneuver them into the nest chamber. After laying the final egg, as she filled in the nest, alternating her hind feet as she scooped the sand, any movements we made were instantly noticed by her and she would pause in her efforts. Once the nest was covered, she headed back to the water.

This nesting event occurred on 24 May 2010 at $0930 \mathrm{hrs}$ during a light rain. The female's measurements were: carapace length, $181.3 \mathrm{~mm}$; carapace width, $126.12 \mathrm{~mm}$; plastron length, $179.31 \mathrm{~mm}$; plastron width, $121.6 \mathrm{~mm}$; bridge width, $63.4 \mathrm{~mm}$; bridge height, $22.1 \mathrm{~mm}$; depth of $67.45 \mathrm{~mm}$; and post-laying mass, $980 \mathrm{~g}$. She was >20 years old. She nested $6 \mathrm{~m}$ from the river's edge, at the edge of vegetation. The nest was $140 \mathrm{~mm}$ deep, $120 \mathrm{~mm}$ wide, and 65 $\mathrm{mm}$ deep to the topmost egg. The female laid 11 eggs with an average length of $33 \mathrm{~mm}$ ( $\mathrm{SE}=$ $0.11 ;$ range $=32.2-33.5 \mathrm{~mm})$, width of $24 \mathrm{~mm}(\mathrm{SE}=0.05 ;$ range $=23.7-24.2 \mathrm{~mm})$, and mass of $15 \mathrm{~g}(\mathrm{SE}=0.04$; range $=14.8-15.2 \mathrm{~g})$. Soil temperature was $20^{\circ} \mathrm{C}$, air temperature was $19.1^{\circ} \mathrm{C}$, and water temperature was $18^{\circ} \mathrm{C}$. The soil had a low moisture rating and the $\mathrm{pH}$ was 7.3. Canopy cover was $0 \%$. We saw 3 hatchlings emerging from the nest on 25 July 2010 , almost exactly 2 months later, around $1730 \mathrm{hrs}$. Their means were: carapace length, $37.98 \mathrm{~mm}$ $(\mathrm{SE}=1.04 ;$ range $=36.56-40.02 \mathrm{~mm}) ;$ carapace width, $38.09 \mathrm{~mm}(\mathrm{SE}=1.08 ;$ range $=36.02-$ $38.58 \mathrm{~mm})$; plastron length, $34.33 \mathrm{~mm}(\mathrm{SE}=0.11$; range $=34.17-34.53 \mathrm{~mm})$; plastron width, $27.39 \mathrm{~mm}(\mathrm{SE}=0.69 ;$ range $=26.28-28.66 \mathrm{~mm}) ;$ bridge width, $10.38 \mathrm{~mm}(\mathrm{SE}=0.16$; range $=$ $10.07-10.56 \mathrm{~mm})$; bridge height, $5.32 \mathrm{~mm}(\mathrm{SE}=0.23$; range $=5.04-5.78 \mathrm{~mm})$; depth of 15.7 $\mathrm{mm}(\mathrm{SE}=0.19 ;$ range $=15.46-16.08 \mathrm{~mm}) ;$ and mass, $9.33 \mathrm{~g}(\mathrm{SE}=0.33 ;$ range $=9-10 \mathrm{~g})$. Soil temperature was $23^{\circ} \mathrm{C}$, air temperature was $22.7^{\circ} \mathrm{C}$, and water temperature was $23^{\circ} \mathrm{C}$. Soil 
moisture, soil $\mathrm{pH}$, and canopy cover remained the same. Soon after emergence, the hatchlings began consuming the shells of their eggs.

When the turtles were aquatic, we would see them walking along the riverbed, exploring $\log$ jams and root masses, poking their heads up for a breath, or swimming, although swimming was less common than walking along the bottom. Within the river on warm days, the turtles often took refuge in root masses protruding from the bank, thick organic mud on the streambed, fallen logs, leaf litter, or under undercut banks. During these days, air temperatures ranged from 27.3 to $42^{\circ} \mathrm{C}\left(\bar{x}=31.4^{\circ} \mathrm{C}, \mathrm{SE}=0.34\right)$, soil temperatures were 19 to $34^{\circ} \mathrm{C}\left(\bar{x}=23.8^{\circ} \mathrm{C}, \mathrm{SE}=\right.$ $0.32)$, and water temperatures were 19 to $29^{\circ} \mathrm{C}\left(\bar{x}=24.1^{\circ} \mathrm{C}, \mathrm{SE}=0.26\right)$. When the turtles were terrestrial, we often found them walking along white-tailed deer (Odocoileus virginianus) trails bordering the bank, through woods, and up mountainsides. One radio-tagged male was following a trail parallel to the river as we walked up a trail perpendicular to the river, tracking him. We reached the deer-trail intersection at the same time and he stopped, looking at us. As we watched, he turned left, onto our trail, and began walking away from us into uplands. Clear paths were not always chosen for travelling, however. Thick grasses and wingstem (Verbesina alternifolia), reaching 1 to $2 \mathrm{~m}$ tall did not deter the turtles from forging through along the ground. If the turtles were not found walking about during the day, we often found them sitting still, legs tucked in and head out, in sparse vegetation. During warmer temperatures in the spring (26.5\%), summer (45\%), and fall (27.5\%), we typically found the turtles nestled or burrowed into shady conditions. Terrestrially, these included matted grasses (dead and alive), thick herbaceous plots, thick shrubs (especially multiflora rose), undercuts along banks, and leaf litter piled against woody debris. Occasionally, we would find individuals below the surface in a deep depression created by a cow hoof in a saturated area of a pasture. 
We observed basking turtles during all seasons except winter. Of all basking we observed, $61 \%$ occurred in the spring and $58 \%$ took place before noon, although the turtles were seen basking from 0821 to $1657 \mathrm{hrs}$. Locations chosen included streambanks, deer trails on mountainsides, clearings in vegetation, rocky beaches, and propped up against matted grasses and woody debris to achieve an approximate $45^{\circ}$ angle towards the sun. Their heads and appendages were usually extended. During the activity, soil, air, and water temperatures ranged from 8 to $33^{\circ} \mathrm{C}\left(\bar{x}=20.4^{\circ} \mathrm{C}, \mathrm{SE}=0.55\right), 8$ to $40^{\circ} \mathrm{C}\left(\bar{x}=27.6^{\circ} \mathrm{C}, \mathrm{SE}=0.72\right)$, and 7 to $27^{\circ} \mathrm{C}(\bar{x}=$ $\left.18.3^{\circ} \mathrm{C}, \mathrm{SE}=0.57\right)$, respectively. Relative humidity varied from 15 to $95.8 \%(\bar{x}=59.7 \%, \mathrm{SE}=$ $2.36)$ and canopy cover was 0 to $100 \%(\bar{x}=36.5 \%, \mathrm{SE}=0.03)$.

We made dietary observations on 70 occasions. Initial observations occurred in April. Prey was slugs and green leaves. A single male was observed stomping for worms, his body bouncing up and down against the ground. In May, common prey consumed included jewelweed (Impatiens spp.), slugs, and worms. The largest variety of prey eaten and the greatest number of eating observations (47\%) occurred in June. These prey items included jewelweed, green dragon (Arisaema dracontium), June bugs (Phyllophaga spp.), slugs, worms, and unidentifiable small mammal remains. On an overcast day, we observed a female worm-stomping. She was standing in a clearing on muddy ground, not long after rain had ended, about $10 \mathrm{~m}$ from the river's edge. Her front right leg was wiggled back and forth against the ground, then her front left leg. Suddenly she began rapidly raising the front end of her body up, slamming into the ground repeatedly. While observed, she did not catch any worms, but she quickly became conscious of being watched and ended her routine. In July, only slugs were found being eaten. Slugs, pokeweed (Phytolacca americana) berries, autumn olive (Elaeagnus umbellata) berries, dandelion (Taraxacum officinale) leaves, and unidentifiable songbird remains made up the prey 
for August. We made final diet observations in September. During this month, pokeweed berries, green leaves, violets (Viola spp.), and wild black cherries (Prunus serotina) were consumed. Overall, slugs were the most highly consumed (67\%). All other prey made up $<1 \%$ of the diet observations.

We observed dominance displays on a couple of occasions, primarily within the river. On 3 October 2009, we saw a male chasing another male during the fall mating season, possibly to clear the area of competing males. Two males were observed nudging each other with their heads on 7 November 2009. They may have been establishing territoriality for their upcoming hibernation spots. A male was found mounted on another male on 1 October 2010, during autumn mating. On 19 November 2010, around the time that the turtles were entering into hibernation, a non-radio-tagged male approached a radio-tagged male in the latter's home range, their necks outstretched. The resident male attempted a bite, causing the other to flee. The single terrestrial dominance display occurred on 14 June 2010. A radio-tagged male was found in his home range next to an unmarked male. When the new male tried to walk away, the resident male bit his front leg. The new male paused, tucking into his shell as the resident male stood with his neck outstretched above him. As the new male again tried to leave, the resident male pursued him, biting. The sequence of aggression appeared to follow this order: the dominant individual bit at the subordinate's eyes first, then for the legs as the latter's head was pulled into its shell; the dominant individual then asserted its dominance by fully extending its neck vertically; if the loser raised its head in the presence of the dominant individual, the dominant one opened its mouth for a few seconds, then started trying to bite the loser again. This continued until the subordinate individual was able to successfully flee. 
Turtles began spending the majority of their time in the river by late October, but continued to move about, and were thus considered not to be hibernating yet. However, by early November, the turtles had stopped moving and began hibernating. At this time, soil temperatures were 7 to $9^{\circ} \mathrm{C}$, air temperatures were 12.2 to $14.5^{\circ} \mathrm{C}$, and water temperature was $7^{\circ} \mathrm{C}$. During hibernation, mean environmental temperatures were as follows: soil, $1.65^{\circ} \mathrm{C}(\mathrm{SE}=$ 0.26 ; range $\left.=-2-9^{\circ} \mathrm{C}\right)$; air, $6.42^{\circ} \mathrm{C}\left(\mathrm{SE}=0.46\right.$; range $\left.=-3-15.1^{\circ} \mathrm{C}\right)$; and water, $3.77^{\circ} \mathrm{C}(\mathrm{SE}=$ 0.34 ; range $=0-8^{\circ} \mathrm{C}$ ). Typical hibernation sites were long, quiet pools that reached a depth of about 1 to $2.5 \mathrm{~m}$ and width of about 20 to $30 \mathrm{~m}$. Average hibernation depth was $0.78 \mathrm{~m}$ ( $\mathrm{SE}=$ 0.05 , range $=0.25-2.5 \mathrm{~m})$ and $3.39 \mathrm{~m}(\mathrm{SE}=0.47$, range $=0.25-20 \mathrm{~m})$ from shore. The turtles would often communally hibernate in the same pools, but were often separated from each other. They would take refuge, covering themselves fully in soft organic substrate, sand, leaf litter, or in the root mass of a fallen tree or one protruding from the bank, or sit exposed on the riverbed. Many of the turtles were found under 2.5 to $10 \mathrm{~cm}$ thick ice that spanned the river, with the nearest flowing water up to $30 \mathrm{~m}$ away. A couple of the turtles were found covered in algae so thick that it was hard to distinguish them from the surrounding rocks.

We saw little movement by the hibernating turtles except during occasional warming cycles when the more shallowly hibernating turtles could feel the shifts in temperature and would become sluggishly active. Beginning in February 2011, the weather began fluctuating between warm and cold periods. The turtles began moving actively when water temperatures were about $10^{\circ} \mathrm{C}$. Temperature fluctuations continued into early March. One radio-tagged female began moving to shore during an unusually warm spell that lasted about 3 days, after which the air temperature dropped to freezing again. We found the female dead, at the edge of the water, all of her legs extended as if she had been walking. We presumed that the water depth $(0.25 \mathrm{~m})$ in 
which she was found was possibly too shallow to act as a buffer against the sudden cold. By this time, all of the turtles had stopped moving and began hibernating again; water temperatures were 7 to $8^{\circ} \mathrm{C}$.

We saw the first turtle emerging from hibernation in 2010 on 12 March. Temperatures were as follows: soil, $10^{\circ} \mathrm{C}$; air, $12^{\circ} \mathrm{C}$; and water, $8^{\circ} \mathrm{C}$; slightly warmer than the beginning hibernation temperatures. In 2011, the first turtle was seen out of hibernation on 19 March when the soil temperature was $13^{\circ} \mathrm{C}$, air temperature was $26.4^{\circ} \mathrm{C}$, and water temperature was $11^{\circ} \mathrm{C}$. Both turtles were male and within a meter of the river's edge, basking. From this point, turtles became active, primarily remaining within or near the river, as the spring mating season began.

\section{DISCUSSION}

\section{Morphometrics and Sex-Ratio}

Adults were larger than juveniles, providing morphometric distinction between juveniles of unknown gender and adult turtles with carapace lengths $>160 \mathrm{~mm}$ that exhibit sexual dimorphism (e.g., concave plastron). Wood turtle males who mate are longer, thicker, and heavier than the females with which they mate. However, in the overall population, the mean measurements of adult males and females were not different from each other. Males that are larger than females may be harder for relenting females to dislodge during mating and may be more reproductively successful once the female's resistance breaks down. Mature wood turtle males tend to have longer carapaces than same-age females in New Jersey (Farrell and Graham 1991). Mean male carapace lengths were larger than that of females in Virginia (Akre 2002) and in a different West Virginia population (Breisch 2006). Conversely, the females of common map turtles (Graptemys geographica), common musk turtles (Sternotherus odoratus), and red-eared 
sliders (Trachemys scripta) were larger than the males in carapace length and mass in Indiana (Conner et al. 2005).

The measurements of our wood turtles in West Virginia (southern extent of the range) fall between the sizes of a New Jersey population (middle of the range) (Farrell and Graham 1991) and a Québec population (northern extent of the range) (Saumure et al. 2007). Our finding reflects previous studies of turtles in northern and southern populations being larger, on average, than those in the middle of the range (Verdon and Donnelly 2005, Greaves and Litzgus 2007). However, in a Québec, Canada study comparing wood turtle populations living in agricultural and forested sites, Saumure and Bider (1998) determined that the agricultural site turtles grew to smaller sizes than their forest counterparts. Interestingly, our turtles, living in an agri-forested environment had similar mean sizes and ranges to the Québec agriculture turtles. The smaller growth sizes of the agricultural site wood turtles were thought to be due to the effect of mutilation on the turtles, caused by agricultural activities (Saumure and Bider 1998). In our site, many of the turtles had punctures and deep cuts on their carapaces that may have been inflicted by agricultural machinery.

Similar to other range results, our youngest male was 7 years of age with a carapace length of $161.6 \mathrm{~mm}$. Our youngest female was 9 years of age with a carapace length of 167.6 $\mathrm{mm}$. The youngest reproductively active male and female were 15 and 16 years of age, respectively. The youngest identifiable males on the Québec agricultural site were 10 years of age with a carapace length of $176.3 \mathrm{~mm}$ and 11 years of age with a carapace length of $157.6 \mathrm{~mm}$ in the forested site. The youngest nesting female, found in the Québec forested site, was 15 years of age with a carapace length of $195.4 \mathrm{~mm}$ (Saumure and Bider 1998). In New Jersey, 
secondary characteristics began to appear when turtles were about 9 years of age; maturity was achieved with reproductive activities about 14 years of age (Farrell and Graham 1991).

The population estimate for our wood turtles was 354 individuals, similar to the population estimate nearly 20 years ago (287 to 337 individuals; Niederberger and Seidel 1999). The sex-ratios of adult wood turtles were about 1:1 in our study, Pennsylvania, New Jersey, Michigan, and Québec (Harding and Bloomer 1979, Farrell and Graham 1991, Kaufmann 1992b, Daigle and Jutras 2005). In New Jersey, wood turtles exhibited a 1.5:1 female skew (Harding and Bloomer 1979). Our juvenile to adult ratio was 1:3.8, a significant difference from 1:1, reflecting the difficulty we had in finding juveniles and possibly indicating a depression in recruitment in this agricultural site; we did not expect the ratio to be equal as juvenile recruitment of wood tutles is often low (Arvisais et al. 2002). In New Jersey, however, hatchling-and-juvenile to subadult-and-adult ratio was about 1:1 (Farrell and Graham 1991).

\section{Home Ranges and Vegetation}

The $50 \%$ home ranges in our study averaged 0.90 ha ( $\mathrm{SE}=0.19,0.09-4.63 \mathrm{ha})$. The $95 \%$ home ranges averaged 5.75 ha $(\mathrm{SE}=1.46 ; 0.62-36.97 \mathrm{ha})$. Wood turtle home ranges followed the stream channel (Strang 1983, Remsberg et al. 2006), a result we found to be particular for males, but females and juveniles extended outward terrestrially. Home ranges averaged 28.3 ha in Québec (Arvisais et al. 2002), 24.3 ha in Algonquin Park, Canada (Quinn and Tate 1991), 3.3 ha with no significant difference between genders in Pennsylvania (Kaufmann 1995), 30.2 ha in Michigan (Remsberg et al. 2006), and 22.7 ha and 61.25 ha at 2 sites in Virginia (Sweeten 2008). Wood turtles returned to the same home ranges yearly (our study, Strang 1983, Quinn and Tate 1991, Arvisais et al. 2002). 
Wood turtles require a variety of cover types for annual activities (Quinn and Tate 1991, Kaufmann 1992a, Compton et al. 2002), with preference for bottomland areas (Strang 1983). In our study, low bare ground and rock cover and high vertical density differentiated wood turtle vegetation plots from random plots, indicating a preference for tall, thick herbaceous vegetation that may provide cover, a variety of vegetative food, and draw in a diverse array of invertebrate prey. Wood turtles also were observed in areas with greater tree richness than at random, additionally indicating a preference for habitat complexity. Agricultural fields, on occasion, were used by the turtles; females were occasionally in active pastures and hayfields bordering the river while males were found in cornfields. These wanderings, however, were usually within the turtles' home ranges and not temporary trips outside of the home range. Compton et al. (2002) developed models from a Maine wood turtle study suggesting the turtles prefer dry, moderately forested habitats at the watershed scale and sparse forests with low canopy cover near water at the local scale. Gender differences in habitat use were exhibited by wood turtles: males were found in streams more than females (Kaufmann 1992a, Compton et al. 2002) while females spent more time in grass-sedge-forb associations (Kaufmann 1992a). Hatchlings showed preferences also for habitat, choosing stream entry points composed of red maple (Acer rubrum), alder (Alnus rugosa), silky dogwood (Cornus amomum), partridgeberry (Mitchella repens), rough bedstraw (Galium asprellum), and various mosses and grasses in New Hampshire (Tuttle and Carroll 2005). In Pennsylvania, the majority of terrestrial activity occurred in alder stands and grass-sedge-forb associations (Kaufmann 1992a), as well as stands of black birch (Betula lenta), oaks (Quercus spp.), and red maple (Strang 1983). In Canada, wood turtles occupied alder swale (30\%), mixed forest (28\%), and grassy areas (12\%) (Quinn and Tate 1991). In 
Québec, forest stands were typically young (16 years), short (1 - $4 \mathrm{~m})$, had few trees (25\%), a moderate upper shrub layer cover (35\%), and low canopy cover (0 - 50\%) (Arvisais et al. 2004). Seasonal Activity Cycles

During spring, activities in our population were mainly aquatic (mating), but the turtles soon left the river to nest and return to their home ranges. Fewer females were terrestrial in the spring than males, possibly related to the females using the river as a refuge between nesting attempts. In summer, the population was predominantly terrestrial. In a Pennsylvania population, the turtles were aquatic only 34\% during summer (Ernst 1986, Kaufmann 1992a). By autumn, most individuals in our population returned to the river for mating and hibernation preparation; in winter, hibernation was aquatic. Males being more aquatic in autumn corresponded with the primary mating season in autumn; the sooner a male arrives, the better chances he may have to mate with a number of females before other males arrive. In Québec, wood turtles were observed in aquatic habitats $59.1 \%$ of the time and in terrestrial habitats $40.9 \%$ (Arvisais et al. 2004).

Here, in the southern extent of the range in West Virginia, turtles emerged from hibernation in mid-March, earlier in the year than their northern counterparts, but during similar environmental temperatures. Courtship followed soon after, occurring from late March to early June and late August to early November, starting earlier and ending later than the northern populations; $35.7 \%$ of our study's mating events were terrestrial, up to $30 \mathrm{~m}$ from the river's edge, which is uncommon for wood turtles that primarily have aquatic mating. In Ontario, Canada, at the northern extent of the wood turtles' range, the turtles emerged from hibernation in mid-April when temperatures were: air, $13.5^{\circ} \mathrm{C}$ and water, $5.0^{\circ} \mathrm{C}$ (Greaves and Litzgus 2007). Turtles returned to the stream during nights $\leq 10^{\circ} \mathrm{C}$ and during days $\leq 20^{\circ} \mathrm{C}$ following hibernation 
emergence (Kaufmann 1992a, Arvisais et al. 2002). In Pennsylvania during mating, air temperatures were 11 to $22.8^{\circ} \mathrm{C}$ and soil and water temperatures were 10.0 to $20.0^{\circ} \mathrm{C}$ (Ernst 1986). Mating occurred from mid-April to mid-May and late August to October in Pennsylvania (Kaufmann 1992a), mid-June in Algonquian Park, Canada (Quinn and Tate 1991), and late March to April and October to November in New Jersey (Farrell and Graham 1991).

Following courtship, nesting was observed in late May to late June in our study and in Virginia (Akre 2002) and in June in Pennsylvania, New Jersey, Michigan, and Québec (Harding and Bloomer 1979, Farrell and Graham 1991, Kaufmann 1992b, Arvisais et al. 2002). Similar to the environmental temperatures in our study, nesting occurred when air and soil temperatures were 22.0 to $26.3^{\circ} \mathrm{C}$ and 21.5 to $25.5^{\circ} \mathrm{C}$, respectively, in Pennsylvania (Ernst 1986). High percentages of wood turtle females returned to the same nesting grounds annually (Walde et al. 2007). In our West Virginia population, preferred nesting beaches were primarily composed of sand intermixed with pebbles with minimal vegetative cover, possibly chosen for their thermal characteristics. Wood turtles have nested also within natural erosion zones (Saumure et al. 2007), agricultural fields (Kaufmann 1992a), gravel pits (Walde et al. 2007), and sandy roadsides (Quinn and Tate 1991). In New Hampshire, sandpits used for nesting had sparse vegetation (Tuttle and Carroll 2005). Sites without shading vegetation were used for nesting by 4 aquatic turtle species (Florida cooter [Pseudemys floridana], common musk turtle [Sternathorus odoratus], yellow-bellied slider [Trachemys scripta], and Florida softshell [Apalone ferox]) in Florida (Aresco 2005) and Macquarie turtles (Emydura macquarii) in Australia (Spencer and Thompson 2003). In our study, beaches were shared among multiple females; depredated nests (indicated by shredded, scattered eggshells surrounding a dug up nest) were often found $<0.5 \mathrm{~m}$ of each other, although predators were never observed. In New 
Hampshire, Marchand et al. (2002) found 22\% of artificial nests to be disturbed within a week of placement; raccoons (Procyon lotor) were the most common predators. Clumped nests and nests in agricultural or disturbed areas were preyed upon to a greater degree than scattered nests or nests near roads or in manicured lawns (Marchand et al. 2002, Marchand and Litvaitis 2004). However, in Québec, Walde et al. (2007) did not observe mammalian predation of wood turtle nests.

Only a couple degrees cooler than the single observed nest emergence in our population, nest emergence occurred when mean soil temperature was $22.1 \pm 7.4^{\circ} \mathrm{C}$ and mean air temperature was $19.4 \pm 5.3^{\circ} \mathrm{C}$ in New Hampshire (Tuttle and Carroll 2005). A single case of possible overwintering in the nest was documented in Vermont (Parren and Rice 2004); however, this is rare for wood turtles and their difficulty in surviving in that situation possibly limits the northern distribution of wood turtles (Walde et al. 2007). Hatchlings emerged on 25 July 2010 for the single observed nest in our study, mid- to late August from early morning until early evening in New Hampshire (Tuttle and Carroll 2005), and August to October in Québec and New Jersey (Harding and Bloomer 1979, Walde et al. 2007). In our study, of the 11 eggs laid, only 1 failed to develop. The 3 hatchlings seen emerging began trying to eat their eggshells soon after, possibly an instinctual need to absorb calcium to begin the process of strengthening and hardening their shells which are soft when the young hatch. In other regions of their range, clutch sizes varied from 5 to 11 individuals in New Jersey (Farrell and Graham 1991), 5 to 18 in Michigan (Harding and Bloomer 1979), and 5 to 20 in Québec (Walde et al. 2007). Our West Virginia hatchlings were larger than their New Hampshire counterparts, suggesting that the trend of southern populations of turtles being larger than middle-of-the-range populations may begin during development in the egg. 
Aquatic environments used by wood turtles include main streams, beaver (Castor canadensis) ponds, marshlands, swamps, wet meadows, lakes, and brooks (Arvisais et al. 2004). Wood turtles in our population tended to walk along the bottom rather than swim, noted also by Brewster and Brewster (1991). Water channels near wood turtle populations varied in width and tended to have sandy substrates with large scattered rocks and logs (Brewster and Brewster 1991, Greaves and Litzgus 2007). Stream width varied from 10 to $30 \mathrm{~m}$ (reaching $60 \mathrm{~m}$ in certain stretches during floods) and stream depth was $\leq 2.5 \mathrm{~m}$ in our study, 3 to $5 \mathrm{~m}$ stream width and 0.3 to $1.5 \mathrm{~m}$ stream depth in Wisconsin (Brewster and Brewster 1991), and 10 to $20 \mathrm{~m}$ stream width and $<2$ m stream depth in Canada (Greaves and Litzgus 2007). In our West Virginia study, temperatures related to aquatic movement were similar to other regional temperatures, but with higher upper limits (air, $42^{\circ} \mathrm{C}$; water, $29^{\circ} \mathrm{C}$; and soil, $34^{\circ} \mathrm{C}$ ) related to our more southern latitude. Aquatic movement occurred in Pennsylvania during temperatures: air, 3.0 to $26.0^{\circ} \mathrm{C}$ and water, 6.0 to $20.0^{\circ} \mathrm{C}$ (Ernst 1986), and in New Jersey during temperatures: air, 3.6 to $24.8^{\circ} \mathrm{C}$ and water and soil, 4.0 to $25.0^{\circ} \mathrm{C}$ (Farrell and Graham 1991).

Our West Virginia wood turtles became primarily terrestrial in late May and early June during the following temperatures: air, 12.2 to $46^{\circ} \mathrm{C}$; soil, 10 to $33^{\circ} \mathrm{C}$; and water, 11 to $34^{\circ} \mathrm{C}$; consistent throughout the range, with higher upper limits in the south. Terrestrial activity became prominent by June in Pennsylvania (Ernst 1968, Kaufmann 1992a) when air temperatures were 14.0 to $32.0^{\circ} \mathrm{C}$ and soil temperatures were 14.0 to $28.0^{\circ} \mathrm{C}$ (Ernst 1986) and in New Jersey when air temperatures were 11.0 to $27.4^{\circ} \mathrm{C}$ and water and soil temperatures were 11.2 to $27.0^{\circ} \mathrm{C}$ (Farrell and Graham 1991). However, during our higher southern extremes, the turtles became inactive, burrowing into vegetation, leaf litter, cow hoof depressions, log jams, and thick mud to escape the heat. The turtles appeared unable to withstand the hot temperatures, 
suggesting a limiting factor to wood turtles along the southern border of their geographic range.

During cooler temperatures, our turtles were often seen walking along deer trails, possibly because travelling along existing paths was less costly energetically or they might provide visual clues characteristic of dry streambeds (Yeomans 1995, Tuttle and Carroll 2005). Although positive geotaxis is beneficial to aquatic and semi-aquatic turtle species for finding water (DeRosa and Taylor 1980, Tuttle and Carroll 2005), movement downhill and uphill along existing paths were observed in our study and by Yeomans (1995) in South Carolina. Perhaps it may also be instinctual for wood turtles to follow trails; Tinklepaugh (1932) determined that wood turtles could find their way through mazes and Tuttle and Carroll (2005) observed that hatchlings followed each other's trails.

Our wood turtles commonly basked at a $45^{\circ}$ angle towards the sun on streambanks, deer trails, vegetation clearings, rocky beaches, and propped up against matted grasses and woody debris primarily before noon. Their heads and appendages were usually extended. In Québec, they basked at stream edges (Saumure and Bider 1998, Arvisais et al. 2002). In Pennsylvania, banks and floodplains along streams were used before noon (Ernst 1986, Kaufmann 1992a). In New Jersey, the turtles basked in streambank depressions at 25 to $80^{\circ}$ angles (Farrell and Graham 1991). In New Hampshire, hatchlings basked after emerging from overnight locations, angled at $45^{\circ}$, front legs extended (Tuttle and Carroll 2005). Basking occurred in our population during temperatures similar to other parts of the wood turtles' range: air, 14.0 to $33.0^{\circ} \mathrm{C}$; water, 12.0 to $24.0^{\circ} \mathrm{C}$; and soil, 14.0 to $32.0^{\circ} \mathrm{C}$ in Pennsylvania (Ernst 1986); and air, 4.0 to $29.4^{\circ} \mathrm{C}$ and water and soil, 3.4 to $34.4^{\circ} \mathrm{C}$ in New Jersey (Farrell and Graham 1991).

In our West Virginia population, the turtles were observed eating from April through September, beginning earlier but terminating at the same time as northern wood turtles. In 
Québec, early July through September was noted as a heavy feeding period (Arvisais et al. 2002). In our study, dietary preference was for slugs (67\%), although worms, June bugs, small mammal and bird remains, autumn olive berries, wild black cherries, pokeweed berries, jewelweed, green dragon, dandelion, and violets were also consumed. Wood turtles were seen in our population stomping the ground to bring earthworms to the surface for consumption, also observed by Kaufmann (1986). Diet was composed of green leaves, fruits, flowers, fungi, and invertebrates, with a preference for fungi $(37 \%)$ and green leaves $(31 \%)$ in Pennsylvania (Strang 1983). Strawberries (Fragaria spp.) and strawberry leaves, blackberries (Rubus spp.), raspberries (Rubus spp.), mushrooms, worms, slugs, and fish carrion were eaten in New Jersey and Maine (Farrell and Graham 1991, Compton et al. 2002). Hatchlings ate slugs, tiny insect larvae, and small green leaves in New Hampshire (Tuttle and Carroll 2005). In Pennsylvania, feeding on land occurred when air temperatures were 23.0 to $33.0^{\circ} \mathrm{C}$, while feeding in water occurred when air temperatures were 18.0 to $22.0^{\circ} \mathrm{C}$ and water temperatures were 14.8 to $19.5^{\circ} \mathrm{C}$ (Ernst 1986).

The sequence of events in an aggressive male:male encounter observed during our study were similar to observations made by Kaufmann (1992b). A ranking system appears to exist in wood turtle populations based on age and mass (Kaufmann 1992b). Harding and Bloomer (1979) observed dominance behavior in captive wood turtles. Males tended to be more dominant in aquatic situations and when of equal or larger size than females, but females were more dominant in terrestrial situations and when larger than males. In Pennsylvania, Kaufmann (1992b) observed a higher percentage of aggressive male:male encounters than non-aggressive, primarily occurring in autumn in water, similar to our observations. 
In our West Virginia population, wood turtles returned to the river in October and hibernated from November to March in thick mud, root masses, or exposed on the riverbed. In Pennsylvania, by October, when daytime temperatures were $\leq 20^{\circ} \mathrm{C}$ and nighttime temperatures were $\leq 10^{\circ} \mathrm{C}$, the majority of the turtles returned to the stream (Kaufmann 1992a). They hibernated from late October to early April under overhanging streambanks, exposed tree roots, or in stream substrate (Kaufmann 1992a). In Québec, wood turtles begin to hibernate in November in the riverbank or on the streambed (Arvisais et al. 2002, Arvisais et al. 2004). Our turtles were occasionally found hibernating under ice in calm stream reaches, similar to hibernation observations of wood turtles in Algonquin Park, Canada (Quinn and Tate 1991), but not in Pennsylvania (Ernst 1986). In our study, the average hibernation depth was 0.78 (range = $0.25-2.5) \mathrm{m}$ and average distance from shore was $3.39($ range $=0.25-20) \mathrm{m}$. The turtles were about $1 \mathrm{~m}$ deep at a mean distance of $1 \mathrm{~m}$ from the shore in Ontario, Canada (Greaves and Litzgus 2007). In Pennsylvania, hibernation depth was 1.0 to $2.3 \mathrm{~m}$ (Ernst 1986).

Five turtles ( 4 radio-tracked [2 males, 1 female, and 1 juvenile] and 1 un-marked female) were found dead by unknown causes during the course of the study. We found turtles walking through active pastures, hayfields, and cornfields, and many adult turtles had puncture wounds and deep cuts in their carapaces. Wood turtle populations depend upon high adult survival as juvenile recruitment tends to be low (Arvisais et al. 2002), but adult survival of turtles living in riparian zones adjacent to agricultural fields may be compromised from injuries inflicted by agricultural machinery. Saumure and Bider (1998) compared the mutilation rates of wood turtles by predators and agricultural activities at 2 site types, forest and agriculture, in southern Québec. At both sites, predator mutilation rates were similar. However, at the agricultural site, humancaused mutilation rates were higher and juvenile numbers were lower than in the forested site. In 
Québec, a wood turtle population declined $19.2 \%$ in 5 years; multiple turtles had mutilation injuries from agricultural equipment, likely incurred while fleeing from the field to the river during haying (Saumure et al. 2007).

\section{MANAGEMENT IMPLICATIONS}

If landowners and farmers are alerted to the presence and needs of turtles on their property, populations may be better conserved on these lands (Kaufmann 1992a); compensation may be available through federal programs for landowners that establish and protect their riparian zones. We recommend that in areas with large-scale agriculture along waterways where wood turtles occur, efforts are made to create, manage, and maintain riparian buffers that can provide essential terrestrial habitat for the turtles to undergo all aspects of their life-histories.

Establishing protected buffer strips along streams occupied by wood turtles would aid in conservation of the species (Arvisais et al. 2002). Although nearly all of our wood turtle observations were within $300 \mathrm{~m}$ of the river's edge, establishing a buffer that large is unrealistic; a $150 \mathrm{~m}$ riparian buffer would include estimated migration distances travelled from streams for the majority of freshwater turtles (Bodie 2001), with $10 \mathrm{~m}$ recommended as the minimum riparian buffer size for wood turtles (Saumure et al. 2007). The buffers should be maintained so that tall, thick, diverse herbaceous vegetation can grow to provide food and shelter for the turtles, and tree diversity should be managed which can provide a variety of seed foods, along with woody debris and canopy cover to provide shelter and shade. For conservation to be effective for wood turtles, extensive areas covering all seasonal habitat types should be protected (Quinn and Tate 1991) and the selection and chronological use of habitat by wood turtles should be a research focus (Arvisais et al. 2004). Additional studies on riparian zone use by turtles, especially those species of federal or international conservation concern, are necessary and 
encouraged (Arvisais et al. 2004); this includes wood turtles, a species threatened by riparian zone degradation (Compton et al. 2002).

\section{ACKNOWLEDGMENTS}

We thank N. S. McCoard, C. L.Pawlik, S. Selego, M. Jones, C. Concepcion, and L. Moon for assistance in the field. Previous drafts of this manuscript were reviewed by N. S. McCoard, E. A. Pawlik, Jr., J. Pitchford, T. K. Pauley, A. A. Billings, P. Bohall-Wood, and E. D. Michael. Many landowners allowed us entrance on to their properties and we thank them for the access. Funding for this project was provided by the Chesapeake Bay Conservation Innovation Grant Program (USDA), the National Fish and Wildlife Foundation, the National Oceanic and Atmospheric Administration, and the West Virginia University Environmental Research Center.

This is scientific article $\mathrm{xxxx}$ of the West Virginia University Agricultural and Forestry Experiment Station.

\section{LITERATURE CITED}

Akre, T. S. B. 2002. Growth, maturity, and reproduction of the wood turtle, Clemmys insculpta (LeConte) in Virginia. Dissertation, George Mason University, Fairfax, Virginia, USA.

Aresco, M. J. 2005. The effect of sex-specific terrestrial movements and roads on the sex ratio of freshwater turtles. Biological Conservation 123:37 - 44.

Arvisais, M., J. -C. Bourgeois, E. Levesque, C. Daigle, D. Masse, and J. Jutrus. 2002. Home range and movements of a wood turtle (Clemmys insculpta) population at the northern limit of its range. Canadian Journal of Zoology 80:402 - 408.

Arvisais, M., E. Levesque, J. -C. Bourgeois, C. Daigle, D. Masse, and J. Jutrus. 2004. Habitat selection by the wood turtle (Clemmys insculpta) at the northern limit of its range. Canadian Journal of Zoology 82:391 - 398. 
Bodie, J. R. 2001. Stream and riparian management for freshwater turtles. Journal of Environmental Management 62:443 - 455.

Bowne, D.R., M. A. Bowers, and J. E. Hines. 2006. Connectivity in an agricultural landscape as reflected by interpond movements of a freshwater turtle. Conservation Biology 20:780 791.

Breisch, A. N. 2006. The natural history and thermal ecology of a population of spotted turtles (Clemmys guttata) and wood turtles (Glyptemys insculpta) in West Virginia. Thesis, Marshall University, Huntington, West Virginia, USA.

Brewster, K. N., and C. M. Brewster. 1991. Movement and microhabitat use by juvenile wood turtles introduced into a riparian habitat. Journal of Herpetology 25:379 - 382.

Brower, J. E., and J. H. Zar. 1984. Field and laboratory methods for general ecology. Second edition. Wm. C. Brown, Dubuque, Iowa, USA.

Cagle, F. R. 1939. A system of marking turtles for future identifications. Copeia 1939:170 - 173.

Carroll, T. E., and D. W. Ehrenfeld. 1978. Intermediate-range homing in the wood turtle, Clemmys insculpta. Copeia 1978:117 - 126.

Committee on the Status of Endangered Wildlife in Canada [COSEWIC]. 2009. Canadian wildlife species at risk. Ottawa, Ontario, Canada. <www.cosewic.gc.ca/eng/sct0/rpt/rpt_csar_e.cfm >. Accessed 15 October 2009.

Compton, B. W., J. M. Rhymer, and M. McCollough. 2002. Habitat selection by wood turtles (Clemmys insculpta): an application of paired logistic regression. Ecology 83:833 - 843.

Conant, R., and J. T. Collins. 1998. A field guide to reptiles and amphibians of eastern and central North America. Third edition, expanded. Houghton Mifflin, New York, New York, USA. 
Conner, C. A., B. A. Douthitt, and T. J. Ryan.. 2005. Descriptive ecology of a turtle assemblage in an urban landscape. American Midland Naturalist 153:428 - 435.

Constantz, G, N. Ailes, and D. Malakoff. 1995. Portrait of a river: the ecological baseline of the Cacapon River. Pine Cabin Run Ecological Laboratory. High View, West Virginia, USA.

Convention on International Trade in Endangered Species of Wild Fauna and Flora [CITES]. 2008. Appendices I, II, and III. International Environment House, Geneva, Switzerland. Daigle, C., and J. Jutras. 2005. Quantitative evidence of decline in a southern Québec wood turtle (Glyptemys insculpta) population. Journal of Herpetology 39:130 - 132.

DeRosa, C. T., and D. H. Taylor. 1980. Homeward orientation mechanisms in three species of turtles (Trionyx spinifera, Chrysemys picta, and Terrapene carolina). Behavioral Ecology and Sociobiology 7:15-23.

Dufrêne, M., and P. Legendre. 1997. Species assemblages and indicator species: the need for a flexible asymmetrical approach. Ecological Monographs 67:345 - 366.

Endangered Species Coalition. 2008. Without a net: top ten wildlife, fish and plants in need of Endangered Species Act protection. <www.stopextinction.org/images/WithoutANet-high.pdf>. Accessed 13 April 2009.

Ernst, C. H. 1968. Evaporative water-loss relationships of turtles. Journal of Herpetology 2:159161.

Ernst, C. H. 1986. Environmental temperatures and activities in the wood turtle, Clemmys insculpta. Journal of Herpetology 20:222 - 229.

Ernst, C. H., J. E. Lovich, and R. W. Barbour. 1994. Turtles of the United States and Canada. Smithsonian Institution, Washington, D.C., USA. 
Ernst, C. H. 2001. An overview of the North American turtle genus Clemmys Ritgen, 1828. Chelonian Conservation and Biology 4:211 - 216.

Farrell, R. F., and T. E. Graham. 1991. Ecological notes on the turtle Clemmys insculpta in northwestern New Jersey. Journal of Herpetology 25:1 - 9 .

Finch, H. 2005. Comparison of the performance of nonparametric and parametric MANOVA test statistics when assumptions are violated. Methodology: European Journal of Research Methods for the Behavioral and Social Sciences 1:27 - 38 .

Greaves, W.F., and J. D. Litzgus. 2007. Overwintering ecology of wood turtles (Glyptemys insculpta) at the species' northern range limit. Journal of Herpetology 41:32 - 40 .

Green, N. B., and T. K. Pauley. 1987. Amphibians and reptiles in West Virginia. University of Pittsburgh, Pennsylvania, USA.

Harding, J. H., and T. J. Bloomer. 1979. The wood turle, Clemmys insculpta ... a natural history. Herp-Bulletin of the New York Herpetological Society 15:9 - 26.

Holman, J. A. 1976. Paleoclimatic implications of "ecologically incompatible" herpetological species (late Pleistocene: southeastern United States). Herpetologica 32:290 - 295.

Jones, M. T., and P. R. Sievert. 2009. Effects of stochastic flood disturbance on adult wood turtles, Glyptemys insculpta, in Massachusetts. Canadian Field Naturalist 123:313 - 322.

Kaufmann, J. H. 1986. Stomping for earthworms by wood turtles, Clemmys insculpta: a newly discovered foraging technique. Copeia 1986:1001 - 1004.

Kaufmann, J. H. 1992a. Habitat use by wood turtles in central Pennsylvania. Journal of Herpetology 26:315 - 321 .

Kaufmann, J. H. 1992b. The social behavior of wood turtles in central Pennsylvania. Herpetological Monographs 6:1 - 25 . 
Kaufmann, J. H. 1995. Home ranges and movements of wood turtles, Clemmys insculpta, in central Pennsylvania. Copeia 1995:22 - 27.

Kozar, M. D., and M. V. Mathes. 2001. Aquifer-characteristics data for West Virginia. WaterResources Investigations Report 01-4036. U.S. Geological Survey, U.S. Department of the Interior.

Kutner, M. H., C. J. Nachtsheim, J. Neter, and W. Li. 2005. Applied linear statistical models. Fifth edition. McGraw-Hill/Irwin, New York, New York, USA.

Lorion, C. M., and B. P. Kennedy. 2009. Relationships between deforestation, riparian forest buffers and benthic macroinvertebrates in neotropical headwater streams. Freshwater Biology 54:165 - 180 .

Lunney, G. H. 1970. Using analysis of variance with a dichotomous dependent variable: an empirical study. Journal of Educational Measurement 7:263 - 269.

Marchand, M. N., J. A. Litvaitis, T. J. Maier, and R. M. DeGraaf. 2002. Use of artificial nests to investigate predation on freshwater turtle nests. Wildlife Society Bulletin 30:1 - 7 .

Marchand, M. N., and J. A. Litvaitis. 2004. Effects of landscape composition, habitat features, and nest distribution on predation rates of simulated turtle nests. Biological Conservation $117: 243-251$

Moll, E. O. 2000. Turtles and tortoises. Pages 118 - 129 in T. Halliday and K. Adler, editors. The encyclopedia of reptiles and amphibians. Facts on File, New York, New York, USA.

Niederberger, A. J. 1993. Aspects of the ecology of the wood turtle, Clemmys insculpta (LeConte), in West Virginia. Thesis, Marshall University, Huntington, West Virginia, USA. 
Niederberger, A. J., and M. E. Seidel. 1999. Ecology and status of a wood turtle (Clemmys insculpta) population in West Virginia. Chelonian Conservation and Biology 3:414 418.

Parmalee, P. W., and W. E. Klippel. 1981. Remains of the wood turtle Clemmys insculpta (Le Conte) froma late Pleistocene deposit in middle Tennessee. American Midland Naturalist $105: 413-416$.

Parren, S. G., and M. A. Rice. 2004. Terrestrial overwintering of hatchling turtles in Vermont nests. Northeastern Naturalist 11:229-233.

Quinn, N. W. S., and D. P. Tate. 1991. Seasonal movements and habitat of wood turtles (Clemmys insculpta) in Algonquin Park, Canada. Journal of Herpetology 25:217 - 220.

Reagan, D. P. 1974. Habitat selection in the three-toed box turtle, Terrapene carolina triunguis. Copeia 1974:512-527.

Remsberg, A. J., T. L. Lewis, P. W. Huber, and K. A. Asmus. 2006. Home ranges of wood turtles (Glyptemys insculpta) in northern Michigan. Chelonian Conservation and Biology $5: 42-47$

Robel, R. J., J. N. Briggs, A. D. Dayton, and L. C. Hulbert. 1970. Relationships between visual obstruction measurements and weight of grassland vegetation. Journal of Range Management 23:295-298.

Robson, D. S., and H. A. Regier. 1964. Sample size in Peterson mark-recapture experiments. Transactions of the American Fisheries Society 93:215 - 226.

Saumure, R. A., and J. R. Bider. 1998. Impact of agricultural development on a population of wood turtles (Clemmys insculpta) in southern Québec, Canada. Chelonian Conservation and Biology 3:37 - 45 . 
Saumure, R. A., T. B. Herman, and R. D. Titman. 2007. Effects of haying and agricultural practices on a declining species: the North American wood turtle, Glyptemys insculpta. Biological Conservation 135:565 - 575 .

Selego, S. M., C. L. Rose, G. T. Merovich, Jr., S. A. Welsh, and J. T. Anderson. 2012. Community-level response of fishes and aquatic macroinvertebrates to stream restoration in a third-order tributary of the Potomac River, USA. International Journal of Ecology, article ID 753634.

Spencer, R. -J., and M. B. Thompson. 2003. The significance of predation in nest site selection of turtles: an experimental consideration of macro- and microhabitat preferences. Oikos $102: 592-600$.

Strang, C. A. 1983. Spatial and temporal activity patterns in two terrestrial turtles. Journal of Herpetology 17:43-47.

Sweeten, S. E. 2008. Home range, hibernacula fidelity, and best management practices for wood turtles (Glyptemys insculpta) in Virginia. Thesis, James Madison University, Harrisonburg, Virginia, USA.

Tinklepaugh, O. L. 1932. Maze learning of a turtle. Journal of Comparitive Psychology 13:201 206.

Turtle Conservation Fund. 2002. A global action plan for conservation of tortoises and freshwater turtles. Strategy and funding prospectus 2002-2007. Conservation International and Chelonian Research Foundation, Washington, D.C., USA. <www.turtleconservationfund.org/wp-content/uploads/2008/02/tcf_action_plan.pdf>. Accessed 15 April 2009. 
Tuttle, S. E., and D. M. Carroll. 2005. Movements and behavior of hatchling wood turtles (Glyptemys insculpta). Northeastern Naturalist 12:331 - 348.

Verdon, E., and M. A. Donnelly. 2005. Population structure of Florida box turtles (Terrapene carolina bauri) at the southernmost limit of their range. Journal of Herpetology 39:572 577.

Walde, A. D., J. R. Bider, D. Masse, R. A. Saumure, and R. D. Titman. 2007. Nesting ecology and hatching success of the wood turtle, Glyptemys insculpta, in Québec. Herpetological Conservation and Biology 2:49 - 60 .

Walters, K., and L. Coen. 2006. A comparison of statistical approaches to analyzing community convergence between natural and constructed oyster reefs. Journal of Experimental Marine Biology and Ecology 330:81 - 95.

West Virginia Division of Natural Resources [WVDNR]: Wildlife Resources Section. 2005. It's about habitat... West Virginia Wildlife Conservation Action Plan. <www.wvdnr.gov/Wildlife/PDFFiles/wvwcap.pdf>. Accessed on 25 March 2009.

West Virginia Natural Heritage Program [WVNHP]. 2007. Rare, threatened and endangered animals. West Virginia Division of Natural Resources. <www.wvdnr.gov/Wildlife/documents/Animals2007.pdf>. Accessed 12 March 2009.

Yeomans, R. S. 1995. Water-finding in adult turtles: random search or oriented behaviour? Animal Behaviour 49:977 - 987. 
Table 1. Averages, standard errors (SE), minimum, and maximum of each morphometric variable recorded for all unique wood turtles ( $n=284$; males, $n=137$; females, $n=88$; juveniles, $n=59$ ) captured and all wood turtles observed mating (males, $n=25$; females, $n$ = 18) along a 13.7-km reach of the Cacapon River, West Virginia, USA during spring 2009 to summer 2011. All measurements are in mm, except mass $(\mathrm{g})$. Within a row, means with the same letter are not different.

\begin{tabular}{|c|c|c|c|c|c|c|c|c|c|c|c|c|c|c|}
\hline \multirow[b]{2}{*}{ Variable } & \multicolumn{4}{|c|}{ Males } & \multicolumn{4}{|c|}{ Females } & \multicolumn{4}{|c|}{ Juveniles } & \multirow[b]{2}{*}{$F_{2,281}$} & \multirow[b]{2}{*}{$P$} \\
\hline & $\bar{x}$ & $\mathrm{SE}$ & Min & Max & $\bar{x}$ & SE & Min & Max & $\bar{x}$ & $\mathrm{SE}$ & Min & Max & & \\
\hline Carapace Length & $194.6^{\mathbf{a}}$ & 1.28 & 160.0 & 232.2 & $180.7^{\mathrm{a}}$ & 1.18 & 167.6 & 206.9 & $102.1^{b}$ & 4.27 & 36.6 & 151.0 & 495.2 & $<0.001$ \\
\hline Carapace Width & $141.7^{\mathrm{a}}$ & 1.01 & 111.4 & 183.6 & $136.9^{\mathrm{a}}$ & 1.25 & 103.0 & 191.1 & $82.8^{b}$ & 2.79 & 36.0 & 116.2 & 375.1 & $<0.001$ \\
\hline Plastron Length & $178.2^{\mathrm{a}}$ & 1.10 & 109.0 & 206.0 & $175.5^{\mathrm{a}}$ & 1.82 & 108.3 & 204.3 & $99.2^{\mathbf{b}}$ & 4.45 & 34.2 & 152.9 & 345.9 & $<0.001$ \\
\hline Plastron Width & $114.2^{\mathrm{a}}$ & 0.95 & 95.0 & 197.4 & $116.9^{\mathrm{a}}$ & 1.57 & 90.8 & 192.3 & $65.9^{b}$ & 2.48 & 26.3 & 93.9 & 281.2 & $<0.001$ \\
\hline Bridge Width & $68.8^{\mathrm{a}}$ & 0.58 & 50.7 & 95.0 & $68.1^{\mathrm{a}}$ & 0.65 & 53.0 & 87.8 & $34.9^{b}$ & 1.65 & 10.1 & 54.9 & 393.2 & $<0.001$ \\
\hline Bridge Height & $23.6^{\mathrm{a}}$ & 0.23 & 13.5 & 36.5 & $21.4^{\mathrm{a}}$ & 0.21 & 15.5 & 26.6 & $11.6^{\mathrm{b}}$ & 0.46 & 5.0 & 20.0 & 426.2 & $<0.001$ \\
\hline Depth & $67.8^{\mathrm{a}}$ & 0.50 & 46.0 & 79.6 & $67.7^{\mathbf{a}}$ & 0.52 & 52.1 & 79.5 & $37.1^{b}$ & 1.51 & 9.4 & 56.1 & 426.5 & $<0.001$ \\
\hline Mass & $1,116.0^{\mathrm{a}}$ & 15.82 & 520.0 & $1,430.0$ & $981.0^{\mathbf{a}}$ & 18.15 & 430.0 & $1,380.0$ & $198.0^{\mathbf{b}}$ & 19.37 & 7.0 & 500.0 & 597.3 & $<0.001$ \\
\hline
\end{tabular}


Table 1 continued

\begin{tabular}{|c|c|c|c|c|c|c|c|c|c|c|}
\hline \multicolumn{4}{|c|}{ Mating Males } & \multicolumn{4}{|c|}{ Mating Females } & \multirow[b]{2}{*}{$t$} & \multirow[b]{2}{*}{$d f$} & \multirow[b]{2}{*}{$P$} \\
\hline $\bar{x}$ & SE & Min & Max & $\bar{x}$ & SE & Min & Max & & & \\
\hline 200.21 & 2.18 & 177.60 & 220.90 & 186.10 & 2.08 & 171.95 & 206.89 & 4.68 & 40.42 & $<0.001$ \\
\hline 146.46 & 1.38 & 134.38 & 165.10 & 142.84 & 1.58 & 128.00 & 155.55 & 1.72 & 37.48 & 0.094 \\
\hline 180.77 & 3.58 & 113.79 & 206.00 & 179.25 & 4.31 & 115.34 & 204.27 & 0.27 & 36.28 & 0.789 \\
\hline 113.12 & 1.97 & 74.50 & 124.00 & 119.72 & 3.27 & 108.04 & 172.42 & 1.73 & 28.86 & 0.095 \\
\hline 69.51 & 1.24 & 56.80 & 84.55 & 68.25 & 1.25 & 61.92 & 81.24 & 0.71 & 39.69 & 0.482 \\
\hline 24.24 & 0.38 & 20.47 & 28.00 & 22.33 & 0.36 & 20.00 & 25.58 & 3.66 & 40.41 & $<0.001 *$ \\
\hline 69.05 & 0.83 & 58.00 & 78.00 & 68.31 & 0.75 & 62.53 & 72.00 & 0.66 & 40.80 & 0.516 \\
\hline $1,154.00$ & 24.75 & 910.00 & 24.75 & $1,043.00$ & 27.72 & 920.00 & $1,300.00$ & 2.99 & 37.87 & $0.005^{*}$ \\
\hline
\end{tabular}

$\overline{{ }^{a, b} \text { Difference between males:juveniles and females:juveniles }(\alpha=0.05)}$

*Difference between males:females (Bonferroni correction: $\alpha=0.05 / 8=0.006$ ) 
Table 2. Radio-telemetry data for wood turtles $(n=31)$ tracked along a 13.7-km reach of the Cacapon River, West Virginia, USA during spring 2009 to summer 2011. Minimum Convex Polygon (MCP) home range sizes (calculated in package Adehabitat, statistical software program R) are in hectares (ha). Home ranges were not generated for turtles tracked $\leq 10$ times.

\begin{tabular}{|c|c|c|c|c|c|c|}
\hline \multirow{3}{*}{$\begin{array}{c}\text { Turtle } \\
\text { Identification }\end{array}$} & \multirow[b]{3}{*}{ Gender } & \multirow{3}{*}{$\begin{array}{c}\text { Number of } \\
\text { Times Tracked }\end{array}$} & \multicolumn{3}{|c|}{ Home Range (ha) } & \multirow[b]{2}{*}{ Maximum Overland } \\
\hline & & & & & & \\
\hline & & & Months Tracked & $50 \%$ & $95 \%$ & Distance from the River $(\mathrm{m})$ \\
\hline 214 & Female & 50 & August $2009-$ July 2011 & 0.26 & 1.01 & 30 \\
\hline 234 & Female & 66 & July 2009 - August 2011 & 1.60 & 6.79 & 153 \\
\hline 253 & Juvenile & 47 & July 2009 - March 2011 & 0.37 & 1.64 & 42 \\
\hline 274 & Female & 48 & October 2009 - August 2011 & 0.72 & 3.73 & 164 \\
\hline 294 & Female & 46 & August 2009 - May 2011 & 1.07 & 1.71 & 58 \\
\hline 313 & Male & 23 & September 2009 - June 2010 & 0.09 & 0.62 & 206 \\
\hline 334 & Male & 40 & August 2009 - October 2010 & 0.89 & 3.55 & 45 \\
\hline 353 & Juvenile & 4 & January 2010 - April 2010 & Burie & flood & 1 \\
\hline 374 & Male & 49 & July 2009 - November 2010 & 0.16 & 1.32 & 20 \\
\hline 393 & Female & 36 & September 2009 - May 2011 & 0.47 & 36.97 & 200 \\
\hline 413 & Male & 55 & July 2009 - July 2011 & 0.54 & 5.29 & 235 \\
\hline 432 & Female & 8 & September 2010 - March 2011 & Died during & e/thaw cycles & 17 \\
\hline
\end{tabular}


Table 2 continued

\begin{tabular}{|c|c|c|c|c|c|c|}
\hline 454 & Male & 75 & June 2009 - July 2011 & 0.52 & 10.37 & 177 \\
\hline 473 & Male & 38 & July 2009 - March 2011 & 4.63 & 6.13 & 68 \\
\hline 494 & Male & 61 & July 2009 - August 2011 & 1.20 & 4.10 & 38 \\
\hline 513 & Female & 40 & September 2009 - June 2011 & 1.00 & 4.28 & 245 \\
\hline 534 & Juvenile & 10 & August 2009 - June 2010 & \multicolumn{2}{|c|}{ No longer heard } & 14 \\
\hline $556 \mathrm{a}$ & Juvenile & 9 & September 2009 - April 2010 & \multicolumn{2}{|c|}{ Shed transmitter } & 27 \\
\hline $556 \mathrm{~b}$ & Juvenile & 39 & May 2010 - August 2011 & 0.56 & 6.43 & 86 \\
\hline 574 & Male & 25 & September 2009 - August 2010 & 0.33 & 4.46 & 24 \\
\hline 594 & Juvenile & 3 & January 2010 - March 2010 & \multicolumn{2}{|c|}{ No longer heard } & 13 \\
\hline 613 & Female & 42 & July 2009 - October 2010 & 0.87 & 4.50 & 190 \\
\hline 633 & Male & 10 & October 2009 - May 2010 & \multicolumn{2}{|c|}{ No longer heard } & 35 \\
\hline 653 & Male & 38 & November 2009 - June 2011 & 0.53 & 3.21 & 65 \\
\hline 674 & Male & 31 & October 2009 - April 2011 & 0.16 & 2.93 & 136 \\
\hline 693 & Female & 55 & October 2009 - July 2011 & 1.33 & 7.77 & 115 \\
\hline 712 & Female & 44 & July 2009 - April 2011 & 2.09 & 7.28 & 226 \\
\hline 732 & Male & 61 & July 2009 - June 2011 & 0.85 & 3.73 & 166 \\
\hline 753 & Male & 2 & July 2009 & \multicolumn{2}{|c|}{ No longer heard } & 18 \\
\hline 775 & Male & 44 & August 2009 - March 2011 & 1.25 & 8.74 & 33 \\
\hline 794 & Male & 31 & June 2009 - May 2010 & 0.14 & 1.38 & 19 \\
\hline
\end{tabular}


Table 3. Structural vegetative characteristics measured at random plots $(n=110)$ and wood turtle plots $(n=110)$ along a $13.7-\mathrm{km}$ reach of the Cacapon River, West Virginia, USA during spring 2009 to summer 2011. The variables recorded within $1-\mathrm{m}^{2}$ plots at the corners of a 10× 10-m plot within a 100-m radius survey circle were: \% canopy cover (CC), \% bare ground and rock cover (BGR), \% leaf litter cover (LL), \% woody debris cover (WD), and vertical density (VD, cm). Measurements were averaged for the whole plot. Means followed by the same letter are not significantly different (Bonferroni correction: $\alpha=0.05 / 5$ tests $=0.01$ ).

\begin{tabular}{|c|c|c|c|c|c|c|c|c|c|c|c|c|c|c|c|c|c|c|c|c|}
\hline \multirow[b]{3}{*}{ Variable } & \multicolumn{4}{|c|}{ Plot Type } & \multirow[b]{3}{*}{$F$} & \multirow[b]{3}{*}{$P$} & \multicolumn{4}{|c|}{ Season } & \multirow[b]{3}{*}{$F$} & \multirow[b]{3}{*}{$P$} & \multicolumn{6}{|c|}{ Year } & \multirow[b]{3}{*}{$F$} & \multirow[b]{3}{*}{$P$} \\
\hline & \multicolumn{2}{|c|}{ Turtle } & \multicolumn{2}{|c|}{ Random } & & & \multicolumn{2}{|c|}{ Spring } & \multicolumn{2}{|c|}{ Summer } & & & \multicolumn{2}{|c|}{2009} & \multicolumn{2}{|c|}{2010} & \multicolumn{2}{|c|}{2011} & & \\
\hline & $\bar{x}$ & SE & $\overline{\bar{x}}$ & SE & & & $\overline{\bar{x}}$ & SE & $\bar{x}$ & SE & & & $\overline{\bar{x}}$ & SE & $\bar{x}$ & SE & $\bar{x}$ & SE & & \\
\hline $\mathrm{CC}$ & $57.2 \mathrm{~A}$ & 2.7 & $54.9 \mathrm{~A}$ & 2.8 & 2.94 & 0.088 & $60.5 \mathrm{~A}$ & 2.6 & $52.0 \mathrm{~A}$ & 2.8 & 3.95 & 0.088 & $58.3 \mathrm{~A}$ & 3.7 & $52.2 \mathrm{~B}$ & 2.7 & $63.9 \mathrm{C}$ & 3.9 & 11.49 & $<0.001$ \\
\hline BGR & $5.4 \mathrm{~A}$ & 0.4 & $12.3 \mathrm{~B}$ & 1.2 & 18.47 & $<0.001$ & $12.5 \mathrm{~A}$ & 1.2 & $5.6 \mathrm{~A}$ & 0.4 & 0.70 & 0.403 & $13.5 \mathrm{~A}$ & 2.0 & $6.7 \mathrm{~A}$ & 0.5 & $9.4 \mathrm{~A}$ & 1.5 & 1.68 & 0.188 \\
\hline LL & $5.0 \mathrm{~A}$ & 0.3 & $5.4 \mathrm{~A}$ & 0.3 & 1.43 & 0.233 & $5.1 \mathrm{~A}$ & 0.4 & $5.2 \mathrm{~A}$ & 0.3 & 0.14 & 0.708 & $5.1 \mathrm{~A}$ & 0.5 & $5.4 \mathrm{~A}$ & 0.3 & $4.7 \mathrm{~A}$ & 0.7 & 0.38 & 0.684 \\
\hline WD & $3.4 \mathrm{~A}$ & 0.3 & $4.0 \mathrm{~A}$ & 0.3 & 3.27 & 0.072 & $3.8 \mathrm{~A}$ & 0.3 & $3.6 \mathrm{~A}$ & 0.3 & 2.02 & 0.156 & $3.4 \mathrm{~A}$ & 0.4 & $3.7 \mathrm{~A}$ & 0.3 & $3.9 \mathrm{~A}$ & 0.6 & 3.47 & 0.033 \\
\hline VD & $75.0 \mathrm{~A}$ & 2.1 & $65.1 \mathrm{~B}$ & 2.2 & 8.09 & 0.005 & $67.4 \mathrm{~A}$ & 2.3 & $72.4 \mathrm{~A}$ & 2.1 & 0.56 & 0.455 & $66.4 \mathrm{~A}$ & 3.0 & $71.6 \mathrm{~A}$ & 2.0 & $70.2 \mathrm{~B}$ & 4.2 & 5.73 & 0.004 \\
\hline
\end{tabular}


Table 4. Diversity and richness means and standard errors (SE) for overall (natives and exotics) vegetative layers (i.e., field: all plants $<1 \mathrm{~m}$ tall, shrub: woody plants $>1 \mathrm{~m}$ tall and $<5 \mathrm{~cm}$ diameter at breast height (dbh), and tree: woody plants $>5 \mathrm{~cm}$ dbh) associated with wood turtle plots $(n=110)$ and random plots $(n=110)$ sampled along a 13.7-km reach of the Cacapon River, West Virginia, USA during spring 2009 to summer 2011. Means followed by the same letter are not significantly different (Bonferroni correction: $\alpha=$ 0.05/6 tests $=0.008)$. Differences in main effect means were not interpreted when significant interactions occurred.

\begin{tabular}{|c|c|c|c|c|c|c|c|c|c|c|c|c|c|}
\hline \multirow[b]{3}{*}{ Variable } & \multirow[b]{3}{*}{ Strata } & \multicolumn{4}{|c|}{ Plot Type } & \multirow[b]{3}{*}{$F$} & \multirow[b]{3}{*}{$P$} & \multicolumn{4}{|c|}{ Season } & \multirow[b]{3}{*}{$F$} & \multirow[b]{3}{*}{$P$} \\
\hline & & \multicolumn{2}{|c|}{ Turtle } & \multicolumn{2}{|c|}{ Random } & & & \multicolumn{2}{|c|}{ Spring } & \multicolumn{2}{|c|}{ Summer } & & \\
\hline & & $\bar{x}$ & $\mathrm{SE}$ & $\bar{x}$ & $\mathrm{SE}$ & & & $\bar{x}$ & SE & $\bar{x}$ & SE & & \\
\hline \multicolumn{14}{|l|}{ Diversity } \\
\hline & Field & 2.01 & 0.06 & 1.92 & 0.05 & 2.64 & 0.106 & $1.87 \mathrm{~A}$ & 0.06 & $2.04 \mathrm{~A}$ & 0.05 & 1.74 & 0.188 \\
\hline & Shrub & 0.33 & 0.04 & 0.22 & 0.03 & 2.14 & 0.145 & $0.15 \mathrm{~A}$ & 0.03 & $0.38 \mathrm{~A}$ & 0.04 & 0.85 & 0.357 \\
\hline & Tree & $0.46 \mathrm{~A}$ & 0.05 & $0.26 \mathrm{~A}$ & 0.04 & 5.53 & 0.020 & $0.26 \mathrm{~A}$ & 0.04 & $0.45 \mathrm{~A}$ & 0.05 & 0.52 & 0.470 \\
\hline \multicolumn{14}{|l|}{ Richness } \\
\hline & Field & 12.66 & 0.58 & 11.55 & 0.43 & 3.81 & 0.052 & $11.20 \mathrm{~A}$ & 0.46 & $1.91 \mathrm{~A}$ & 0.54 & 1.65 & 0.200 \\
\hline & Shrub & $1.32 \mathrm{~A}$ & 0.12 & $1.16 \mathrm{~A}$ & 0.12 & 0.26 & 0.614 & $0.81 \mathrm{~A}$ & 0.10 & $1.62 \mathrm{~A}$ & 0.13 & 0.71 & 0.401 \\
\hline & Tree & 1.67 & 0.15 & 1.07 & 0.11 & 3.39 & 0.067 & 1.02 & 0.14 & 1.68 & 0.12 & 3.73 & 0.055 \\
\hline
\end{tabular}


Table 4 continued

\begin{tabular}{|c|c|c|c|c|c|c|c|}
\hline \multicolumn{6}{|c|}{ Year } & \multirow[b]{3}{*}{$F$} & \multirow[b]{3}{*}{$P$} \\
\hline \multicolumn{2}{|c|}{2009} & \multicolumn{2}{|c|}{2010} & \multicolumn{2}{|c|}{2011} & & \\
\hline $\bar{x}$ & SE & $\bar{x}$ & $\mathrm{SE}$ & $\bar{x}$ & SE & & \\
\hline 1.88 & 0.07 & 2.11 & 0.05 & 1.64 & 0.10 & 11.06 & $<0.001$ \\
\hline 0.09 & 0.04 & 0.39 & 0.04 & 0.17 & 0.05 & 6.73 & 0.001 \\
\hline $0.26 \mathrm{~A}$ & 0.07 & $0.42 \mathrm{~A}$ & 0.04 & $0.32 \mathrm{~A}$ & 0.07 & 1.60 & 0.205 \\
\hline 11.28 & 0.53 & 13.45 & 0.49 & 9.34 & 0.83 & 10.50 & $<0.001$ \\
\hline $0.58 \mathrm{~A}$ & 0.12 & $1.68 \mathrm{~A}$ & 0.12 & $0.80 \mathrm{AB}$ & 0.14 & 8.89 & $<0.001$ \\
\hline $1.13 \mathrm{~A}$ & 0.23 & $1.57 \mathrm{~A}$ & $0.11 \mathrm{~A}$ & 1.11 & 0.20 & 1.28 & 0.281 \\
\hline
\end{tabular}


Table 5. Multiple comparison contrasts (significant and interaction simple effects [within years]) related to vegetation (overall [native and exotic] and natives-only) surveys associated with wood turtle plots $(\mathrm{T} ; n=110)$ and random plots $(\mathrm{R} ; n=110)$ sampled along a $13.7-\mathrm{km}$ reach of the Cacapon River, West Virginia, USA during spring 2009 to summer 2011. The vegetative layers were field: \% cover of woody and herbaceous plants < $1 \mathrm{~m}$ tall; shrub: abundance of woody plants $>1 \mathrm{~m}$ tall, $<5 \mathrm{~cm}$ in diameter at breast height (dbh); and tree: abundance of woody plants $>5 \mathrm{~cm}$ dbh per 100-m radius survey circle.

\begin{tabular}{|c|c|c|c|}
\hline Stratus & Contrast & Difference & $P$ \\
\hline \multicolumn{4}{|l|}{ Overall Field Diversity } \\
\hline & T 2009 - R 2009 & 0.290 & 0.356 \\
\hline & T 2010 - R 2010 & 0.149 & 0.634 \\
\hline & T $2011-$ R 2011 & 0.355 & 0.243 \\
\hline & Т 2009 - Т 2011 & 0.586 & 0.003 \\
\hline & R 2010 - T 2011 & 0.491 & 0.006 \\
\hline & T $2010-$ T 2011 & 0.639 & $<0.001$ \\
\hline \multicolumn{4}{|l|}{ Native Field Diversity } \\
\hline & $2010-2011$ & 0.291 & 0.008 \\
\hline \multicolumn{4}{|l|}{ Overall Field Richness } \\
\hline & T $2009-$ R 2009 & 2.427 & 0.438 \\
\hline & T 2010 - R 2010 & 2.197 & 0.116 \\
\hline & T 2011 - R 2011 & 4.076 & 0.059 \\
\hline & T 2010 - R 2009 & 3.559 & 0.020 \\
\hline & Т $2009-$ T 2011 & 5.380 & 0.002 \\
\hline & R 2010 - T 2011 & 4.314 & 0.008 \\
\hline & T $2010-$ T 2011 & 6.511 & $<0.001$ \\
\hline \multicolumn{4}{|l|}{ Native Field Richness } \\
\hline & T 2009 - R 2009 & 2.260 & 0.188 \\
\hline & T 2010 - R 2010 & 1.684 & 0.092 \\
\hline & T 2011 - R 2011 & 2.747 & 0.110 \\
\hline & T 2010 - R 2009 & 2.858 & 0.008 \\
\hline & T $2009-$ T 2011 & 3.583 & 0.009 \\
\hline & T $2010-$ T 2011 & 4.181 & \\
\hline \multicolumn{4}{|l|}{ Overall Shrub Diversity } \\
\hline & T 2009 - R 2009 & 0.012 & 1.000 \\
\hline & T 2010 - R 2010 & 0.092 & 0.006 \\
\hline & T 2011 - R 2011 & 0.047 & 0.892 \\
\hline & T 2010 - R 2009 & 0.120 & 0.006 \\
\hline & Т $2010-$ T 2009 & 0.108 & 0.017 \\
\hline & T $2010-$ T 2011 & 0.106 & 0.053 \\
\hline \multicolumn{4}{|l|}{ Overall Shrub Richness } \\
\hline
\end{tabular}


Table 5 continued

\begin{tabular}{|c|c|c|c|}
\hline \multicolumn{4}{|l|}{ Overall Tree Richness } \\
\hline & T Spring - R Spring & 0.444 & 0.001 \\
\hline & T Summer - R Summer & 0.154 & 0.479 \\
\hline & R Summer - R Spring & 0.574 & $<0.001$ \\
\hline & T Summer - R Spring & 0.420 & $<0.001$ \\
\hline \multicolumn{4}{|l|}{ Native Tree Richness } \\
\hline & T $2009-$ R 2009 & 0.133 & 0.828 \\
\hline & T 2010 - R 2010 & 0.106 & 0.683 \\
\hline & T 2011 - R 2011 & 0.343 & 0.054 \\
\hline & T 2010 - R 2009 & 0.317 & 0.010 \\
\hline & R 2011 - R 2009 & 0.443 & 0.002 \\
\hline
\end{tabular}


Table 6. Diversity and richness means and standard errors (SE) for native vegetative layers (i.e., field: all plants $<1 \mathrm{~m}$ tall, shrub: woody plants $>1 \mathrm{~m}$ tall and $<5 \mathrm{~cm}$ diameter at breast height $(\mathrm{dbh})$, and tree: woody plants $>5 \mathrm{~cm} \mathrm{dbh}$ ) associated with wood turtle plots $(n=110)$ and random plots $(n=110)$ sampled along a 13.7-km reach of the Cacapon River, West Virginia, USA during spring 2009 to summer 2011. Means followed by the same letter are not significantly different (Bonferroni correction: $\alpha=0.05 / 6$ tests $=$ 0.008). Differences in main effect means were not interpreted when significant interactions occurred.

\begin{tabular}{|c|c|c|c|c|c|c|c|c|c|c|c|c|c|}
\hline \multirow[b]{3}{*}{ Variable } & \multirow[b]{3}{*}{ Strata } & \multicolumn{4}{|c|}{ Plot Type } & \multirow[b]{3}{*}{$F$} & \multirow[b]{3}{*}{$P$} & \multicolumn{4}{|c|}{ Season } & \multirow[b]{3}{*}{$F$} & \multirow[b]{3}{*}{$P$} \\
\hline & & \multicolumn{2}{|c|}{ Turtle } & \multicolumn{2}{|c|}{ Random } & & & \multicolumn{2}{|c|}{ Spring } & \multicolumn{2}{|c|}{ Summer } & & \\
\hline & & $\bar{x}$ & SE & $\bar{x}$ & SE & & & $\bar{x}$ & $\mathrm{SE}$ & $\bar{x}$ & SE & & \\
\hline \multicolumn{14}{|l|}{ Diversity } \\
\hline & Field & $1.67 \mathrm{~A}$ & 0.06 & $1.54 \mathrm{~A}$ & 0.05 & 2.47 & 0.12 & $1.49 \mathrm{~A}$ & 0.06 & $1.71 \mathrm{~A}$ & 0.05 & 0.24 & 0.627 \\
\hline & Shrub & $0.08 \mathrm{~A}$ & 0.02 & $0.04 \mathrm{~A}$ & 0.02 & 0.09 & 0.770 & $0.01 \mathrm{~A}$ & 0.01 & $0.11 \mathrm{~A}$ & 0.02 & 2.88 & 0.091 \\
\hline & Tree & $0.38 \mathrm{~A}$ & 0.05 & $0.31 \mathrm{~A}$ & 0.05 & 0.50 & 0.481 & $0.25 \mathrm{~A}$ & 0.04 & $0.43 \mathrm{~A}$ & 0.05 & 0.58 & 0.448 \\
\hline \multicolumn{14}{|l|}{ Richness } \\
\hline & Field & 8.65 & 0.42 & 7.65 & 0.32 & 3.30 & 0.070 & $7.28 \mathrm{~A}$ & 0.32 & $8.91 \mathrm{~A}$ & 0.40 & 0.09 & 0.764 \\
\hline & Shrub & $0.53 \mathrm{~A}$ & 0.08 & $0.44 \mathrm{~A}$ & 0.08 & 0.03 & 0.872 & $0.24 \mathrm{~A}$ & 0.04 & $0.69 \mathrm{~A}$ & 0.09 & 3.09 & 0.080 \\
\hline & Tree & 1.35 & 0.12 & 1.31 & 0.14 & 0.01 & 0.915 & $1.07 \mathrm{~A}$ & 0.11 & $1.56 \mathrm{~A}$ & 0.14 & 0.21 & 0.651 \\
\hline
\end{tabular}


Table 6 continued

\begin{tabular}{|c|c|c|c|c|c|c|c|}
\hline \multicolumn{6}{|c|}{ Year } & \multirow[b]{3}{*}{$F$} & \multirow[b]{3}{*}{$P$} \\
\hline \multicolumn{2}{|c|}{2009} & \multicolumn{2}{|c|}{2010} & \multicolumn{2}{|c|}{2011} & & \\
\hline $\bar{x}$ & SE & $\bar{x}$ & SE & $\bar{x}$ & SE & & \\
\hline $1.49 \mathrm{AB}$ & 0.07 & $1.75 \mathrm{~A}$ & 0.05 & $1.33 \mathrm{~B}$ & 0.10 & 7.02 & 0.001 \\
\hline $0.01 \mathrm{~A}$ & 0.01 & $0.11 \mathrm{~A}$ & 0.02 & $0.00 \mathrm{~A}$ & 0.00 & 1.43 & 0.241 \\
\hline $0.15 \mathrm{~A}$ & 0.04 & $0.42 \mathrm{~A}$ & 0.05 & $0.36 \mathrm{~A}$ & 0.07 & 3.64 & 0.028 \\
\hline 7.34 & 0.41 & 9.12 & 0.37 & 6.39 & 0.56 & 8.65 & $<0.001$ \\
\hline $0.25 \mathrm{~A}$ & 0.07 & $0.68 \mathrm{~A}$ & 0.09 & $0.20 \mathrm{~A}$ & 0.06 & 1.80 & 0.138 \\
\hline 0.68 & 0.13 & 1.61 & 0.14 & 1.34 & 0.19 & 6.90 & 0.002 \\
\hline
\end{tabular}


Table 7. Seasonal proportions of the overall wood turtle $(n=1,443$ captures) population and of males $(n=751)$, females $(n=524)$, and juveniles $(n=168)$ based on terrestrial $(\mathrm{T})$ or aquatic $(\mathrm{A})$ occurrence along a 13.7-km reach of the Cacapon River, West Virginia, USA during spring 2009 to summer 2011.

\begin{tabular}{|c|c|c|c|c|c|c|c|c|}
\hline \multirow[b]{2}{*}{ Season } & \multicolumn{2}{|c|}{ Population } & \multicolumn{2}{|c|}{ Male } & \multicolumn{2}{|c|}{ Female } & \multicolumn{2}{|c|}{ Juvenile } \\
\hline & $\mathrm{A}$ & $\mathrm{T}$ & $\mathrm{A}$ & $\mathrm{T}$ & $\mathrm{A}$ & $\mathrm{T}$ & $\mathrm{A}$ & $\mathrm{T}$ \\
\hline Spring & 0.36 & 0.64 & 0.25 & 0.75 & 0.46 & 0.54 & 0.33 & 0.67 \\
\hline Summer & 0.23 & 0.77 & 0.31 & 0.69 & 0.14 & 0.86 & 0.14 & 0.86 \\
\hline Autumn & 0.59 & 0.41 & 0.63 & 0.37 & 0.52 & 0.48 & 0.58 & 0.42 \\
\hline Winter & 0.99 & 0.01 & 0.98 & 0.02 & 1.00 & 0.00 & 1.00 & 0.00 \\
\hline
\end{tabular}


Table 8. Environmental variables (mean, standard error, and min - max) related to wood turtles $(n=1,419$ captures) being aquatic (A) or terrestrial (T) depending on season along a 13.7-km reach of the Cacapon River, West Virginia, USA during spring 2009 to summer 2011. Headings are as follows: soil temperature $(\mathrm{ST})$, air temperature $(\mathrm{AT})$, water temperature $(\mathrm{WT})$, soil moisture $(\mathrm{SM} ; 1=\mathrm{dry}, 10=$ saturated), and relative humidity $(\mathrm{RH})$.

\begin{tabular}{|c|c|c|c|c|c|c|c|c|c|c|c|c|c|}
\hline \multirow[b]{2}{*}{ Season } & \multirow[b]{2}{*}{ Location } & \multicolumn{4}{|c|}{$\mathrm{ST}\left({ }^{\circ} \mathrm{C}\right)$} & \multicolumn{4}{|c|}{$\mathrm{AT}\left({ }^{\circ} \mathrm{C}\right)$} & \multicolumn{4}{|c|}{$\mathrm{WT}\left({ }^{\circ} \mathrm{C}\right)$} \\
\hline & & $\bar{x}$ & $\mathrm{SE}$ & Min & $\operatorname{Max}$ & $\bar{x}$ & SE & Min & $\operatorname{Max}$ & $\bar{x}$ & SE & Min & Max \\
\hline \multirow[t]{2}{*}{ Spring } & $\mathrm{A}$ & 12.3 & 5.0 & 5.0 & 27.0 & 16.2 & 8.3 & 5.1 & 35.5 & 12.0 & 4.4 & 7.0 & 25.5 \\
\hline & $\mathrm{T}$ & 19.7 & 4.3 & 10.0 & 33.0 & 26.7 & 6.5 & 12.2 & 40.6 & 18.2 & 3.7 & 11.0 & 27.0 \\
\hline \multirow[t]{2}{*}{ Summer } & A & 23.4 & 3.1 & 17.0 & 34.0 & 29.2 & 4.1 & 20.0 & 42.0 & 23.6 & 2.6 & 19.0 & 29.0 \\
\hline & $\mathrm{T}$ & 22.6 & 2.8 & 16.0 & 31.0 & 29.8 & 11.0 & 18.5 & 46.0 & 24.2 & 2.7 & 17.0 & 34.0 \\
\hline \multirow[t]{2}{*}{ Autumn } & A & 10.6 & 6.3 & -2.0 & 23.0 & 14.6 & 5.7 & 1.6 & 27.0 & 10.3 & 3.7 & 1.0 & 19.0 \\
\hline & $\mathrm{T}$ & 13.9 & 3.7 & 7.0 & 25.0 & 18.0 & 5.6 & 5.7 & 29.5 & 13.6 & 3.5 & 7.0 & 18.5 \\
\hline \multirow[t]{2}{*}{ Winter } & A & 4.8 & 4.3 & 0.0 & 13.5 & 9.3 & 6.9 & -3.0 & 34.4 & 4.6 & 3.8 & 0.0 & 11.0 \\
\hline & $\mathrm{T}$ & 5.0 & 3.5 & 0.0 & 10.0 & 4.7 & 5.2 & -2.7 & 12.0 & 4.0 & 2.8 & 0.0 & 8.0 \\
\hline
\end{tabular}


Table 8 continued

\begin{tabular}{|c|c|c|c|c|c|c|c|}
\hline \multicolumn{4}{|c|}{ SM } & \multicolumn{4}{|c|}{ RH } \\
\hline$\overline{\bar{x}}$ & $\mathrm{SE}$ & Min & Max & $\bar{x}$ & SE & Min & Max \\
\hline 6.5 & 2.0 & 1.0 & 10.0 & 60.0 & 31.1 & 13.6 & 98.6 \\
\hline 6.0 & 2.6 & 1.0 & 10.0 & 69.0 & 20.4 & 15.0 & 99.5 \\
\hline 4.3 & 2.5 & 1.0 & 10.0 & 61.3 & 16.8 & 19.0 & 95.5 \\
\hline 3.9 & 2.8 & 1.0 & 10.0 & 71.5 & 15.1 & 18.0 & 97.7 \\
\hline 4.9 & 2.6 & 1.0 & 10.0 & 61.0 & 21.1 & 20.0 & 96.5 \\
\hline 5.3 & 2.6 & 1.0 & 10.0 & 67.6 & 21.8 & 23.9 & 97.5 \\
\hline 3.2 & 3.1 & 1.0 & 10.0 & 63.9 & 26.2 & 10.0 & 100.0 \\
\hline 4.5 & 2.5 & 1.0 & 8.0 & 52.5 & 24.4 & 18.0 & 87.0 \\
\hline
\end{tabular}


Table 9. Locations of mating wood turtle pairs $(n=28)$ along a $13.7-\mathrm{km}$ reach of the Cacapon River, West Virginia, USA during late March to early June (Spring) and late August to early November (Autumn), 2009 to 2011.

\begin{tabular}{|c|c|c|c|c|}
\hline Season & Location & $\begin{array}{c}\text { Distance from Water } \\
(\mathrm{m})\end{array}$ & $\begin{array}{c}\text { Distance from Shore } \\
(\mathrm{m})\end{array}$ & Water Depth (m) \\
\hline Autumn & Aquatic & & 1.00 & 0.30 \\
\hline Autumn & Aquatic & & 0.20 & 0.25 \\
\hline Autumn & Aquatic & & 1.00 & 0.30 \\
\hline Autumn & Aquatic & & 1.50 & 0.50 \\
\hline Autumn & Aquatic & & 2.00 & 0.50 \\
\hline Autumn & Aquatic & & 2.00 & 0.50 \\
\hline Autumn & Aquatic & & 7.00 & 0.75 \\
\hline Autumn & Aquatic & & 7.00 & 0.75 \\
\hline Autumn & Aquatic & & 10.00 & 1.00 \\
\hline Autumn & Terrestrial & 3.00 & & \\
\hline Autumn & Terrestrial & 0.00 & & \\
\hline Autumn & Terrestrial & 2.00 & & \\
\hline Autumn & Terrestrial & 10.00 & & \\
\hline Autumn & Terrestrial & 15.00 & & \\
\hline Autumn & Terrestrial & 15.00 & & \\
\hline Autumn & Terrestrial & 20.00 & & \\
\hline Autumn & Terrestrial & 20.00 & & \\
\hline
\end{tabular}


Table 9 continued

\begin{tabular}{|c|c|c|c|c|}
\hline Autumn & Terrestrial & 30.00 & & \\
\hline Spring & Aquatic & & 0.30 & 0.30 \\
\hline Spring & Aquatic & & 0.00 & 0.25 \\
\hline Spring & Aquatic & & 0.00 & 0.25 \\
\hline Spring & Aquatic & & 0.50 & 0.25 \\
\hline Spring & Aquatic & & 1.00 & 0.25 \\
\hline Spring & Aquatic & & 2.00 & 0.30 \\
\hline Spring & Aquatic & & 2.00 & 0.50 \\
\hline Spring & Aquatic & & 3.00 & 1.00 \\
\hline Spring & Aquatic & & 7.00 & 1.00 \\
\hline Spring & Terrestrial & 20.00 & & \\
\hline
\end{tabular}



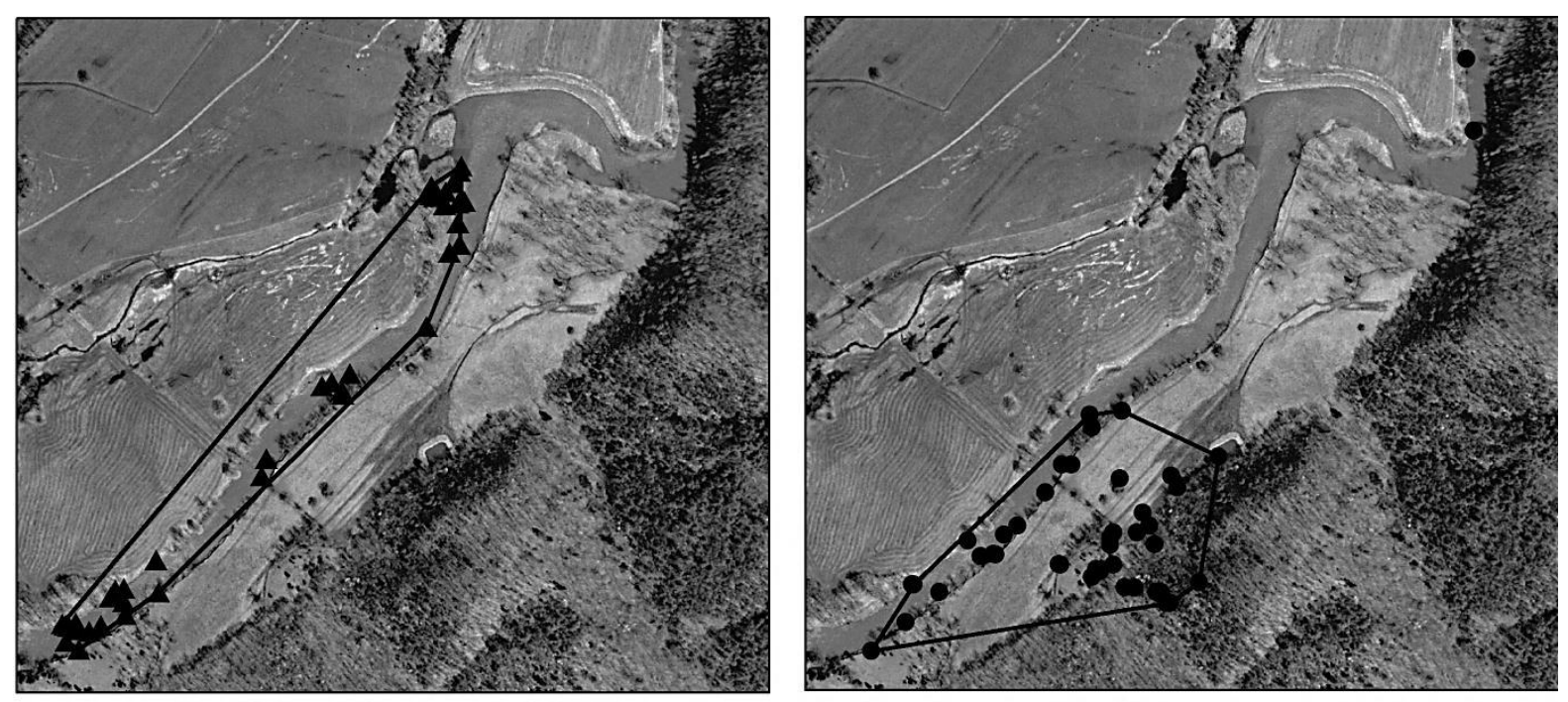

$100 \quad 200 \quad 400$ Meters

Triangle: Male Turtle 473 95\% Home Range: 6.13 ha

Circle: Female Turtle 712 95\% Home Range: 7.28 ha

Square: Juvenile Turtle 556b 95\% Home Range: 6.43 ha

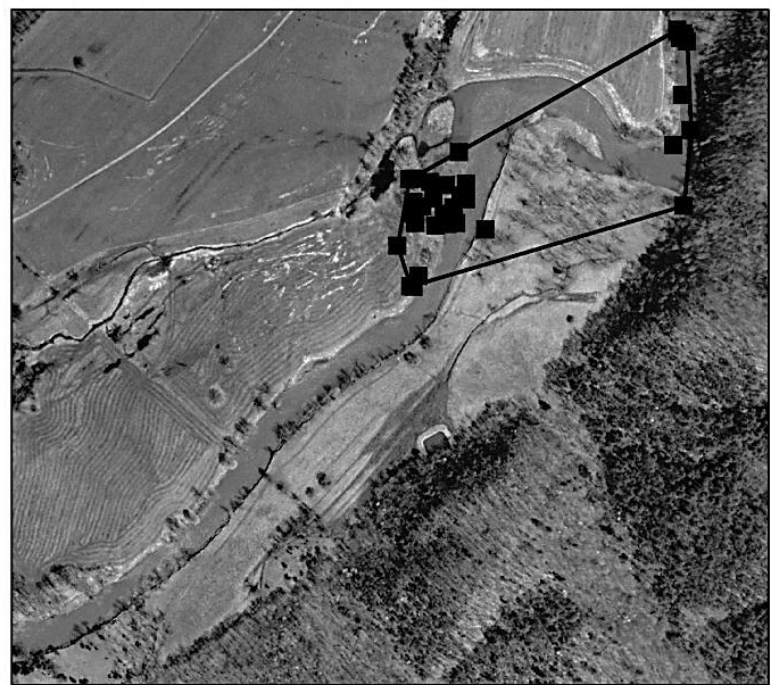

Figure 1. Examples of home ranges for a male, female, and juvenile wood turtle in West Virginia, USA during spring 2009 to summer 2011. The Cacapon River flows through the center of each picture. Non-forested patches are agricultural land: hay fields, cornfields, and cattle pasture. The forested area to the right of each picture is mountainous. 

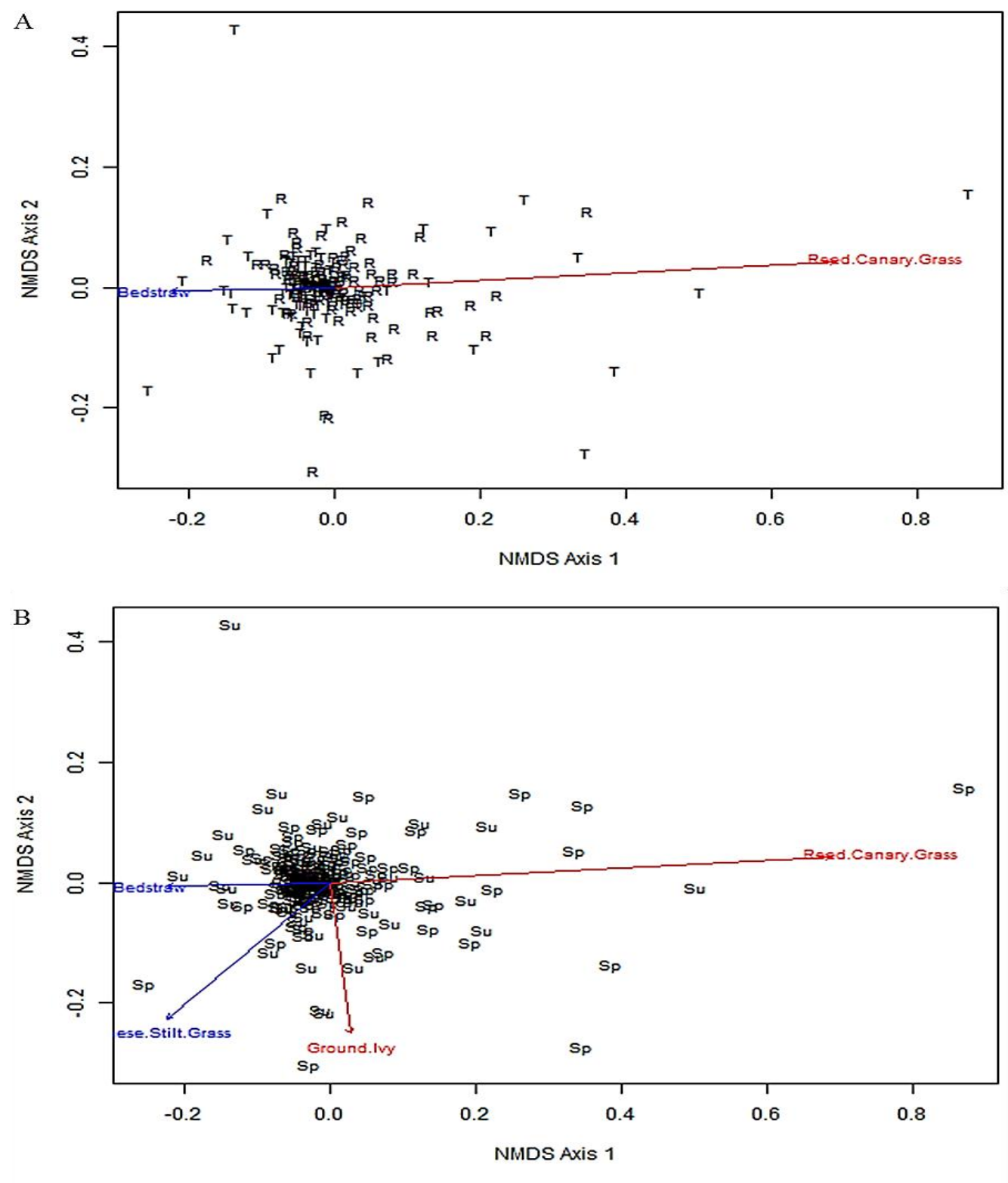

Figure 2. Non-metric multidimensional scaling (NMDS) plot of indicator species vegetation that differentiated the overall (natives and exotics) field (all plants $<1 \mathrm{~m}$ tall) community (A) between plots with wood turtles (T; blue: bedstraw) and random plots (R; red: reed canary grass) and (B) in spring (Sp;red: reed canary grass and ground ivy) and summer ( $\mathrm{Su}$; blue: Japanese stilt grass and bedstraw) along the Cacapon River, West Virginia, USA. 
A
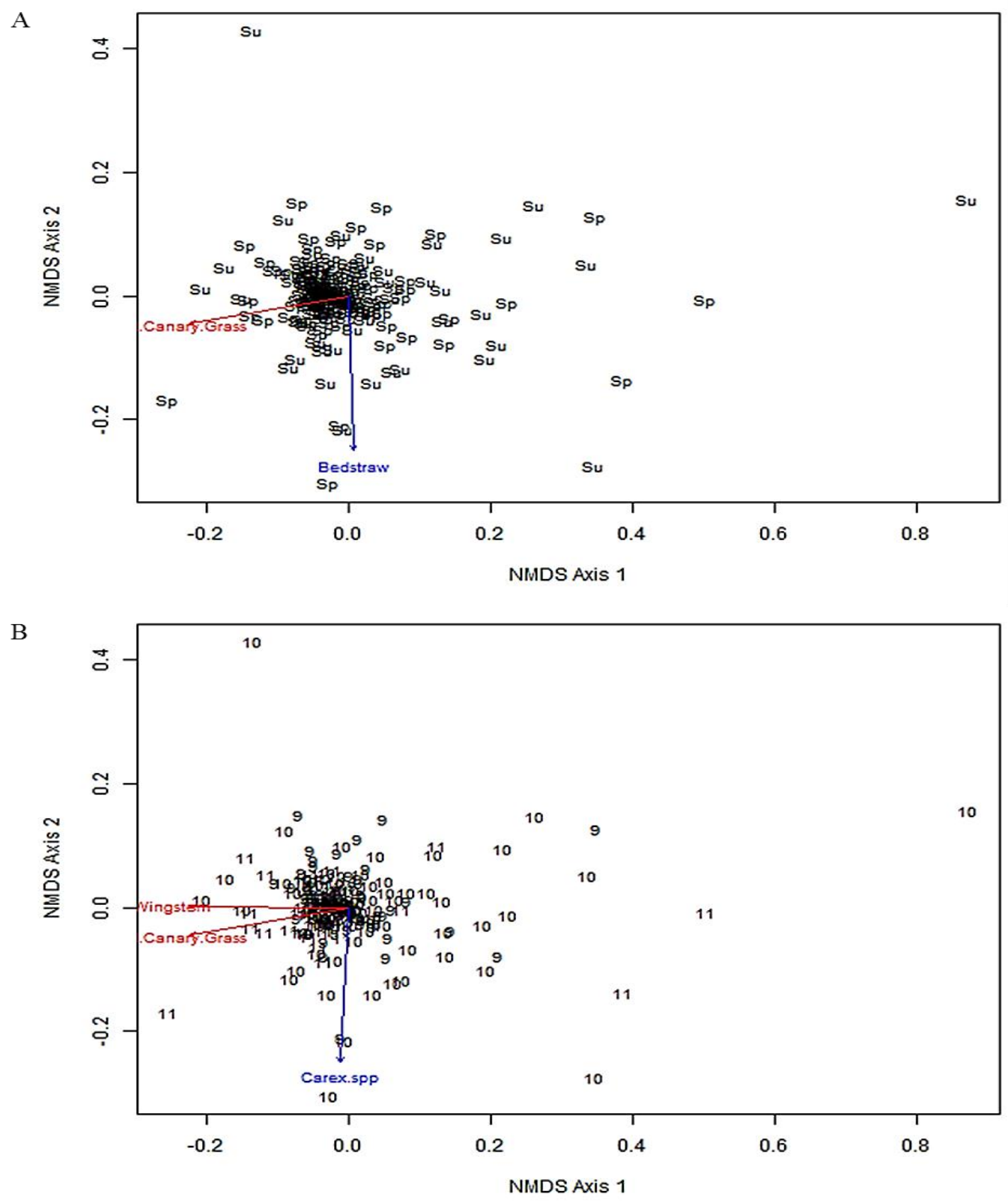

Figure 3. Non-metric multidimensional scaling (NMDS) plot of indicator species vegetation that differentiated the native field (all plants $<1 \mathrm{~m}$ tall) community (A) in spring (Sp; red: reed canary grass) and summer (Su; blue: bedstraw) and (B) in 2009 (9; blue: Carex spp.) and 2011 (11; red: Japanese stilt grass and bedstraw) along the Cacapon River, West Virginia, USA. No indicators were present for 2010 . 


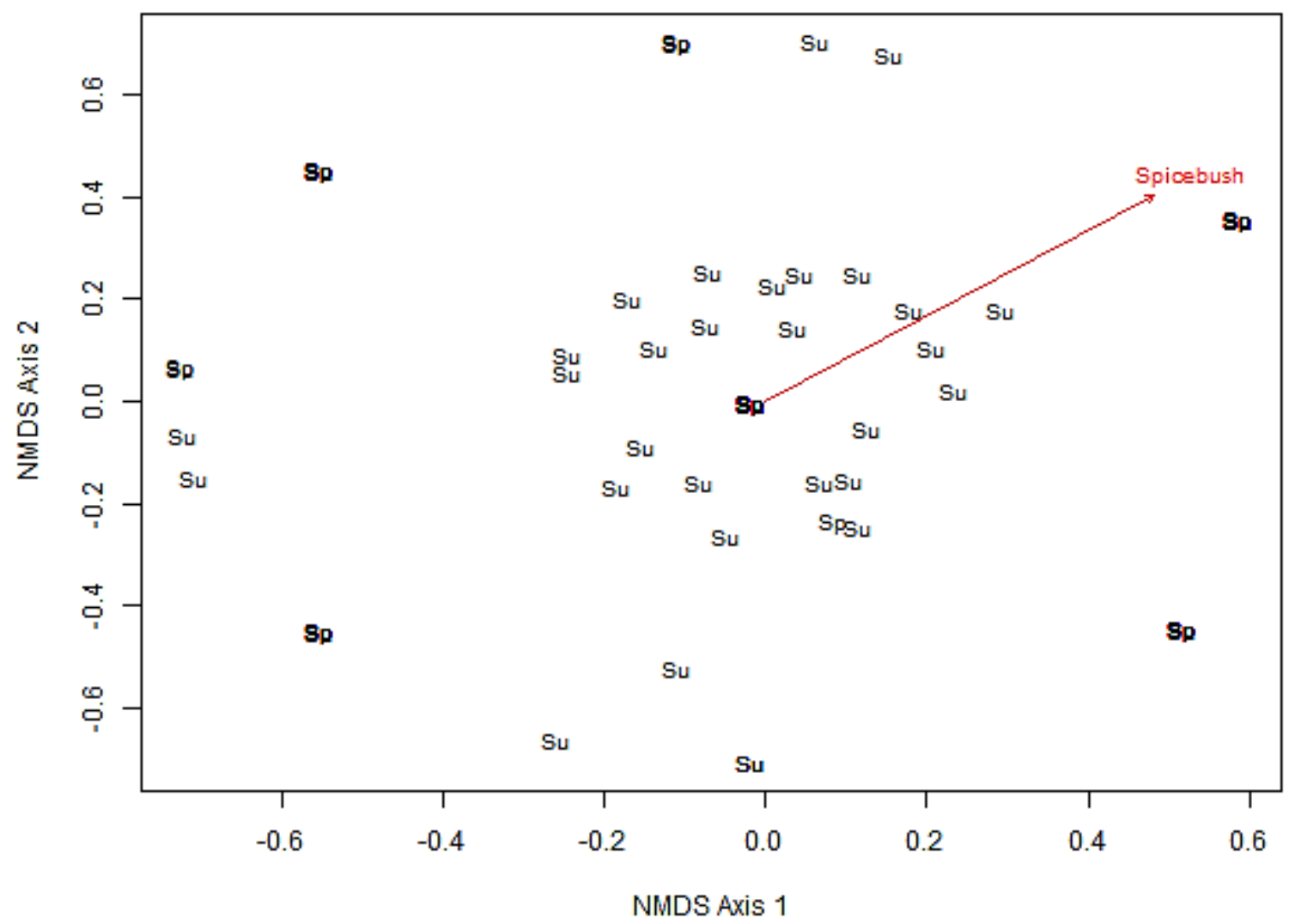

Figure 4. Non-metric multidimensional scaling (NMDS) plot of the indicator species that differentiated the native shrub (woody plants $>1 \mathrm{~m}$ tall and $<5 \mathrm{~cm}$ in diameter at breast height) community in spring and summer (Su; red: Spicebush) along the Cacapon River, West Virginia, USA during 2009 to 2011 . No indicators were present for spring. 

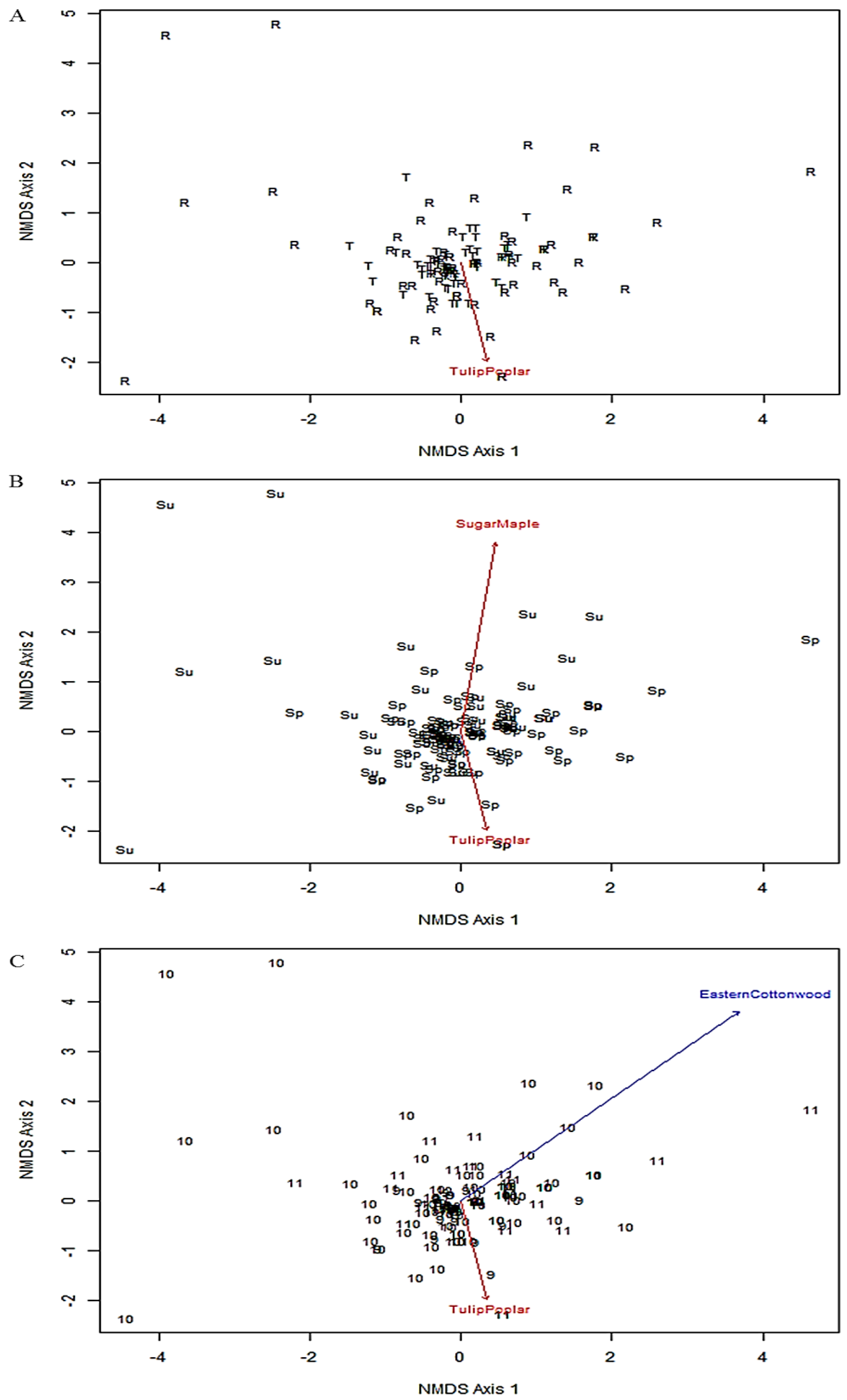
Figure 5. Non-metric multidimensional scaling (NMDS) plot of indicator species vegetation that differentiated the native tree ( $>5 \mathrm{~cm}$ diameter at breast height) community (A) between plots with wood turtles (T; red: tulip poplar) and random plots $(\mathrm{R}),(\mathrm{B})$ in spring $(\mathrm{Sp})$ and summer $(\mathrm{Su}$; red: sugar maple and tulip poplar), and (C) in 2009 (9), 2010 (10; red: tulip poplar), and 2011 (11; blue: eastern cottonwood) along the Cacapon River, West Virginia, USA. No indicators were present for random plots, spring, or 2009. 


\section{CHAPTER IV}

28 November 2012

Kathryn R. P. McCoard

West Virginia University

Division of Forestry and Natural Resources, P. O. Box 6125, Morgantown, WV 26506

Phone 740/464-1024

roamingwild@gmail.com

RH: McCoard et al.・ Range Limitations of Wood Turtles

Factors Affecting Wood Turtles at the Southern Limits of Their Range in the Central

\section{Appalachians}

KATHRYN R. P. MCCOARD West Virginia University, Division of Forestry and Natural Resources, P.O. Box 6125, Morgantown, West Virginia 26506 USA

NOAH S. MCCOARD Natural Resource Conservation Service, McMechen Service Center, One Ball Park Drive, McMechen, West Virginia 26040 USA

PHILIP J. TURK West Virginia University, Department of Statistics, P.O. Box 6330, Morgantown, West Virginia 26506 USA

JAMES T. ANDERSON West Virginia University, Division of Forestry and Natural Resources and Environmental Research Center, P.O. Box 6125, Morgantown, West Virginia 26506 $U S A^{l}$

1jim.anderson@mail.wvu.edu

Written in the style of:

The Journal of Wildlife Management 
ABSTRACT Boundaries of geographic ranges are formed by topographical features and environmental variables, limiting the distributions of species. Studies of limitations of wood turtles (Glyptemys insculpta) at the northern extent of their geographic range are common; however, few studies have been conducted to determine range limitations affecting the distribution of the species at the southern extent of its range. Our study objectives were to (1) determine aquatic and terrestrial habitat characteristics relevant to the presence or absence of the species, (2) determine the approximate southern geographic boundary of wood turtles in the Cacapon River Watershed, West Virginia, and (3) identify potential dispersal barriers to the west or south of the current range. We conducted random surveys along the Lost and North rivers during summer 2010. Of the 100 sites surveyed, $64 \%$ contained wood turtles. Proximity to the Cacapon River, elevation, stream depth, canopy cover, slope, and soil temperatures influenced the presence of wood turtles. Field layer species richness and diversity were higher in sites with turtles, especially along the North River. Shrub richness and tree diversity and richness were higher along the North River compared to the Lost River. Community composition differed between rivers, regardless of turtle status, in the field and shrub layers and differed in the site $\times$ river interaction in the tree layer. From our results, the primary factors limiting wood turtles at the southern limits of their range in West Virginia include inability to disperse over high elevations, agricultural influences decreasing habitat availability and turtle survivorship, and an intolerance to high temperatures. We recommend that in areas with agriculture along waterways where wood turtles occur, efforts be made to create, manage, and maintain riparian buffers that can provide essential terrestrial habitat and promote adult survivorship and population stability; these are important management and conservation goals for the species, particularly along their southern geographic border. 
KEY WORDS agricultural effects, dispersal limitations, Glyptemys insculpta, range limits, West Virginia.

The geographic range of a species can be considered to be the primary unit of biogeography (Brown et al. 1996). Barriers such as mountains, coastlines, deserts, and cold temperatures greatly influence features of geographic ranges, including size, shape, and position (Hecnar 1999). These features are influenced also by environmental variables and ecological functions that limit a species' distribution and abundance, aiding in the formation of the dynamic borders of geographic ranges (Brown et al. 1996). Reptile and amphibian populations affected by range edge-effects may be vulnerable to extirpation (Lehtinen et al. 2003) at faster rates than interior range populations where the environment is more stable and suitable for the species (Channell and Lomolino 2000). Peripheral populations can be important components to the overall species because they may be genetically adapted to the variable edge environment and can better respond to climate change through shifting the range boundary (Hunter and Hutchinson 1994).

Possibly intrinsic to a species are the ecological relations (e.g., environmental tolerances, resource needs, life history characteristics) that limit the species' geographic distribution (Brown et al. 1996). Range sizes for turtles, which are similar within families and genera within families, are likely to be a species attribute, dependent upon habitat use, diet, body size, and available land area, operating primarily in ecological time (Hecnar 1999). Food availability, habitat productivity, over-wintering nest survival, egg incubation period, and hibernation survival may be factors limiting turtle species at the northern extent of their geographic ranges (Costanzo et al. 1995, Hecnar 1999, Arvisais et al. 2002, Greaves and Litzgus 2007, Walde et al. 2007). Wood turtles (Glyptemys insculpta), have been studied extensively in the northern portion of their range, but further aspects of their habitat use and population dynamics need to be 
better understood for conservation efforts to be effective (Quinn and Tate 1991, Kaufmann 1992, Bodie 2001), and data gaps occur in the southern portion of their range.

The geographic range of wood turtles extends from eastern West Virginia and northern Virginia north along the Atlantic states to Nova Scotia, Canada, and west along the Great Lakes to eastern Minnesota (Harding and Bloomer 1979, Conant and Collins 1998, Endangered Species Coalition 2008). During the Pleistocene, the range extended to the south as far as Georgia and Tennessee (Holman 1976, Parmalee and Klippel 1981), but the southern border began moving north as the glaciers melted (Pielou 1991). They currently occur in 17 states along the Great Lakes and northeastern United States, and in 4 southeastern Canadian provinces. Habitat destruction and alteration have resulted in decline of this species throughout its range (Ernst 2001). In 1992, wood turtles were listed in the Convention on International Trade in Endangered Species of Wild Flora and Fauna Appendix II for regulated trade (CITES 2008). In 2000, the species was listed as vulnerable in the IUCN Red List (Hilton-Taylor 2000). During 2007, the species was listed as threatened by the Committee on the Status of Endangered Wildlife in Canada, an updated status from the species' special concern listing in 1996 (COSEWIC 2008). By 2008, they were listed as one of the top 10 species recognized as threatened or endangered in the United States that is the most in need of protection by the Endangered Species Act (Endangered Species Coalition 2008). In West Virginia, the species is listed as an S2, or a species considered to be very rare and imperiled (WVNHP 2007), and is a priority 1 Species in Greatest Need of Conservation (SGNC) in the Wildlife Conservation Action Plan (WVDNR 2005).

The wood turtle is an edge species that requires multiple cover types for various annual activities (Quinn and Tate 1991, Kaufmann 1992, Compton et al. 2002), with an affinity for 
lowland, or bottomland areas (Strang 1983), especially riparian zones (Arvisais et al. 2004). At the watershed scale, the turtles tend to select fairly dry, moderately forested areas close to waterways, but at closer scales they select areas with low density canopy cover near water (Compton et al. 2002). It is rare to find wood turtles crossing hilly, xeric, or extensively exposed terrain, even when these areas occur between suitable habitat patches (Carroll and Ehrenfeld 1978). They are a semi-aquatic species and will spend time on land and in the water depending on season and activity (Ernst 1986, Farrell and Graham 1991, Kaufmann 1992, Arvisais et al. 2002). They are adapted to cool climates (Ernst 2001) and are active throughout the year except for the coldest months (Carroll and Ehrenfeld 1978). Individuals rarely travel farther than $300 \mathrm{~m}$ from the stream edge (Brewster and Brewster 1991, Quinn and Tate 1991, Kaufmann 1992, Arvisais et al. 2002, McCoard 2012) and may be considered dependent upon riparian zones due to their high rate of evaporative body-water loss (Ernst 1968). Their home ranges are elongated and follow stream edges (Strang 1983). Individuals may travel up to $500 \mathrm{~m}$ from their typical home ranges for temporary periods and can travel a sustained maximum speed on land of 200 $\mathrm{m} /$ hour (hr), with the fastest recorded speed of $396 \mathrm{~m} / \mathrm{hr}$, and a sustained maximum downstream swimming speed of $350 \mathrm{~m} / \mathrm{hr}$ (Kaufmann 1995).

Studies of wood turtles have focused mainly on life history traits and behaviors to determine why the species' distribution may be limited at the northern extent of its range (Arvisais et al. 2002, 2004; Walde et al. 2007; Greaves and Litzgus 2009). Few have focused on characteristics of the habitat to explain distributional limits of the species, although dependence on highly oxygenated, flowing water for hibernation has been suggested as a range limitation (Greaves and Litzgus 2008). Additionally, few studies have been conducted to determine range limitations affecting the distribution of the species at the southern extent of its range. Dispersal 
barriers may limit a species occurrence in distant, but suitable habitat (Brown et al. 1996) and may influence where the range of wood turtles ends to the south. Turtle distributions often follow along large river systems (Iverson 1986) and lie within specific drainage basins (Hecnar 1999). Records of wood turtles indicate that they occur no farther south than the Potomac River Watershed Drainage (WVDNR 2008, Virginia Herpetological Society 2011), within which lies the Cacapon River Watershed in the Eastern Panhandle of West Virginia. The objectives of our study were to (1) determine aquatic and terrestrial habitat characteristics relevant to the presence or absence of the species, (2) determine the approximate southern geographic boundary of wood turtles in the Cacapon River Watershed, West Virginia, and (3) identify potential dispersal barriers to the west or south of the current range. Data gathered from our study will aid in understanding the habitat needs of wood turtles at the southern limit of their range and be valuable when planning management and conservation strategies.

\section{STUDY AREA}

West Virginia's Ridge and Valley region, within the eastern panhandle, receives about $76 \mathrm{~cm}$ of precipitation annually (Kozar and Mathes 2001). The highest elevation (1,482 m) in West Virginia is reached on Spruce Knob, Pendleton County, at the western edge of the eastern panhandle, and the lowest elevation $(73 \mathrm{~m})$ is reached in Harper's Ferry, Jefferson County, at the eastern edge of the eastern panhandle (Green and Pauley 1987). The Cacapon River Watershed, composed of the Lost, North, and Cacapon rivers, occurs in the Ridge and Valley physiographic province of West Virginia; it was 79\% forested, $19 \%$ agriculture, and $2 \%$ residential, barren, or water cover (NPS 1982). The upstream half of the Cacapon River Watershed is heavily farmed, with crops and pastures occurring up to the edge of the river (Constantz et al. 1995, Niederberger and Seidel 1999). Pastureland is commonly unfenced and cattle are allowed free access to the 
river (K.R.P. McCoard, West Virginia University, personal observation, Constantz et al. 1995), resulting in riparian vegetation that is often degraded or absent (Guiliano and Homyack 2004), and resulting in greater rates of erosion (Saumure et al. 2007).

Within the watershed, the riparian overstory vegetation was dominated by coniferous and deciduous species including sycamore (Platanus occidentalis), red maple (Acer rubrum), tulip poplar (Liriodendron tulipifera), black walnut (Juglans nigra) (Niederberger and Seidel 1999), white pine (Pinus strobus), and chestnut oak (Quercus prinus) (Constantz et al. 1995). The midstory layer was primarily composed of multiflora rose (Rosa multiflora) and spicebush (Lindera benzoin) (Niederberger and Seidel 1999) as well as autumn olive (Elaeagnus umbellata) and Japanese barberry (Berberis thunbergii) (K.R.P. McCoard, personal observation). The herbaceous layer was dominated by ground ivy (Glechoma hederacea), bluebells (Mertensia virginica), and reed canary grass (Phalaris arundinacea) (Niederberger and Seidel 1999) in addition to wingstem (Verbesina alternifolia), jewelweed (Impatiens spp.), wood sorrel (Oxalis spp.), and violets (Viola spp.) (K.R.P. McCoard, personal observation).

\section{METHODS}

We conducted initial surveys for wood turtles within the Cacapon River Watershed during spring and summer 2009. These surveys indicated that the species became less abundant south of the Cacapon River along the North and Lost rivers (also observed by T. K. Pauley, Marshall University, and G. Constantz, Cacapon Institute, personal communications). To determine the proportion of 100 random sites that would be surveyed during summer 2010 for wood turtles along the North and Lost rivers, we divided the individual lengths of the rivers by the combined length of both rivers. Site locations were determined by randomly generating 61 distances for the North River, because the North River accounted for $61 \%$ of the combined river lengths, and 
39 distances for the Lost River from their headwaters to confluence with the Cacapon River. The distances were then plotted in ArcMap to obtain universal transverse mercator (UTM) coordinates to locate the sites on the ground. The survey sites were separated by 30.2 to $6,752.8$ $\mathrm{m}(\bar{x}=1,329.1, \mathrm{SE}=135.4)$.

We sampled for presence or absence of wood turtles from 17 June to 6 August 2010 (Appendix Ic), when the wood turtles were primarily terrestrial (Ernst 1986, Farrell and Graham 1991, Quinn and Tate 1991, Niederberger and Seidel 1999, McCoard 2012). To estimate a detection probability, we conducted an independent-observer, double sampling method (Mazerolle et al. 2007) in August 2011, but the primary observer documented more turtles than the alternate sampling team, leading to an estimated detection probability of 1.0. We acknowledge that this value is not possible in the field. At each sampling location, we established a 100-m radius survey circle with the central point occurring in the middle of the river. To determine presence or absence of wood turtles, we intensively surveyed each circle on foot. We captured the turtles by hand under permits from the West Virginia Division of Natural Resources and the West Virginia University Animal Care and Use Committee, protocol \# 090408. We recorded gender and life stage (i.e., juvenile, adult) of each turtle. The measurements we took to the nearest millimeter $(\mathrm{mm})$ using $200-\mathrm{mm}( \pm 0.2 \mathrm{~mm})$ Mitutoyo $^{\mathrm{TM}}$ dial calipers (Mitutoyo America Corporation, Aurora, IL) included carapace length and width, plastron length and width, bridge height and width, and depth. We measured mass to the nearest gram (g) using 1,000-g ( $\pm 10 \mathrm{~g})$ or 2,500-g ( $\pm 20 \mathrm{~g})$ Pesola $^{\circledR}$ spring scales (Pesola AG, Baar, Switzerland). We identified males by their concave plastron and longer, thicker pre-anal tail (Harding and Bloomer 1979). We considered juveniles to be $\leq 160 \mathrm{~mm}$ in carapace length (Dubois et al. 2008) unless an individual displayed distinctive secondary sexual characteristics at that size or smaller. To 
estimate age, we counted rings on scutes, from 0 to $>20$ years (Greaves and Litzgus 2009). We recorded date, time, Global Positioning System (GPS) location, weather conditions, observed activity when captured, perpendicular distance from the river's edge, and depth in water (if in the water) for each capture. As presence or absence of the species was the factor of interest, we did not mark the turtles for recapture. After data collection, we released the turtles at their original capture locations.

Within each survey circle, we measured terrestrial and aquatic habitat characteristics. We conducted vegetation surveys within a 10 x 10-m plot, modified from McCoard (2008), within the survey circle. We generated 2 integers randomly from the set $\{1,2\}$ to determine whether we would begin at the upstream (1) or downstream end (2) of the survey circle and which side of the river (1, river right; 2 , river left) to place the plot. We generated an additional 2 integers randomly between 1 and 50 to select (1) the number of meters along the river and (2) the number of meters perpendicular from the river to place the plot. All trees within the plot with diameters larger than $5 \mathrm{~cm}$ diameter at breast height (dbh), we identified and measured. All shrubs within the plot, including saplings, taller than $1 \mathrm{~m}$ and $<5 \mathrm{~cm}$ in diameter, were identified and their number of stems counted. We surveyed the field layer (woody and herbaceous plants $<1 \mathrm{~m}$ in height) in $1-\mathrm{m}^{2}$ sub-plots in each corner of the $10 \times 10-\mathrm{m}$ plot. We identified and estimated percent cover of each species, as well as leaf litter, woody debris, and bare ground and rock and averaged the 4 values for the whole plot. At the center of each sub-plot, we used a Robel pole (Robel et al. 1970) to determine vertical density from visual obstruction readings taken $4 \mathrm{~m}$ from the pole (1-m height) in all 4 cardinal directions, and averaged for the plot. We measured canopy cover (\%; Robert E. Lemmon Forest Densiometer Model C, Bartlesville, OK) and recorded a description of the local cover type (e.g., pasture, crop field, wetland, forest) from the 
center of the 10 x 10-m plot. We estimated cover class rankings for trees, shrubs, and the field layer for the entire 100-m radius survey plot using the categorical variables of the following cover class ratings $(1-5 \%=1,6-25 \%=2,26-50 \%=3,51-75 \%=4,76-95 \%=5$, and 96 $-100 \%=6)($ Balcombe et al. 2005) to assess if a general percent cover of the vegetation layers was preferred by wood turtles. We derived elevation, slope, and aspect from ArcMap shapefiles (Environmental Systems Research Institute, Inc., Redlands, CA).

To gain close approximates of the environment being used, we recorded terrestrial data in the center of the vegetation plots when turtles were absent or aquatic and directly under the turtles, when terrestrial. We collected a single reading of soil temperature $( \pm 1 \%$ of scale; Forestry-Suppliers soil thermometer, Jackson, MS $)$, soil pH $\left( \pm 0.01\right.$; Oakton ${ }^{\circledR}$ double junction waterproof $\mathrm{pH}$ tester 30; Oakton Instruments, Vernon Hills, IL), soil moisture $(1=$ dry, $10=$ saturated; 22.86-cm Lincoln soil moisture meter; Lincoln Irrigation, Lincoln, NE), air temperature $\left( \pm 1^{\circ} \mathrm{C}\right)$, and relative humidity $\left( \pm 5 \%\right.$; Oakton ${ }^{\circledR}$ digital max-min thermohygrometer). When the turtles were present, we measured aquatic data directly over the turtles and at a randomly generated number (1 to 100) of meters from the upstream survey circle's edge in the river when the turtles were absent. The data we recorded included depth $(\mathrm{cm})$ and width $(\mathrm{m})$ of the stream, water temperature $\left({ }^{\circ} \mathrm{C} ; 15.24-\mathrm{cm}\right.$ Enviro-Safe ${ }^{\circledR}$ armor case pocket thermometer; H-B Instrument Company, Collegeville, PA), and water $\mathrm{pH}( \pm 0.01)$. We conducted a pebble count (modified from Wolman 1954) by measuring 50 random rocks within the stream occurring in the survey circle to determine if an average rock size was preferred by the turtles. Within the 100-m radius survey plot, we estimated a cover class ranking for exposed rocks within the stream bed using a similar scoring system as for the vegetation surveys. 


\section{Statistical Analyses}

We performed statistical analyses in R 2.10.1 (R Development Core Team, www.r-project.org, accessed 15 January 2010) or SAS ${ }^{\circledR} 9.2$ (SAS Institute Inc., Cary, NC) with $\alpha=0.05$. For each analysis, we checked for normality and equal variances, and transformed data and removed outliers as necessary. We compared morphometric data among genders (i.e., males, females, and juveniles) using 1-way analysis of variance (ANOVA; $\alpha=0.05 / 8$ tests $=0.006$ ) which assumes that the probability distributions of each factor level are normal with constant variance, and that the responses are random and independent of other factor level responses (Lunney 1970, Kutner et al. 2005). To determine between which genders differences occurred, we used Tukey honest significant differences (Tukey HSD; similar assumptions to ANOVA [Keselman and Rogan 1978], and based on the studentized range distribution [Faraway 2005]) at 95\% confidence.

We calculated (1) overall (natives and exotics) and (2) natives-only vegetative species diversity $(H)$ and richness $(S)$ (diversity and specnumber functions, vegan package, $\mathrm{R}$ ) for the field, shrub, and tree layers, testing between site types (e.g., presence, absence of turtles), rivers, and site $\times$ river interactions using univariate ANOVAs $(\alpha=0.05 / 6$ tests $=0.008)$ and Tukey tests, if significant effects occurred. Normality and equal variances were checked on all models; to approximate normality in the overall vegetation, we exponentially transformed field diversity and removed 3 outliers, and square-root (plus 1) transformed shrub richness, tree diversity, and tree richness. In the native vegetation, we exponentially transformed field diversity, square-root transformed field richness, shrub diversity and richness, square-root (plus 1) transformed tree diversity, and $\log$ (plus 1) transformed tree richness. We reduced the vegetation community datasets by excluding species that accounted for $<5 \%$ of all observations. To compare community composition of the 3 vegetation layers between sites, rivers, and site $\times$ river 
interactions, we used permutational multivariate analysis of variance (PerMANOVA, 1,000 permutations, Euclidean distance; adonis function, vegan package, R) because our abundances were skewed with many zeros present (Tuyo et al. 2005). PerMANOVA is robust to departures from parametric distribution assumptions and suitable for community composition analysis (Walters and Coen 2006, Lorion and Kennedy 2009). If the community composition was significant among sites or rivers, we used indicator species analysis (ISA, indval function, labdsv package, R) to determine characteristic species, calculating the indicator values for each species by taking the product of its relative frequency and its relative average abundance within each category (Dufrêne and Legendre 1997). We used an indicator value threshold of 0.25 and $\alpha=$ 0.05 ( $p$-values generated through randomization procedures; Dufrêne and Legendre 1997) to determine which species characterized the site types and rivers. We plotted the characteristic species with their significant main effects (i.e., site type, river) using non-metric multidimensional scaling (NMDS) ordination (metaMDS and envfit functions, vegan package, $\mathrm{R})$.

To determine which variables were important in determining the presence of wood turtles, we considered an initial 29 terrestrial and aquatic habitat variables for logistic regression model membership. We centered and scaled all quantitative predictor variables. An eigenanalysis revealed mild issues with multicollinearity. Therefore, we removed stream order, land use, and river from the pool of possible variables. Due to small sample size with respect to the initial number of independent variables, we proceeded with logistic regression using Firth's penalized maximum likelihood estimation. For the same reason, we did not include interaction effects in the model. Using least absolute shrinkage and selection operator (LASSO) regression, a penalized method used for variable selection in high-dimensional data (Zhang and Huang 2008), 
in conjunction with corrected Akaike Information Criteria (AIC ${ }_{c}$; Hurvich and Tsai 1989) and Bayesian Information Criteria (BIC), we selected an initial candidate set of 12 variables. We conducted penalized likelihood ratio tests on the log-odds ratios and computed 95\% profile penalized likelihood confidence intervals for the odds ratios. We conducted model reduction and proceeded by sequentially pooling terms exhibiting the largest $P$-value until all term parameter estimates were significant at the (uncorrected) 0.05 level. We used logistic regression diagnostics to verify the fit of the model.

To determine the wood turtles' range within the study area, we used an adaptive local convex hull (a-LoCoH, Adehabitat package, $\mathrm{R}$ [Getz et al. 2007]) to form an isopleth around all turtle locations. We compared values and areas of the utilization distributions (UD) using $\hat{a}$ (asymptote of the UD construction) and $a_{1}$ (maximum distance between any 2 turtle capture points) between $95 \%$ and $100 \%$ isopleths. We calculated the value of $\hat{a}$ by plotting the UD area against increasing values of the parameter $a$ until an asymptote was reached at 50,000 m. We calculated the value of $a_{1}$ by measuring the distance between the 2 most separated points, at about 71,000 m. To determine the most accurate UD, we exported the UDs and capture locations into ArcMap and overlaid them on elevation and hillshade shapefile layers.

\section{RESULTS}

\section{Morphometrics}

Two males were captured and measured in 1 site, but single turtles were observed in all other locations $(n=64)$ with the confirmed presence of the turtles. Five wood turtles were observed in water and escaped without being captured and measured. The captured wood turtles $(n=60)$ differed in all morphometric variables (Table 1). Males $(n=27)$ were larger than females $(n=$ 22) in mean carapace length, mean bridge height, and mean mass. Adult males and females were 
larger than juveniles $(n=11)$ in all characteristics. Males ranged in age from 8 to $>20$ years; however $52 \%$ were $>20$ years old. Females ranged in age from 9 to $>20$ years, with $36 \%>20$ years old. Many of the carapace and plastral scutes on the adults were worn so that annual rings could not be counted, thus an average age could not be provided. Juveniles ranged in age from 2 to 7 years, with an average age of 5 years $(\mathrm{SE}=0.54)$. Of the turtles captured along the North River $(n=39)$, ages appeared to vary without pattern. However, along the Lost River, the first 13 of 21 (62\%) turtles captured (as surveys moved downstream) were about 20 years or older.

\section{Vegetation analysis}

We recorded a total of 125 ( $72 \%$ native) species (some species were recorded in more than 1 layer) within the field $(n=112)$, shrub $(n=29)$, and tree $(n=26)$ layers; some species were recorded in multiple layers (Appendix IIc). Mean overall (natives and exotics) field diversity was greater at sites with turtles than sites without turtles $\left(F_{1,93}=22.02, P<0.001\right)$ and along the North River than the Lost River $\left(F_{1,93}=53.20, P<0.001\right.$; Table 2, Table 3), as was mean native field diversity (sites $\left[F_{1,96}=9.25, P=0.003\right]$; rivers $\left[F_{1,96}=46.42, P<0.001\right.$; Table 4]). Mean overall field richness was greater at sites with turtles than without turtles $\left(F_{1,96}=10.12, P=\right.$ $0.002)$ and along the North River compared to the Lost River $\left(F_{1,96}=61.22, P<0.001\right)$, as was mean native field richness (sites $\left[F_{1,96}=9.23, P=0.005\right]$; rivers $\left[F_{1,96}=55.89, P<0.001\right]$ ). Overall field community composition was similar among the rivers (pseudo- $F_{1,96}=1.46, P=$ 0.232 ) and in the site $\times$ river interaction (pseudo- $F_{1,96}=2.49, P=0.055$ ), but differed among sites with and without turtles (pseudo- $F_{1,96}=8.81, P=0.001$ ). Three species differentiated sites with wood turtles from those without the turtles (wingstem [indicator value (IV): 0.46, $P=$ 0.459], reed canary grass [IV: $0.25, P=0.748$ ], and deertongue grass [Panicum clandestinum; IV: $34, P=0.213]$ ); however, none of these species were significant. Native field composition 
was similar among the sites (pseudo- $F_{1,96}=0.05, P=0.978$ ) and in the site $\times$ river interaction (pseudo- $\left.F_{1,96}=1.78, P=0.166\right)$, but differed among rivers (pseudo- $F_{1,96}=8.84, P=0.002$ ) Wingstem (IV: $0.55, P=0.018)$ and reed canary grass (IV: $0.40, P=0.013$ ) characterized the Lost River compared to the North River (Figure 1).

Mean overall shrub diversity was similar among all variables $\left(F_{1,96} \geq 0.00, P \geq 0.041\right.$ [Bonferroni correction: $\alpha=0.05 / 6$ tests $=0.008]$ ). Mean overall shrub richness differed in the site $\times$ river interaction, with mean shrub richness being higher in sites with turtles than without along the Lost River $\left(F_{1,96}=13.20, P<0.001\right.$; Appendix IIIc). Mean native shrub richness $\left(F_{1,96}=14.61, P<0.001\right)$ was higher along the North River than the Lost River. Overall shrub community composition did not differ between sites (pseudo- $F_{1,96}=0.85, P=0.501$ ) or rivers (pseudo- $F_{1,96}=2.17, P=0.068$ ), although the interaction was significant (pseudo- $F_{1,96}=3.10, P$ $=0.013$ ). Native shrub composition did not differ between sites (pseudo- $F_{1,96}=1.19, P=0.318$ ) or the site $\times$ river interaction (pseudo- $F_{1,96}=1.78, P=0.138$ ), but differed between rivers (pseudo- $F_{1,96}=3.09, P=0.014$ ). Spicebush (overall, IV: $0.28, P=0.005$; native, IV: $0.28, P=$ 0.004) differentiated the North River from the Lost River (Figure 2), but no indicator species occurred to differentiate the sites overall.

The overall tree layer did not differ in mean diversity $\left(F_{1,96} \geq 0.55, P \geq 0.117\right)$ or mean richness $\left(F_{1,96} \geq 0.00, P \geq 0.041\right)$ among any of the variables. Mean native tree diversity $\left(F_{1,96}=\right.$ 9.86, $P=0.002)$ and mean native tree richness $\left(F_{1,96}=20.66, P<0.001\right)$ were higher along the North River than the Lost River. Overall tree community composition was similar between sites (pseudo- $F_{1,96}=2.53, P=0.022$ [Bonferroni correction: $\alpha=0.05 / 3$ tests $\left.=0.017\right]$ ) and rivers (pseudo- $F_{1,96}=2.05, P=0.067$ ), but differed in the site $\times$ river interaction $\left(\right.$ pseudo- $F_{1,96}=3.23$, $P=0.005)$. Native tree composition was similar between sites (pseudo- $F_{1,96}=2.53, P=0.026$ ) 
and rivers (pseudo- $F_{1,96}=2.05, P=0.046$ ), but differed in the site $\times$ river interaction (pseudo$\left.F_{1,96}=3.23, P=0.003\right)$. Witch-hazel (Hamamelis virginianus; overall, IV: $0.08, P=0.048 ;$ native, IV: $0.08, P=0.043$ ) and ironwood (Ostrya virginiana, IV: $0.08, P=0.049$ ) were more likely to be within sites without turtles than those with turtles (Figure 3). No indicator species occurred to differentiate the rivers. The indicator values were below the 0.25 threshold of Dufrêne and Legendre (1997), however, and may not be ecologically important in distinguishing between sites with and without wood turtles.

\section{Environmental Variable Model}

Sites with the presence of wood turtles were compared to sites without the turtles to determine, through generating a logistic regression model, which variables influenced the presence of the turtles. The final, reduced habitat variable model using LASSO regression and AICc contained the 6 variables: elevation, distance from the Cacapon River, stream depth, canopy cover, slope, and soil temperature (Table 5). The full model containing all 12 terms had an $\mathrm{AIC}_{\mathrm{c}}$ value equal to 45.816 and a $\mathrm{BIC}$ value of 79.683. The reduced model had an $\mathrm{AIC}_{\mathrm{c}}$ value of 53.235 and a BIC value of 71.472. The generalized coefficient of determination per Nagelkerke (1991) for the reduced model was 0.7595 . The Hosmer-Lemeshow Goodness of Fit test was not significant ( $P$ $=0.94$ ) suggesting that the logistic response function was appropriate. Logistic regression diagnostics also verified the fit of the model. A model-based plot of the predicted probability of site occupancy as a function of distance from the Cacapon River (with other predictor variables set to a nominal level) was produced to determine a predicted termination of the wood turtles' range within the Cacapon River Watershed (Figure 4). 


\section{Site Occupancy Probability}

The $95 \%$ and $100 \%$ isopleths for $\hat{a}$ and $a_{1}$ were similar in distribution and area. Area of the $\hat{a}$ $100 \%$ UD was 13,400 ha and covered more occupied lowland habitat than the $a_{1} 100 \%$ UD at 14,000 ha. However, 95\% isopleths are more commonly used (Getz et al. 2007) and gave a more representative UD consistent with field observations of wood turtle locations than the $100 \%$ isopleths. Area of the $\hat{a} 95 \%$ UD was about 11,800 ha and covered more occupied lowland habitat than the $a_{1} 95 \%$ UD at an area of 11,700 ha. We considered the $\hat{a} 95 \%$ UD to be representative of the actual wood turtle distribution along the North and Lost rivers among the 4 UD's generated (Figure 5). Based on the UD produced from field surveys, the approximate termination of the wood turtles' range within the Cacapon River Watershed occurs where the 2 rivers lose their floodplains and flow primarily through upland habitat; this result did not coincide with the absence of agricultural lands, as agriculture was present further along the river headwaters than the turtles were found. Due to the rare status of wood turtles, however, no further specific locality information will be provided.

\section{DISCUSSION}

\section{Morphometrics}

In our wood turtle population in West Virginia, along the southern limit of the species' range, males were larger than females in mean carapace length, mean bridge height, and mean mass. In Virginia, along another portion of the species' southern range limit, males had longer mean carapaces and larger mean head widths than females (Akre 2002). At the species' northern range limit in the Sudbury District of Ontario, Canada, females were larger in mean plastron length, mean carapace width, and mean carapace height (depth) while males were larger in mean carapace length, mean head width, and mean mass (Greaves and Litzgus 2009). Greaves and 
Litzgus (2009) determined that individuals in the northern and southern portions of the geographic range tend to be larger than those in the middle of the range, a trend noted also by Verdon and Donnelly (2005) for Florida box turtles (Terrapene carolina bauri). Increasing energy reserves for winter survival and greater reproductive ability in the north and longer foraging periods associated with a longer growing season in the south have been suggested as possible reasons for these observations (Greaves and Litzgus 2009). For a more thorough comparison of wood turtle body sizes across their geographic range, see Greaves and Litzgus (2009).

\section{Vegetation}

Wood turtles were present in sites with high field layer richness and diversity compared to sites without the turtles, with the vegetative complexity possibly providing a greater variety of edible plant matter and cover for the turtles. The field layer had a higher influence on the presence of the turtles than shrubs or trees did, as no differences were observed between sites with and without turtles in regard to those vegetative layers. The North River was higher in overall vegetation species diversity and richness than the Lost River, a result that may have been tied to the North River's larger and more forested floodplain (K. R. P. M., personal observation), providing a larger area for a greater number of species to colonize and thrive. Riparian zones, where wood turtles are primarily found, tend to support greater wildlife richness and diversity than surrounding uplands (Doyle 1990, McComb et al. 1993, Palmer and Bennett 2006). The high wildlife use of riparian zones is closely associated with complex vegetative structure and composition (Stauffer and Best 1980, Giuliano and Homyack 2004), as may be reflected in the wood turtles occurring in sites with greater vegetative diversity. 
Abundant tree species in our study were similar to the dominant tree species occurring within the floodplain habitat of wood turtles in Virginia, including tulip poplar, sycamore, and ironwood (Akre 2002), although ironwood and witch-hazel were associated with our sites lacking wood turtles. Additional non-dominant species that were observed in our study were considered dominant in Virginia's wood turtle habitat, including box elder (Acer negundo), river birch (Betula nigra), slippery elm (Ulmus rubra), common pawpaw (Asimina triloba), and ash (Fraxinus spp.) (Akre 2002). Wood turtles in our study preferred deciduous and mixed forests with low tree density (35\%), moderate canopy cover (53\%), low shrub cover (25\%), and high herbaceous cover $(85 \%)$. They were within forests $(81 \%)$ more often than in adjacent agricultural fields (16\%) or residential developments (3\%). At the northern limits of their range in Quebec, Canada, wood turtles tend to select young (16 years) mixed forests with low tree cover $(25 \%)$, low canopy closure $(\leq 50 \%)$, and moderate shrub cover $(35 \%)$ (Arvisais et al. 2004). Edge habitats may help balance feeding and basking for the species, as higher food availability exists in forests with high canopy closure, but areas of low canopy closure provide suitable basking sites (Compton et al. 2002). Habitat selection is gender-specific to a degree: females prefer scrub-shrub in the spring, but choose other cover types (e.g., forests, fields, wetlands) further into the year while males preferred scrub-shrub over other habitats throughout the year (Tingley et al. 2010). In Nova Scotia, Canada, females were positively associated with a dense herbaceous layer and leaf litter (Tingley et al. 2010).

\section{Environmental Influences Acting as Southern Range Limitations}

Geographic ranges are affected by characteristics of extant species (e.g., demographics, life histories, and dispersal) and their environmental requirements and tolerances that were influenced by former environments (Brown et al. 1996). Near range boundaries, abundances of a 
species are usually low (Brown et al. 1996) and patch occupancy can reach zero despite presence of suitable patches (Shively and Jackson 1985, Holt and Keitt 2000). Range limits can be formed because there is lower quality habitat at the periphery of a species' range and the matrix habitat between suitable patches is unfriendly to dispersers (Holt and Keitt 2000). Habitat fragmentation, which can increase the area of non-habitat matrix, and isolation of suitable patches can decrease population sizes through metapopulation processes along the borders of geographic ranges (Lawton 1994, Brown et al. 1996). Wood turtles in our study may be showing initial signs of the formation of a metapopulation. Three routes of metapopulation dynamics that could form range limits include gradients in habitat availability (e.g., lack of suitable habitat at the range periphery leads to higher extinction than colonization rates), gradients in local extinction rates (e.g., stochastic environmental factors may have greater influence on populations in peripheral patches), and gradients in local colonization rates (e.g., biotic or abiotic factors can negatively affect a population's dispersal numbers or survivability while dispersing); all 3 scenarios lead to decreasing patch occupancy at the range edge (Holt and Keitt 2000). Habitat fragmentation from anthropogenic activities can create metapopulations (Forney and Gilpin 1989) and lower the persistence of faunal populations limited to patches (Bennett 1990); this effect may be more severe in populations along range boundaries that are already subjected to environmental fluctuations, including climate change which can influence northern range expansion and southern range contraction (e.g., loss of populations) of temperate wildlife species (Parmesan and Yohe 2003), such as wood turtles.

Agricultural practices often fragment forested landscapes and can increase the mortality rates of wildlife, including turtles, decreasing population sustainability (Saumure et al. 2007). A lack of patch connectivity will lead to metapopulation extinction (Hess 1996). In a laboratory 
setting, metapopulations of Drosophila pseudobscura and D. hydei created by fragmentation had increased probabilities of extinction (Forney and Gilpin 1989). In Kansas, peripheral populations of northern bobwhite (Colinus virginianus), ring-necked pheasants (Phasianus colchicus), and eastern cottontails (Sylvilagus floridanus) had greater density-independent variations in population growth rate and lower abundances than populations in the interior of the species' ranges, responses possibly related to greater environmental fluctuations experienced by the peripheral populations (Williams et al. 2003). Freshwater turtles experience environmental and resource variations (Yeomans 1995) that may influence the boundaries of their geographic ranges.

Hecnar (1999) suggested that turtle ranges are influenced by the positions of coastlines, mountain ranges, deserts, and extreme temperatures on each continent. Wood turtles in our study tended to prefer low elevations (also noted by Strang 1983, Jones and Sievert 2009, Tingley et al. 2009, Tingley et al. 2010) and low slopes. They tend to avoid crossing dry, open, and hilly terrain (Carroll and Ehrenfeld 1978). In Massachusetts, Jones and Sievert (2009) determined that the majority of wood turtles prefer home ranges with stream gradients $<1 \%$, possibly to avoid displacement by flooding in high-relief areas. Moderate changes in elevation can be traversed, as individuals can cross the boundaries of different stream systems. In a simultaneous study (McCoard 2012) a radio-tagged male's signal was lost in June 2010 in one stream system ( $275 \mathrm{~m}$ elevation) and the male was found a month later in another system; the male appeared to have travelled about $3.5 \mathrm{~km}$ over elevations that reached about $350 \mathrm{~m}$. This event was not the result of a flooding event carrying the male downstream because he was found upstream of his prior location. A radio-telemetered female wood turtle was found in a different stream system 2 years after her signal was lost from its original capture system in the Delaware 
Water Gap National Recreation Area (Behler and Castellano 2005). Dispersal of this type is most likely aided by olfaction as the orienting mechanism (Carroll and Ehrenfeld 1978, Barzilay 1980, Tuttle and Carroll 2005), in addition to other cues for finding water, such as light effects on clear days, as was noted in adult yellow-bellied pond sliders (Trachemys scripta scripta) that were displaced $300 \mathrm{~m}$ from a water body in unfamiliar territory and non-randomly oriented to the water (Yeomans 1995). However, freshwater turtle species may not easily or regularly travel overland between water bodies because of high physiological costs (Yeomans 1995). A dispersing individual could also be limited by its perceptual range, or its ability to 'see' patches in the landscape (Alderman and Hinsley 2007), which is likely low for small, ground-dwelling wood turtles. Topography may have a large influence on restricting an animal's perceptual range (Alderman and Hinsley 2007). In Pennsylvania, Strang (1983) never observed a wood turtle travel farther than $88 \mathrm{~m}$ up a mountain from its lowland boundary. Kaufmann (1986) observed individuals $420 \mathrm{~m}$ in elevation in Pennsylvania.

Increasing stream depth, typically associated with larger streams, was preferred by wood turtles in our study. In a similar study, decreasing stream width was determined to influence the upstream dispersal and range termination of Sabine map turtles (Graptemys ouachitensis sabinensis) (Shively and Jackson 1985). Elevation and stream size are typically intertwined, as large, low gradient streams tend to occur in low elevations (Quist et al. 2004). Wood turtles have a strong preference for lowlands and may be dependent upon their large, permanent streams (Strang 1983), partly for winter hibernation and as a buffer against extreme temperatures (Greaves and Litzgus 2009). These factors may promote an avoidance of long-distance dispersal in wood turtles and prevent their crossing mountains into unfamiliar territory, such as to the south of their current range. 
Range loss and contraction tend to begin in the periphery of historical ranges, consistent with the contagion hypothesis which predicts that a species' range will recede from a point of disturbance, typically anthropogenic, towards the opposite periphery (Channell and Lomolino 2000). The historical range of wood turtles may already be decreasing as populations of the turtles are in decline from the effects of anthropogenic practices (Harding and Bloomer 1979). Riparian zones upon which wood turtles may be dependant (Ernst 1968) are often transformed by human uses such as cultivation, cattle grazing, and urbanization (Bodie 2001). Habitat destruction and alteration may have increased with advances in agricultural practices (Saumure et al. 2007). In the Cacapon River Watershed, the Lost River and upper Cacapon River are polluted due to free access of the rivers by cattle (Constanz et al. 1995). Of all the major rivers in the Cacapon River Watershed, the Lost River has the highest density of cattle-access sites, the highest average fecal coliform levels, and a degraded riparium (Constantz et al. 1995).

Agriculture along the upstream one-half to three-quarters of the Lost River was observed to consist mainly of unfenced cattle pastures and cornfields that were planted up to the edge of the river (also noted by Constantz et al. 1995). The sporadic occurrence of wood turtles along the Lost River, with only individuals $\geq 20$ years being found along the severest areas of agriculture, may indicate that this southern population is slowly declining as a result of the agricultural practices. If this population is not allowed to recover, the range of wood turtles within West Virginia will contract inward along the river. Increasing predator abundance, especially raccoons (Procyon lotor), has been associated with an increase in agricultural practices, decreasing the success of turtle nests (Ernst et al. 1994) and juvenile recruitment into local populations (Daigle and Jutras 2005), although cornfields may provide suitable conditions for nesting, as observed by Kaufmann (1992) in Pennsylvania. In Quebec, Canada, Saumure and 
Bider (1998) documented 2.7 times the number of human-caused shell injuries and $23 \%$ fewer juvenile wood turtles in an agricultural site than in a forested site. Saumure et al. (2007) reported a $10-13 \%$ decline and an $18 \%$ decline in survivorship of adult and juvenile wood turtles, respectively, over a 2-year period in Quebec, Canada, as a result of agricultural activities. In the same population, injuries to wood turtles from farm machinery increased $11.5 \%$ over $4-5$ years (Saumure et al. 2007). Agriculture in Iowa, at the western limit of the wood turtles' range, has altered the flooding regime, drowning wood turtle nests and lowering recruitment rates (Spradling et al. 2010). In Nova Scotia, Canada, Tingley et al. (2009) found 5 turtles dead in the course of 2 years, the mortalities having occurred during both the first and second hay harvests.

Fragmented habitats, such as agriculture intermixed with forest as in our study, experience changes in the physical environment, including increased air temperatures from vegetation loss and a resulting increase in soil temperatures (Saunders et al. 1991, Stevens and Husband 1998); the warmer temperatures lead to a greater potential for desiccation during foraging (Saunders et al. 1991), more so for aquatic than terrestrial turtles (Bentley and SchmidtNielsen 1966). The cloacal temperature of wood turtles is closely correlated with substrate temperatures (Farrell and Graham 1991) and the species has a high rate of evaporative bodywater loss (Ernst 1968). In the highly exposed pasture and cropland along the Lost River, conditions promoting the desiccation of the turtles are abundant. The turtles are thus confined to suitable habitat patches that are scattered along the river in the few areas where cattle and crops are not present and mountains provide for occasional lowland "coves." Dispersal between the patches, through the inhospitable agriculture, may rarely occur; this possible rarity in dispersal may be a factor in range termination (Shively and Jackson 1985). If wood turtles are migrating or dispersing between the separated habitat patches, it may be occurring at a low rate. In 
Virginia, painted turtles (Chrysemys picta) migrated between ponds as seldom as once per year (Bowne et al. 2006). This may explain why only wood turtle adults $>20$ years were found in habitat patches along the most heavily agriculturalized portions of the Lost River. These forest patches may be too small and separated to support long-term viability or promote dispersal of individuals or populations inhabiting them, as was observed for small mammals (Bennett 1990, Stevens and Husband 1998). In Québec, Canada, translocated male wood turtles unidirectionally crossed mowed hayfields without pausing at the edge, suggesting that the hayfields were not viewed as non-habitat, yet their movements were long and straight, possibly indicating urgency by the turtles to find cover (Saumure et al. 2010). In Connecticut, over a 10-year period since the study area was opened for recreation, the average age of 2 wood turtle populations increased as the population sizes decreased; at the end of the 10 years, both populations had declined $100 \%$ (Garber and Burger 1995). Perhaps the older age of the turtles along the upstream portion of the Lost River is indicative of a similar decline.

In our study, we found increasing soil temperatures to be associated with the presence of wood turtles, but a threshold must exist where soil temperatures become too extreme. When terrestrial, wood turtles were found tucked into exposed tree roots, leaf litter caught in the stems of shrubs, in depressions created by cow hooves in saturated soil, under fallen logs, and under vegetation during days of high temperatures, and burrowed into thick mud on the riverbed when aquatic. They became immobile for several days until cooler temperatures arrived. Wood turtles are a cold-tolerant species that avoids high temperatures (Holman 1976). Individuals will seek cover and become inactive to prevent their body temperatures reaching a critical level when environmental temperatures rise (Ernst 1986); in Pennsylvania, one male was found sitting in a shallow mud puddle in a cattle pasture during hot summer days while other individuals were 
found under vegetation, fallen logs, or flood debris (Ernst 1986). In Switzerland, many reptiles with restricted distributional ranges were strongly influenced by temperature (Guisan and Hofer 2003). Environmental temperatures above those occurring in West Virginia must be too extreme for the turtles to tolerate and survive; for example, they could not adapt to the warming conditions of their southern historic range and became extirpated from that region (Parmalee and Klippel 1981). Although the species used to be found as far south as Tennessee and Georgia based on fossil records from the Pleistocene (Holman 1976, Parmalee and Klippel 1981), a period of episodic glaciation (0.01 - 1.6 million years ago, Pough et al. 2005), its current range does not extend south of the eastern panhandle of West Virginia and northern Virginia. Near the current southern boundary, maximum daily temperature in July reached about $29{ }^{\circ} \mathrm{C}$ (Parmalee and Klippel 1981), similar to the optimal body temperature of $30^{\circ} \mathrm{C}$ that recently fed wood turtle individuals try to maintain (Dubois et al. 2008). In Tennessee, where the turtles formerly occurred, the maximum daily temperatures in July were $32-35^{\circ} \mathrm{C}$ (Parmalee and Klippel 1981), in contrast to the northern limit of the species' range where mean daily temperatures in June August were about $18{ }^{\circ} \mathrm{C}$ (Greaves and Litzgus 2008). These values represent a temperature range within which wood turtles can function and survive.

Along the North River, residential development is the primary anthropogenic disturbance, and agricultural impacts on wood turtles are minimal to moderate. Road mortality and collection could possibly be among the leading causes of the species' decline along this river. Local residents living near some of the survey sites said that wood turtles were found crossing the roads during spring. Roads disrupt landscape connectivity for freshwater turtles and are a source of high mortality (Bowne et al. 2006). In a Connecticut study, 4 of 7 turtles found dead had been crushed by cars (Garber and Burger 1995). Road mortality, however, was not a focus in our 
study and is merely a suggestion of a factor that may affect wood turtles along the North River. The population(s) along this river appears to be healthy as the ages of observed individuals ranged from 2 to $>20$ without age clustering along any sampled section.

From our results, the primary factors that appear to limit wood turtles at the southern limits of their range in West Virginia include inability to disperse over high elevations to reach other large rivers, agricultural influences decreasing habitat availability and turtle survivorship, and an intolerance to high temperatures. Wood turtles are declining throughout their range, primarily because of habitat destruction and fragmentation (Harding and Bloomer 1979); to prevent the status of the species from becoming more critical, conservation and management of local populations, and education of landowners about the needs of wood turtles on their properties, are essential for the species' persistence (Kaufmann 1992, Channell and Lomolino 2000, Remsberg et al. 2006). Our study focused on environmental conditions that limit the distribution of a species along one border of its range (Brown et al. 1996), but the information gained is valuable for better understanding how to protect and promote populations of wood turtles occurring in West Virginia, at the southern extent of the species' geographic range. Future studies of wood turtle populations adjacent to agriculture along their southern boundary should focus on (1) inter-patch movements and possible metapopulation formation and (2) demographic rates to determine if recruitment is occurring, or if older adults primarily remain. These efforts should guide conservation and management practices for promoting adult survivorship (Saumure et al. 2007) and stability of small turtle populations (Congdon et al. 1993, Congdon et al. 1994) at the environmentally stochastic peripheries of their geographic ranges. 


\section{MANAGEMENT IMPLICATIONS}

Our results indicate that preferred wood turtle habitat occurs along deep streams of shallowly sloped, low elevation floodplains; wood turtle habitat with these criteria should be protected and managed to maintain the health and survival of the species. Wood turtles rarely travel $>300 \mathrm{~m}$ from stream edges (Arvisais et al. 2002; McCoard 2012); our captures were within $100 \mathrm{~m}$ of the North and Lost rivers. We recommend that in agricultural areas along waterways where wood turtles occur, 50-m wide riparian buffers (encompassing 95\% of our captures) are created and managed (10 m minimum width [Saumure et al. 2007]; $150 \mathrm{~m}$ width, $95 \%$ of freshwater turtle migration distances [Bodie 2001]; $235 \mathrm{~m}$ maximum width, female migrations [Tingley et al. 2009]) to provide and connect habitat patches, promote gene flow, and increase wood turtle population viability (Bennett 1990, Beier and Noss 1998). We suggest riparian zones be managed for native plants (e.g., wingstem, various grasses, wild black cherry, and black walnut), with efforts made to create and maintain diverse and dense herbaceous communities that will provide a varying diet and cool, moist microclimate conditions. The riparian zone should be managed to provide moderate tree canopy cover (about 50\%), low tree density (about $30-40 \%$ ), and low shrub cover (about 25\%) with occasional mowing treatments to reduce establishment of dense woody vegetation, but still provide shelter, shade, and food for the turtles. Compensation through federal programs may be provided for landowners who protect their riparian buffers.

\section{ACKNOWLEDGMENTS}

We thank C. Cooey, C. L. Pawlik, R. M. Jones, and J. A. Jones for assistance in the field. Previous drafts of this manuscript were reviewed by J. Pitchford, E. A. Pawlik, Jr., J. B. McCoard, T. K. Pauley, E. D. Michael, P. Bohall-Wood, and A. A. Billings. Many landowners allowed us entrance on to their properties and we thank them for the access. Funding for this 
project was provided by the West Virginia University Division of Forestry and Natural

Resources, the National Oceanic and Atmospheric Administration, and the West Virginia

University Environmental Research Center. This is scientific article xxxx of the West Virginia

University Agricultural and Forestry Experiment Station.

\section{LITERATURE CITED}

Akre, T. S. B. 2002. Growth, maturity, and reproduction of the wood turtle, Clemmys insculpta (LeConte) in Virginia. Dissertation, George Mason University, Fairfax, USA.

Alderman, J., and S. A. Hinsley. 2007. Modelling the third dimension: incorporating topography into the movement rules of an individual-based spatially explicit population model. Ecological Complexity 4:169-181.

Arvisais, M., J. -C. Bourgeois, E. Levesque, C. Daigle, D. Masse, and J. Jutrus. 2002. Home range and movements of a wood turtle (Clemmys insculpta) population at the northern limit of its range. Canadian Journal of Zoology 80:402-408.

Arvisais, M., E. Levesque, J. -C. Bourgeois, C. Daigle, D. Masse, and J. Jutrus. 2004. Habitat selection by the wood turtle (Clemmys insculpta) at the northern limit of its range. Canadian Journal of Zoology 82:391-398.

Balcombe, C. K., J. T. Anderson, R. H. Fortney, J. S. Rentch, W. N. Grafton, and W. S. Kordek. 2005. A comparison of plant communities in mitigation and reference wetlands in the mid-Appalachians. Wetlands 25:130-142.

Barzilay, S. 1980. Orientation and homing of the wood turtle (Clemmys insculpta). Dissertation, Rutgers University, New Brunswick, New Jersey, USA.

Behler, J. L., and C. M. Castellano. 2005. Glyptemys insculpta (North American wood turtle). Terrestrial movement. Herpetological Review 36:311. 
Beier, P., and R. F. Noss. 1998. Do habitat corridors provide connectivity? Conservation Biology $12: 1241-1252$.

Bennett, A. F. 1990. Habitat corridors and the conservation of small mammals in a fragmented forest environment. Landscape Ecology 4:109-122.

Bentley, P. J., and K. Schmidt-Nielsen. 1966. Cutaneous water-loss in reptiles. Science $151: 1547-1549$.

Bodie, J. R. 2001. Stream and riparian management for freshwater turtles. Journal of Environmental Management 62:443-455.

Bowne, D. R., M. A. Bowers, and J. E. Hines. 2006. Connectivity in an agricultural landscape as reflected by interpond movements of a freshwater turtle. Conservation Biology 20:780791.

Brewster, K. N., and C. M. Brewster. 1991. Movement and microhabitat use by juvenile wood turtles introduced into a riparian habitat. Journal of Herpetology 25:379-382.

Brown, J. H., G. C. Stevens, and D. M. Kaufman. 1996. The geographic range: size, shape, boundaries, and internal structure. Annual Review of Ecology and Systematics 27:597623.

Carroll, T. E., and D. W. Ehrenfeld. 1978. Intermediate-range homing in the wood turtle, Clemmys insculpta. Copeia 1978:117-126.

Channell, R., and M. V. Lomolino. 2000. Trajectories to extinction: spatial dynamics of the contraction of geographical ranges. Journal of Biogeography 27:169-179.

Committee on the Status of Endangered Wildlife in Canada (COSEWIC). 2008. Canadian wildlife species at risk. Ottawa, Ontario, Canada. <www.cosewic.gc.ca/eng/sct0/rpt/rpt_csar_e.cfm >. Accessed 15 October 2009. 
Compton, B. W., J. M. Rhymer, and M. McCollough. 2002. Habitat selection by wood turtles (Clemmys insculpta): an application of paired logistic regression. Ecology 83:833-843.

Conant, R., and J. T. Collins. 1998. A field guide to reptiles and amphibians of eastern and central North America. Third edition, expanded. Houghton Mifflin, New York, New York, USA.

Congdon, J. D., A. E. Dunham, and R. C. van Loben Sels. 1993. Delayed sexual maturity and demographics of Blanding's turtles (Emydoidea blandingii): implications for conservation and management of long-lived organisms. Conservation Biology 7:826833.

Congdon, J. D., A. E. Dunham, and R. C. van Loben Sels. 1994. Demographics of common snapping turtles (Chelydra serpentine): implications for conservation and management of long-lived organisms. American Zoologist 34:397-408.

Constantz, G, N. Ailes, and D. Malakoff. 1995. Portrait of a river: the ecological baseline of the Cacapon River. Pine Cabin Run Ecological Laboratory. High View, West Virginia, USA.

Costanzo, J. P., J. B. Iverson, M. F. Wright, and R. E. Lee, Jr. 1995. Cold hardiness and overwintering strategies of hatchlings in an assemblage of northern turtles. Ecology 76:1772-1785.

Convention on International Trade in Endangered Species of Wild Fauna and Flora (CITES). 2008. Appendices I, II, and III. International Environment House, Geneva, Switzerland.

Daigle, C., and J. Jutras. 2005. Quantitative evidence of decline in a southern Quebec wood turtle (Glyptemys insculpta) population. Journal of Herpetology 39:130-132.

Doyle, A. T. 1990. Use of riparian and upland habitats by small mammals. Journal of Wildife 
Management 71:14-23.

Dubois, Y., G. Blouin-Demers, and D. Thomas. 2008. Temperature selection in wood turtles (Glyptemys insculpta) and its implications for energetics. Ecoscience 15:398-406.

Dufrêne, M., and P. Legendre. 1997. Species assemblages and indicator species: the need for a flexible asymmetrical approach. Ecological Monographs 67:345-366.

Endangered Species Coalition. 2008. Without a net: top ten wildlife, fish and plants in need of Endangered Species Act protection. www.StopExtinction.org. <www.stopextinction.org/images/WithoutANet-high.pdf>. Accessed 13 April 2009.

Ernst, C. H. 1968. Evaporative water-loss relationships of turtles. Journal of Herpetology 2:159161.

Ernst, C. H. 1986. Environmental temperatures and activities in the wood turtle, Clemmys insculpta. Journal of Herpetology 20:222-229.

Ernst, C. H. 2001. An overview of the North American turtle genus Clemmys Ritgen, 1828. Chelonian Conservation and Biology 4:211-216.

Ernst, C. H., J. E. Lovich, and R. W. Barbour. 1994. Turtles of the United States and Canada. Smithsonian Institution, Washington, D.C., USA.

Faraway, J. J. 2005. Linear models with R. Chapman and Hall/CRC, Boca Raton, Florida, USA.

Farrell, R. F., and T. E. Graham. 1991. Ecological notes on the turtle Clemmys insculpta in northwestern New Jersey. Journal of Herpetology 25:1-9.

Forney, K. A., and M. E. Gilpin. 1989. Spatial structure and population extinction: a study with Drosophila flies. Conservation Biology 3:45-51.

Garber, S. D., and J. Burger. 1995. A 20-yr. study documenting the relationship between turtle decline and human recreation. Ecological Applications 5:1151-1162. 
Getz, W. M., S. Fortmann-Roe, P. C. Cross, A. J. Lyons, S. J. Ryan, and C. C. Wilmers. 2007. LoCoH: nonparametric kernel methods for constructing home ranges and utilization distributions. PLoS ONE 2:1-11.

Giuliano, W. M., and J. D. Homyack. 2004. Short-term grazing exclusion effects on riparian small mammal communities. Journal of Range Management 57:346-350.

Greaves, W. F., and J. D. Litzgus. 2007. Overwintering ecology of wood turtles (Glyptemys insculpta) at the species' northern range limit. Journal of Herpetology 41:32-40.

Greaves, W. F., and J. D. Litzgus. 2008. Chemical, thermal, and physical properties of sites selected for overwintering by northern wood turtles (Glyptemys insculpta). Canadian Journal of Zoology 86:659-667.

Greaves, W. F. and J. D. Litzgus. 2009. Variation in life-history characteristics among populations of North American wood turtles: a view from the north. Journal of Zoology 2009:1-12.

Green, N. B., and T. K. Pauley. 1987. Amphibians and reptiles in West Virginia. University of Pittsburgh, Pennsylvania, USA.

Guisan, A., and U. Hofer. 2003. Predicting reptile distributions at the mesoscale: relation to climate and topography. Journal of Biogeography 30:1233-1243.

Harding, J. H., and T. J. Bloomer. 1979. The wood turtle, Clemmys insculpta ... a natural history. Herp_-Bulletin of the New York Herpetological Society 15:9-26.

Hecnar, S. J. 1999. Patterns of turtle species' geographic range size and a test of Rapoport's rule. Ecography 22:436-446.

Hess, G. R. 1996. Linking extinction to connectivity and habitat destruction in metapopulation models. American Naturalist 148:226-236. 
Hilton-Taylor, C. (Comp.). 2000. 2000 International Union on the Conservation of Nature (IUCN) Red List of Threatened Species. IUCN, Giland, Switzerland.

Holman, J. A. 1976. Paleoclimatic implications of "ecologically incompatible" herpetological species (late Pleistocene: southeastern United States). Herpetologica 32:290-295.

Holt, R. D., and T. H. Keitt. 2000. Alternative causes for range limits: a metapopulation perspective. Ecology Letters 3:41-47.

Hunter, M. L., Jr., and A. Hutchinson. 1994. The virtues and shortcomings of parochialism: conserving species that are locally rare, but globally common. Conservation Biology 8:1163-1165.

Hurvich, C. M., and C. -L. Tsai. 1989. Regression and time series model selection in small samples. Biometrika 76:297-307.

Iverson, J. B. 1986. Checklist with distribution maps of the turtles of the world. Privately printed, Paust Printing, Richmond, Indiana, USA.

Jones, M. T., and P. R. Sievert. 2009. Effects of stochastic flood disturbance on adult wood turtles, Glyptemys insculpta, in Massachusetts. Canadian Field Naturalist 123:313-322.

Kaufmann, J. H. 1986. Stomping for earthworms by wood turtles, Clemmys insculpta: a newly discovered foraging technique. Copeia 1986:1001-1004.

Kaufmann, J. H. 1992. Habitat use by wood turtles in central Pennsylvania. Journal of Herpetology 26:315-321.

Kaufmann, J. H. 1995. Home ranges and movements of wood turtles, Clemmys insculpta, in central Pennsylvania. Copeia 1995:22-27.

Keselman, H. J., and J. C. Rogan. 1978. A comparison of the modified-Tukey and Scheffe 
methods of multiple comparisons for pairwise contrasts. Journal of the American Statistical Association 73:47-52.

Kozar, M. D., and M. V. Mathes. 2001. Aquifer-characteristics data for West Virginia. WaterResources Investigations Report 01-4036. U.S. Geological Survey, U.S. Department of the Interior. Charleston, USA.

Kutner, M. H., C. J. Nachtsheim, J. Neter, and W. Li. 2005. Applied linear statistical models. Fifth edition. McGraw-Hill/Irwin, New York, New York, USA.

Lawton, J. H. 1994. Population dynamic principles. Philosophical Transactions of the Royal Society of London B 344:61-68.

Lehtinen, R. M., J. -B. Ramanamanjato, and J. G. Raveloarison. 2003. Edge effects and extinction proneness in a herpetofauna from Madagascar. Biodiversity and Conservation 12:1357-1370.

Lorion, C. M., and B. P. Kennedy. 2009. Relationships between deforestation, riparian forest buffers and benthic macroinvertebrates in neotropical headwater streams. Freshwater Biology 54:165-180.

Lunney, G. H. 1970. Using analysis of variance with a dichotomous dependent variable: an empirical study. Journal of Educational Measurement 7:263-269.

Mazerolle, M. J., L. L. Bailey, W. L. Kendall, J. A. Royle, S. J. Converse, and J. D. Nichols. 2007. Making great leaps forward: accounting for detectability in herpetological field studies. Journal of Herpetology 41:672-689.

McCoard, N. S. 2008. Ecology, reproduction, and morphometrics of the common ribbonsnake (Thamnophis sauritus) and the eastern gartersnake (Thamnophis sirtalis) in West Virginia. Thesis, Marshall University, Huntington, USA. 
McCoard, K. R. P. 2012. Riparian ecological community assessment with an emphasis on wood turtles (Glyptemys insculpta) in the Cacapon River watershed, West Virginia. Dissertation, West Virginia University, Morgantown, USA.

McComb, W. C., K. McGarigal, and R. G. Anthony. 1993. Small mammal and amphibian abundance in streamside and upslope habitats of mature Douglas-fir stands, western Oregon. Northwest Science 67:7-15.

Nagelkerke, N. J. D. 1991. A note on a general definition of the coefficient of determination. Biometrika 78:691-692.

National Park Service [NPS]. 1982. Draft wild and scenic river study: Cacapon River, West Virginia. Department of Interior, USA.

Niederberger, A. J., and M. E. Seidel. 1999. Ecology and status of a wood turtle (Clemmys insculpta) population in West Virginia. Chelonian Conservation and Biology 3:414-418.

Palmer, G. C., and A. F. Bennett. 2006. Riparian zones provide for distinct bird assemblages in forest mosaics of south-east Australia. Biological Conservation 130:447-457.

Parmalee, P. W., and W. E. Klippel. 1981. Remains of the wood turtle Clemmys insculpta (Le Conte) from a late Pleistocene deposit in middle Tennessee. American Midland Naturalist 105:413-416.

Parmesan, C., and G. Yohe. 2003. A globally coherent fingerprint of climate change impacts across natural systems. Nature 421:37 - 42 .

Pielou, E. C. 1991. After the ice: the return of life to glaciated North America. University of Chicago, Illinois, USA.

Pough, F. H., C. M. Janis, and J. B. Heiser. 2005. Vertebrate life. Seventh edition. Pearson Prentice Hall, Upper Saddle River, New Jersey, USA. 
Quinn, N. W. S., and D. P. Tate. 1991. Seasonal movements and habitat of wood turtles (Clemmys insculpta) in Algonquin Park, Canada. Journal of Herpetology 25:217-220.

Quist, M. C., W. A. Hubert, and F. J. Rahel. 2004. Elevation and stream-size thresholds affect distributions of native and exotic warmwater fishes in Wyoming. Journal of Freshwater Ecology 19:227-236.

Remsberg, A. J., T. L. Lewis, P. W. Huber, and K. A. Asmus. 2006. Home ranges of wood turtles (Glyptemys insculpta) in northern Michigan. Chelonian Conservation and Biology $5: 42-47$.

Robel, R. J., J. N. Briggs, A. D. Dayton, and L. C. Hulbert. 1970. Relationships between visual obstruction measurements and weight of grassland vegetation. Journal of Range Management 23:295-298.

Saumure, R. A., and J. R. Bider. 1998. Impact of agricultural development on a population of wood turtles (Clemmys insculpta) in southern Quebec, Canada. Chelonian Conservation and Biology 3:37-45.

Saumure, R. A., T. B. Herman, and R. D. Titman. 2007. Effects of haying and agricultural practices on a declining species: the North American wood turtle, Glyptemys insculpta. Biological Conservation 135:565-575.

Saumure, R. A., T. B. Herman, and R. D. Titman. 2010. Effects of patch size and habitat structure on the movements of adult male wood turtles, Glyptemys insculpta. Herpetological Conservation and Biology 5:403-413.

Saunders, D. A., R. J. Hobbs, and C. R. Margules. 1991. Biological consequences of ecosystem fragmentation: a review. Conservation Biology 5:18-32.

Shively, S. H., and J. F. Jackson. 1985. Factors limiting the upstream distribution of the Sabine 
map turtle. American Midland Naturalist 114:292-303.

Spradling, T. A., J. W. Tamplin, S. S. Dow, and K. J. Meyer. 2010. Conservation genetics of a peripherally isolated population of the wood turtle (Glyptemys insculpta) in Iowa. Conservation Genetics 11:1667-1677.

Stauffer, D. F., and L. B. Best. 1980. Habitat selection by birds of riparian communities: evaluating effects of habitat alterations. Journal of Wildlife Management 44:1-15.

Stevens, S. M., and T. P. Husband. 1998. The influence of edge on small mammals: evidence from Brazilian Atlantic forest fragments. Biological Conservation 85:1-8.

Strang, C. A. 1983. Spatial and temporal activity patterns in two terrestrial turtles. Journal of Herpetology 17:43-47.

Tingley, R., D. G. McCurdy, M. D. Pulsifer, and T. B. Herman. 2009. Spatio-temporal differences in the use of agricultural fields by male and female wood turtles (Glyptemys insculpta) inhabiting an agri-forest mosaic. Herpetological Conservation and Biology 4:185-190.

Tingley, R., T. B. Herman, M. D. Pulsifer, D. G. McCurdy, and J. P. Stephens. 2010. Intraspecific niche partitioning obscures the importance of fine-scale habitat data in species distribution models. Biodiversity and Conservation 19:2455-2467.

Tuttle, S. E., and D. M. Carroll. 2005. Movements and behavior of hatchling wood turtles (Glyptemys insculpta). Northeastern Naturalist 12:331-348.

Tuyo, F., A. Boyra, P. Sanchez-Jerez, and R. J. Haroun. 2005. Multivariate analysis of the bentho-demersal ichthyofauna along soft bottoms of the Eastern Atlantic: comparison between unvegetated substrates, seagrass meadows and sandy bottoms beneath sea-cage fish farms. Marine Biology 147:1229-1237. 
Virginia Herpetological Society. 2011. Wood turtle, Glyptemys insculpta.

<www.virginiaherpetologicalsociety.com/reptiles/turtles/wood-turtle/wood_turtle.htm>. Accessed 10 March 2011.

Verdon, E., and M. A. Donnelly. 2005. Population structure of Florida box turtles (Terrapene carolina bauri) at the southernmost limit of their range. Journal of Herpetology 39:572577.

Walde, A. D., J. R. Bider, D. Masse, R. A. Saumure, and R. D. Titman. 2007. Nesting ecology and hatching success of the wood turtle, Glyptemys insculpta, in Quebec. Herpetological Conservation and Biology 2:49-60.

Walters, K., and L. Coen. 2006. A comparison of statistical approaches to analyzing community convergence between natural and constructed oyster reefs. Journal of Experimental Marine Biology and Ecology 330:81-95.

West Virginia Division of Natural Resources [WVDNR]: Wildlife Resources Section. 2005. It's about habitat... West Virginia Wildlife Conservation Action Plan. <www.wvdnr.gov/Wildlife/PDFFiles/wvwcap.pdf>. Accessed on 25 March 2009.

West Virginia Division of Natural Resources [WVDNR]. 2008. Wood turtle data. Wildlife Diversity Database.

West Virginia Natural Heritage Program [WVNHP]. 2007. Rare, threatened and endangered animals. West Virginia Division of Natural Resources.

Williams, C. K., A. R. Ives, and R. D. Applegate. 2003. Population dynamics across geographical ranges: time-series analyses of three small game species. Ecology 84:26542667.

Wolman, M. G. 1954. A method of sampling coarse river-bed material. Transactions of the 
American Geophysical Union 35:951-956.

Yeomans, R. S. 1995. Water-finding in adult turtles: random search or oriented behaviour? Animal Behaviour 49:977-987.

Zhang, C. -H., and J. Huang. 2008. The sparsity and bias of the Lasso selection in highdimensional linear regression. Annals of Statistics 36:1567-1594.

Associate Editor: 
Table 1. Morphological characteristics of a wood turtle population (males, $n=27$; females, $n=22$; juveniles, $n=11$ ) at the southern limits of their range along the North and Lost rivers of West Virginia, USA, during summer 2010. Means (followed by the same letter are not different $(P>0.006[\alpha=0.05 / 8])$ across genders), standard errors $(\mathrm{SE})$, and ranges (min and max) are given for each characteristic. All measurements are in mm, except mass (g).

\begin{tabular}{|c|c|c|c|c|c|c|c|c|}
\hline \multirow{2}{*}{$\begin{array}{c}\text { Morphometric } \\
\text { Variable }\end{array}$} & \multicolumn{2}{|c|}{ Males } & \multicolumn{2}{|c|}{ Females } & \multicolumn{2}{|c|}{ Juveniles } & \multirow[b]{2}{*}{$F_{2,57}$} & \multirow[b]{2}{*}{$P$} \\
\hline & $\bar{x}$ & $\mathrm{SE}$ & $\bar{x}$ & SE & $\bar{x}$ & SE & & \\
\hline Carapace length $^{\mathrm{a}}$ & $192.9 \mathrm{~A}$ & 3.38 & $176.8 \mathrm{~B}$ & 2.80 & $119.1 \mathrm{C}$ & 7.32 & 69.94 & $<0.001$ \\
\hline Carapace width ${ }^{\mathrm{b}}$ & $139.3 \mathrm{~A}$ & 2.04 & $135.4 \mathrm{~A}$ & 2.20 & $93.4 \mathrm{~B}$ & 5.01 & 63.56 & $<0.001$ \\
\hline Plastron length $^{\mathrm{c}}$ & $179.0 \mathrm{~A}$ & 1.96 & $174.2 \mathrm{~A}$ & 2.55 & 117.7B & 7.59 & 75.15 & $<0.001$ \\
\hline Plastron width $^{\mathrm{d}}$ & $111.7 \mathrm{~A}$ & 1.12 & $112.2 \mathrm{~A}$ & 1.79 & $76.6 \mathrm{~B}$ & 4.86 & 64.19 & $<0.001$ \\
\hline Bridge width $^{\mathrm{e}}$ & $68.0 \mathrm{~A}$ & 1.28 & $65.6 \mathrm{~A}$ & 1.57 & $40.5 \mathrm{~B}$ & 2.84 & 57.04 & $<0.001$ \\
\hline Bridge height ${ }^{\mathrm{f}}$ & $23.7 \mathrm{~A}$ & 0.41 & $21.0 \mathrm{~B}$ & 4.47 & $13.2 \mathrm{C}$ & 1.06 & 66.98 & $<0.001$ \\
\hline Depth $^{\mathrm{g}}$ & $67.8 \mathrm{~A}$ & 1.21 & $65.4 \mathrm{~A}$ & 1.12 & $44.2 \mathrm{~B}$ & 2.62 & 55.34 & $<0.001$ \\
\hline Mass ${ }^{h}$ & $1,072.0 \mathrm{~A}$ & 43.16 & $903.0 \mathrm{~B}$ & 43.12 & $276.0 \mathrm{C}$ & 42.10 & 60.37 & $<0.001$ \\
\hline
\end{tabular}

${ }^{\mathrm{a}}$ Carapace length: male (min - max: 160.22 - 226.20); female (min - max: $\left.150.48-197.98\right)$; juvenile (min - max: 74.21 - 149.41)

${ }^{\mathrm{b}}$ Carapace width: male (min - max: 119.80 - 160.28); female (min - max: 118.67 - 153.42); juvenile (min - max: 65.14 - 119.35) 
Table 1 continued

${ }^{c}$ Plastron length: male (min - max: 157.74 - 199.78); female (min - max: 150.50 - 193.58); juvenile (min - max: 73.69 - 144.85)

${ }^{\mathrm{d}}$ Plastron width: male ( $\min$ - $\max : 99.93$ - 122.65); female ( $\left.\min -\max : 95.18-126.25\right)$; juvenile $(\min -\max : 48.57-100.45)$

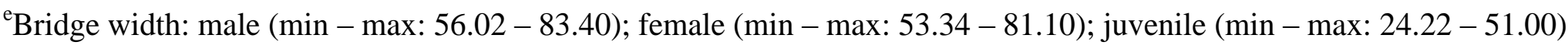

${ }^{\mathrm{f}}$ Bridge height: male (min - max: 19.22 - 26.85); female ( $\left.\min -\max : 15.24-24.97\right)$; juvenile (min - max: $\left.9.10-14.55\right)$

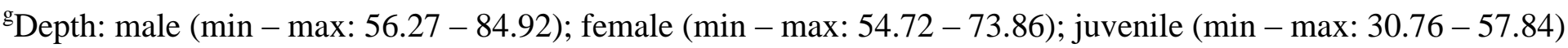

${ }^{h}$ Mass: male (min - max: 580.00 - 1,400.00); female (min - max: 480.00 - 1,180.00); juvenile (min - max: 70.00 - 460.00) 
Table 2. Diversity and richness means and standard errors (SE) for overall (natives and exotics) vegetative layers (field: woody and herbaceous plants $<1 \mathrm{~m}$ tall; shrub: woody plants $>1 \mathrm{~m}$ tall, $<5 \mathrm{~cm}$ in diameter at breast height (dbh); and tree: woody plants $>5 \mathrm{~cm}$ dbh) associated with sites related to the presence $(\mathrm{P})$ or absence $(\mathrm{A})$ of wood turtles sampled along the Lost (L) and North (N) rivers, Cacapon River Watershed, West Virginia, USA, during summer 2010. Means followed by the same letter are not different $(\alpha=0.05 / 6$ tests $=0.008$ ); main effects were not interpreted when belonging to a significant interaction.

\begin{tabular}{|c|c|c|c|c|c|c|c|c|c|c|c|c|c|}
\hline \multirow[b]{2}{*}{ Variable } & \multirow[b]{2}{*}{ Strata } & \multicolumn{2}{|c|}{ Presence Sites } & \multicolumn{2}{|c|}{ Absence Sites } & \multirow[b]{2}{*}{$F$} & \multirow[b]{2}{*}{$P$} & \multicolumn{2}{|c|}{ North River } & \multicolumn{2}{|c|}{ Lost River } & \multirow[b]{2}{*}{$F$} & \multirow[b]{2}{*}{$P$} \\
\hline & & $\bar{x}$ & SE & $\bar{x}$ & SE & & & $\bar{x}$ & SE & $\bar{x}$ & SE & & \\
\hline \multicolumn{14}{|l|}{ Diversity } \\
\hline & Field & $2.27 \mathrm{~A}$ & 0.07 & $1.79 \mathrm{~B}$ & 0.09 & 22.02 & $<0.001$ & $2.37 \mathrm{~A}$ & 0.05 & $1.68 \mathrm{~B}$ & 0.09 & 53.20 & $<0.001$ \\
\hline & Shrub & $0.50 \mathrm{~A}$ & 0.05 & $0.41 \mathrm{~A}$ & 0.07 & 1.21 & 0.274 & $0.48 \mathrm{~A}$ & 0.05 & $0.46 \mathrm{~A}$ & 0.07 & 0.00 & 0.969 \\
\hline & Tree & $0.52 \mathrm{~A}$ & 0.06 & $0.41 \mathrm{~A}$ & 0.09 & 0.55 & 0.459 & $0.53 \mathrm{~A}$ & 0.06 & $0.39 \mathrm{~A}$ & 0.08 & 2.50 & 0.117 \\
\hline \multicolumn{14}{|l|}{ Richness } \\
\hline & Field & $15.34 \mathrm{~A}$ & 0.71 & $11.11 \mathrm{~B}$ & 0.92 & 10.12 & 0.002 & $16.84 \mathrm{~A}$ & 0.63 & $9.10 \mathrm{~B}$ & 0.65 & 61.22 & $<0.001$ \\
\hline & Shrub & 1.89 & 0.14 & 1.94 & 0.28 & 0.01 & 0.912 & 2.13 & 0.17 & 1.56 & 0.21 & 5.40 & 0.022 \\
\hline & Tree & $1.81 \mathrm{~A}$ & 0.15 & $1.75 \mathrm{~A}$ & 0.31 & 0.44 & 0.510 & $1.84 \mathrm{~A}$ & 0.16 & $1.72 \mathrm{~A}$ & 0.29 & 0.74 & 0.391 \\
\hline
\end{tabular}


Table 3. Tukey tests (significant or, when relevant, interaction simple effects [site differences within rivers]) with $95 \%$ confidence intervals (CI) related to vegetative (field layer: woody and herbaceous plants, $<1 \mathrm{~m}$ tall; shrub: woody plants $>1 \mathrm{~m}$ tall, $<5 \mathrm{~cm}$ in diameter at breast height (dbh); and tree: woody plants $>5 \mathrm{~cm}$ dbh) diversity and richness within sites with the presence (P) or absence (A) of wood turtles along the Lost and North rivers, Cacapon River Watershed, West Virginia, during summer 2010.

\begin{tabular}{|c|c|c|c|c|c|}
\hline Variable & Contrast & Difference & Lower CI & Upper CI & $P$ \\
\hline \multicolumn{6}{|c|}{ Overall Field Diversity } \\
\hline & $\mathrm{P}-\mathrm{A}$ & 3.905 & 2.587 & 5.224 & $<0.001$ \\
\hline & North - Lost & 4.715 & 3.416 & 6.014 & $<0.001$ \\
\hline \multicolumn{6}{|c|}{ Native Field Diversity } \\
\hline & $\mathrm{P}-\mathrm{A}$ & 2.413 & 1.287 & 3.539 & $<0.001$ \\
\hline & North - Lost & 3.748 & 2.640 & 4.856 & $<0.001$ \\
\hline \multicolumn{6}{|c|}{ Overall Field Richness } \\
\hline & $\mathrm{P}-\mathrm{A}$ & 4.233 & 2.394 & 6.071 & $<0.001$ \\
\hline & North - Lost & 7.029 & 5.220 & 8.838 & $<0.001$ \\
\hline \multicolumn{6}{|c|}{ Native Field Richness } \\
\hline & $\mathrm{P}-\mathrm{A}$ & 0.506 & 0.267 & 0.746 & $<0.001$ \\
\hline & North - Lost & 0.875 & 0.639 & 1.11 & $<0.001$ \\
\hline \multicolumn{6}{|c|}{ Overall Shrub Richness } \\
\hline & P: Lost - A: Lost & 0.322 & 0.006 & 0.639 & 0.044 \\
\hline & P: North - A: North & -0.262 & -0.538 & 0.015 & 0.071 \\
\hline & A: North - A: Lost & 0.539 & 0.210 & 0.867 & $<0.001$ \\
\hline \multicolumn{6}{|c|}{ Native Shrub Richness } \\
\hline & North - Lost & 0.472 & 0.223 & 0.721 & $<0.001$ \\
\hline \multicolumn{6}{|c|}{ Native Tree Diversity } \\
\hline & North - Lost & 0.122 & 0.044 & 0.201 & 0.003 \\
\hline \multicolumn{6}{|c|}{ Native Tree Richness } \\
\hline & North - Lost & 0.446 & 0.248 & 0.643 & $<0.001$ \\
\hline
\end{tabular}


Table 4. Diversity and richness means and standard errors (SE) for native vegetative layers (field: woody and herbaceous plants <1 $\mathrm{m}$ tall; shrub: woody plants $>1 \mathrm{~m}$ tall, $<5 \mathrm{~cm}$ in diameter at breast height (dbh); and tree: woody plants $>5 \mathrm{~cm}$ dbh) associated with sites related to the presence $(\mathrm{P})$ or absence $(\mathrm{A})$ of wood turtles sampled along the Lost $(\mathrm{L})$ and North $(\mathrm{N})$ rivers, Cacapon River Watershed, West Virginia, USA, during summer 2010. Means followed by the same letter are not different $(\alpha=0.05 / 6$ tests $=0.008)$. No site $\times$ river interactions were significant $(P>0.009)$.

\begin{tabular}{|c|c|c|c|c|c|c|c|c|c|c|c|c|c|}
\hline \multirow[b]{2}{*}{ Variable } & \multirow[b]{2}{*}{ Strata } & \multicolumn{2}{|c|}{ Presence Sites } & \multicolumn{2}{|c|}{ Absence Sites } & \multirow[b]{2}{*}{$F$} & \multirow[b]{2}{*}{$P$} & \multicolumn{2}{|c|}{ North River } & \multicolumn{2}{|c|}{ Lost River } & \multirow[b]{2}{*}{$F$} & \multirow[b]{2}{*}{$P$} \\
\hline & & $\bar{x}$ & SE & $\bar{x}$ & SE & & & $\bar{x}$ & $\mathrm{SE}$ & $\bar{x}$ & SE & & \\
\hline \multicolumn{14}{|l|}{ Diversity } \\
\hline & Field & $1.89 \mathrm{~A}$ & 0.07 & $1.38 \mathrm{~B}$ & 0.11 & 9.25 & 0.003 & $1.96 \mathrm{~A}$ & 0.07 & $1.28 \mathrm{~B}$ & 0.09 & 46.42 & $<0.001$ \\
\hline & Shrub & $0.14 \mathrm{~A}$ & 0.04 & $0.12 \mathrm{~A}$ & 0.05 & 0.01 & 0.923 & $0.18 \mathrm{~A}$ & 0.04 & $0.05 \mathrm{~A}$ & 0.03 & 6.97 & 0.010 \\
\hline & Tree & $0.48 \mathrm{~A}$ & 0.06 & $0.40 \mathrm{~A}$ & 0.09 & 0.14 & 0.71 & $0.57 \mathrm{~A}$ & 0.07 & $0.26 \mathrm{~B}$ & 0.07 & 9.86 & 0.002 \\
\hline \multicolumn{14}{|l|}{ Richness } \\
\hline & Field & $10.44 \mathrm{~A}$ & 0.53 & $7.58 \mathrm{~B}$ & 0.71 & 8.23 & 0.005 & $11.54 \mathrm{~A}$ & 0.49 & $6.08 \mathrm{~B}$ & 0.47 & 55.89 & $<0.001$ \\
\hline & Shrub & $0.77 \mathrm{~A}$ & 0.12 & $0.83 \mathrm{~A}$ & 0.19 & 0.36 & 0.550 & $1.05 \mathrm{~A}$ & 0.14 & $0.38 \mathrm{~B}$ & 0.13 & 14.61 & $<0.001$ \\
\hline & Tree & $1.77 \mathrm{~A}$ & 0.15 & $1.72 \mathrm{~A}$ & 0.31 & 0.01 & 0.903 & $2.18 \mathrm{~A}$ & 0.19 & $1.08 \mathrm{~B}$ & 0.18 & 20.66 & $<0.001$ \\
\hline
\end{tabular}


Table 5. Penalized likelihood ratio tests on the log-odds ratios and 95\% profile penalized likelihood confidence intervals (CI; original data scale) computed for a model containing microhabitat variables related to the presence of wood turtles along the Lost and North rivers, Cacapon River Watershed, West Virginia, USA, during summer 2010. Distance refers to the distance (km) of the Lost and North rivers to the Cacapon River.

\begin{tabular}{|c|c|c|c|c|c|c|c|c|c|c|c|c|c|}
\hline \multirow{4}{*}{$\begin{array}{l}\text { Variable } \\
\text { Distance }(\mathrm{km})\end{array}$} & & & & & \multicolumn{5}{|c|}{ Penalized Likelihood Ratio Tests on the } & \multirow{2}{*}{\multicolumn{4}{|c|}{$\begin{array}{c}\text { 95\% Profile Penalized Likelihood } \\
\text { Confidence Intervals }\end{array}$}} \\
\hline & \multicolumn{2}{|c|}{ Presence } & \multicolumn{2}{|c|}{ Absence } & \multicolumn{5}{|c|}{ Log-odds Ratios } & & & & \\
\hline & $\bar{x}$ & SE & $\bar{x}$ & SE & Coefficient & SE & & $\mathrm{CI}$ & $P$ & \multirow{2}{*}{$\begin{array}{l}\text { Unit } \\
1.00\end{array}$} & \multirow{2}{*}{$\begin{array}{c}\text { Estimate } \\
0.84\end{array}$} & \multicolumn{2}{|c|}{$95 \% \mathrm{CI}$} \\
\hline & 24.8 & 1.3 & 48.3 & 2.3 & -2.29 & 0.75 & -4.08 & -0.98 & $<0.001$ & & & 0.74 & 0.93 \\
\hline Elevation (m) & 299.9 & 8.9 & 430.0 & 16.1 & -1.84 & 0.56 & -3.14 & -0.85 & $<0.001$ & 1.00 & 0.98 & 0.97 & 0.99 \\
\hline Stream Depth $(\mathrm{cm})$ & 54.5 & 2.8 & 32.8 & 3.7 & 0.80 & 0.42 & 0.01 & 1.70 & 0.047 & 1.00 & 1.03 & 1.00 & 1.07 \\
\hline Canopy Cover (\%) & 52.9 & 3.6 & 44.9 & 5.5 & 1.71 & 0.56 & 0.72 & 3.08 & $<0.001$ & 1.00 & 1.06 & 1.02 & 1.11 \\
\hline Slope $\left(^{\circ}\right)$ & 8.4 & 0.8 & 10.1 & 1.4 & -1.27 & 0.44 & -2.30 & -0.49 & 0.001 & 1.00 & 0.84 & 0.73 & 0.93 \\
\hline Soil Temperature $\left({ }^{\circ} \mathrm{C}\right)$ & 22.9 & 0.3 & 21.9 & 0.8 & 1.07 & 0.42 & 0.29 & 2.00 & 0.008 & 1.00 & 1.40 & 1.09 & 1.86 \\
\hline
\end{tabular}




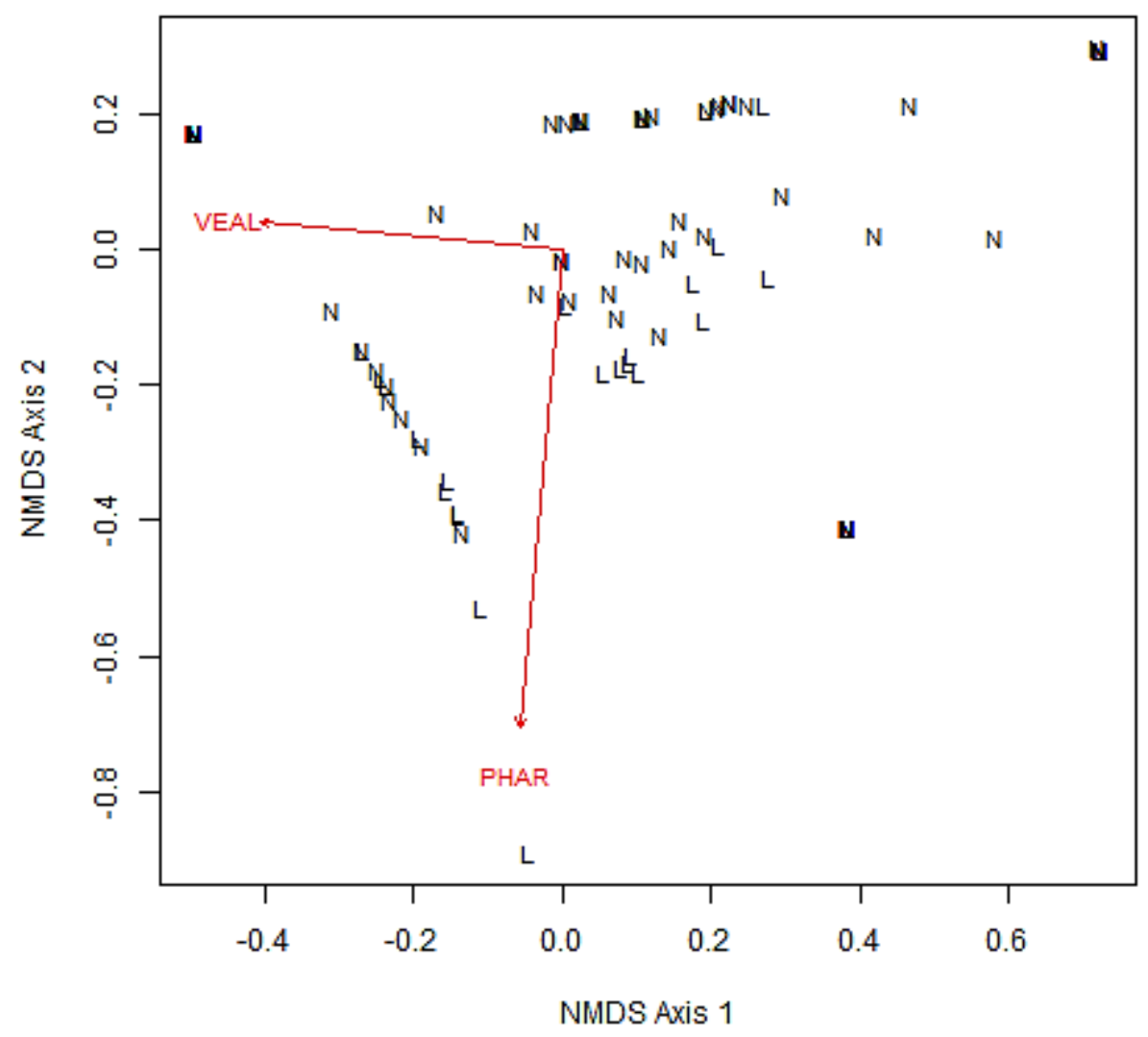

Figure 1. Non-metric multidimensional scaling (NMDS) plot (vegan package, R) of native field layer (woody and herbaceous plants <1 m tall) indicator species along the Lost (L) River, Cacapon River Watershed, West Virginia, USA, during summer 2010 surveys for wood turtles. The species were wingstem (VEAL) and reed canary grass (PHAR). No indicator species occurred along the North (N) River, or with regards to the presence or absence of wood turtles. 

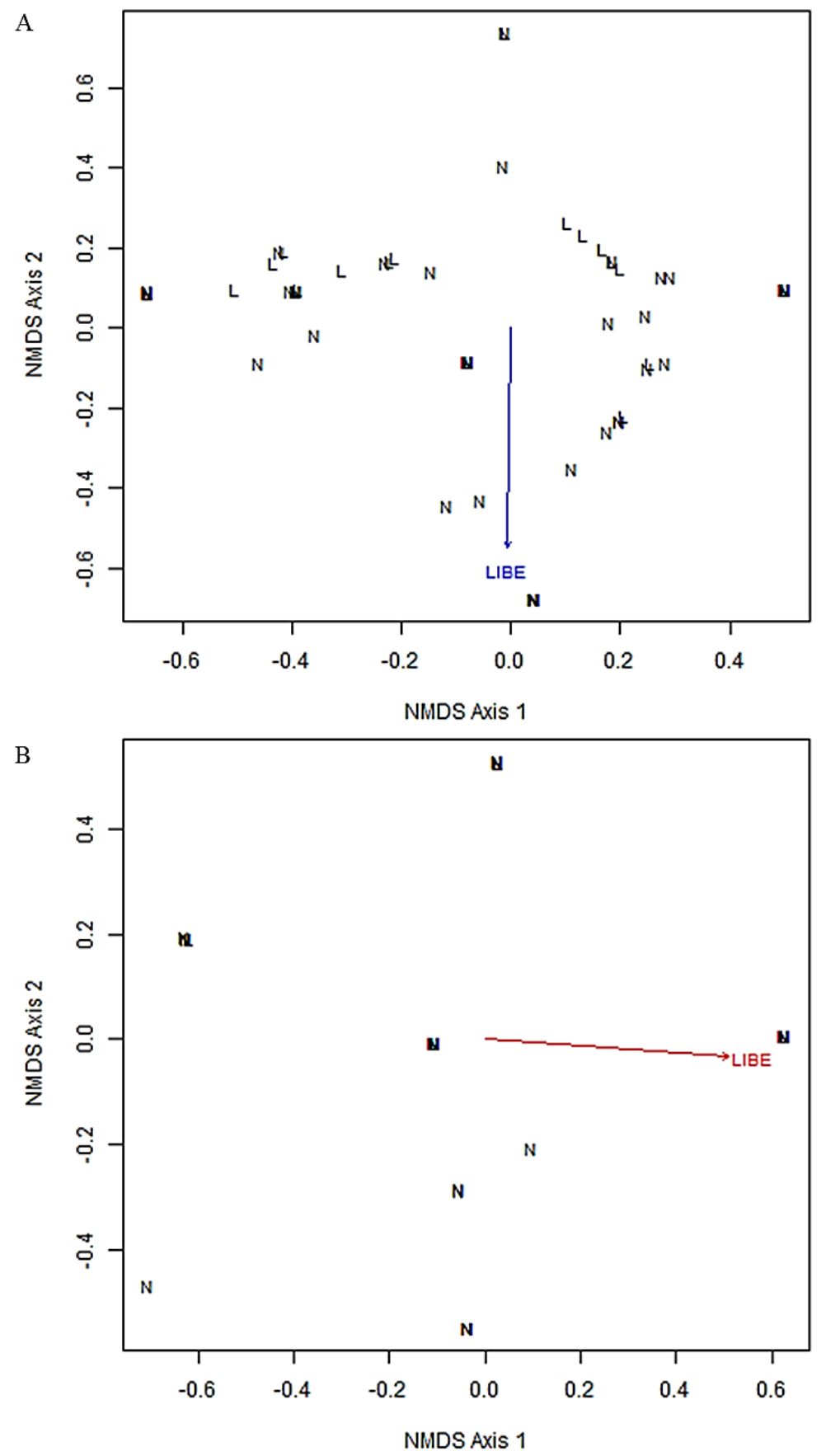

Figure 2. Non-metric multidimensional scaling (NMDS) plot (vegan package, R) of (A) overall (natives and exotics) and (B) native shrub ( $>1 \mathrm{~m}$ tall, $<5 \mathrm{~cm}$ in diameter at breast height) 
indicator species observed along the North (N) River, Cacapon River Watershed, West Virginia, USA, during summer 2010 surveys for wood turtles. The only indicator species was spicebush (LIBE). No indicator species occurred along the Lost (L) River, or with regards to the presence or absence of wood turtles. 

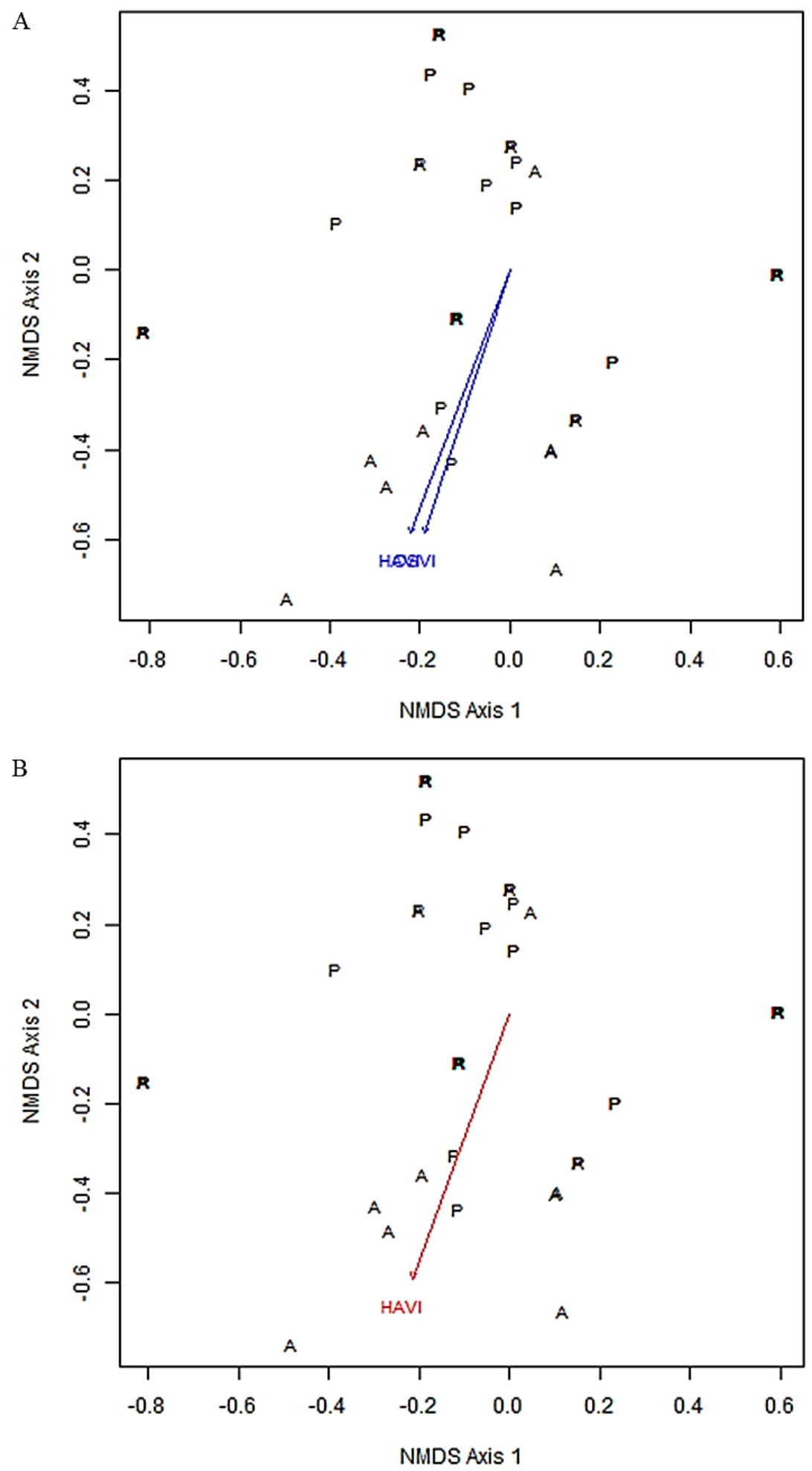

Figure 3. Non-metric multidimensional scaling (NMDS) plot (vegan package, R) of (A) overall (natives and exotics) and (B) native tree ( $>5 \mathrm{~cm}$ in diameter at breast height) indicator species 
observed in sites with the absence (A) of wood turtles along the Lost and North rivers, Cacapon River Watershed, West Virginia, USA, during summer 2010 surveys for wood turtles. The species were witch-hazel (HAVI) and ironwood (OSVI). No indicator species occurred in sites with wood turtles $(\mathrm{P})$, or with regards to river. 


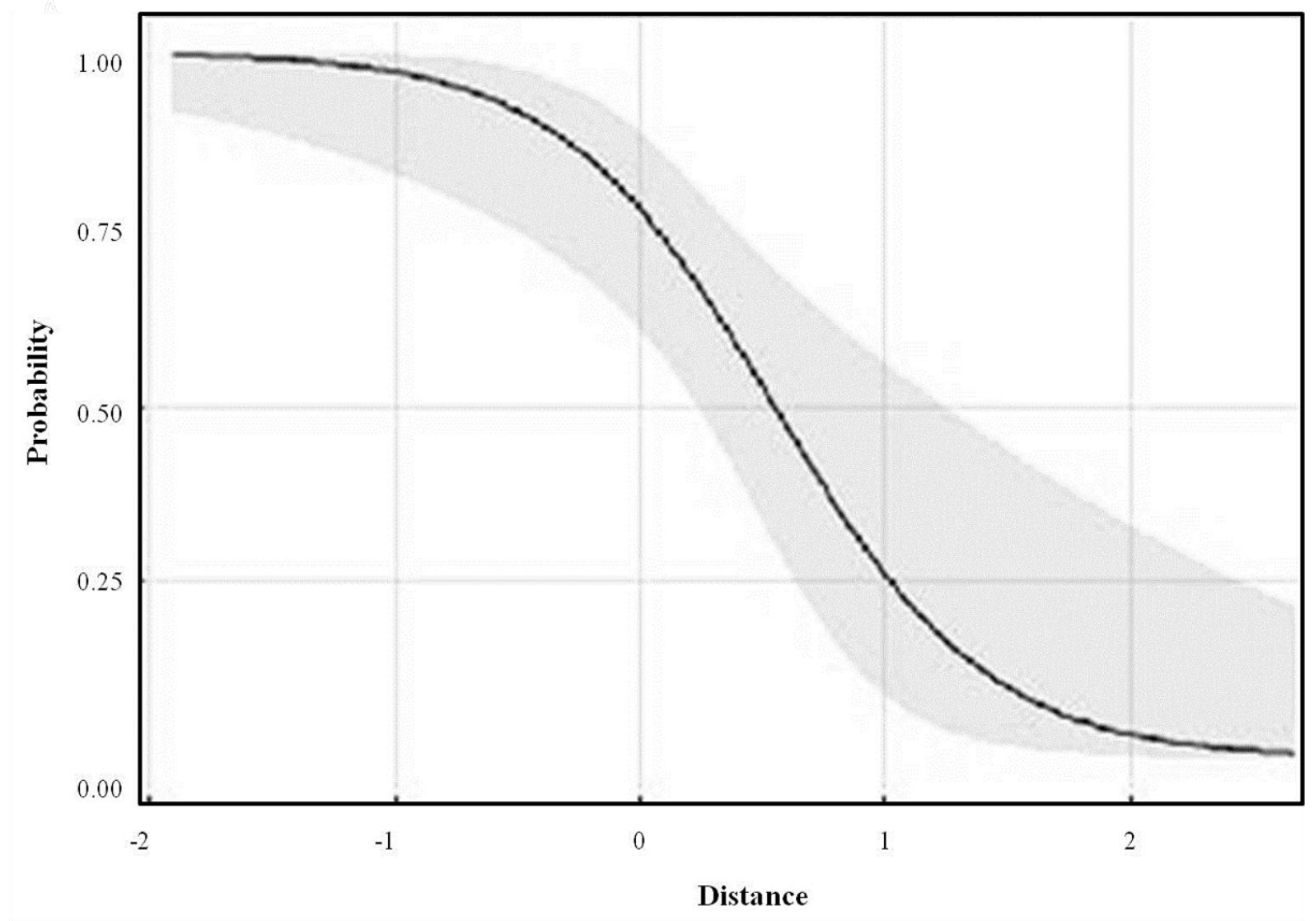

Figure 4. Log-odds model-based plot of the predicted probability of wood turtle site occupancy along the North and Lost rivers as a function of standardized distance (centered and scaled) from the Cacapon River, Cacapon River Watershed, West Virginia, USA. On the original data scale and using the lower prediction limit, the $50 \%$ and $0 \%$ predicted probabilities of site occupancy occurs about 39 and $77 \mathrm{~km}$, respectively, from the North and Lost rivers' confluence with the Cacapon River. 


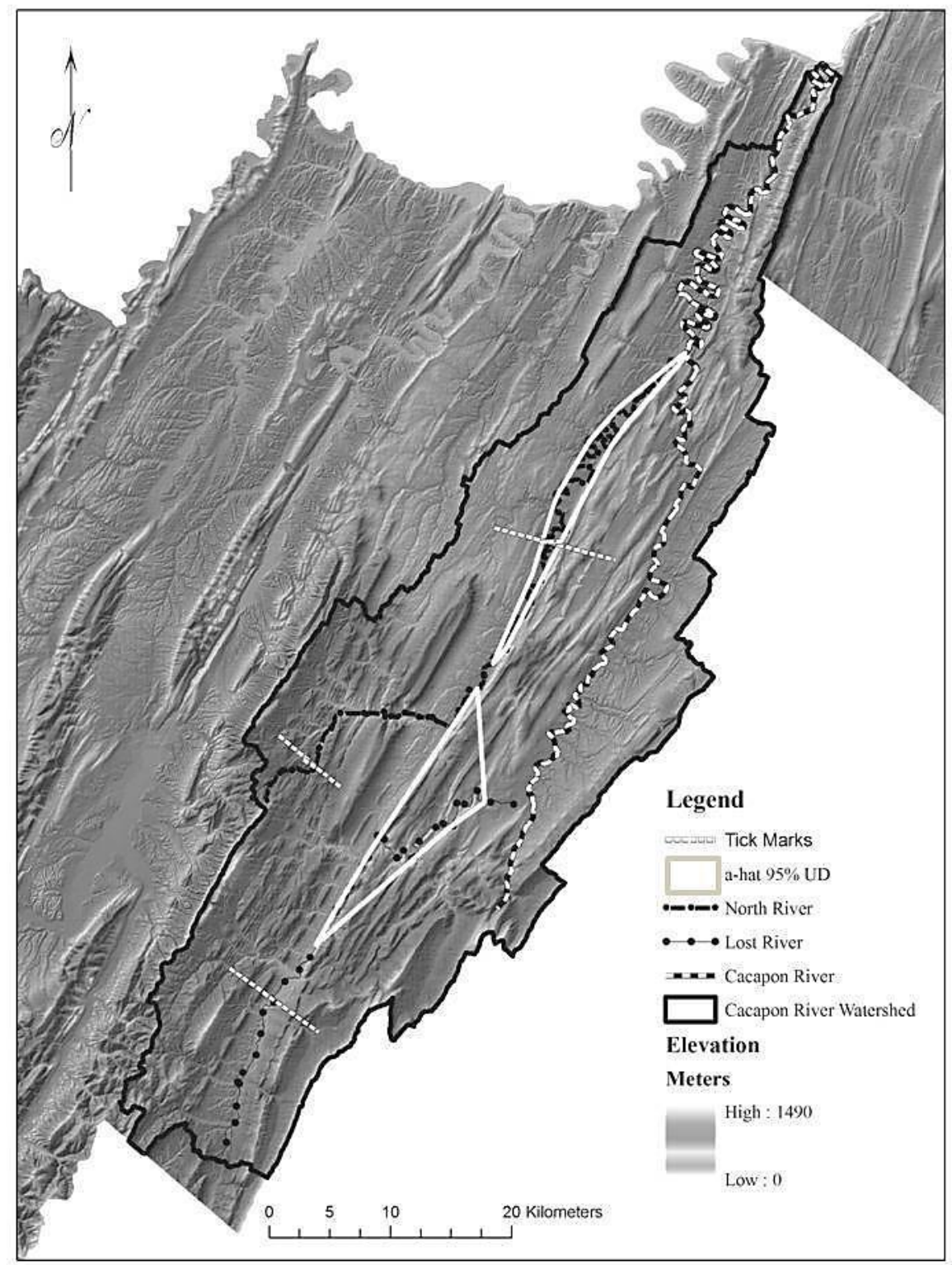

Figure 5. The Cacapon River Watershed is composed of the Cacapon River and its 2 major tributaries, the North and Lost rivers, in the eastern panhandle of West Virginia, USA. A 95\% utilization distribution (UD; adaptive local convex hull, Adehabitat package, R) for wood turtles was generated from Lost and North river sampling efforts during summer 2010. Model-driven cutpoints (tick marks) for $50 \%$ and $0 \%$ predicted probabilities of site occupancy along the North and Lost rivers are overlaid on the map. 


\section{CHAPTER V}

Conclusions, Managerial Summary, and Future Research Suggestions

Kathryn R. P. McCoard roamingwild@gmail.com West Virginia University Division of Forestry and Natural Resources

PO Box 6125

Morgantown, WV 26506 
Riparian zones provide many ecosystem services, including pollution filtration, decreases in stream bank erosion, flood impact absorption, and cooling of stream temperatures (Constantz et al. 1995). Management of riparian zones is necessary for them to continue providing beneficial services (Purcell et al. 2002, Suren et al. 2005) for both in-stream and riparian wildlife. Sources of stream degradation (e.g., silt, nutrients), often originating from adjacent agricultural and developmental areas, must be identified and reduced (Bodie 2001) as part of an effective management strategy. Degraded streams that receive restorative effects, such as planting of riparian vegetation and establishment of in-stream step-pools, can increase in biological and structural integrity similar to that of reference sites (Purcell et al. 2002). The main purpose of many stream restoration projects is to stabilize banks or protect stream infrastructure (Palmer et al. 2005), as well as improve water quality, a service that riparian zones can provide. Small streams (first - third order), such as the Cacapon River, are best selected for receiving restoration for purposes such as reducing nutrient loads carried in runoff from agricultural fields (Craig et al. 2008).

Vegetative structure and composition have an impact on which wildlife species are present within the riparian zone (Golet et al. 2008), so improvement of the habitat through restoration can be reflected through studies of riparian faunal responses. Few studies, however, have focused on the success of stream restoration projects by monitoring terrestrial wildlife (Golet et al. 2008). Deforestation of this critical habitat decreases downstream fish abundance and diversity and degrades in-stream habitat (Jones et al. 1999). Revegetation of riparian zones increases bird, amphibian, and reptile richness and small mammal diversity as well as shifting community compositions from species characteristic of dry, open canopy habitats to those found in more mesic environments (Taylor and McDaniel 1998). Young restored sites often contain 
early successional riparian species and older restored sites contain higher abundances and richness of various species (e.g., birds, bats, and beetles) that are similar to remnant riparian stands (Golet et al. 2008). Stream restoration can be considered successful in terms of riparian faunal response if the restored riparia provides benefits (e.g., foraging, breeding, nesting, and migratory habitat) for special-status species and largely restores the native faunal community (Golet et al. 2008). Along a reach of the Cacapon River, wildlife (i.e., birds, small mammals, and anurans) responses to river restoration using a before-after control-impact design were assessed through transects, trapping grids (Figure 1), and call surveys.

Multiple animal species live in or temporarily use riparian zones, including amphibians (e.g., Rudolph and Dickson 1990, Crawford and Semlitsch 2007), reptiles (e.g., Bodie 2001), small mammals (e.g., Hannon et al. 2002), and birds (e.g., Thurmond et al. 1995, Machtans et al. 1996). These transitional areas are used by wildlife for a variety of life history aspects that include nesting (Saumure et al. 2007), juvenile dispersal (Machtans et al. 1996), and foraging (Golet et al. 2008). Some animals are dependent upon riparian zones for every aspect of life, such as streamside salamanders, travelling less than $40 \mathrm{~m}$ from stream edges (Crawford and Semlitsch 2007), and wood turtles (Glyptemys insculpta), which rarely travel further than $300 \mathrm{~m}$ from stream edges (Brewster and Brewster 1991; Quinn and Tate 1991; Kaufmann 1992; Arvisais et al. 2002; McCoard 2012, Chapter 3). This interaction of wildlife and riparian zones demonstrates the great need for the conservation and restoration of this essential habitat if the ecological value of the ecosystem is to be maintained. Riparian zones adjacent to agriculture can quickly become degraded and lose value as wildlife habitat, a detrimental loss to those species that require the habitat for their persistence. In the Cacapon River Watershed, many stretches of the riparian zone have been diminished and degraded (Constantz et al. 1995). Environmental 
and habitat data were collected (Figure 2) for wood turtles living along the Cacapon, Lost, and North rivers, adjacent to agricultural and developed lands, at the southern extent of their range, to assess natural history aspects of a species dependent upon the riparian zone.

\section{OBJECTIVES}

Study 1: The response of terrestrial wildlife to stream restoration was studied based on the following objective, with its corresponding hypotheses.

1. Compare the ecological communities of birds, small mammals, and anurans between the restoration reach (RR), upstream (RS 1) and downstream (RS 2) reference sites, and upstream (CS 1) and downstream (CS 2) control sites before and after the restoration impact.

$\mathrm{H}_{\mathrm{o} 1}$ : The abundances, richness, diversity, and evenness of birds, small mammals, and anurans will not differ between sites.

$\mathrm{H}_{\mathrm{a} 1}$ : The restoration reach will increase in bird, small mammal, and anuran abundances, richness, diversity, and evenness compared to control sites, but not yet equal to reference sites.

$\mathrm{H}_{\mathrm{o} 2}$ : Community compositions will not change within sites during the course of the study.

$\mathrm{H}_{\mathrm{a} 2}$ : Only the restoration reach community composition will undergo a change post-impact.

Study 2: The ecology of wood turtles within the Cacapon River riparian zone, adjacent to agricultural lands, was studied based on the following objective. As this was an observational study, no formal hypotheses were formulated. 
1. Identify natural history characteristics of wood turtles along the upper Cacapon River by determining:

a. Morphometrics of males, females, and juveniles;

b. Home range sizes of males, females, and juveniles;

c. Activity cycles, including mating, nesting, basking, diet, terrestriality, and hibernating activities.

Study 3: The factors affecting wood turtles along the Lost and North rivers, at the southern limits of their range in West Virginia, were studied based on the following objectives, with their corresponding hypotheses.

1. Determine aquatic and terrestrial habitat characteristics relevant to the presence or absence of wood turtles along the Lost and North rivers.

$\mathrm{H}_{\mathrm{o}}$ : Wood turtles are not limited by geographic or environmental features beyond their southern range boundary.

$\mathrm{H}_{\mathrm{a}}$ : Wood turtles are limited by geographic and environmental features that are unsuitable for their survival beyond their southern range boundary.

2. Determine the approximate southern geographic boundary of wood turtles within the Cacapon River Watershed.

$\mathrm{H}_{\mathrm{o}}$ : The geographic range of wood turtles does not reach a southern termination within the Cacapon River Watershed.

$\mathrm{H}_{\mathrm{a}}$ : The geographic range of wood turtles reaches a southern termination within the Cacapon River Watershed.

3. Identify potential dispersal barriers to the west or south of the wood turtles' current range in West Virginia. 
$\mathrm{H}_{\mathrm{o}}$ : Wood turtles are not limited in their ability to disperse south or west of their current range extent.

$\mathrm{H}_{\mathrm{a}}$ : Wood turtles are limited in their ability to disperse by geographic features, such as river size and mountain elevation, preventing range expansion to the south or west.

\section{RESULTS}

\section{Responses of riparian fauna to stream restoration}

Birds (Figure 3) were counted along 50-m transects running parallel to the river, within the combined 12 sampling units along a single side of the river within the restoration reach, reference sites, and control sites. Seventy-nine species were observed during May 2009 August 2011, of which 5 were the most abundant: red-winged blackbirds (Agelaius phoeniceus), song sparrows (Melospiza melodia), American crows (Corvus brachyrhynchos), blue jays (Cyanocitta cristata), and downy woodpeckers (Picoides pubescens). The 5 abundant species and total abundances were not different among the sites, sampling months, or in the interaction of sites $\times$ months, most likely a result of the 5 species dominating all sites year-round. The restoration reach and reference sites were similar in bird composition and abundance pre- versus post-impact. However, when the restoration abundance was compared directly to control site abundance pre- versus post-impact, the restoration reach had higher abundances post-impact.

Bird richness, diversity, and evenness were similar among sites, but richness and diversity differed in the interaction of sites $\times$ sampling months. The restoration reach and reference sites were similar in diversity indices, but the restoration reach was higher in richness and diversity than the control sites post-impact. The restoration reach was rich in habitat heterogeneity (e.g., edges, interior forests, and agricultural fields were present) pre-impact, and 
the addition of cattle fencing and riparian plantings allowed the riparian buffers to increase in vegetative complexity post-impact, drawing in and supporting more birds than the control sites, and indicating restoration success. The reference reaches may not have differed from the restoration reach because they provided similar habitat heterogeneity during the course of the study.

Small mammals were trapped, ear-tagged (Figure 4), and identified to species within the combined 24 sampling units of the restoration reach, reference sites, and control sites. Six species were captured during July to August 2009, June to August 2010, and May to August 2011. Overall species abundance and Peromyscus spp. (deer mouse and white-footed mouse complex, $96.4 \%$ of all captures) abundance were similar among sites and in site $\times$ time period interactions. No difference occurred in the pre- versus post-impact comparing the restoration reach and the reference sites. However, in the pre- versus post-impact comparing the restoration reach and the control sites, the control sites had higher abundances post-impact compared to the restoration reach. The restoration reach was highly degraded initially post-impact, affecting mice numbers, but by 2011, the restoration reach Peromyscus spp. population trend paralleled those of the reference and control reaches, indicating riparian restoration success, although the numbers had not yet equaled those found within the more structurally complex control sites. Higher overall abundances across sites were observed during July 2010 compared to June 2010, but this result does not appear to be related to the restoration as it was observed in all sites, and it does not appear to be related to time of year (e.g., births or dispersal of young) because the trend minimally repeated in June and July 2011 and addition of young into the population through August did not retain the higher abundances. Higher Peromyscus spp. abundances across sites were observed primarily in May with lowest numbers in August. 
Small mammal diversity, richness, and evenness were similar among sites, time periods, and the interaction of sites $\times$ time periods. No differences in richness, diversity, or evenness were observed pre- versus post-impact between the restoration reach compared individually to the reference reaches or to the control reaches. Peromyscus spp. accounted for nearly all of the captures, dominating all of the sites. The 5 other species were captured in such low numbers as to be non-influential in the analyses.

Frog and toads (Figure 5) were monitored through frog call surveys based on the North American Amphibian Monitoring Protocol (NAAMP) that were conducted along one side of the river, at each of the 12 sampling units, occurring collectively within the restoration reach, reference sites, and control sites. Eight species were heard calling during April, June, and August of 2009, 2010, and 2011. Overall, the restoration reach appeared to have greater availability of anuran breeding microhabitats (e.g., coves, macro-depressions) compared to the other sites, regardless of restoration status. High temperatures and drought occurred during the restoration (May to June 2010) and floods (March and May 2011) swept away many breeding microhabitats post-impact, but the species may be adapted to these habitat dynamics and appeared not to be affected. Anuran richness was similar among sites, time periods, and in the site $\times$ time interaction. Perhaps the number of breeding pools was limiting and influenced the distributions of the frog and toad species observed along the river; the species used the pools available, leading to no differences in species richness among sites or related to restoration status.

Of the 8 species observed, the odds of hearing them calling were similar among sites, sampling units within sites, and restoration status, and was not influenced by cloud cover (sky code) or wind speed (wind code). American bullfrogs (Lithobates catesbeianus), pickerel frogs 
(L. palustris), green frogs (L. clamitans), and upland chorus frogs (Pseudacris feriarum) also did not have greater chances of calling during certain times of the year or that were dependent on the air temperatures measured during the study. American toads (Anaxyrus americanus), gray treefrogs (Hyla versicolor), and spring peepers (P. crucifer) had greater odds of calling depending on time of year. The American toads called primarily during April, with decreasing intensity during June and silence in August. The gray treefrogs called during April, June, and August, with increasing chances of calling during June and August. The spring peepers called primarily during April, with lower odds of calling during June and silence during August. The calling of a single species, Fowler's toad (Anaxyrus fowleri), was influenced by air temperature, with the chances of their calling increasing at about $18^{\circ} \mathrm{C}$. This species tends to breed later in the year than American toads and may perhaps have a calling temperature threshold around $18^{\circ} \mathrm{C}$.

\section{Natural history aspects of Wood Turtles}

Thirty-one wood turtles were radio-tracked (Figure 6) and an additional 254 marked from spring 2009 to summer 2011 along a 13.7-km reach of the Cacapon River to assess natural history aspects of the species living in an agri-forest environment. Males and females were similar in most morphometric characteristics, but males observed to be reproductively active were longer, thicker to allow for bigger appendages, and heavier than the females with whom they mated. Seasonal influences affected whether the turtles were primarily aquatic or terrestrial based on gender, but the general trend was for aquatic activities in autumn and winter and terrestrial activities in spring and summer. Activities that the turtles were observed undergoing were mating (Figure 7), nesting, burrowing during high temperatures, wandering through vegetation or the river, basking, foraging (Figure 8), and hibernating. The home ranges of the turtles included the stream, riparian areas, and nearby agricultural lands, especially for females who wandered 
terrestrially more often than males. When the turtles were in agricultural fields (i.e., active pastures, cornfields, and hay fields), they were typically walking between forested areas (hay fields) or to wet depressions created by cow hoofs to cool off (pasture) or foraging (moist soil of cornfields; Figure 9). About 75 to $85 \%$ of all activities, however, occurred within the riparian zone or stream. This disproportionate use of riparian zones demonstrates the importance of the habitat to the daily activities and natural history strategies of wood turtles.

\section{Southern range limitations of Wood Turtles}

A total of 100 random sites along the North and Lost rivers of the Cacapon River Watershed were surveyed for wood turtles during summer 2010. A section of the species' southern range boundary potentially occurred within the watershed, so the purpose was to distinguish between habitat within and outside of the range to determine the differences affecting the distribution of the turtles and what factors may be limiting further dispersal to the south and west. Sixty-four sites contained wood turtles as the rivers drew consecutively closer to their confluence with the Cacapon River. The 29 measured environmental variables were reduced through LASSO (least absolute shrinkage and selection operator) regression in conjunction with AICc (Akaike Information criterion for finite sample sizes with a penalty for extra parameters) to 6 parameters of importance in a final habitat model: decreasing elevation, decreasing distance from confluence with the Cacapon River, increasing stream depth, increasing canopy cover, decreasing slope, and increasing soil temperature. Sites with wood turtles had higher herbaceous diversity and richness than sites without the turtles, but did not differ in vegetation characteristics related to shrubs, trees, or community composition (Figure 10). 


\section{MANAGEMENT IMPLICATIONS}

Riparian Restoration-Management of riparian buffers along agricultural fields should include cattle exclusion fencing and vegetation plantings to positively influence terrestrial wildlife responses to stream restoration. Through these actions, the herbaceous layer can recover from grazing by growing thick and tall for wildlife cover and food, and woody plantings should provide additional cover and perches for birds and semi-arboreal small mammals. By restoring the riparian zone, contiguity of habitat can be established for the riparian zone to continue serving as movement corridors for wildlife. Additional edge habitat would be created for edgedependent species, as well as provide temporary cover for grassland birds using adjacent agricultural fields and for forest-interior species coming to the riparian zone for water access. In addition, by terracing eroded streambanks, pockets of water in which anurans can breed may form in the lower terraces that are more frequently flooded, but still have their structure maintained from establishment of woody plantings, warm season grasses, and other seed bank species.

Wood Turtles - Maintaining riparian zones, that include native species such as wingstem (Verbesina alternifolia), wood sorrel (Oxalis spp.), sedges (Carex spp.), goldenrod (Solidago spp.), black walnut (Juglans nigra), and tulip poplar (Liriodendron tulipifera), within the wood turtles' range in low elevation, shallowly sloped floodplains adjacent to deep streams should aid in increasing the abundance of wood turtles. Management of wood turtles, especially those living in riparian areas adjacent to agricultural lands, would best be focused on restoring and maintaining riparian zones, upon which the species depends, so that the habitat can begin or continue to support persistent wildlife populations. The vegetative structure should be maintained so that high vertical density, composed primarily of native herbaceous plants, and 
moderate canopy cover can be established. Landowners should be worked with to allow riparian buffers of at least $10 \mathrm{~m}$ in width to be fenced off from agricultural fields as a step towards allowing regeneration of vegetation. If larger riparian buffers could be protected, female wood turtles would be better protected during their nesting migrations and summertime wanderings because of a decreased threat from predator exposure or injury from agricultural machinery. A healthy and maintained riparian zone, even those bordering agricultural lands, should thus be able to provide all of the needs that wood turtles would have to live out their life histories successfully.

Wood turtles near the extreme periphery of their range along the Lost River, however, may require more intensive management plans. The first $62 \%$ of wood turtles found along the Lost River (moving downstream) were 20 years or older and the individuals were scattered between sites without turtles. The population(s) along the Lost River may be developing into a metapopulation, as occupied patches become, and remain, separated by extensive agricultural fields. Management of these turtles would require identification and protection of suitable, occupied patches as well as restoration and maintenance of riparian corridors linking the habitat patches; these corridors may ultimately develop into permanently used habitat which would increase the amount of habitat available, resulting in population growth and stability. Landowners along the Lost River should be educated on the ecological values of wood turtles and worked with, through cost-share programs, to fence off and protect riparian buffers to aid in wood turtle persistence. Monitoring would be required throughout the restoration of the riparian corridors to determine if the wood turtles are successfully using and becoming established in them as well as to determine if reproduction and recruitment are occurring to maintain the population. If reproduction is not occurring, a suggested management technique would be to 
translocate reproductively active individuals into the restored habitat to promote population growth.

\section{FUTURE RESEARCH SUGGESTIONS}

The restoration reach should continue to be monitored as time length post-impact increases to determine if the results observed in this study were temporary responses to the restoration, or if, as the riparian zone matures, a greater diversity of species occupies the habitat. Additional reaches should be restored within the same watershed to determine if similar results are obtained, and if, through restoring more of one agriculturally-impacted watershed, species diversity improves throughout the watershed instead of only the locally restored sections.

To determine the degree to which structurally complex vegetation influences terrestrial wildlife diversity in riparian zones, restored sites of various ages should be compared to mature stands and to stands with selective cutting (and resulting growth of shrubs) to determine how abundances, richness, diversity, and composition of species changes in response to restored riparian stands as they progress towards a mature stand (with minimal shrub cover). If overall responses are highest in the selective-cutting stand, and in successional riparian zones that have adequate cover of herbaceous, mid-story, and canopy species, perhaps restored zones should be selectively managed (i.e., mowing, selective tree cutting) to always provide diverse niches within the stands to promote wildlife diversity.

The impact of the log-vanes on anuran breeding microhabitat formation should be monitored, as the log-vanes are designed to direct the water's flow away from the banks to reduce erosion. As the water is directed away, small coves may not form along the river banks; these microhabitats are essential for providing shallow, detritus-filled pools free of large fish for tadpoles to develop, sometimes for up to 2 years (e.g., American bullfrogs). 
Wood turtles were observed eating a variety of items, including the fruits of invasive species such as pokeweed (Phytolacca americana) and autumn olive (Elaeagnus umbellata). Invasive vegetation alters riparian habitats and the species compositions they support. A future study should focus on how wood turtles facilitate the spread of invasive plants by consuming their fruits and depositing the seeds elsewhere during their extensive wanderings.

\section{LITERATURE CITED}

Arvisais, M., J. -C. Bourgeois, E. Levesque, C. Daigle, D. Masse, and J. Jutrus. 2002. Home range and movements of a wood turtle (Clemmys insculpta) population at the northern limit of its range. Canadian Journal of Zoology 80:402-408.

Bodie, J. R. 2001. Stream and riparian management for freshwater turtles. Journal of Environmental Management 62:443-455.

Brewster, K. N., and C. M. Brewster. 1991. Movement and microhabitat use by juvenile wood turtles introduced into a riparian habitat. Journal of Herpetology 25:379-382.

Constantz, G, N. Ailes, and D. Malakoff. 1995. Portrait of a river: the ecological baseline of the Cacapon River. Pine Cabin Run Ecological Laboratory, High View, West Virginia, USA.

Craig, L. S., M. A. Palmer, D. C. Richardson, S. Filoso, E. S. Bernhardt, B. P. Bledsoe, M. W. Doyle, P. M. Groffman, B. A. Hassett, S. S. Kaushal, P. M. Mayer, S. M. Smith, and P. R. Wilcock. 2008. Stream restoration strategies for reducing river nitrogen loads. Frontiers in Ecology and the Envrionment 6:529-538.

Crawford, J. A., and R. D. Semlitsch. 2007. Estimation of core terrestrial habitat for streambreeding salamanders and delineation of riparian buffers for protection of biodiversity. Conservation Biology 21:152-158.

Golet, G. H., T. Gardali, C. A. Howell, J. Hunt, R. A. Luster, W. Rainey, M. D. Roberts, J. 
Silveira, H. Swagerty, and N. Williams. 2008. Wildlife response to riparian restoration on the Sacramento River. San Francisco Estuary and Watershed Science 6: article 1.

Hannon, S. J., C. A. Paszkowski, S. Boutin, J. DeGroot, S. E. Macdonald, M. Wheatley, and B. R. Eaton. 2002. Abundance and species composition of amphibians, small mammals, and songbirds in riparian forest buffer strips of varying widths in the boreal mixedwood of Alberta. Canadian Journal of Forest Research 32:1784-1800.

Jones, E. B. D. III, G. S. Helfman, J. O. Harper, and P. V. Bolstad. 1999. Effects of riparian forest removal on fish assemblages in southern Appalachian streams. Conservation Biology 13:1454-1465.

Kaufmann, J. H. 1992. Habitat use by wood turtles in central Pennsylvania. Journal of Herpetology 26:315-321.

Machtans, C. S., M. -A. Villard, and S. J. Hannon. 1996. Use of riparian buffer strips as movement corridors by forest birds. Conservation Biology 10:1366-1379.

McCoard, K. R. P. 2012. Riparian ecological community assessment with an emphasis on wood turtles in the Cacapon River watershed, West Virginia. Dissertation, West Virginia University, Morgantown, USA.

Palmer, M. A., E. Bernhardt, J. D. Allan, and the National River Restoration Science Synthesis Working Group. 2005. Standards for ecologically successful river restoration. Journal of Applied Ecology 42:208-217.

Purcell, A. H., C. Friedrich, and V. H. Resh. 2002. An assessment of a small urban stream restoration project in northern California. Restoration Ecology 10:685-694.

Quinn, N. W. S., and D. P. Tate. 1991. Seasonal movements and habitat of wood turtles (Clemmys insculpta) in Algonquin Park, Canada. Journal of Herpetology 25:217-220. 
Rudolph, D. C., and J. G. Dickson. 1990. Streamside zone width and amphibian and reptile abundance. Southwestern Naturalist 35:472-476.

Saumure, R. A., T. B. Herman, and R. D. Titman. 2007. Effects of haying and agricultural practices on a declining species: the North American wood turtle, Glyptemys insculpta. Biological Conservation 135:565-575.

Suren, A. M., T. Riis, B. J. F. Biggs, S. McMurtrie, and R. Barker. 2005. Assessing the effectiveness of enhancement activities in urban streams: I. Habitat responses. River Research and Applications 21:381-401.

Taylor, J. P., and K. C. McDaniel. 1998. Restoration of saltcedar (Tamarix sp.)-infested floodplains on the Bosque del Apache National Wildlife Refuge. Weed Technology 12:345-352.

Thurmond, D. P., K. V. Miller, and T. G. Harris. 1995. Effect of streamside management zone width on avifauna communities. Southern Journal of Applied Forestry 19:166-169. 


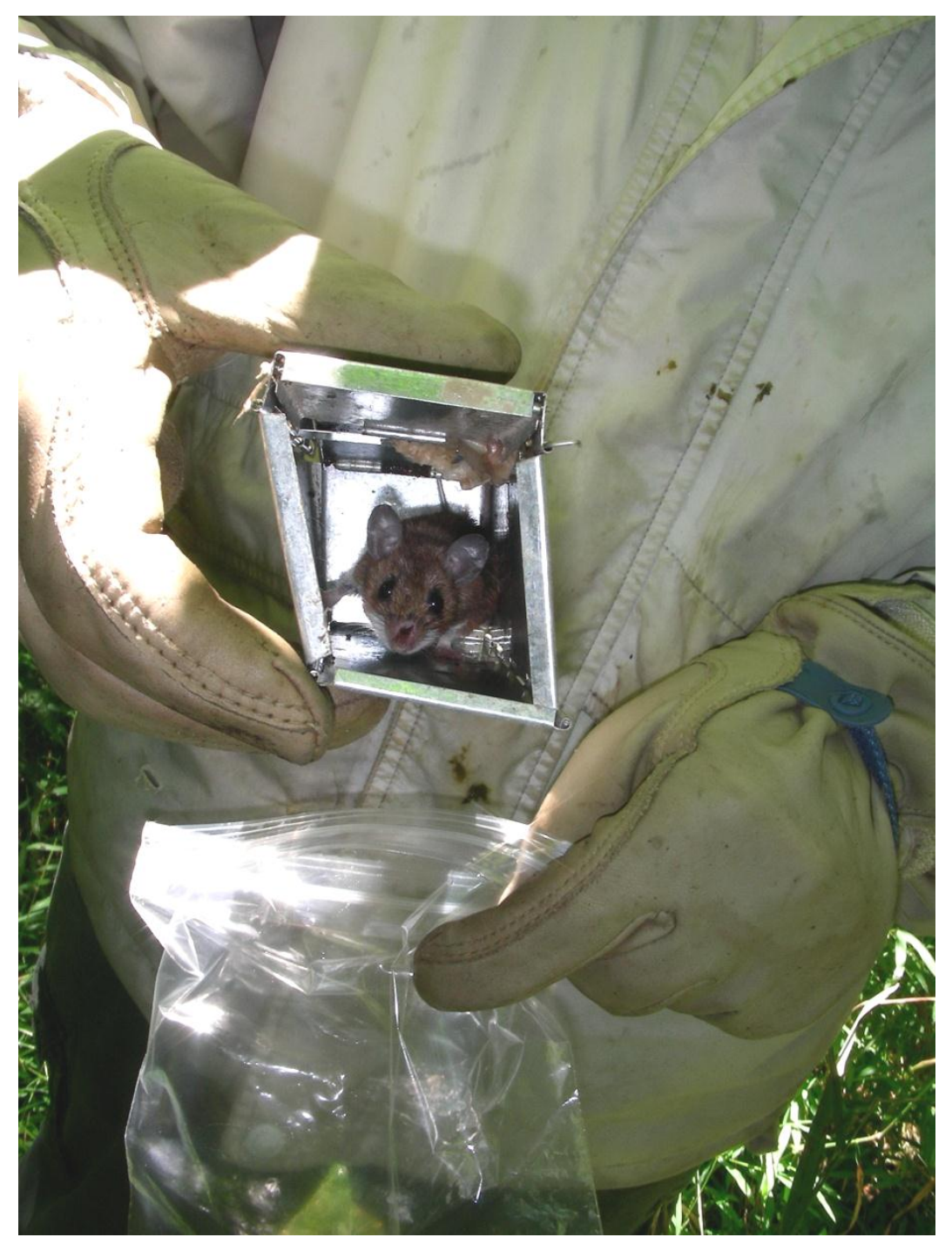

Figure 1. Photograph of Noah McCoard with a Peromyscus spp. individual to be processed, captured in a Sherman live-trap at the upstream control site, Cacapon River, West Virginia, USA, in August 2009. 


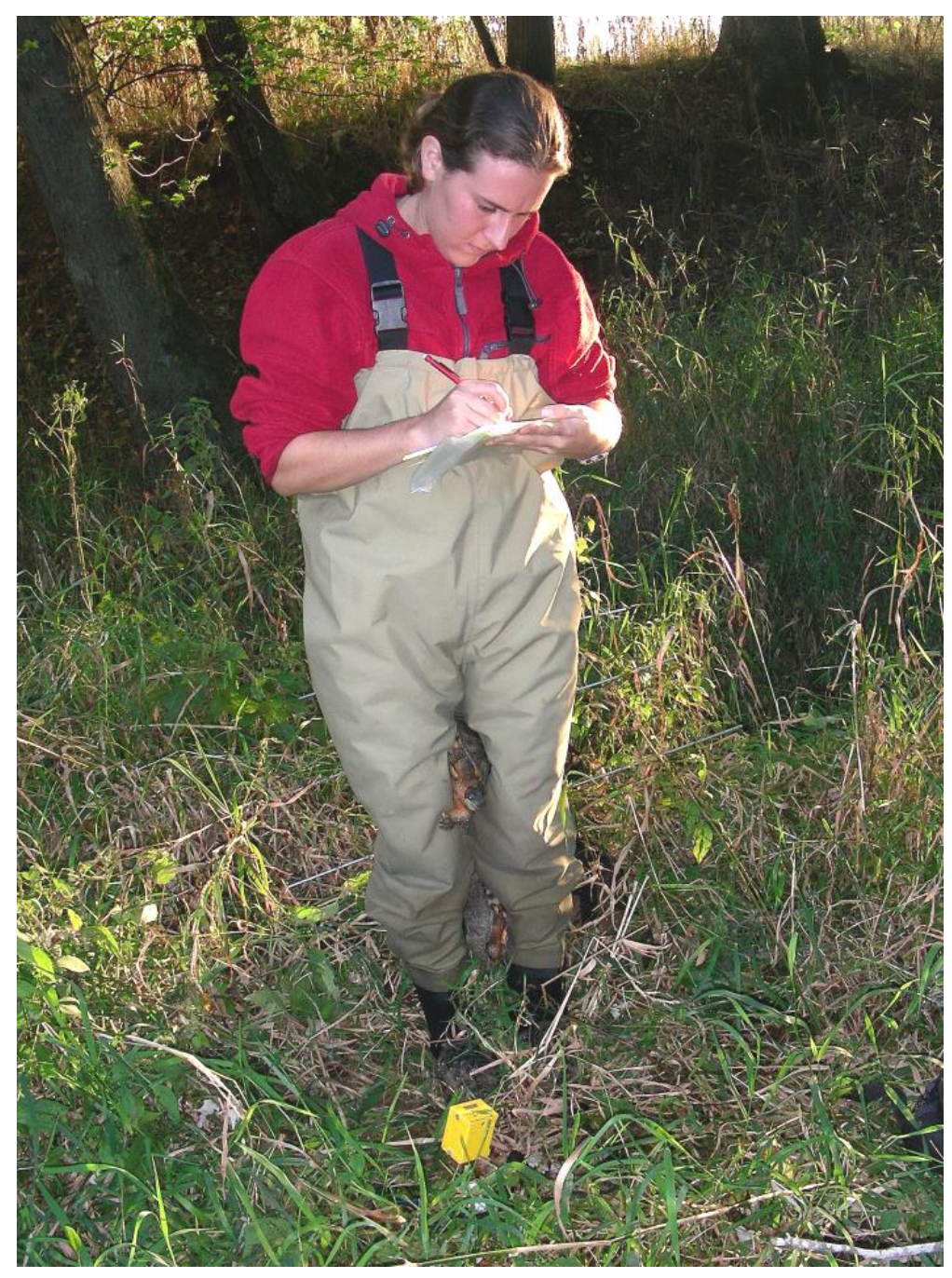

Figure 2. Photograph of Kathryn McCoard processing 2 wood turtles and their habitat along the Cacapon River, West Virginia, USA, in October 2010. 


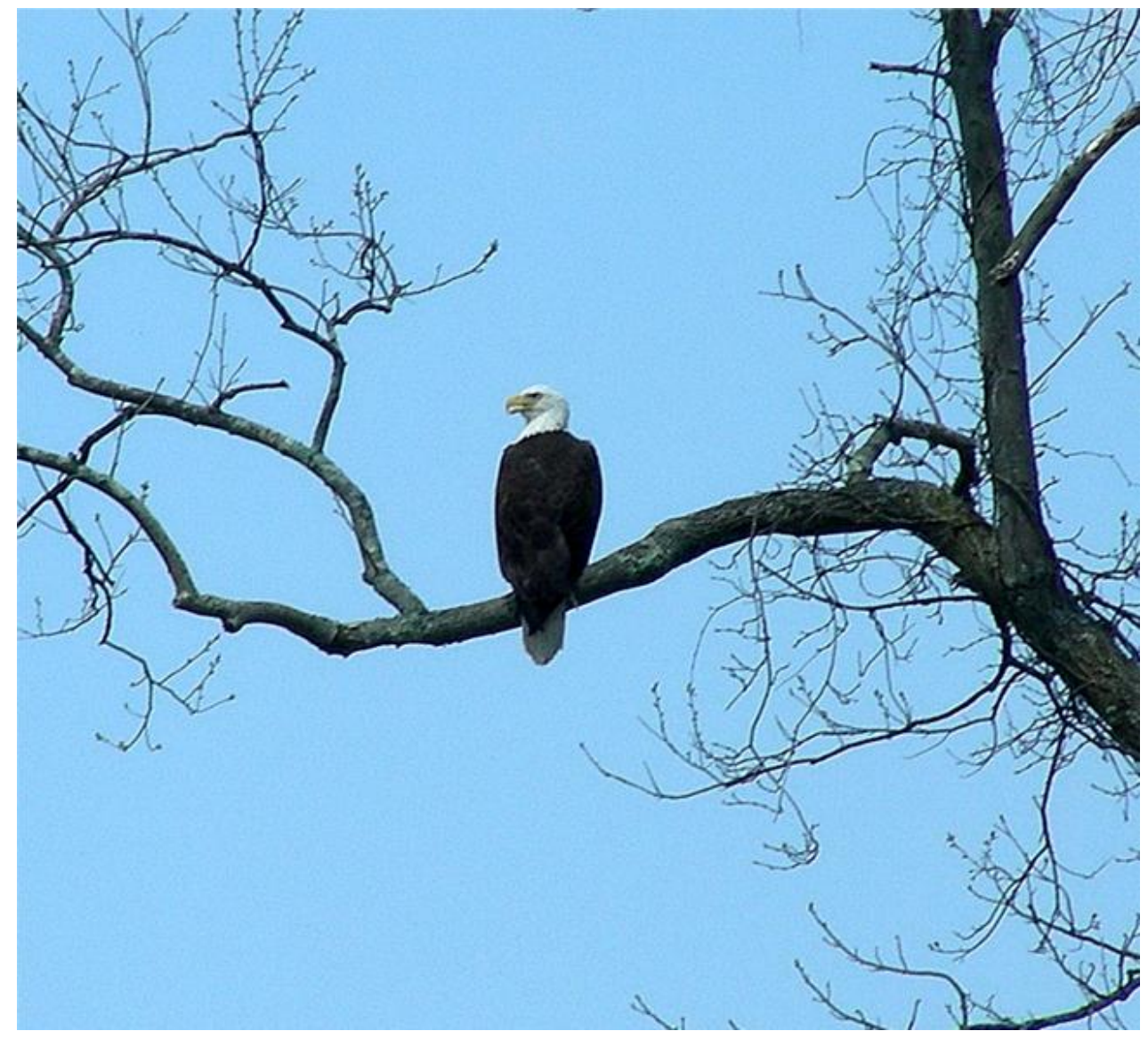

Figure 3. Photograph of a bald eagle, one of the many bird species recorded along the 13.7-km study reach of the Cacapon River, West Virginia, USA; it was taken along the restoration reach, April 2009. 


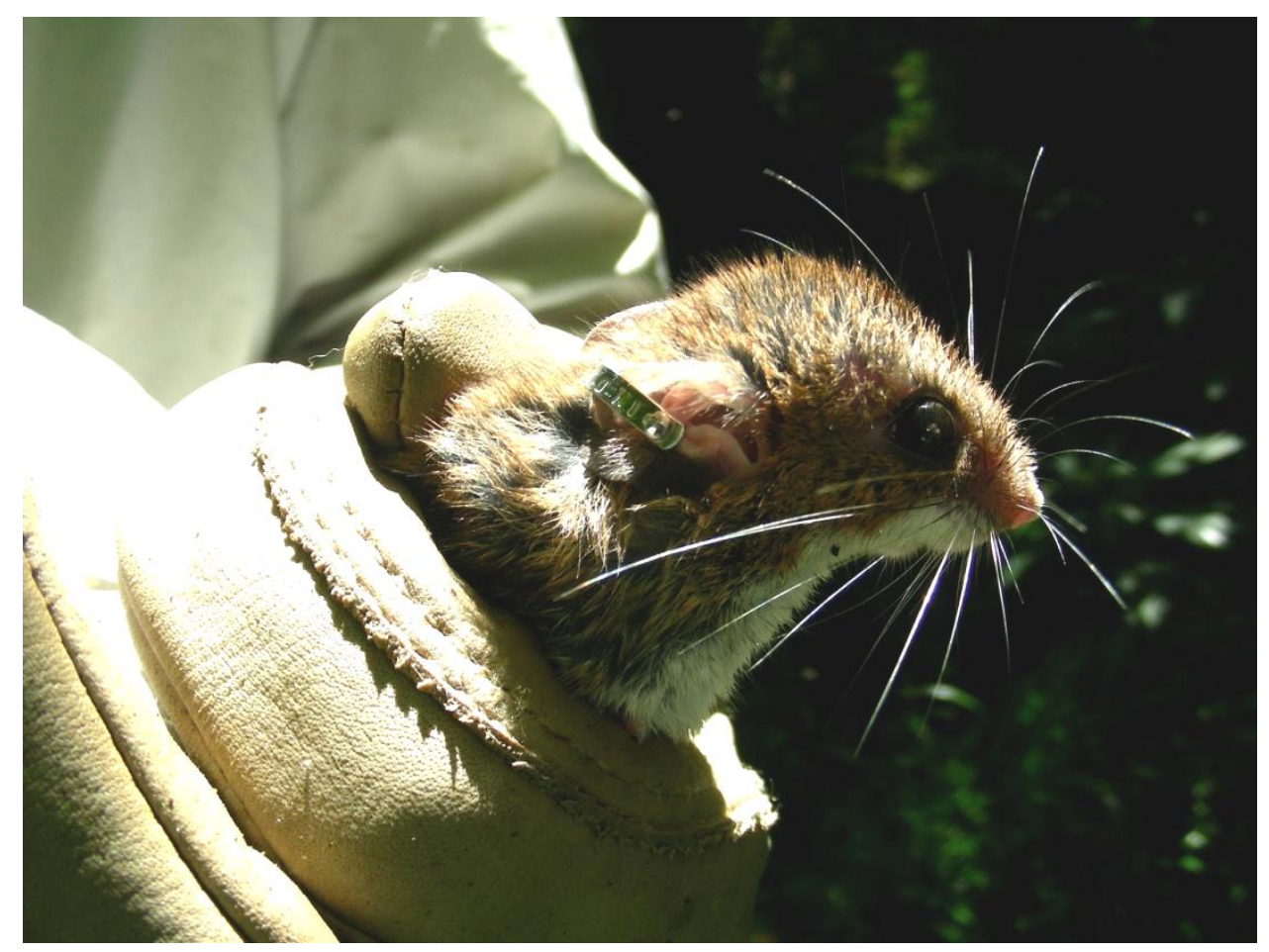

Figure 4. Photograph of Noah McCoard holding an ear-tagged Peromyscus spp. individual during small mammal trapping, taken at the upstream control site, Cacapon River, West Virginia, USA in August 2009. 


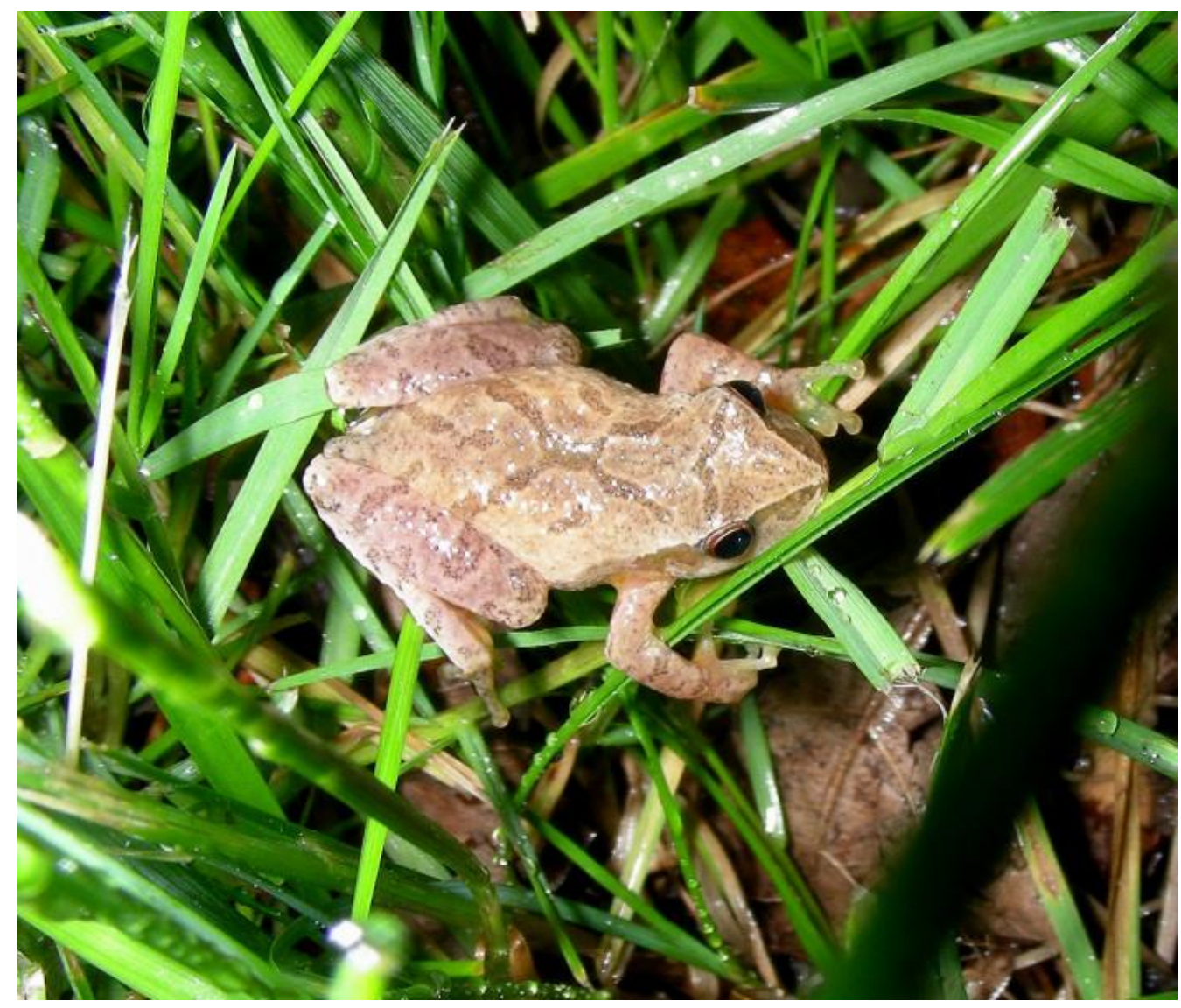

Figure 5. Photograph of a spring peeper, the most abundant anuran species along the 13.7-km study reach of the Cacapon River, West Virginia, USA; it was taken at the restoration reach, June 2010. 


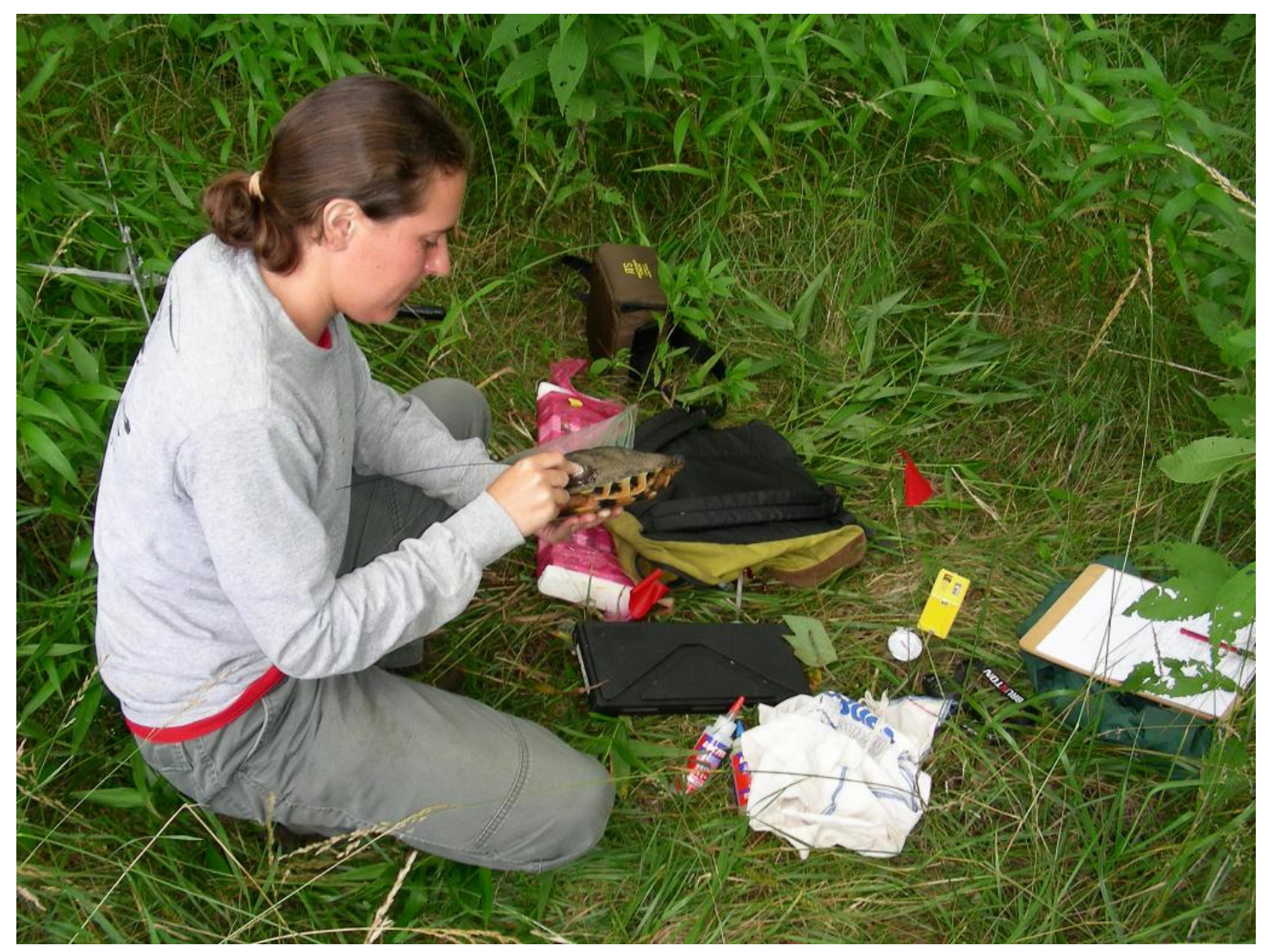

Figure 6. Photograph of Kathryn McCoard preparing a wood turtle for radio-tracking by attaching a transmitter with epoxy to the rear corner of the carapace after the turtle was processed, along the Cacapon River, West Virginia, USA in July 2009. 


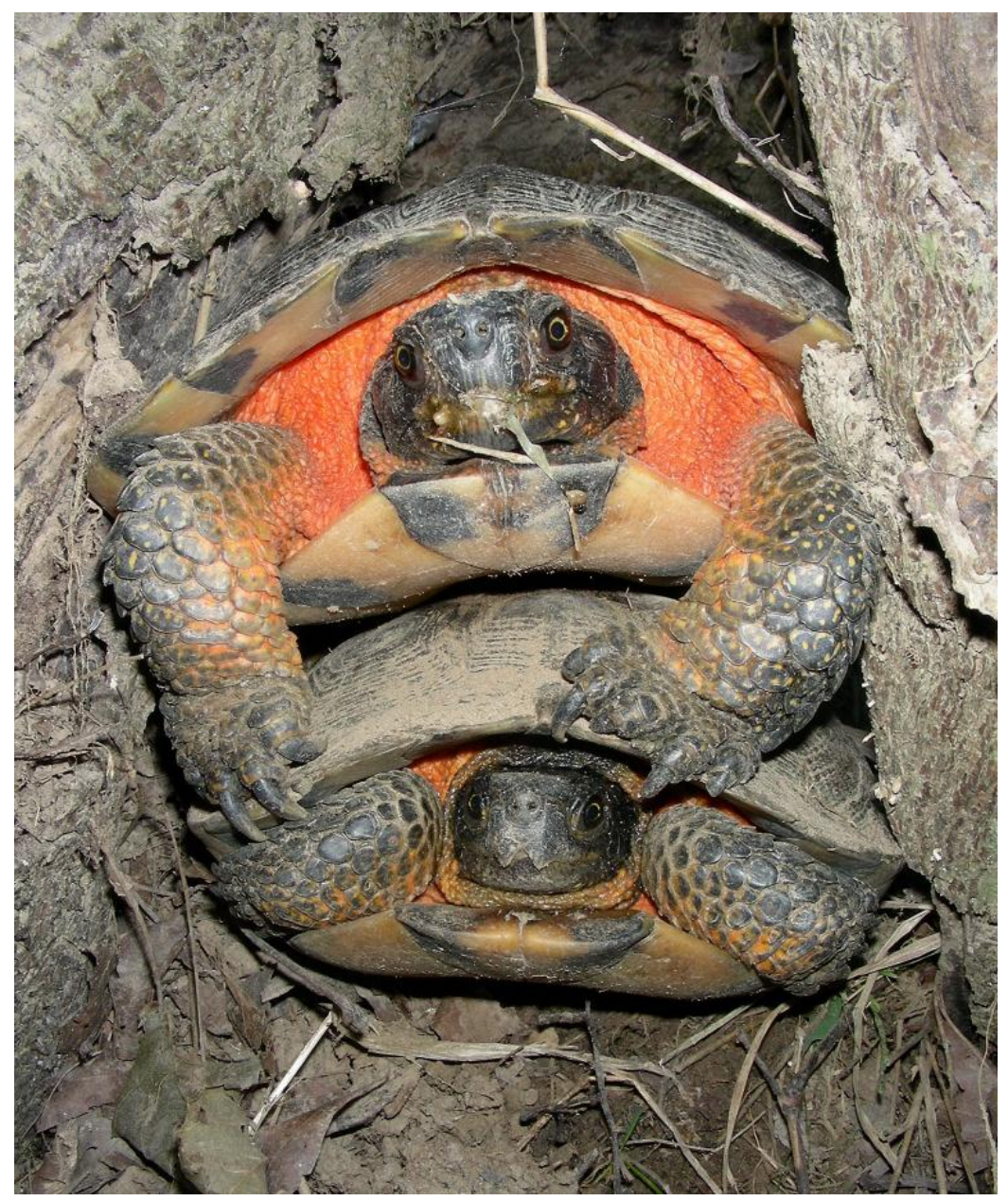

Figure 7. Photograph of wood turtles mating terrestrially along the Cacapon River, West Virginia, USA during September 2010; the reproductive males (top) in this population were longer, heavier, and thicker (to support larger appendages) than the reproductive females (bottom). 


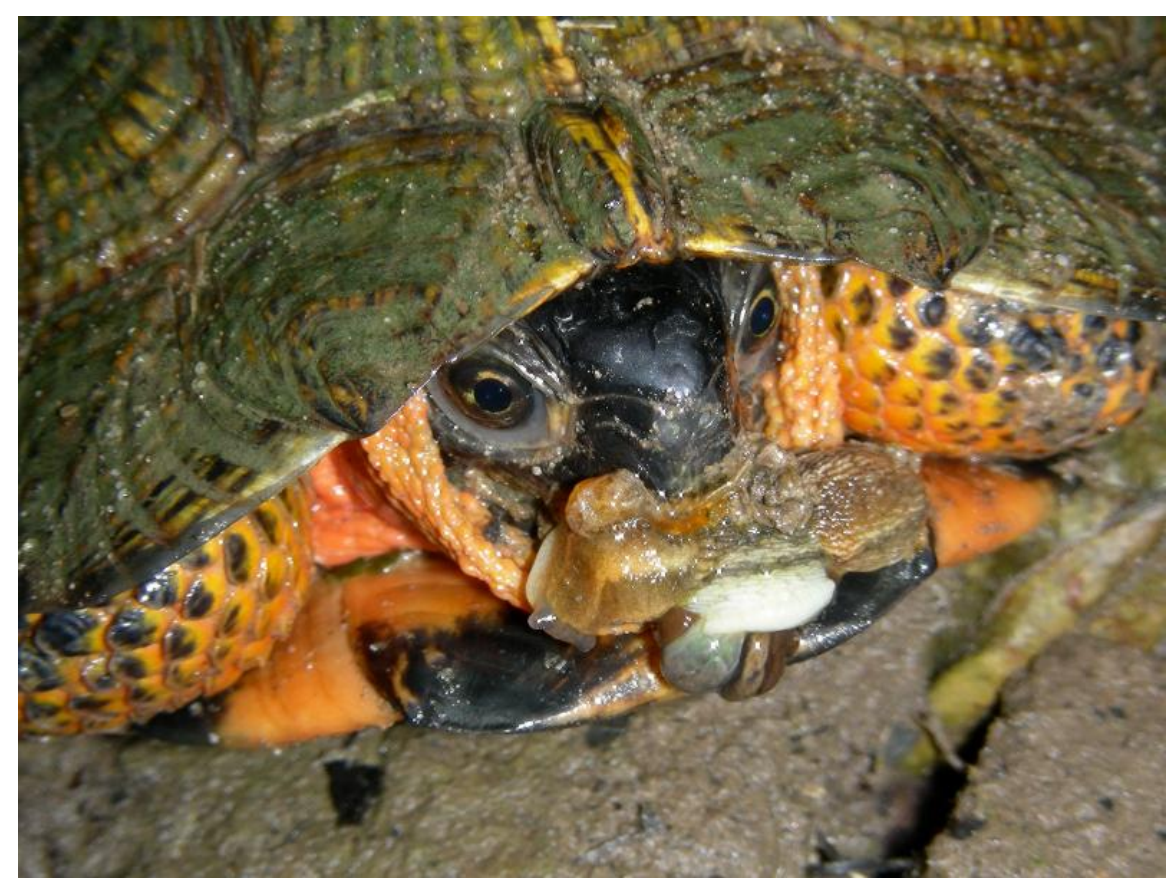

Figure 8. Photograph of a juvenile wood turtle eating a slug, the primary prey of the turtles along the Cacapon River, West Virginia, USA in May 2010. 


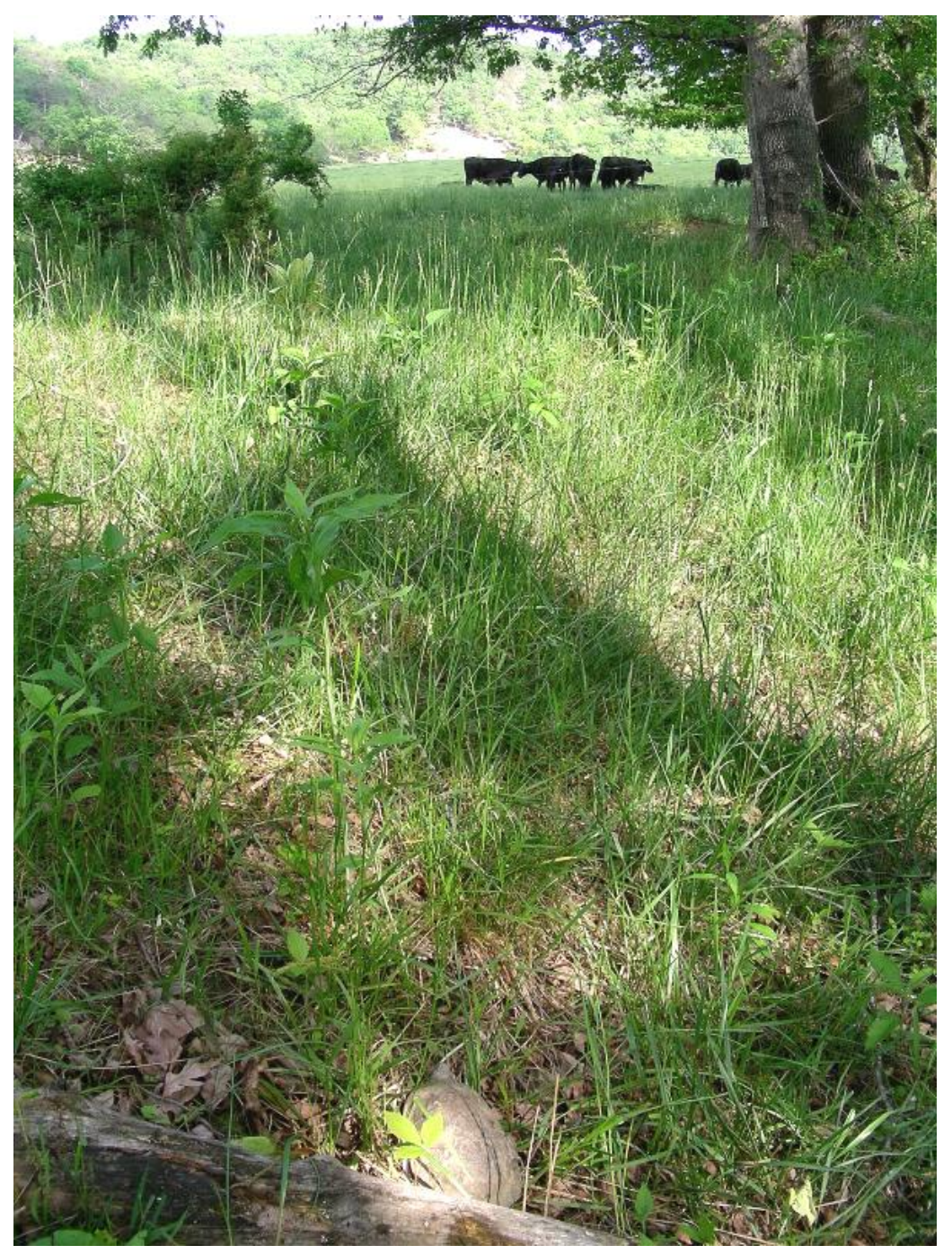

Figure 9. Photograph of a wood turtle (bottom) walking through an active pasture along the Cacapon River, West Virginia, USA in May 2010. 


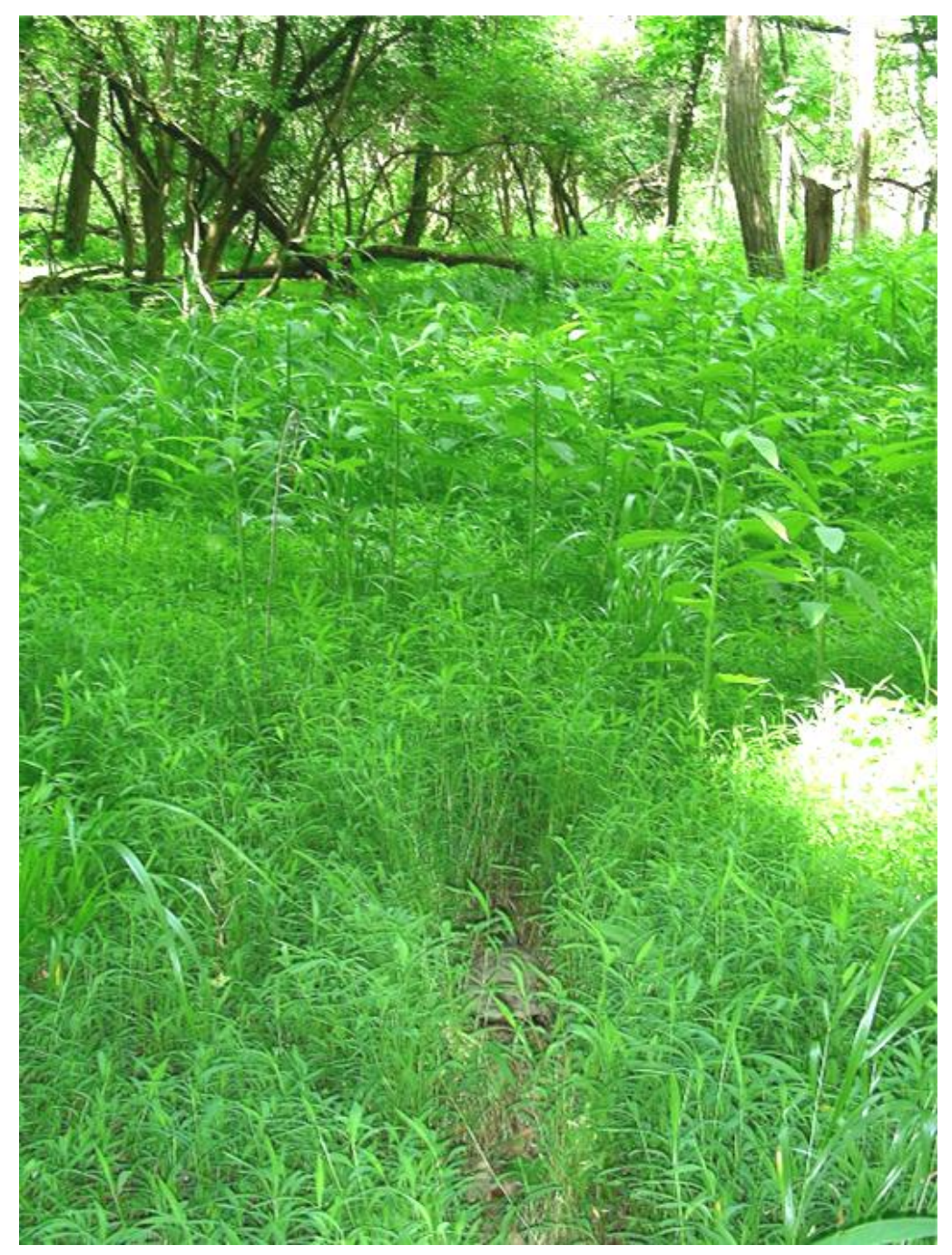

Figure 10. Photograph of a wood turtle making a trail through the tall, thick herbaceous vegetation of typical wood turtle habitat along the Cacapon, Lost, and North rivers, in June 2010. 
Appendix Ia. List of vegetation (means and standard errors, SE) recorded within sites associated with a streambank restoration project along a reach of the Cacapon River, West Virginia, USA during June 2009, 2010, and 2011. The vegetation was documented in three layers: field: $\%$ cover of woody and herbaceous plants $<1 \mathrm{~m}$ tall; shrub: abundance of woody plants $>1 \mathrm{~m}$ tall, $<5$ $\mathrm{cm}$ in diameter at breast height (dbh); and tree: abundance of woody plants $>5 \mathrm{~cm}$ dbh per $100-\mathrm{m}$ radius survey circle.

\begin{tabular}{|c|c|c|c|c|c|c|c|}
\hline \multirow[b]{2}{*}{ Common Name } & \multirow[b]{2}{*}{ Scientific Name } & \multicolumn{2}{|c|}{ Field } & \multicolumn{2}{|c|}{ Shrub } & \multicolumn{2}{|c|}{ Tree } \\
\hline & & $\bar{x}$ & SE & $\bar{x}$ & SE & $\bar{x}$ & SE \\
\hline American elm & Ulmus americana & & & & & 0.028 & 0.028 \\
\hline Arrowleaf tearthumb & Polygonum sagittatum & 0.191 & 0.011 & & & & \\
\hline Aster & Aster spp. & 0.365 & 0.014 & & & & \\
\hline Autumn olive & Elaeagnus umbellata & 0.035 & 0.003 & 1.042 & 0.551 & & \\
\hline Bedstraw & Galium spp. & 0.330 & 0.108 & & & & \\
\hline Big bluestem & Andropogon gerardi & 0.486 & 0.230 & & & & \\
\hline Black locust & Robinia pseudoacacia & & & & & 0.042 & 0.024 \\
\hline Black walnut & Juglans nigra & & & & & 0.181 & 0.067 \\
\hline Black willow & Salix nigra & 0.156 & 0.110 & & & 0.083 & 0.043 \\
\hline Blackberry & Rubus spp. & 0.122 & 0.093 & & & & \\
\hline Blue-eyed grass & Sisyrinchium angustifolium & 0.017 & 0.017 & & & & \\
\hline Bottlebrush grass & Elymus hystrix & 0.104 & 0.059 & & & & \\
\hline Boxelder & Acer negundo & 0.156 & 0.082 & & & 0.028 & 0.028 \\
\hline Broad-leaf plantain & Plantago major & 0.208 & 0.074 & & & & \\
\hline Bush clover & Lespedeza spp. & 0.156 & 0.070 & & & & \\
\hline Carrot & Umbelliferae & 0.139 & 0.080 & & & & \\
\hline Chickweed & Stellaria spp. & 0.208 & 0.096 & & & & \\
\hline Common cinquefoil & Potentilla simplex & 0.139 & 0.063 & & & & \\
\hline Common milkweed & Asclepias syriaca & 0.125 & 0.056 & & & & \\
\hline Cottonwood & Populus deltoides & 0.087 & 0.087 & & & 0.083 & 0.038 \\
\hline Crown vetch & Coronilla varia & 0.052 & 0.039 & & & & \\
\hline Curly dock & Rumex crispus & 0.694 & 0.204 & & & & \\
\hline Daisy fleabane & Erigeron strigosus & 0.017 & 0.017 & & & & \\
\hline Dandelion & Taraxacum officinale & 0.243 & 0.073 & & & & \\
\hline Deertongue grass & Panicum clandestinum & 3.333 & 0.617 & & & & \\
\hline Dogbane & Аросупит spp. & 0.035 & 0.035 & & & & \\
\hline Eastern red cedar & Juniperus virginiana & 0.035 & 0.035 & 0.083 & 0.043 & 0.042 & 0.031 \\
\hline Fall phlox & Phlox paniculata & 0.052 & 0.039 & & & & \\
\hline False nettle & Boehmeria cylindrica & 0.052 & 0.039 & & & & \\
\hline False Solomon seal & Maianthemum racemosum & 0.104 & 0.064 & & & & \\
\hline Four-leaved wild yam & Dioscorea quaternata & 0.017 & 0.017 & & & & \\
\hline Garlic mustard & Alliaria petiolata & 0.816 & 0.223 & & & & \\
\hline Geranium & Geranium spp. & 0.139 & 0.058 & & & & \\
\hline
\end{tabular}


Appendix Ia continued

\begin{tabular}{|c|c|c|c|c|c|c|c|}
\hline Goldenrod & Solidago spp. & 0.677 & 0.216 & & & & \\
\hline Grape & Vitis spp. & 0.069 & 0.042 & & & & \\
\hline Grass & Grass spp. & 3.611 & 1.080 & & & & \\
\hline Green ash & Fraxinus pennsylvanica & 0.017 & 0.017 & 0.028 & 0.028 & 0.042 & 0.024 \\
\hline Green dragon & Arisaema dracontium & 0.608 & 0.148 & & & & \\
\hline Greenbrier & Smilax spp. & 0.104 & 0.059 & & & & \\
\hline Ground-ivy & Glechoma hederacea & 3.420 & 0.619 & & & & \\
\hline Hackberry & Celtis occidentalis & & & & & 0.028 & 0.020 \\
\hline Hickory & Carya spp. & 0.035 & 0.035 & & & 0.208 & 0.131 \\
\hline Hog peanut & Amphicarpaea bracteata & 0.174 & 0.062 & & & & \\
\hline Horse nettle & Solanum carolinense & 0.590 & 0.148 & & & & \\
\hline Jack in the pulpit & Arisaema triphyllum & 0.156 & 0.055 & & & & \\
\hline Japanese barberry & Berberis thunbergii & 0.174 & 0.094 & 3.542 & 1.408 & & \\
\hline Japanese honeysuckle & Lonicera japonica & 1.146 & 0.317 & & & & \\
\hline Japanese stilt grass & Microstegium vimineum & 3.455 & 0.669 & & & & \\
\hline Jewelweed & Impatiens spp. & 0.330 & 0.105 & & & & \\
\hline Lady's thumb & Polygonum spp. & 3.403 & 0.492 & & & & \\
\hline May-apple & Podophyllum peltatum & 0.104 & 0.104 & & & & \\
\hline Mile-a-minute & Polygonum perfoliatum & 0.243 & 0.141 & & & & \\
\hline Mint & Mentha spp. & 1.024 & 0.194 & & & & \\
\hline Monkey flower & Mimulus ringens & 0.122 & 0.071 & & & & \\
\hline Morrow's honeysuckle & Lonicera morrowii & & & 0.028 & 0.028 & & \\
\hline Moss & Moss spp. & 0.052 & 0.052 & & & & \\
\hline Multiflora rose & Rosa multiflora & 2.101 & 0.517 & 4.264 & 1.013 & & \\
\hline Osage-orange & Maclura pomifera & & & & & 0.097 & 0.074 \\
\hline Pawpaw & Asimina triloba & & & 0.139 & 0.139 & & \\
\hline Poison ivy & Toxicodendron radicans & 0.816 & 0.221 & & & & \\
\hline Pokeweed & Phytolacca americana & 0.052 & 0.039 & & & & \\
\hline Queen Ann's lace & Daucus carota & 0.174 & 0.079 & & & & \\
\hline Red clover & Trifolium pratense & 0.139 & 0.058 & & & & \\
\hline Red maple & Acer rubrum & 0.087 & 0.045 & & & 0.042 & 0.024 \\
\hline Red oak & Quercus rubra & & & & & 0.014 & 0.014 \\
\hline Redbud & Cercis canadensis & & & 0.014 & 0.014 & & \\
\hline Reed canary grass & Phalaris arundinacea & 17.188 & 2.279 & & & & \\
\hline Rice cutgrass & Leersia oryzoides & 0.955 & 0.378 & & & & \\
\hline Rush & Juncus spp. & 0.069 & 0.042 & & & & \\
\hline Sassafras & Sassafras albidum & 0.017 & 0.017 & & & & \\
\hline Scouring rush & Equisetum hyemale & 0.069 & 0.055 & & & & \\
\hline Sedge & Carex spp. & 4.010 & 0.895 & & & & \\
\hline Sensitive fern & Onoclea sensibilis & 0.017 & 0.017 & & & & \\
\hline Shepard's purse & Capsella bursa-pastoris & 0.017 & 0.017 & & & & \\
\hline Silver maple & Acer saccharinum & 0.191 & 0.101 & & & 0.319 & 0.106 \\
\hline Slippery elm & Ulmus rubra & 0.104 & 0.054 & & & 0.111 & 0.054 \\
\hline Spicebush & Lindera benzoin & 0.174 & 0.097 & 0.458 & 0.417 & & \\
\hline Stinging nettle & Urtica dioica & 0.174 & 0.111 & & & & \\
\hline
\end{tabular}




\begin{tabular}{|c|c|c|c|c|c|c|c|}
\hline \multicolumn{8}{|c|}{ Appendix Ia continued } \\
\hline Sugar maple & Acer saccharum & & & & & 0.139 & 0.064 \\
\hline Sycamore & Platanus occidentalis & 0.660 & 0.285 & 0.778 & 0.443 & 0.806 & 0.189 \\
\hline Tree of heaven & Ailanthus altissima & 0.104 & 0.059 & 0.139 & 0.093 & 0.083 & 0.051 \\
\hline Velvet grass & Holcus lanatus & 0.017 & 0.017 & & & & \\
\hline Violet & Viola spp. & 1.372 & 0.224 & & & & \\
\hline Virginia creeper & Parthenocissus quinquefolia & 0.087 & 0.071 & & & & \\
\hline White ash & Fraxinus americana & 0.035 & 0.035 & & & & \\
\hline White avens & Geum canadense & 0.035 & 0.035 & & & & \\
\hline White clover & Trifolium repens & 0.087 & 0.045 & & & & \\
\hline White oak & Quercus alba & & & & & 0.014 & 0.014 \\
\hline Wild black cherry & Prunus serotina & 0.017 & 0.017 & & & 0.028 & 0.020 \\
\hline Wild ginger & Asarum canadense & 0.017 & 0.017 & & & & \\
\hline Wild onion & Allium canadense & 0.868 & 0.176 & & & & \\
\hline Wild peppergrass & Lepidium virginicum & 0.017 & 0.017 & & & & \\
\hline Wingstem & Verbesina alternifolia & 6.979 & 0.781 & & & & \\
\hline Wood sorrel & Oxalis spp. & 2.188 & 0.226 & & & & \\
\hline Yellow hop clover & Trifolium aureum & 0.069 & 0.034 & & & & \\
\hline Yellow rocket & Barbarea vulgaris & 0.035 & 0.035 & & & & \\
\hline
\end{tabular}


Appendix IIa. Diversity index means and standard errors (SE) for the site $\times$ time interactions related to overall (natives and exotics) vegetative layers (field: \% cover of woody and herbaceous plants $<1 \mathrm{~m}$ tall; shrub: abundance of woody plants $>1 \mathrm{~m}$ tall, $<5 \mathrm{~cm}$ in diameter at breast height (dbh); and tree: abundance of woody plants $>5 \mathrm{~cm} \mathrm{dbh}$ ) per 100-m radius survey circle sampled along a 13.7-km reach of the Cacapon River, West Virginia, USA, during June 2009, 2010, and 2011. Sites were associated with a river restoration project: RR, 1,100 m restoration reach; RS, reference site; and CS, control site.

\begin{tabular}{|c|c|c|c|c|c|c|c|c|c|}
\hline \multirow[b]{3}{*}{ Stratus } & \multirow[b]{3}{*}{ Index } & \multicolumn{8}{|c|}{ Site $\times$ Time } \\
\hline & & \multicolumn{2}{|c|}{$\mathrm{CS} \times 2009$} & \multicolumn{2}{|c|}{$\mathrm{CS} \times 2010$} & \multicolumn{2}{|c|}{$\mathrm{CS} \times 2011$} & \multicolumn{2}{|c|}{$\mathrm{RR} \times 2009$} \\
\hline & & $\bar{x}$ & SE & $\bar{x}$ & $\mathrm{SE}$ & $\bar{x}$ & $\mathrm{SE}$ & $\bar{x}$ & $\mathrm{SE}$ \\
\hline \multicolumn{10}{|l|}{ Field } \\
\hline & Diversity & 1.74 & 0.18 & 2.09 & 0.17 & 1.81 & 0.30 & 2.06 & 0.25 \\
\hline & Richness & 9.25 & 1.18 & 12.13 & 1.67 & 12.25 & 2.61 & 12.50 & 1.71 \\
\hline & Evenness & 0.67 & 0.05 & $0.73 \mathrm{~A}$ & 0.03 & 0.62 & 0.06 & $0.72 \mathrm{~A}$ & 0.05 \\
\hline \multicolumn{10}{|l|}{ Shrub } \\
\hline & Diversity & 0.15 & 0.15 & 0.16 & 0.10 & 0.23 & 0.12 & 0.11 & 0.11 \\
\hline & Richness & 0.75 & 0.50 & 0.88 & 0.30 & 0.88 & 0.35 & 1.00 & 0.33 \\
\hline & Evenness & 0.35 & 0.17 & 0.61 & 0.18 & 0.48 & 0.18 & $0.73 \mathrm{~A}$ & 0.16 \\
\hline \multicolumn{10}{|l|}{ Tree } \\
\hline & Diversity & 0.17 & 0.11 & 0.38 & 0.20 & 0.17 & 0.11 & 0.00 & 0.00 \\
\hline & Richness & 0.88 & 0.30 & 1.25 & 0.56 & 1.25 & 0.16 & 0.50 & 0.19 \\
\hline & Evenness & 0.02 & 0.18 & 0.49 & 0.18 & 1.00 & 0.01 & 0.50 & 0.19 \\
\hline
\end{tabular}




\section{Appendix IIa continued}

\begin{tabular}{|c|c|c|c|c|c|c|c|c|c|c|c|}
\hline \multicolumn{12}{|c|}{ Site $\times$ Time } \\
\hline \multicolumn{2}{|c|}{$\mathrm{RR} \times 2010$} & \multicolumn{2}{|c|}{$\mathrm{RR} \times 2011$} & \multicolumn{2}{|c|}{$\mathrm{RS} \times 2009$} & \multicolumn{2}{|c|}{$\mathrm{RS} \times 2010$} & \multicolumn{2}{|c|}{$\mathrm{RS} \times 2011$} & \multirow[b]{2}{*}{$F$} & \multirow[b]{2}{*}{$P$} \\
\hline$\overline{\bar{x}}$ & SE & $\overline{\bar{x}}$ & SE & $\overline{\bar{x}}$ & SE & $\overline{\bar{x}}$ & SE & $\bar{x}$ & SE & & \\
\hline 2.13 & 0.11 & 1.77 & 0.11 & 1.70 & 0.13 & 2.37 & 0.06 & 2.18 & 0.16 & 1.46 & 0.231 \\
\hline 13.38 & 0.60 & 10.63 & 0.86 & 11.38 & 0.98 & 14.5 & 0.91 & 13.50 & 2.02 & 0.89 & 0.480 \\
\hline 0.65 & 0.05 & 0.58 & 0.05 & $0.51 \mathrm{~B}$ & 0.04 & $0.75 \mathrm{~A}$ & 0.03 & $0.72 \mathrm{~A}$ & 0.07 & 4.72 & 0.003 \\
\hline 0.02 & 0.02 & 0.37 & 0.14 & 0.09 & 0.09 & 0.32 & 0.12 & 0.11 & 0.07 & 2.05 & 0.105 \\
\hline 0.75 & 0.37 & $1.50 \mathrm{~A}$ & 0.33 & $0.25 \mathrm{~B}$ & 0.25 & $1.75 \mathrm{~A}$ & 0.25 & 0.75 & 0.31 & 4.46 & 0.004 \\
\hline 0.43 & 0.18 & $0.85 \mathrm{~A}$ & 0.12 & $0.13 \mathrm{~B}$ & 0.13 & $0.86 \mathrm{~A}$ & 0.06 & 0.44 & 0.17 & 4.79 & 0.003 \\
\hline 0.08 & 0.08 & 0.56 & 0.20 & 0.00 & 0.00 & 0.45 & 0.34 & 0.73 & 0.22 & 2.99 & 0.093 \\
\hline 0.75 & 0.25 & 2.13 & 0.44 & 0.25 & 0.16 & 1.75 & 0.25 & 2.50 & 0.47 & 2.84 & 0.036 \\
\hline 0.62 & 0.18 & 0.96 & 0.02 & 0.25 & 0.16 & 0.97 & 0.02 & 0.97 & 0.01 & 2.39 & 0.066 \\
\hline
\end{tabular}

Bonferroni correction: $\alpha=0.05 / 9$ tests $=0.006$; means followed by different letters are significantly different 
Appendix IIIa. Diversity index means and standard errors (SE) for the site $\times$ time interactions related to native vegetative layers (field: \% cover of woody and herbaceous plants < $1 \mathrm{~m}$ tall; shrub: abundance of woody plants $>1 \mathrm{~m}$ tall, $<5 \mathrm{~cm}$ in diameter at breast height (dbh); and tree: abundance of woody plants $>5 \mathrm{~cm} \mathrm{dbh}$ ) per 100-m radius survey circle sampled along a 13.7-km reach of the Cacapon River, West Virginia, USA, during June 2009, 2010, and 2011. Sites were associated with a river restoration project: RR, 1,100 m restoration reach; RS, reference site; and CS, control site.

\begin{tabular}{|c|c|c|c|c|c|c|c|c|c|}
\hline \multirow[b]{3}{*}{ Stratus } & \multirow[b]{3}{*}{ Index } & \multicolumn{8}{|c|}{ Site $\times$ Time } \\
\hline & & \multicolumn{2}{|c|}{$\mathrm{CS} \times 2009$} & \multicolumn{2}{|c|}{$\mathrm{CS} \times 2010$} & \multicolumn{2}{|c|}{$\mathrm{CS} \times 2011$} & \multicolumn{2}{|c|}{$\mathrm{RR} \times 2009$} \\
\hline & & $\bar{x}$ & SE & $\bar{x}$ & SE & $\bar{x}$ & SE & $\bar{x}$ & SE \\
\hline \multicolumn{10}{|l|}{ Field } \\
\hline & Diversity & 1.29 & 0.10 & 1.64 & 0.11 & 1.51 & 0.16 & 1.66 & 0.12 \\
\hline & Richness & 5.25 & 0.39 & 7.63 & 0.73 & 8.50 & 1.05 & 8.13 & 0.60 \\
\hline & Evenness & $0.74 \mathrm{~A}$ & 0.03 & $0.78 \mathrm{~A}$ & 0.02 & 0.64 & 0.04 & 0.71 & 0.03 \\
\hline \multicolumn{10}{|l|}{ Shrub } \\
\hline & Diversity & 0.00 & 0.00 & 0.00 & 0.00 & 0.00 & 0.00 & 0.09 & 0.05 \\
\hline & Richness & 0.38 & 0.11 & 0.25 & 0.09 & 0.25 & 0.09 & 0.38 & 0.15 \\
\hline & Evenness & 0.74 & 0.03 & 0.78 & 0.02 & 0.64 & 0.04 & 0.81 & 0.03 \\
\hline \multicolumn{10}{|l|}{ Tree } \\
\hline & Diversity & 0.17 & 0.06 & 0.38 & 0.11 & 0.17 & 0.06 & 0.00 & 0.00 \\
\hline & Richness & 0.88 & 0.17 & 1.25 & 0.32 & 1.13 & 0.13 & 0.50 & 0.11 \\
\hline & Evenness & 0.62 & 0.11 & 0.49 & 0.11 & 0.87 & 0.07 & 0.50 & 0.11 \\
\hline
\end{tabular}




\section{Appendix IIIa continued}

\begin{tabular}{|c|c|c|c|c|c|c|c|c|c|c|c|}
\hline \multicolumn{12}{|c|}{ Site $\times$ Time } \\
\hline \multicolumn{2}{|c|}{$\mathrm{RR} \times 2010$} & \multicolumn{2}{|c|}{$\mathrm{RR} \times 2011$} & \multicolumn{2}{|c|}{$\mathrm{RS} \times 2009$} & \multicolumn{2}{|c|}{$\mathrm{RS} \times 2010$} & \multicolumn{2}{|c|}{$\mathrm{RS} \times 2011$} & \multirow[b]{2}{*}{$F$} & \multirow[b]{2}{*}{$P$} \\
\hline$\overline{\bar{x}}$ & SE & $\bar{x}$ & SE & $\bar{x}$ & SE & $\bar{x}$ & SE & $\bar{x}$ & SE & & \\
\hline 1.78 & 0.05 & 1.42 & 0.05 & 1.28 & 0.09 & 1.98 & 0.04 & 1.76 & 0.09 & 1.69 & 0.170 \\
\hline 8.63 & 0.19 & 7.50 & 0.38 & 7.50 & 0.48 & 9.75 & 0.37 & 8.75 & 0.80 & 1.12 & 0.359 \\
\hline 0.70 & 0.03 & 0.58 & 0.03 & $0.51 \mathrm{~B}$ & 0.02 & $0.76 \mathrm{~A}$ & 0.02 & $0.74 \mathrm{~A}$ & 0.04 & 4.72 & 0.003 \\
\hline 0.00 & 0.00 & 0.00 & 0.00 & 0.00 & 0.00 & 0.00 & 0.00 & 0.00 & 0.00 & 1.00 & 0.418 \\
\hline 0.38 & 0.11 & 0.50 & 0.11 & 0.00 & 0.00 & 0.25 & 0.09 & 0.00 & 0.00 & 0.61 & 0.660 \\
\hline 0.70 & 0.03 & 0.58 & 0.03 & 0.51 & 0.02 & 0.76 & 0.02 & 0.74 & 0.04 & 0.92 & 0.462 \\
\hline 0.08 & 0.05 & 0.57 & 0.11 & 0.00 & 0.00 & 0.31 & 0.07 & 0.64 & 0.12 & 2.58 & 0.051 \\
\hline 0.75 & 0.14 & 2.13 & 0.25 & 0.25 & 0.09 & 1.50 & 0.11 & 2.25 & 0.24 & 2.56 & 0.052 \\
\hline 0.62 & 0.10 & 0.96 & 0.01 & 0.25 & 0.09 & 0.96 & 0.01 & 0.97 & 0.01 & 2.21 & 0.084 \\
\hline
\end{tabular}

Bonferroni correction: $\alpha=0.05 / 9$ tests $=0.006$; means followed by different letters are significantly different 
Appendix Ib. Means and standard errors (SE) of vegetation recorded within 110 random plots and 110 plots associated with wood turtle captures along the Cacapon River, West Virginia, USA during spring 2009 - summer 2011. The vegetation was documented in three layers: field (\% cover of woody and herbaceous plants $<1 \mathrm{~m}$ tall), shrubs (abundance of woody plants $>1 \mathrm{~m}$ tall, $<5 \mathrm{~cm}$ diameter at breast height $(\mathrm{dbh})$ ), and trees (abundance of woody plants $>5 \mathrm{~cm} \mathrm{dbh}$ ).

\begin{tabular}{|c|c|c|c|c|c|c|c|}
\hline \multirow[b]{2}{*}{ Common Name } & \multirow[b]{2}{*}{ Scientific Name } & \multicolumn{2}{|c|}{ Field } & \multicolumn{2}{|c|}{ Shrub } & \multicolumn{2}{|c|}{ Tree } \\
\hline & & $\bar{x}$ & SE & $\bar{x}$ & SE & $\bar{x}$ & $\mathrm{SE}$ \\
\hline American elm & Ulmus americana & & & & & 0.01 & 0.01 \\
\hline Arrowleaf tearthumb & Polygonum sagittatum & 0.37 & 0.09 & & & & \\
\hline Aster & Aster spp. & 0.20 & 0.08 & & & & \\
\hline Autumn olive & Elaeagnus umbellata & 0.07 & 0.03 & 1.57 & 0.35 & & \\
\hline Bedstraw & Galium spp. & 0.77 & 0.10 & & & & \\
\hline Big bluestem & Andropogon gerardi & 0.17 & 0.08 & & & & \\
\hline Bittersweet & Solanum dulcamara & 0.07 & 0.04 & & & & \\
\hline Black birch & Betula lenta & & & 0.03 & 0.03 & 0.01 & 0.01 \\
\hline Black gum & Nyssa sylvatica & & & & & 0.01 & 0.01 \\
\hline Black huckleberry & Gaylussacia baccata & & & 0.46 & 0.46 & & \\
\hline Black locust & Robinia pseudoacacia & 0.01 & 0.01 & 0.10 & 0.05 & 0.07 & 0.02 \\
\hline Black oak & Quercus velutina & 0.01 & 0.01 & & & & \\
\hline Black walnut & Juglans nigra & & & & & 0.14 & 0.03 \\
\hline Black willow & Salix nigra & 0.07 & 0.04 & 0.34 & 0.19 & 0.05 & 0.02 \\
\hline Blackberry & Rubus spp. & 0.29 & 0.07 & 0.31 & 0.17 & & \\
\hline Black-eyed Susan & Rudbeckia hirta & 0.03 & 0.03 & & & & \\
\hline Blood root & Sanguinaria canadensis & 0.01 & 0.01 & & & & \\
\hline Blueberry & Vaccinium spp & 0.02 & 0.01 & & & & \\
\hline Blue-eyed grass & Sisyrinchium mисronatum & 0.01 & 0.01 & & & & \\
\hline Bottlebrush grass & Hystrix patula & 0.11 & 0.04 & & & & \\
\hline Boxelder & Acer negundo & 0.06 & 0.03 & 0.12 & 0.07 & 0.04 & 0.02 \\
\hline Bush clover & Lespedeza spp. & 0.10 & 0.04 & & & & \\
\hline Cardinal flower & Lobelia cardinalis & 0.01 & 0.01 & & & & \\
\hline Carrot & Umbelliferae & 0.07 & 0.03 & & & & \\
\hline Chickory & Cichorium intybus & 0.01 & 0.01 & & & & \\
\hline Chickweed & Stellaria spp. & 0.10 & 0.04 & & & & \\
\hline Christmas fern & Polystichum acrostichoides & 0.12 & 0.04 & & & & \\
\hline Cigar tree & Catalpa bignonioides & & & 0.01 & 0.01 & 0.02 & 0.02 \\
\hline Cinnamon fern & Osmunda cinnamomea & 0.01 & 0.01 & & & & \\
\hline Common cinquefoil & Potentilla simplex & 0.53 & 0.10 & & & & \\
\hline
\end{tabular}




\begin{tabular}{|c|c|c|c|c|c|c|c|}
\hline \multicolumn{8}{|c|}{ Appendix Ib continued } \\
\hline Common milkweed & Asclepias syriaca & 0.11 & 0.04 & & & \multirow{5}{*}{0.05} & \multirow[b]{4}{*}{0.02} \\
\hline Common teasal & Dipsacus sylvestris & 0.15 & 0.08 & & & & \\
\hline Common yarrow & Achillea millefolium & 0.02 & 0.02 & & & & \\
\hline Cottonwood & Populus deltoides & 0.03 & 0.03 & & & & \\
\hline Crown vetch & Coronilla varia & 0.43 & 0.19 & & & & \\
\hline Crab-apple & Malus spp. & & & 0.01 & 0.01 & & \\
\hline Curly dock & Rumex crispus & 0.38 & 0.08 & & & & \\
\hline Daisy fleabane & Erigeron strigosus & 0.07 & 0.02 & & & & \\
\hline Dandelion & Taraxacum officinale & 0.26 & 0.07 & & & & \\
\hline Deertongue grass & Panicum clandestinum & 3.14 & 0.32 & & & & \\
\hline Dogbane & Apocynum spp. & 0.02 & 0.02 & & & & \\
\hline Eastern red cedar & Juniperus virginiana & 0.03 & 0.02 & 0.29 & 0.17 & 0.05 & 0.02 \\
\hline Fall phlox & Phlox paniculata & 0.19 & 0.10 & & & & \\
\hline False nettle & Pilea pumila & 0.34 & 0.10 & & & & \\
\hline False oregano & Phyla spp. & 0.01 & 0.01 & & & & \\
\hline False Solomon seal & Maianthemum racemosum & 0.04 & 0.02 & & & & \\
\hline Flowering dogwood & Cornus florida & 0.02 & 0.01 & & & 0.01 & 0.01 \\
\hline Forget-me-not & Myosotis laxa & 0.05 & 0.05 & & & & \\
\hline Foxglove & Aureolaria laevigata & 0.03 & 0.03 & & & & \\
\hline Garlic mustard & Alliaria petiolata & 0.48 & 0.10 & & & & \\
\hline Goldenrod & Solidago spp. & 0.53 & 0.10 & & & & \\
\hline Grape & Vitis spp. & 0.23 & 0.06 & 0.03 & 0.03 & & \\
\hline Grass & Grass spp. & 7.61 & 0.87 & & & & \\
\hline Green ash & Fraxinus pennsylvanica & 0.03 & 0.02 & 0.03 & 0.02 & 0.05 & 0.01 \\
\hline Green dragon & Arisaema dracontium & 0.26 & 0.06 & & & & \\
\hline Greenbrier & Smilax spp. & 0.40 & 0.08 & 0.31 & 0.15 & & \\
\hline Ground ivy & Glechoma hederacea & 2.76 & 0.35 & & & & \\
\hline Hackberry & Celtis occidentalis & & & & & 0.01 & 0.01 \\
\hline Hawkweed & Hieracium spp. & 0.01 & 0.01 & & & & \\
\hline Hawthorn & Crataegus spp. & & & & & 0.01 & 0.01 \\
\hline Hay-scented fern & Dennstaedtia punctilobula & 0.18 & 0.09 & & & & \\
\hline Hemlock & Tsuga canadensis & 0.01 & 0.01 & & & 0.01 & 0.01 \\
\hline Hickory & Carya spp. & 0.06 & 0.02 & & & 0.13 & 0.03 \\
\hline Hog peanut & Amphicarpaea bracteata & 0.45 & 0.08 & & & & \\
\hline Horse nettle & Solanum carolinense & 0.55 & 0.11 & & & & \\
\hline Ironwood & Ostrya virginiana & 0.06 & 0.02 & & & 0.07 & 0.04 \\
\hline Jack-in-the-pulpit & Arisaema triphyllum & 0.19 & 0.05 & & & & \\
\hline Japanese barberry & Berberis thunbergii & 0.22 & 0.07 & 5.10 & 1.87 & & \\
\hline Japanese honeysuckle & Lonicera japonica & 1.68 & 0.33 & & & & \\
\hline Japanese stilt grass & Microstegium vimineum & 6.07 & 0.56 & & & & \\
\hline Jewelweed & Impatiens spp. & 0.81 & 0.13 & & & & \\
\hline Joe-pye-weed & Eupatorium fistulosum & 0.25 & 0.10 & & & & \\
\hline Jointed grass & Arthraxon hispidus & 0.18 & 0.07 & & & & \\
\hline Lady's thumb & Polygonum spp. & 2.94 & 0.31 & & & & \\
\hline Lichen & Lichen spp. & 0.05 & 0.05 & & & & \\
\hline Maidenhair fern & Adiantum pedatum & 0.02 & 0.02 & & & & \\
\hline May-apple & Podophyllum peltatum & 0.05 & 0.04 & & & & \\
\hline Mile-a-minute & Polygonum perfoliatum & 0.27 & 0.08 & & & & \\
\hline
\end{tabular}




\begin{tabular}{|c|c|c|c|c|c|c|c|}
\hline \multicolumn{8}{|c|}{ Appendix Ib continued } \\
\hline Mint & Mentha spp. & 0.85 & 0.11 & & & & \\
\hline Moneywort & Lysimachia nummularia & 0.01 & 0.01 & & & & \\
\hline Monkey flower & Mimulus ringens & 0.06 & 0.03 & & & & \\
\hline Morning glory & Ipomoea coccinea & 0.01 & 0.01 & & & & \\
\hline Morrow's honeysuckle & Lonicera morrowii & & & 0.77 & 0.32 & & \\
\hline Moss & Moss spp. & 0.12 & 0.06 & & & & \\
\hline Multiflora rose & Rosa multiflora & 2.40 & 0.44 & 9.00 & 1.82 & & \\
\hline Osage-orange & Maclura pomifera & & & & & 0.03 & 0.02 \\
\hline Pawpaw & Asimina triloba & 0.02 & 0.01 & 0.25 & 0.10 & 0.03 & 0.01 \\
\hline Peppermint & Mentha $\times$ piperita & 0.07 & 0.05 & & & & \\
\hline Plantain & Plantago spp. & 0.18 & 0.10 & & & & \\
\hline Poison ivy & Toxicodendron radicans & 0.96 & 0.14 & & & & \\
\hline Pokeweed & Phytolacca americana & 0.07 & 0.05 & & & & \\
\hline Purpletop grass & Triens flavus & 0.25 & 0.18 & & & & \\
\hline Queen Ann's lace & Daucus carota & 0.15 & 0.04 & & & & \\
\hline Red clover & Trifolium pratense & 0.07 & 0.03 & & & & \\
\hline Red maple & Acer rubrum & 0.18 & 0.04 & 0.01 & 0.01 & 0.08 & 0.02 \\
\hline Red oak & Quercus rubra & 0.02 & 0.01 & & & 0.01 & 0.01 \\
\hline Redbud & Cercis canadensis & & & 0.01 & 0.01 & 0.03 & 0.01 \\
\hline Reed canary grass & Phalaris arundinacea & 11.41 & 1.26 & & & & \\
\hline Rice cutgrass & Leersia oryzoides & 0.73 & 0.22 & & & & \\
\hline River birch & Betula nigra & 0.04 & 0.03 & 0.09 & 0.09 & 0.02 & 0.02 \\
\hline Rue anemone & Thalictrum thalictroides & 0.03 & 0.01 & & & & \\
\hline Rush & Juncus spp & 0.13 & 0.05 & & & & \\
\hline Sassafras & Sassafras albidum & 0.03 & 0.02 & 0.01 & 0.01 & 0.03 & 0.03 \\
\hline Scouring rush & Equisetum hyemale & 0.02 & 0.02 & & & & \\
\hline Scrub pine & Pinus virginiana & & & 0.01 & 0.01 & & \\
\hline Sedge & Carex spp & 3.32 & 0.49 & & & & \\
\hline Self-heal & Prunella vulgaris & 0.01 & 0.01 & & & & \\
\hline Sensitive fern & Onoclea sensibilis & 0.09 & 0.05 & & & & \\
\hline Shepard's purse & Capsella bursa-pastoris & 0.01 & 0.01 & & & & \\
\hline Silky dogwood & Cornus oblique & & & 0.02 & 0.02 & & \\
\hline Silver maple & Acer saccharinum & 0.06 & 0.03 & & & 0.10 & 0.04 \\
\hline Slippery elm & Ulmus rubra & 0.10 & 0.04 & 0.01 & 0.01 & 0.07 & 0.02 \\
\hline Smooth alder & Alnus serrulata & & & 0.02 & 0.02 & & \\
\hline Spearmint & Mentha spicata & 0.06 & 0.06 & & & & \\
\hline Spicebush & Lindera benzoin & 0.56 & 0.15 & 2.42 & 1.02 & & \\
\hline Spring avens & Geum vernum & 0.01 & 0.01 & & & & \\
\hline Stinging nettle & Urtica dioica & 0.13 & 0.05 & & & & \\
\hline Sugar maple & Acer saccharum & 0.01 & 0.01 & 0.01 & 0.01 & 0.19 & 0.04 \\
\hline Sycamore & Platanus occidentalis & 0.38 & 0.11 & 0.39 & 0.16 & 0.62 & 0.08 \\
\hline Thistle & Cirsium spp & 0.13 & 0.06 & & & & \\
\hline Tree of heaven & Ailanthus altissima & 0.13 & 0.04 & 0.14 & 0.07 & 0.06 & 0.03 \\
\hline Tulip poplar & Liriodendron tulipifera & 0.08 & 0.02 & 0.01 & 0.01 & 0.17 & 0.03 \\
\hline Velvet grass & Holcus lanatus & 0.02 & 0.01 & & & & \\
\hline Violet & Viola spp & 1.44 & 0.16 & & & & \\
\hline Virginia creeper & Parthenocissus quinquefolia & 0.53 & 0.13 & & & & \\
\hline White ash & Fraxinus americana & 0.01 & 0.01 & & & & \\
\hline White clover & Trifolium repens & 0.21 & 0.05 & & & & \\
\hline
\end{tabular}


Appendix Ib continued

\begin{tabular}{|c|c|c|c|c|c|c|c|}
\hline White oak & Quercus alba & 0.01 & 0.01 & & & 0.01 & 0.01 \\
\hline Wild black cherry & Prunus serotina & 0.06 & 0.03 & 0.03 & 0.02 & 0.03 & 0.01 \\
\hline Wild geranium & Geranium spp. & 0.09 & 0.03 & & & & \\
\hline Wild ginger & Asarum canadense & 0.01 & 0.01 & & & & \\
\hline Wild oats & Chasmanthium latifolium & 0.16 & 0.09 & & & & \\
\hline Wild onion & Allium canadense & 0.35 & 0.07 & & & & \\
\hline Wild peppergrass & Lepidium virginicum & 0.01 & 0.01 & & & & \\
\hline Wild stonecrop & Sedum ternatum & 0.03 & 0.02 & & & & \\
\hline Wild yam & Dioscorea villosa & 0.01 & 0.01 & & & & \\
\hline Wineberry & Rubus phoenicolasius & 0.03 & 0.02 & 0.04 & 0.02 & & \\
\hline Wingstem & Verbesina alternifolia & 7.84 & 0.57 & & & & \\
\hline Witch-hazel & Hamamelis virginianus & 0.03 & 0.02 & & & 0.05 & 0.03 \\
\hline Wood sorrel & Oxalis spp & 1.89 & 0.18 & & & & \\
\hline Yellow hop clover & Trifolium aureum & 0.02 & 0.01 & & & & \\
\hline Yellow rocket & Barbarea vulgaris & 0.01 & 0.01 & & & & \\
\hline
\end{tabular}


Appendix IIb. Interaction diversity and richness means and standard errors (SE) for overall (natives and exotics) vegetative layers (i.e., field: all plants $<1 \mathrm{~m}$ tall, shrub: woody plants $>1 \mathrm{~m}$ tall and $<5 \mathrm{~cm}$ diameter at breast height (dbh), and tree: woody plants $>5 \mathrm{~cm}$ $\mathrm{dbh})$ associated with wood turtle plots $(n=110)$ and random plots $(n=110)$ sampled along a 13.7-km reach of the Cacapon River,

West Virginia, USA during spring 2009 to summer 2011.

\begin{tabular}{|c|c|c|c|c|c|c|c|c|c|c|c|}
\hline \multirow[b]{3}{*}{ Variable } & \multirow[b]{3}{*}{ Strata } & \multicolumn{8}{|c|}{ Plot $\times$ Season Interaction } & \multirow[b]{3}{*}{$F$} & \multirow[b]{3}{*}{$P$} \\
\hline & & \multicolumn{2}{|c|}{ Turtle $\times$ Spring } & \multicolumn{2}{|c|}{ Turtle $\times$ Summer } & \multicolumn{2}{|c|}{ Random $\times$ Spring } & \multicolumn{2}{|c|}{ Random $\times$ Summer } & & \\
\hline & & $\bar{x}$ & $\mathrm{SE}$ & $\bar{x}$ & $\mathrm{SE}$ & $\bar{x}$ & SE & $\bar{x}$ & $\mathrm{SE}$ & & \\
\hline \multicolumn{12}{|l|}{ Diversity } \\
\hline & Field & 1.63 & 0.12 & 2.14 & 0.06 & 1.97 & 0.06 & 1.81 & 0.08 & 4.62 & 0.033 \\
\hline & Shrub & 0.10 & 0.05 & 0.41 & 0.05 & 0.17 & 0.04 & 0.32 & 0.07 & 2.32 & 0.129 \\
\hline & Tree & 0.49 & 0.11 & 0.45 & 0.06 & 0.17 & 0.04 & 0.47 & 0.09 & 5.68 & 0.018 \\
\hline \multicolumn{12}{|l|}{ Richness } \\
\hline & Field & 9.17 & 0.90 & 13.91 & 0.67 & 12.00 & 0.51 & 10.64 & 0.79 & 1.50 & 0.222 \\
\hline & Shrub & 0.48 & 0.16 & 1.62 & 0.13 & 0.95 & 0.11 & 1.61 & 0.31 & 0.08 & 0.780 \\
\hline & Tree & 0.82 & 0.35 & 1.62 & 0.16 & 0.70 & 0.12 & 1.83 & 0.19 & 13.68 & $<0.001$ \\
\hline
\end{tabular}

Bonferroni correction: $\alpha=0.05 / 6$ tests $=0.008$ 
Appendix IIb continued

Plot $\times$ Year Interaction

\begin{tabular}{|c|c|c|c|c|c|c|c|c|c|c|c|c|c|}
\hline \multicolumn{2}{|c|}{ Turtle $\times 2009$} & \multicolumn{2}{|c|}{ Turtle $\times 2010$} & \multicolumn{2}{|c|}{ Turtle $\times 2011$} & \multicolumn{2}{|c|}{ Random $\times 2009$} & \multicolumn{2}{|c|}{ Random $\times 2010$} & \multicolumn{2}{|c|}{ Random $\times 2011$} & \multirow[b]{2}{*}{$F$} & \multirow[b]{2}{*}{$P$} \\
\hline $\bar{x}$ & $\mathrm{SE}$ & $\bar{x}$ & SE & $\bar{x}$ & SE & $\bar{x}$ & $\mathrm{SE}$ & $\bar{x}$ & SE & $\bar{x}$ & SE & & \\
\hline 1.92 & 0.09 & 2.27 & 0.07 & 1.33 & 0.15 & 1.86 & 0.11 & 1.95 & 0.06 & 1.90 & 0.12 & 5.24 & 0.006 \\
\hline 0.08 & 0.04 & 0.51 & 0.05 & 0.09 & 0.06 & 0.11 & 0.06 & 0.26 & 0.05 & 0.24 & 0.07 & 7.25 & 0.001 \\
\hline 0.43 & 0.12 & 0.48 & 0.06 & 0.43 & 0.11 & 0.08 & 0.04 & 0.36 & 0.06 & 0.22 & 0.09 & 0.38 & 0.682 \\
\hline 11.44 & 0.78 & 15.29 & 0.72 & 6.05 & 0.75 & 11.12 & 0.73 & 11.53 & 0.58 & 12.08 & 1.12 & 9.32 & $<0.001$ \\
\hline 0.52 & 0.14 & 1.92 & 0.14 & 0.50 & 0.21 & 0.65 & 0.20 & 1.43 & 0.20 & 1.04 & 0.19 & 3.50 & 0.032 \\
\hline 1.67 & 0.42 & 1.73 & 0.17 & 1.50 & 0.30 & 0.58 & 0.14 & 1.40 & 0.16 & 0.79 & 0.25 & 0.88 & 0.415 \\
\hline
\end{tabular}

Bonferroni correction: $\alpha=0.05 / 6$ tests $=0.008$ 
Appendix IIIb. Interaction diversity and richness means and standard errors (SE) for native vegetative layers (i.e., field: all plants <1 $\mathrm{m}$ tall, shrub: woody plants $>1 \mathrm{~m}$ tall and $<5 \mathrm{~cm}$ diameter at breast height $(\mathrm{dbh})$, and tree: woody plants $>5 \mathrm{~cm}$ dbh) associated with wood turtle plots $(n=110)$ and random plots $(n=110)$ sampled along a 13.7-km reach of the Cacapon River, West Virginia, USA during spring 2009 to summer 2011.

\begin{tabular}{|c|c|c|c|c|c|c|c|c|c|c|c|}
\hline \multirow[b]{3}{*}{ Variable } & \multirow[b]{3}{*}{ Strata } & \multicolumn{8}{|c|}{ Plot $\times$ Season Interaction } & \multirow[b]{3}{*}{$F$} & \multirow[b]{3}{*}{$P$} \\
\hline & & \multicolumn{2}{|c|}{ Turtle $\times$ Spring } & \multicolumn{2}{|c|}{ Turtle $\times$ Summer } & \multicolumn{2}{|c|}{ Random $\times$ Spring } & \multicolumn{2}{|c|}{ Random $\times$ Summer } & & \\
\hline & & $\bar{x}$ & $\mathrm{SE}$ & $\bar{x}$ & $\mathrm{SE}$ & $\bar{x}$ & SE & $\bar{x}$ & $\mathrm{SE}$ & & \\
\hline \multicolumn{12}{|l|}{ Diversity } \\
\hline & Field & 1.30 & 0.12 & 1.80 & 0.06 & 1.56 & 0.06 & 1.50 & 0.10 & 3.25 & 0.073 \\
\hline & Shrub & 0.00 & 0.00 & 0.11 & 0.03 & 0.01 & 0.01 & 0.12 & 0.05 & 2.22 & 0.138 \\
\hline & Tree & 0.21 & 0.07 & 0.45 & 0.06 & 0.27 & 0.05 & 0.38 & 0.10 & 0.141 & 0.708 \\
\hline \multicolumn{12}{|l|}{ Richness } \\
\hline & Field & 6.03 & 0.63 & 9.58 & 0.49 & 7.77 & 0.36 & 7.39 & 0.61 & 1.27 & 0.26 \\
\hline & Shrub & 0.17 & 0.07 & 0.65 & 0.10 & 0.27 & 0.06 & 0.78 & 0.20 & 1.44 & 0.232 \\
\hline & Tree & 0.72 & 0.20 & 1.58 & 0.14 & 1.20 & 0.13 & 1.53 & 0.34 & 0.04 & 0.848 \\
\hline
\end{tabular}

Bonferroni correction: $\alpha=0.05 / 6$ tests $=0.008$ 
Appendix IIIb continued

Plot $\times$ Year Interaction

\begin{tabular}{|c|c|c|c|c|c|c|c|c|c|c|c|c|c|}
\hline \multicolumn{2}{|c|}{ Turtle $\times 2009$} & \multicolumn{2}{|c|}{ Turtle $\times 2010$} & \multicolumn{2}{|c|}{ Turtle $\times 2011$} & \multicolumn{2}{|c|}{ Random × 2009} & \multicolumn{2}{|c|}{ Random $\times 2010$} & \multicolumn{2}{|c|}{ Random $\times 2011$} & \multirow[b]{2}{*}{$F$} & \multirow[b]{2}{*}{$P$} \\
\hline$\overline{\boldsymbol{x}}$ & $\mathrm{SE}$ & $\bar{x}$ & SE & $\bar{x}$ & SE & $\bar{x}$ & SE & $\bar{x}$ & $\mathrm{SE}$ & $\bar{x}$ & SE & & \\
\hline 1.56 & 0.10 & 1.90 & 0.07 & 1.07 & 0.20 & 1.42 & 0.10 & 1.59 & 0.07 & 1.54 & 0.11 & 4.31 & 0.015 \\
\hline 0.00 & 0.00 & 0.14 & 0.04 & 0.00 & 0.00 & 0.03 & 0.03 & 0.07 & 0.03 & 0.00 & 0.00 & 2.52 & 0.083 \\
\hline 0.22 & 0.08 & 0.51 & 0.06 & 0.21 & 0.12 & 0.08 & 0.04 & 0.34 & 0.07 & 0.49 & 0.10 & 3.79 & 0.024 \\
\hline 7.78 & 0.63 & 10.43 & 0.54 & 4.20 & 0.69 & 6.88 & 0.50 & 7.75 & 0.44 & 8.21 & 0.77 & 8.65 & $<0.001$ \\
\hline 0.22 & 0.08 & 0.78 & 0.12 & 0.15 & 0.11 & 0.27 & 0.10 & 0.58 & 0.13 & 0.25 & 0.09 & 1.68 & 0.189 \\
\hline 0.78 & 0.21 & 1.81 & 0.16 & 0.70 & 0.33 & 0.58 & 0.14 & 1.40 & 0.22 & 1.88 & 0.23 & 6.90 & 0.001 \\
\hline
\end{tabular}

Bonferroni correction: $\alpha=0.05 / 6$ tests $=0.008$ 


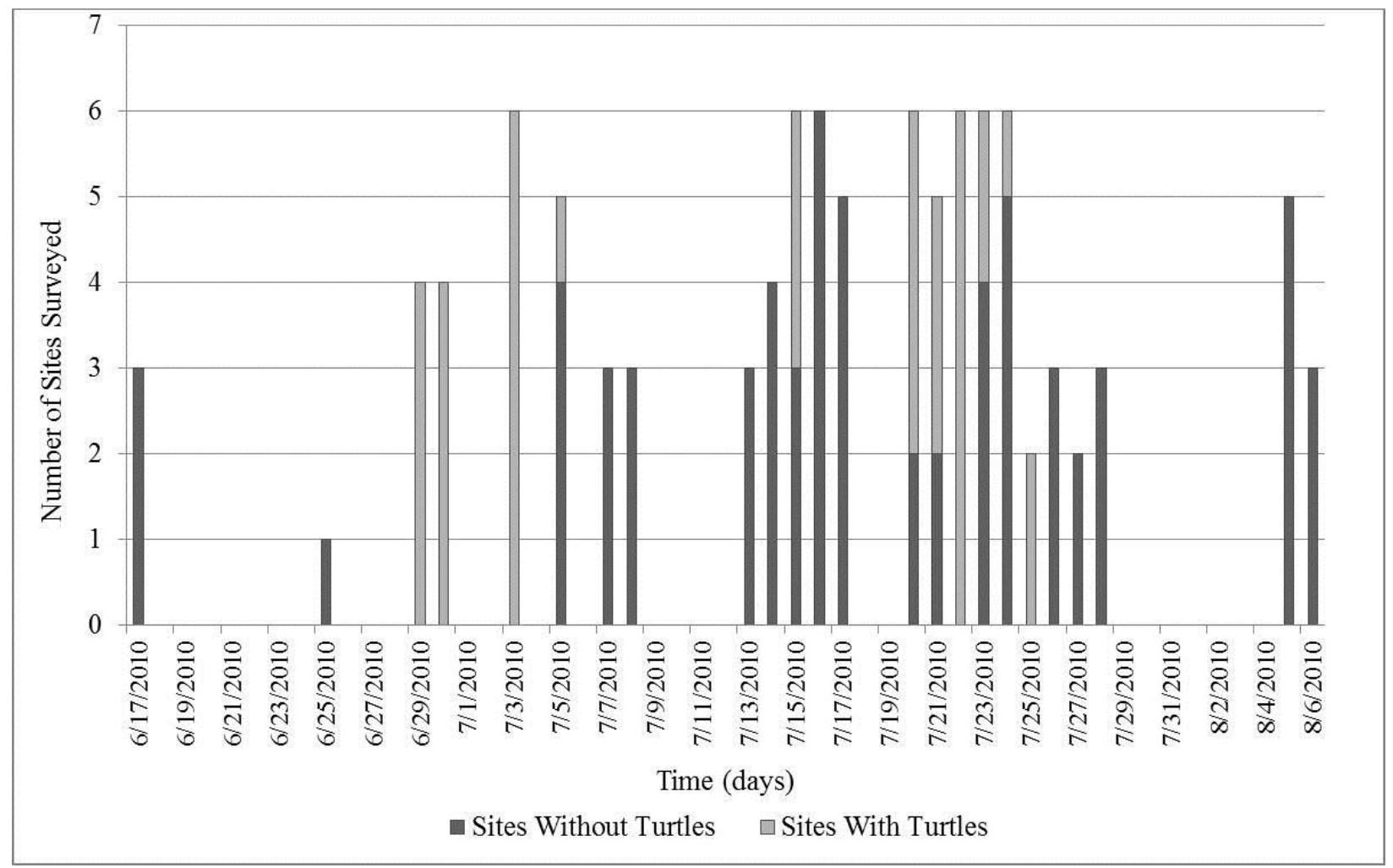

Appendix Ic. Random sampling plots were surveyed along the North River $(n=61)$ and Lost River ( $n=39$ ), Cacapon River watershed, West Virginia, USA during June to August 2010 for the presence of wood turtles. 
Appendix IIc. Means and standard errors (SE) of vegetation (field: \% cover of woody and herbaceous plants $<1 \mathrm{~m}$ tall; shrubs: abundance of woody plants $>1 \mathrm{~m}$ tall, $<5 \mathrm{~cm}$ diameter at breast height (dbh); and trees: abundance of woody plants $>5 \mathrm{~cm} \mathrm{dbh}$ ) recorded within 100 random sites along the Lost and North rivers, Cacapon River Watershed, West Virginia, during summer 2010.

\begin{tabular}{|c|c|c|c|c|c|c|c|}
\hline \multirow[b]{2}{*}{ Common Name } & \multirow[b]{2}{*}{ Scientific Name } & \multicolumn{2}{|c|}{ Field } & \multicolumn{2}{|c|}{ Shrub } & \multicolumn{2}{|c|}{ Tree } \\
\hline & & $\bar{x}$ & SE & $\bar{x}$ & SE & $\bar{x}$ & SE \\
\hline Arrowleaf tearthumb & Polygonum sagittatum & 0.45 & 0.11 & & & & \\
\hline Aster & Aster spp. & 0.18 & 0.15 & & & & \\
\hline Autumn olive & Elaeagnus umbellata & 0.10 & 0.05 & 2.74 & 0.64 & & \\
\hline Bedstraw & Galium spp. & 1.16 & 0.16 & & & & \\
\hline Big bluestem & Andropogon gerardi & 0.03 & 0.03 & & & & \\
\hline Bittersweet & Solanum dulcamara & 0.16 & 0.08 & & & & \\
\hline Blackberry & Rubus spp. & 0.48 & 0.14 & 0.69 & 0.36 & & \\
\hline Black-eyed Susan & Rudbeckia hirta & 0.05 & 0.05 & & & & \\
\hline Black birch & Betula lenta & & & 0.07 & 0.07 & 0.02 & 0.02 \\
\hline Black gum & Nyssa sylvatica & & & & & 0.01 & 0.01 \\
\hline Black huckleberry & Gaylussacia baccata & & & 1.01 & 1.01 & & \\
\hline Black locust & Robinia pseudoacacia & 0.01 & 0.01 & 0.21 & 0.11 & 0.06 & 0.02 \\
\hline Black oak & Quercus velutina & 0.01 & 0.01 & & & & \\
\hline Black walnut & Juglans nigra & & & & & 0.15 & 0.05 \\
\hline Black willow & Salix nigra & 0.09 & 0.06 & 0.75 & 0.41 & 0.05 & 0.03 \\
\hline Blueberry & Vaccinium spp. & 0.04 & 0.03 & & & & \\
\hline Bottlebrush grass & Elymus hystrix & 0.13 & 0.07 & & & & \\
\hline Boxelder & Acer negundo & & & 0.26 & 0.16 & 0.06 & 0.03 \\
\hline Broad-leaf plantain & Plantago major & 0.13 & 0.05 & & & & \\
\hline Bush clover & Lespedeza spp. & 0.08 & 0.08 & & & & \\
\hline Cardinal-flower & Lobelia cardinalis & 0.01 & 0.01 & & & & \\
\hline Carrot & Umbelliferae & 0.03 & 0.02 & & & & \\
\hline Cigar tree & Catalpa bignonioides & & & 0.02 & 0.02 & 0.05 & 0.05 \\
\hline Chickory & Cichorium intybus & 0.03 & 0.03 & & & & \\
\hline Chickweed & Stellaria spp. & 0.09 & 0.04 & & & & \\
\hline Christmas fern & Polystichum acrostichoides & 0.14 & 0.06 & & & & \\
\hline Cinnamon fern & Osmunda cinnamomea & 0.03 & 0.03 & & & & \\
\hline Cockspur hawthorn & Crataegus crus-galli & & & & & 0.01 & 0.01 \\
\hline Common cinquefoil & Potentilla simplex & 0.60 & 0.13 & & & & \\
\hline Common milkweed & Asclepias syriaca & 0.11 & 0.05 & & & & \\
\hline Common teasel & Dipsacus fullonum & 0.33 & 0.17 & & & & \\
\hline
\end{tabular}




\begin{tabular}{|c|c|c|c|c|c|c|c|}
\hline Common yarrow & Achillea millefolium & 0.04 & 0.04 & & & & \\
\hline Cottonwood & Populus deltoides & & & & & 0.02 & 0.02 \\
\hline Crown vetch & Coronilla varia & 0.85 & 0.41 & & & & \\
\hline Curly dock & Rumex crispus & 0.18 & 0.07 & & & & \\
\hline Daisy fleabane & Erigeron strigosus & 0.14 & 0.05 & & & & \\
\hline Dandelion & Taraxacum officinale & 0.24 & 0.05 & & & & \\
\hline Deertongue grass & Panicum clandestinum & 3.61 & 0.50 & & & & \\
\hline Dogbane & Аросупит spp. & 0.03 & 0.03 & & & & \\
\hline Eastern red cedar & Juniperus virginiana & 0.04 & 0.04 & 0.21 & 0.17 & 0.05 & 0.03 \\
\hline Fall phlox & Phlox paniculata & 0.39 & 0.23 & & & & \\
\hline False nettle & Boehmeria cylindrica & 0.44 & 0.13 & & & & \\
\hline False Solomon seal & Maiantheтит racemosum & 0.01 & 0.01 & & & & \\
\hline Flowering dogwood & Cornus florida & 0.04 & 0.03 & & & 0.02 & 0.01 \\
\hline Forget-me-not & Myosotis laxa & 0.11 & 0.10 & & & & \\
\hline Four-leaved wild yam & Dioscorea quaternata & 0.01 & 0.01 & & & & \\
\hline Foxglove & Aureolaria laevigata & 0.08 & 0.08 & & & & \\
\hline Garlic mustard & Alliaria petiolata & 0.13 & 0.04 & & & & \\
\hline Geranium & Geranium spp. & 0.10 & 0.05 & & & & \\
\hline Goldenrod & Solidago spp. & 0.55 & 0.14 & & & & \\
\hline Grape & Vitis spp. & 0.44 & 0.13 & & & & \\
\hline Grass & Grass spp. & 11.53 & 1.53 & & & & \\
\hline Green ash & Fraxinus pennsylvanica & 0.06 & 0.05 & 0.04 & 0.03 & 0.07 & 0.03 \\
\hline Green dragon & Arisaema dracontium & 0.04 & 0.02 & & & & \\
\hline Greenbrier & Smilax spp & 0.73 & 0.16 & 0.74 & 0.32 & & \\
\hline Ground-ivy & Glechoma hederacea & 1.58 & 0.24 & & & & \\
\hline Hay-scented fern & Dennstaedtia punctilobula & 0.20 & 0.15 & & & & \\
\hline Heal-all & Prunella vulgaris & 0.03 & 0.02 & & & & \\
\hline Hemlock & Tsuga canadensis & 0.03 & 0.03 & & & 0.01 & 0.01 \\
\hline Hickory & Carya spp. & 0.09 & 0.04 & & & 0.13 & 0.05 \\
\hline Hog peanut & Amphicarpaea bracteata & 0.66 & 0.15 & & & & \\
\hline Horse nettle & Solanum carolinense & 0.43 & 0.16 & & & & \\
\hline Ironwood & Ostrya virginiana & 0.11 & 0.05 & & & 0.27 & 0.18 \\
\hline Jack in the pulpit & Arisaema triphyllum & 0.18 & 0.08 & & & & \\
\hline Japanese barberry & Berberis thunbergii & 0.25 & 0.13 & 8.56 & 3.97 & & \\
\hline Japanese honeysuckle & Lonicera japonica & 1.84 & 0.50 & & & & \\
\hline Japanese stilt grass & Microstegium vimineum & 8.49 & 0.91 & & & & \\
\hline Jewelweed & Impatiens spp. & 1.26 & 0.26 & & & & \\
\hline Joe-pye-weed & Eupatorium fistulosum & 0.55 & 0.22 & & & & \\
\hline Jointed grass & Arthraxon hispidus & 0.29 & 0.12 & & & & \\
\hline Lady's thumb & Polygonum spp. & 2.94 & 0.37 & & & & \\
\hline Maidenhair fern & Adiantum pedatum & 0.04 & 0.04 & & & & \\
\hline May-apple & Podophyllum peltatum & 0.01 & 0.01 & & & & \\
\hline Mile-a-minute & Polygonum perfoliatum & 0.31 & 0.12 & & & & \\
\hline Mint & Mentha spp. & 0.70 & 0.15 & & & & \\
\hline Moneywort & Lysimachia nummularia & 0.01 & 0.01 & & & & \\
\hline Monkey flower & Mimulus ringens & 0.05 & 0.03 & & & & \\
\hline Morning glory & Ipomoea coccinea & 0.03 & 0.03 & & & & \\
\hline Morrow's honeysuckle & Lonicera morrowii & & & 0.53 & 0.24 & & \\
\hline Moss & Moss spp. & 0.14 & 0.09 & & & & \\
\hline Multiflora rose & Rosa multiflora & 2.21 & 0.62 & 16.77 & 3.79 & & \\
\hline Pawpaw & Asimina triloba & 0.04 & 0.03 & 0.33 & 0.17 & 0.03 & 0.02 \\
\hline
\end{tabular}


Appendix IIc continued

\begin{tabular}{|c|c|c|c|c|c|c|c|}
\hline Peppermint & Mentha $\times$ piperita & 0.16 & 0.12 & & & & \\
\hline Poison ivy & Toxicodendron radicans & 1.09 & 0.23 & & & & \\
\hline Pokeweed & Phytolacca americana & 0.03 & 0.03 & & & & \\
\hline Queen Ann's lace & Daucus carota & 0.16 & 0.06 & & & & \\
\hline Red clover & Trifolium pratense & 0.01 & 0.01 & & & & \\
\hline Red maple & Acer rubrum & 0.33 & 0.08 & 0.02 & 0.02 & 0.13 & 0.04 \\
\hline Red oak & Quercus rubra & 0.03 & 0.02 & & & & \\
\hline Redbud & Cercis canadensis & & & & & 0.05 & 0.03 \\
\hline Reed canary grass & Phalaris arundinacea & 7.59 & 1.55 & & & & \\
\hline Rice cutgrass & Leersia oryzoides & 0.51 & 0.33 & & & & \\
\hline River birch & Betula nigra & 0.09 & 0.06 & 0.20 & 0.19 & 0.05 & 0.03 \\
\hline Rue anemone & Thalictrum thalictroides & 0.06 & 0.03 & & & & \\
\hline Rush & Juncus spp. & 0.14 & 0.09 & & & & \\
\hline Sassafras & Sassafras albidum & 0.05 & 0.05 & 0.01 & 0.01 & 0.07 & 0.06 \\
\hline Scrub pine & Pinus virginiana & & & 0.01 & 0.01 & & \\
\hline Sedge & Carex spp. & 1.95 & 0.38 & & & & \\
\hline Sensitive fern & Onoclea sensibilis & 0.16 & 0.10 & & & & \\
\hline Shepard's purse & Capsella bursa-pastoris & 0.01 & 0.01 & & & & \\
\hline Silky dogwood & Cornus obliqua & & & 0.05 & 0.05 & & \\
\hline Slippery elm & Ulmus rubra & 0.09 & 0.06 & 0.03 & 0.03 & 0.03 & 0.02 \\
\hline Smooth alder & Alnus serrulata & & & 0.05 & 0.05 & & \\
\hline Spearmint & Mentha spicata & 0.13 & 0.13 & & & & \\
\hline Spicebush & Lindera benzoin & 1.03 & 0.30 & 5.06 & 2.21 & & \\
\hline Stinging nettle & Urtica dioica & 0.08 & 0.04 & & & & \\
\hline Sugar maple & Acer saccharum & 0.01 & 0.01 & 0.01 & 0.01 & 0.30 & 0.07 \\
\hline Sycamore & Platanus occidentalis & 0.19 & 0.07 & 0.29 & 0.15 & 0.92 & 0.15 \\
\hline Thistle & Cirsium spp. & 0.11 & 0.08 & & & & \\
\hline Tree of heaven & Ailanthus altissima & 0.21 & 0.08 & 0.20 & 0.13 & 0.07 & 0.05 \\
\hline Tulip poplar & Liriodendron tulipifera & 0.13 & 0.05 & 0.01 & 0.01 & 0.36 & 0.06 \\
\hline Velvet grass & Holcus lanatus & 0.03 & 0.03 & & & & \\
\hline Violet & Viola spp. & 1.44 & 0.26 & & & & \\
\hline Virginia creeper & Parthenocissus quinquefolia & 0.96 & 0.27 & & & & \\
\hline White clover & Trifolium repens & 0.36 & 0.08 & & & & \\
\hline White oak & Quercus alba & 0.03 & 0.02 & & & & \\
\hline Wild black cherry & Prunus serotina & 0.06 & 0.04 & 0.05 & 0.04 & 0.03 & 0.02 \\
\hline Wild ginger & Asarum canadense & 0.01 & 0.01 & & & & \\
\hline Wild oats & Chasmanthium latifolium & 0.35 & 0.20 & & & & \\
\hline Wild onion & Allium canadense & 0.06 & 0.03 & & & & \\
\hline Wild stonecrop & Sedum ternatum & 0.04 & 0.04 & & & & \\
\hline Wineberry & Rubus phoenicolasius & 0.01 & 0.01 & 0.13 & 0.09 & & \\
\hline Wingstem & Verbesina alternifolia & 8.51 & 0.80 & & & & \\
\hline Witch-hazel & Hamamelis virginiana & 0.08 & 0.04 & & & 0.16 & 0.12 \\
\hline Wood sorrel & Oxalis spp. & 1.89 & 0.24 & & & & \\
\hline
\end{tabular}


Appendix IIIc. Diversity and richness means and standard errors (SE) for vegetative layers (field: woody and herbaceous plants <1 m tall; shrub: woody plants $>1 \mathrm{~m}$ tall, $<5 \mathrm{~cm}$ in diameter at breast height (dbh); and tree: woody plants $>5 \mathrm{~cm}$ dbh) associated with the interaction of sites (presence $[\mathrm{P}]$ or absence $[\mathrm{A}]$ of wood turtles) and rivers (Lost $[\mathrm{L}]$ and North $[\mathrm{N}]$ rivers), Cacapon River Watershed, West Virginia, USA, during summer 2010.

\begin{tabular}{|c|c|c|c|c|c|c|c|c|c|c|c|}
\hline \multirow[b]{2}{*}{ Variable } & \multirow[b]{2}{*}{ Strata } & \multicolumn{2}{|c|}{$\mathrm{P} \times \mathrm{N}$} & \multicolumn{2}{|c|}{$A \times N$} & \multicolumn{2}{|c|}{$\mathrm{P} \times \mathrm{L}$} & \multicolumn{2}{|c|}{$A \times L$} & \multirow[b]{2}{*}{$F$} & \multirow[b]{2}{*}{$P$} \\
\hline & & $\bar{x}$ & SE & $\bar{x}$ & SE & $\bar{x}$ & SE & $\bar{x}$ & SE & & \\
\hline \multicolumn{12}{|l|}{ Diversity } \\
\hline & Field & 2.46 & 0.06 & 2.16 & 0.09 & 1.89 & 0.13 & 1.43 & 0.08 & 0.00 & 0.979 \\
\hline & Shrub & 0.46 & 0.06 & 0.51 & 0.10 & 0.59 & 0.08 & 0.29 & 0.10 & 4.27 & 0.041 \\
\hline & Tree & 0.54 & 0.08 & 0.51 & 0.11 & 0.29 & 0.10 & 0.51 & 0.13 & 1.49 & 0.225 \\
\hline \multicolumn{12}{|l|}{ Richness } \\
\hline & Field & 17.67 & 0.73 & 14.83 & 1.16 & 10.57 & 0.96 & 7.39 & 0.69 & 0.03 & 0.857 \\
\hline & Shrub & 1.84 & 0.17 & 2.83 & 0.38 & 2.00 & 0.26 & 1.06 & 0.30 & 13.20 & $<0.001$ \\
\hline & Tree & 1.86 & 0.19 & 1.78 & 0.30 & 1.38 & 0.29 & 2.11 & 0.52 & 1.20 & 0.277 \\
\hline
\end{tabular}

Bonferroni correction: $\alpha=0.05 / 6$ tests $=0.008$ 